LUZIA NOMURA

DEFINIÇÃO E ESTABELECIMENTO DE PROCESSOS DE FÁBRICA DE SOFTWARE EM UMA ORGANIZAÇÃO DE TI DO SETOR PÚBLICO

São Paulo

2008 
LUZIA NOMURA

\section{DEFINIÇÃO E ESTABELECIMENTO DE PROCESSOS DE FÁBRICA DE SOFTWARE EM UMA ORGANIZAÇÃO DE TI DO SETOR PÚBLICO}

Tese apresentada à Escola Politécnica da Universidade de São Paulo para a obtenção do Título de Doutor em Engenharia.

São Paulo 
LUZIA NOMURA

\section{DEFINIÇÃO E ESTABELECIMENTO DE PROCESSOS DE FÁBRICA DE SOFTWARE EM UMA ORGANIZAÇÃO DE TI DO SETOR PÚBLICO}

Tese apresentada à Escola Politécnica da Universidade de São Paulo para a obtenção do Título de Doutor em Engenharia.

Área de Concentração:

Engenharia de Produção

Orientador:

Prof. Dr.

Mauro de Mesquita Spinola

São Paulo 
Este exemplar foi revisado e alterado em relação à versão original, sob responsabilidade única do autor e com a anuência de seu orientador.

São Paulo, de abril de 2008.

Assinatura do autor

Assinatura do orientador

FICHA CATALOGRÁFICA

Nomura, Luzia

Definição e estabelecimento de processos de fábrica de software em uma organização de TI do setor público / L. Nomura. -- São Paulo, 2008.

$217 p$.

Tese (Doutorado) - Escola Politécnica da Universidade de São Paulo. Departamento de Engenharia de Produção.

1. Processo de software 2. Reuso de software I. Universidade e São Paulo. Escola Politécnica. Departamento de Engenharia de Produção II. t. 


\section{AGRADECIMENTOS}

Ao Prof. Dr. Mauro de Mesquita Spinola, por todo o apoio, incentivo, aprendizado e orientação no desenvolvimento deste trabalho e artigos publicados.

Ao Prof. Dr. Marcelo Pessôa pelo estímulo, sugestões e ensinamentos.

Aos Professores Doutores membros da banca examinadora do exame de Qualificação e Defesa Final, pelas valiosas contribuições para o desenvolvimento e consolidação deste trabalho.

Ao pessoal do Elabsoft, Grupo GTI e Oficina de Artigos pela solidariedade e aprendizado adquirido, em especial aos colegas: Tonini, Vagner, Oswaldo, Rodrigo, e Paulo Almeida. À Ivelise e Lidia pela atenção e suporte dispensados.

A Empresa pesquisada por proporcionar a oportunidade única de realizar este estudo e pelo apoio à pesquisa. Agradeço muito a participação, colaboração e incentivo dos profissionais, com os quais compartilhei e adquiri preciosos conhecimentos.

Aos meus familiares pelo auxílio, torcida e carinho, em especial aos meus irmãos Jorge e Ricardo.

Ao Raul pela força, carinho, e presença constante, principalmente nos momentos mais difíceis.

A todos aqueles que de forma direta ou indireta contribuíram para a consecução deste objetivo, meus sinceros agradecimentos. 


\section{RESUMO}

Um crescente número de empresas produtoras de software tem adotado um modelo organizacional de Fábrica de Software (FS), que facilita a terceirização por intermédio da segmentação das atividades e adoção de um sistema de produção mais flexível, dinâmico e controlado. Uma FS pode atender a múltiplas demandas de natureza e escopos distintos com o intuito de prover as necessidades específicas de cada cliente. Em face da diversidade e complexidade deste contexto, uma das questões principais a resolver é como mapear todos os processos envolvidos, identificando claramente o que, quem e, sobretudo como cada trabalho deve ser executado e controlado, visando o alinhamento dos processos à estrutura organizacional e conceitual de FS com foco nos processos de integração, alinhamento e reuso. Este estudo tem como objetivo mapear, definir, reestruturar e estabelecer processos de Fábrica de Software, conduzidos pelo método de pesquisaação em uma organização produtora de software do setor público, considerando seu contexto operacional, técnico e cultura organizacional. O desenvolvimento, execução, acompanhamento e resultados são descritos pelos ciclos da pesquisa-ação envolvendo o estudo de estruturas organizacionais, metodologias de desenvolvimento de sistemas, e mudanças organizacionais. Para isso foram definidas uma Estrutura Organizacional de Referência de FS, uma Arquitetura de Definição de Processos para FS e uma Metodologia de Desenvolvimento de Sistemas e Integração com foco organizacional, concebidos e desenvolvidos com base na literatura, experiência profissional e pesquisa empírica, que serviram como guia de condução da pesquisa-ação, culminando na associação do estudo empírico com o estudo teórico. As contribuições empíricas e teóricas geradas referem-se à melhoria dos processos organizacionais e operacionais de uma empresa de TI do setor público com base nos conceitos de FS.

Palavras-chave: fábrica de software; reuso de software; definição de processo de software; melhoria de processo de software; organização pública de TI 


\begin{abstract}
A growing number of software producing companies have adopted an organizational model of Software Factory (SF), which facilitates outsourcing by segmenting activities and by adopting a more flexible, dynamic and controlled production system. A SF can serve the multiple demands of different nature and scopes with the purpose of providing each customer's specific needs. Because of the diversity and complexity of this context, one of the main issues to be solved is how to map all the processes involved, clearly identifying what, who and mainly how each work must be executed and controlled, aiming at aligning the processes to the organizational and conceptual structure of SF focusing on the integration, aligning and reuse processes. The purpose of this study is mapping, defining, restructuring and establishing the Software Factory process, conducted by the action research method in a software producing organization of the public sector, considering its operational, technical and organizational culture context. The development, execution, follow-up and results are described by the action research cycles involving the study of organizational structures, system development methodologies and organizational changes. For this, a Reference Organizational Structure of SF, and Processes Definition Architecture for SF and a Integration System Development Methodology with organizational focus were defined, conceived and developed based on the literature, professional experience and empirical research, which served as a guiding line of the action research, peaking at the association of the empirical study with the theoretical study. The generated empirical and theoretical contributions refer to the improvement of the organizational and operational processes based on the SF concepts.
\end{abstract}

Keywords: software factory; software reuse; software process definition; software process improvement; public organization of IT 


\section{SUMÁRIO}

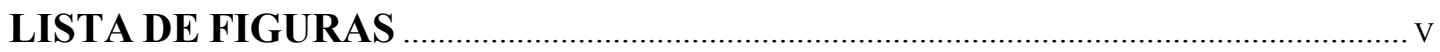

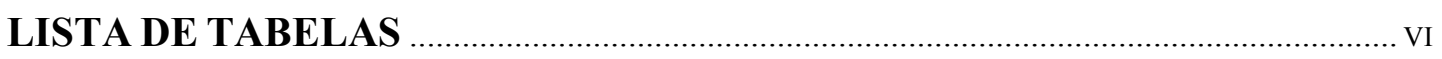

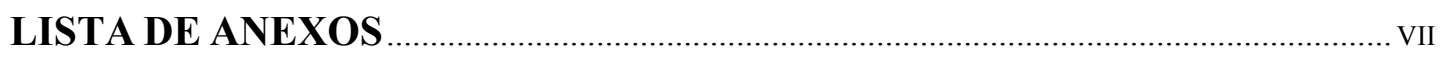

LISTA DE ABREVIATURAS E SIGLAS …………………………………………..... VIII

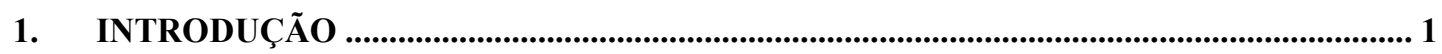

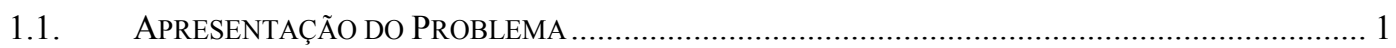

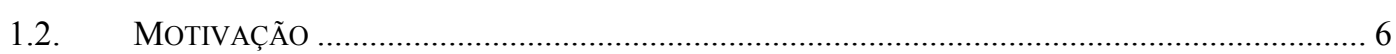

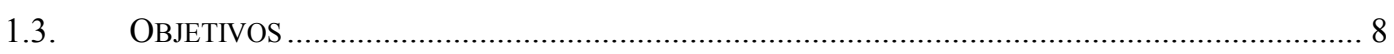

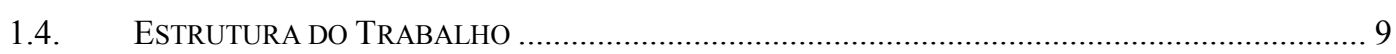

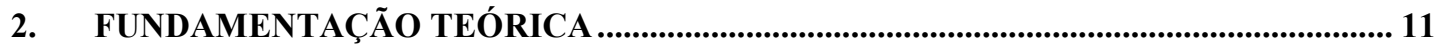

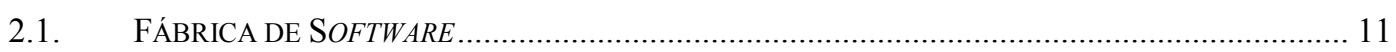

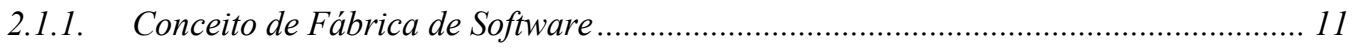

2.1.2. Frameworks organizacionais de Fábricas de Software ........................................... 17

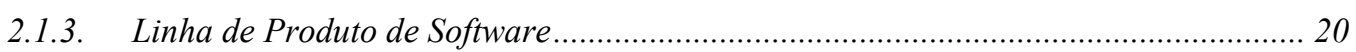

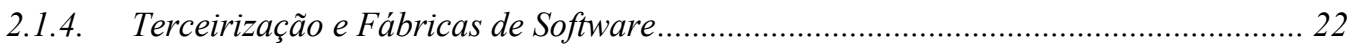

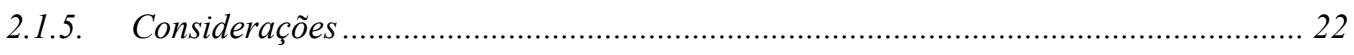

2.2. CONTRIBUIÇÕES DA ENGENHARIA DE PRODUÇÃo ............................................................... 23

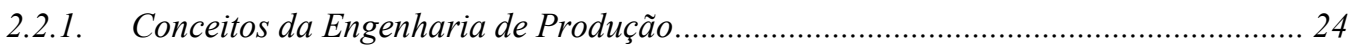

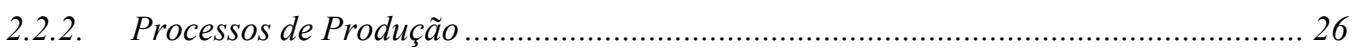

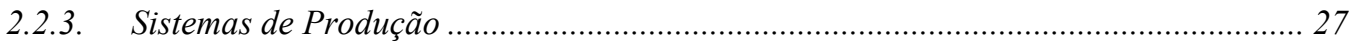

2.2.4. Planejamento e Controle de Produção ……………………………………............ 29

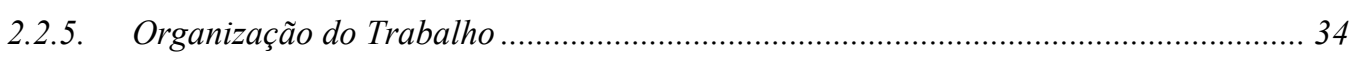

2.2.6. Gestão por Competências .................................................................................. 37

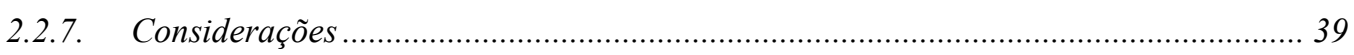

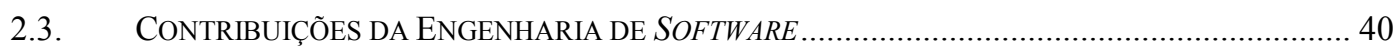

2.3.1. Conceitos de Engenharia de Software................................................................... 40

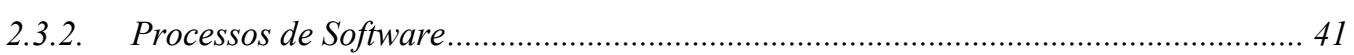

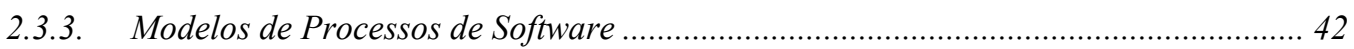

2.3.4. RUP - Processo Unificado da Rational................................................................... 44

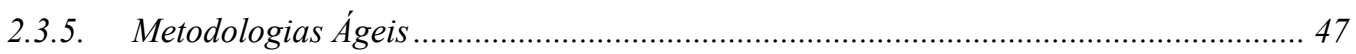

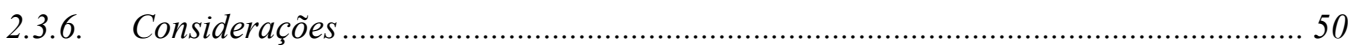

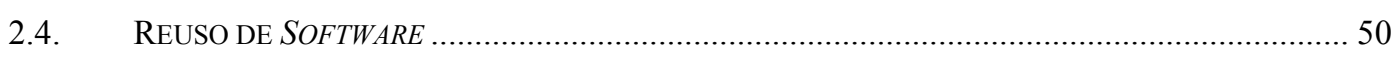

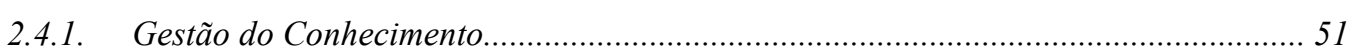




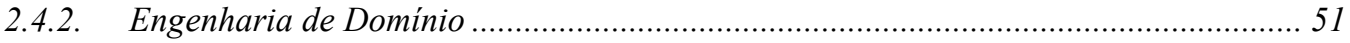

2.4.3. Conceito e Classificação do Reuso de Software ....................................................... 54

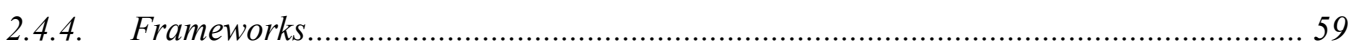

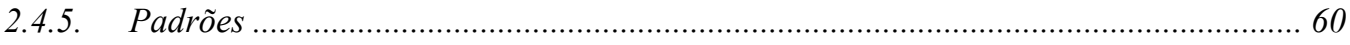

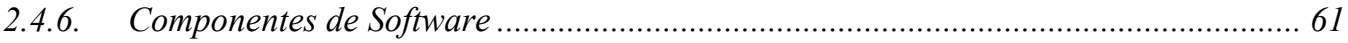

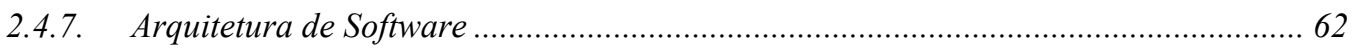

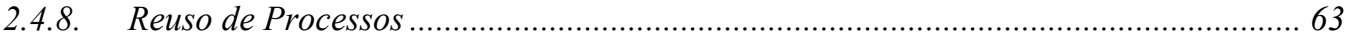

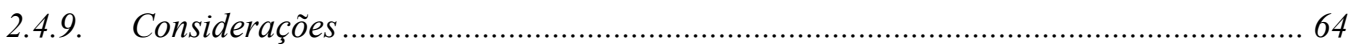

2.5. Modelos de Melhores PrÁticas e Normas de Qualidade ..................................... 65

2.5.1. Norma ISO 9001:2000 - Sistemas de Gestão da Qualidade - Requisitos.................... 65

2.5.2. Norma ISO/IEC 9126 - Qualidade do Produto de Software ........................................ 67

2.5.3. Norma ISO/IEC 12207 - Ciclo de Vida do Software ............................................... 68

2.5.4. CMMI - Modelo Integrado da Maturidade da Capacidade ......................................... 69

2.5.5. PMBOK - Modelo de Processos de Gestão de Projetos................................................. 71

2.5.6. ITIL - Biblioteca de Infra-Estrutura de Tecnologia da Informação............................ 73

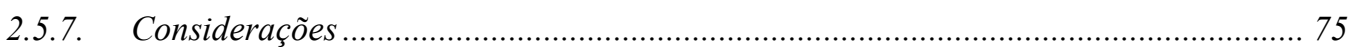

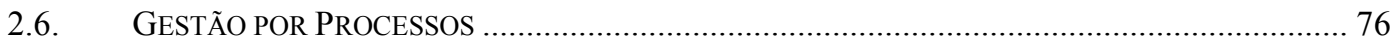

2.6.1. Conceito de Gestão por Processos .................................................................... 76

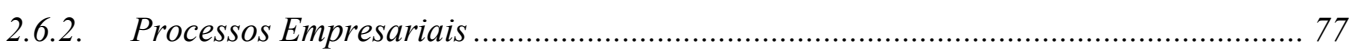

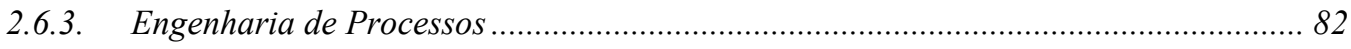

2.6.4. Modelagem de Processos ....................................................................................... 83

2.6.5. BPMN - Notação de Modelagem de Processos de Negócios ......................................... 85

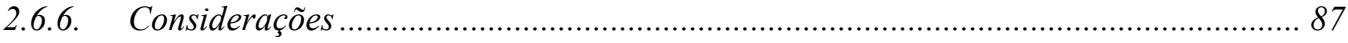

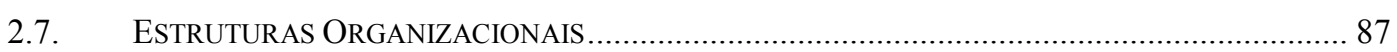

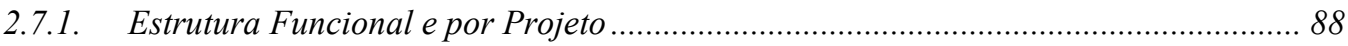

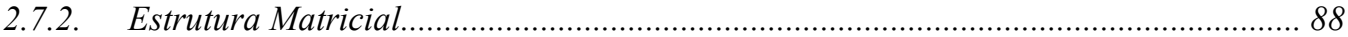

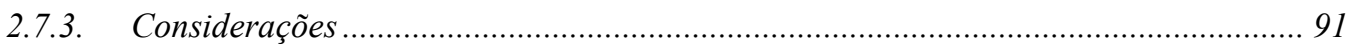

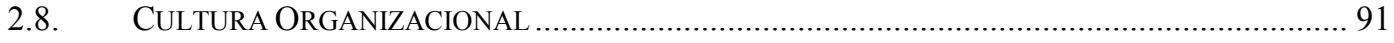

2.8.1. Características das Organizações Públicas............................................................. 92

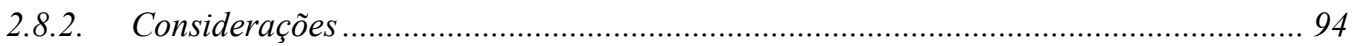

2.9. FUNDAMENTAÇÃO TEÓRICA - CONSIDERAÇÕES FINAIS ................................................ 95

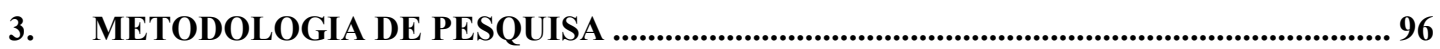

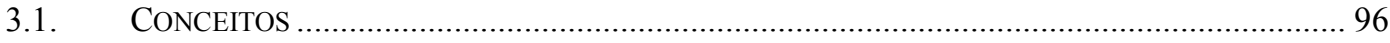

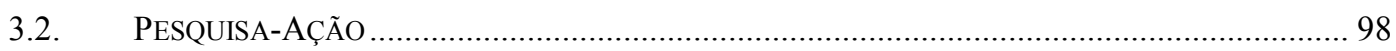

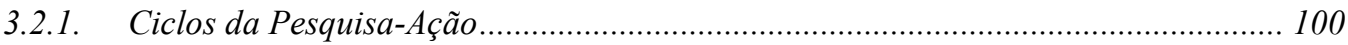

3.3. CARACTERIZAÇÃO DA PESQUISA ................................................................................. 101

4. FASE PRELIMINAR - CARACTERIZAÇÃO DA EMPRESA ....................................... 108 


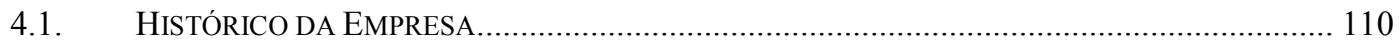

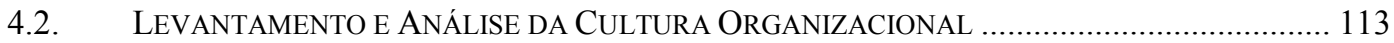

5. CICLO 1 - ESTRUTURA ORGANIZACIONAL.............................................................. 116

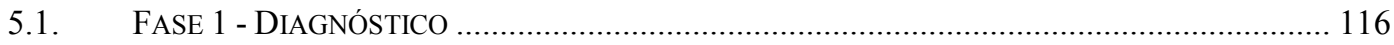

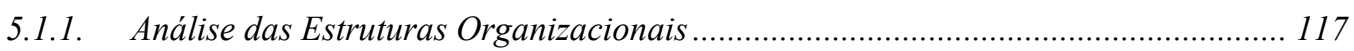

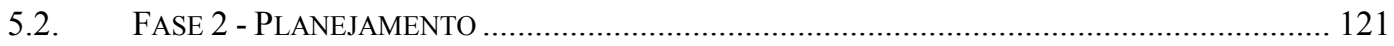

5.3. FASE 3 - EXECUÇÃO: CONSTRUÇÃO DOS MOdelos ...................................................... 121

5.3.1. Estrutura Organizacional de Referência de FS.................................................... 121

5.3.2. Modelo Dinâmico de Referência de FS.............................................................. 129

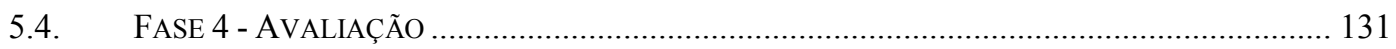

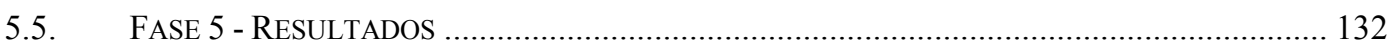

6. CICLO 2 - MAPEAMENTO, DEFINIÇÃO E ESTABELECIMENTO DOS PROCESSOS 134

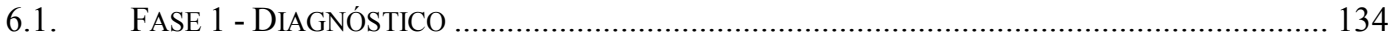

6.1.1. Análise das Metodologias de Desenvolvimento de Sistemas.................................... 134

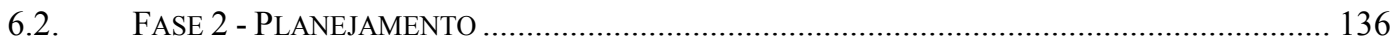

6.3. FASE 3.1 - EXECUÇÃO: CONSTRUÇ̃̃o DOS MOdELOS …………………………………... 140

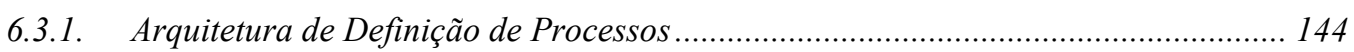

6.3.2. Modelo de Definição de Processos ........................................................................ 146

6.3.3. Diagrama de Modelagem de Processos .............................................................. 151

6.4. FASE 3.2 - EXeCuÇão: MAPEAMENTO E DeFInIÇÃo dos Processos ………………….... 154

6.4.1. Categorias de Processos .................................................................................. 154

6.4.2. Mapeamento dos Processos ................................................................................... 159

6.4.3. Definição e Estabelecimento dos Processos - A MDSI ............................................. 161

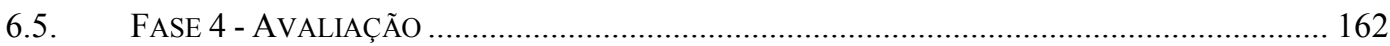

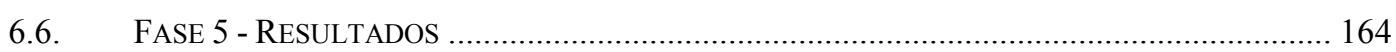

7. CICLO 3 - ANÁLISE DO IMPACTO DAS MUDANÇAS NOS PROCESSOS ................. 171

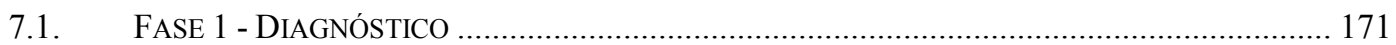

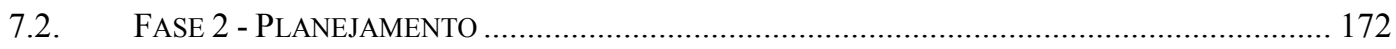

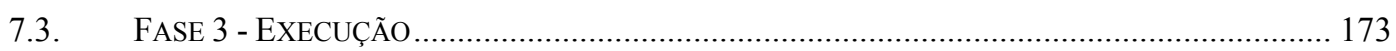

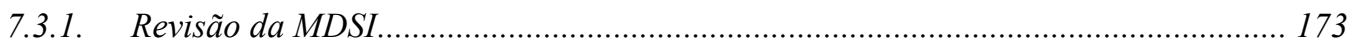

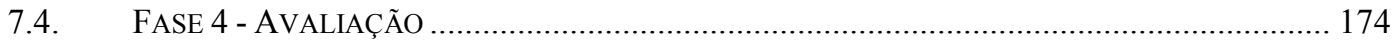

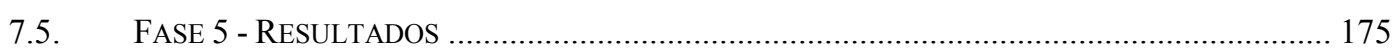

7.5.1. Diagrama dos Componentes Organizacionais de Análise da FS............................. 176

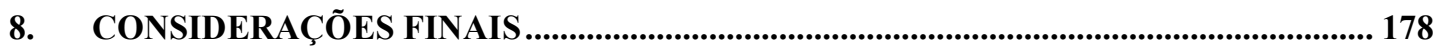

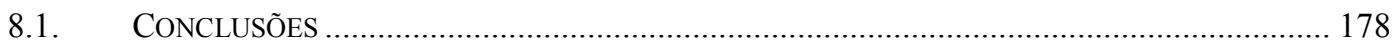




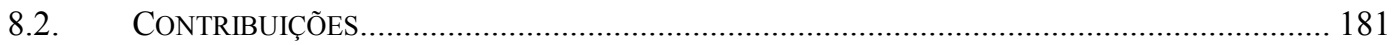

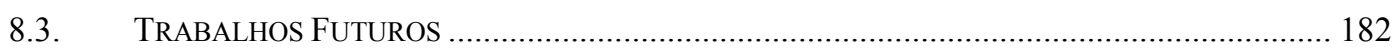

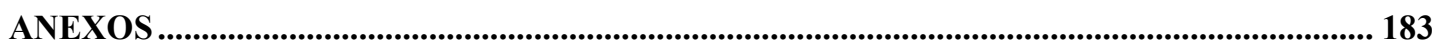

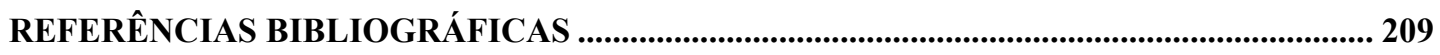




\section{LISTA DE FIGURAS}

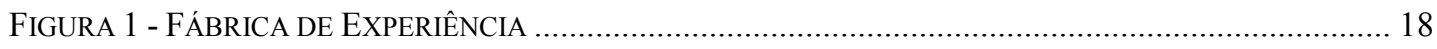

FIGURA 2 - ENGENHARIA DE SOFTWARE BASEADA EM COMPONENTES .................................................. 19

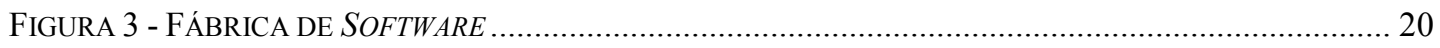

Figura 4 - ATIVIDAdes básicas do Planejamento e Controle da Produção ................................. 30

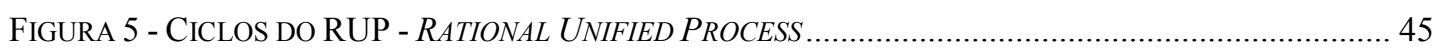

FigURA 6 - ISO/IEC 12207 - PROCESSOS DO CICLO DE VIDA DO SOFTWARE ……………….................... 69

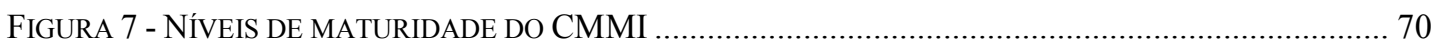

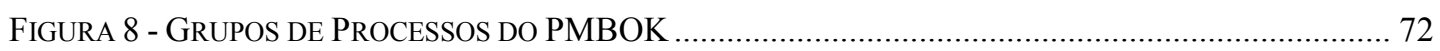

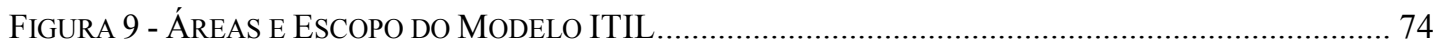

FigURA 10 - COMPONENTES DA ESTRATÉGIA DE FUNCIONAMENTO DE UMA ORGANIZAÇÃO................... 77

FigURA 11 - EXEMPLO DE DiAGRAMA BPMN- BUSINESS PROCESS MODELING NOTATION ...................... 86

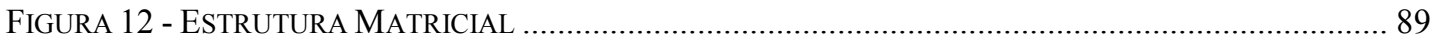

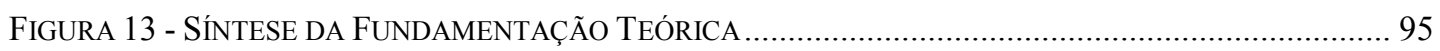

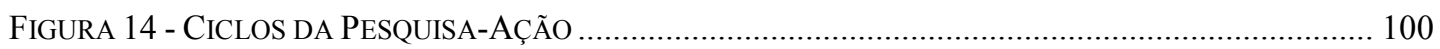

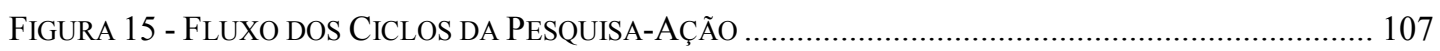

Figura 16 - ESTRUTURA ORGanizacional DA EMPRESATI - ProJETIZADA ........................................ 119

Figura 17 - ESTRUTURA ORganizACIONAL DA EMPRESATI - MATRICIAL ……………………….... 120

FigURA 18 - ESTRUTURA ORgANIZACIONAL DE REFERÊNCIA DE FÁBricA DE SOFTWARE …................. 123

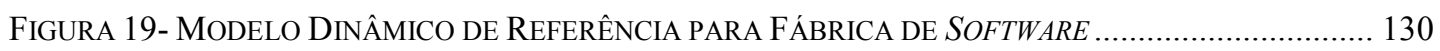

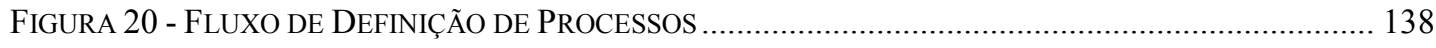

FIGURA 21 - VISÃO FUNCIONAL VERSUS VISÃO POR PROCESSOS............................................................ 141

FIGURA 22 - NÍVEIS DE GRANULARIDADE DO PROCESSO DE SOFTWARE …………………….............. 143

Figura 23 - ARquitetura de Definição de Processo Para FÁbrica de SOFTWARE ……………... 145

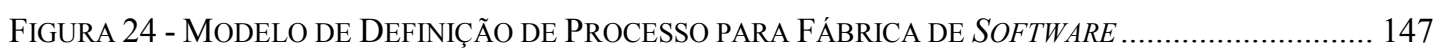

Figura 25 - Modelo de Processos De Negócios ..................................................................... 152

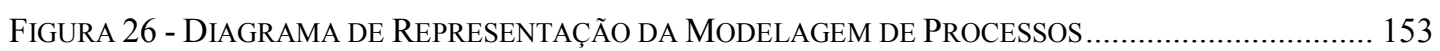

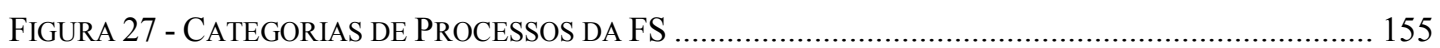

Figura 28 - ESTRUTURA ORganizacional DA EMPRESATI - ORIENTADA A CliENTES ...................... 172

FIGURA 29- DIAGRAMA DOS COMPONENTES ORGANIZACIONAIS DE ANÁLISE DA FS............................. 177 


\section{LISTA DE TABELAS}

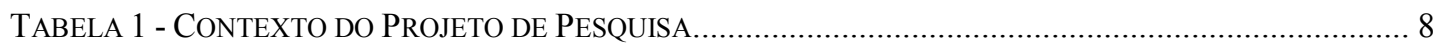

TABELA 2 - COMPILAÇ̃̃o de TRABALHOS SOBRE FÁBrica de SOFTWARE ............................................... 15

TABELA 3 - ÁREAS DE DECISÃo EM OPERAÇÕES - MANUFATURA X SERVIÇOS........................................ 25

Tabela 4 - Processo de Decisão no Planejamento da ProduÇão ................................................... 32

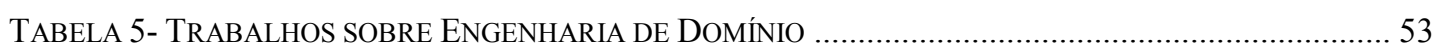

TABELA 6 - ARTEFATOS REUSÁVEIS NO DESENVOLVIMENTO DE SOFTWARE …………………………... 55

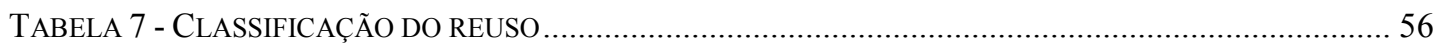

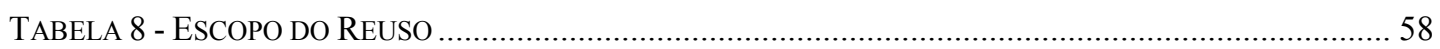

TABELA 9 - ARTEFATOS REUSÁVEIS NO DESENVOLVIMENTO DE SOFTWARE ……………….................. 58

TABELA 10 - CATEGORIAS DE REUSO BASEADOS NO RUP........................................................................ 58

TABELA 11- NÚCLEOS DAS ÁREAS FUNCIONAIS DO ITIL ……………………………….................. 74

TABela 12 - Principais MÉTodos de PesQuisa na EP ..................................................................... 97

TABela 13 - Seis Passos do Ciclo de CONDUÇ̃̃o A PARTIR de COUGHLAN E COGHLAN......... 101

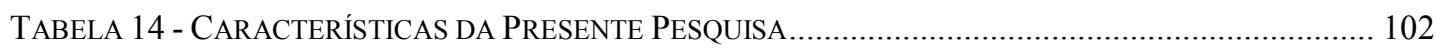

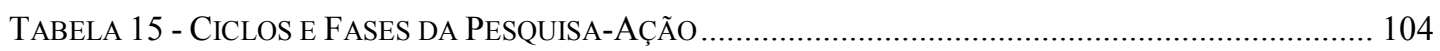

TABELA 16 - ARTEFATOS POSSÍveIS DE SEREM REUSADOS No MODELO DE FS ...................................... 150

Tabela 17 - Modelos de Melhores Práticas associados aos Processos da FS ....................... 167 


\section{LISTA DE ANEXOS}

ANeXo 1- Visão Estratégica - MACROfluXo do Processo de Negócio 183

ANEXo 2 - VISÃo FUNCIONAL - MATRIZ DE ATIVIDADES INTEGRADA - UNIDADE ORGANIZACIONAL 184 ANEXo 3 -Visão TÁTICA - FluXo do Processo-PAdRÃo de NeGÓCIO 185

ANEXO 4 - ESPECIFICAÇÃO DO PROCESSO-PADRÃO - MANUAL DA MDSI ............................................. 188

ANEXo 5 - MATRIZ DE ATIVIDADES INTEGRADAS DO PROCESSO-PADRÃO ............................................. 192

ANEXo 6 - FluXo do Processo de MANUTENÇão EVolutiva E AdAPTATIVA ................................... 193

ANEXo 7 - FluXo do PRoCESSO de MANUTENÇão CORRETIVA E ABEND ………………………….... 194

ANEXO 8 - ATRIBUIÇÕES DAS ÁREAS FUNCIONAIS DA FS..................................................................... 195

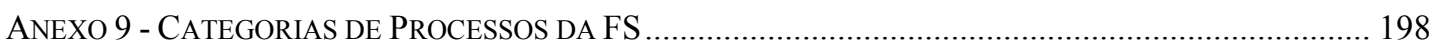

ANEXo 10 - ÁREAS DE DOMÍNIO DE NEGÓCIOS DO SETOR PÚBLICO....................................................... 199

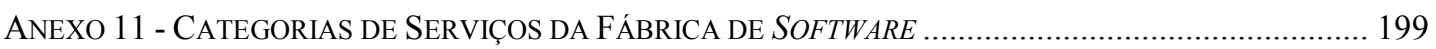

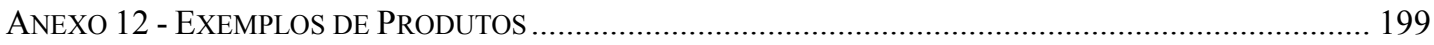

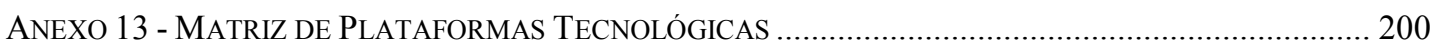

ANEXo 14- MATRIZ DE FERRAMENTAS, TÉCNICAS E METOdologias ................................................... 200

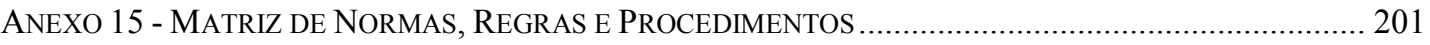

ANEXo 16 - MATRIZ de ARTEFATOS DE REUSO SUGERIDOS ................................................................... 201

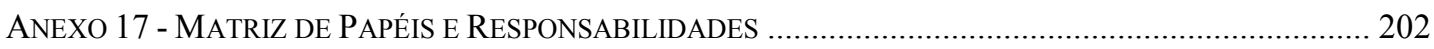

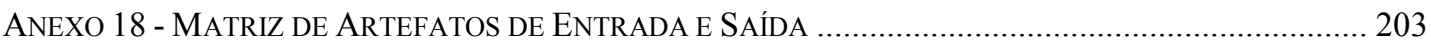

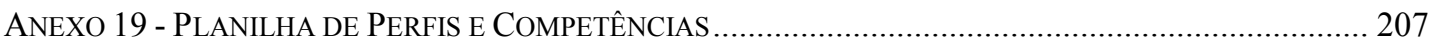

ANeXo 20 - Site da MDSI - Metodologia de Desenvolvimento de Sistemas E InTEGRaÇÃo .. 207

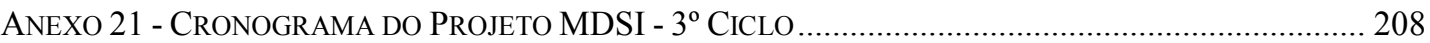




\section{LISTA DE ABREVIATURAS E SIGLAS}

AD - Administrador de Dados

APF - Análise de Pontos de Função

BPM - Business Process Management

BPMN - Business Process Modeling Notation

CASE - Computer Aided Software Engineering

CBSE - Component Based Software Engineering

CMI - Conselho Municipal de Informática

CMMI - Capability Maturity Model Integration

DBA - Data Base Administrator

DBC - Desenvolvimento Baseado em Componentes

ED - Engenharia de Domínio

EP - Engenharia de Produção

EPN - Engenharia de Processos de Negócios

ERP - Enterprise Resource Planning

ES - Engenharia de Software

FS - Fábrica de Software

GCS - Gestão da Configuração de Software

IDEF0 - Integration Definition Language for Function Modeling

IFPUG - International Function Point Users Group

ISO - International Organization for Standardization

ITIL - Information Technology Infrastructure Library

MDSI - Metodologia de Desenvolvimento de Sistemas e Integração

MSF - Microsoft Solution Framework

PA - Pesquisa-Ação

PCP - Planejamento e Controle de Produção

PMBOK - Project Management Body of Knowledge

PMO - Project Management Office

PMI - Project Management Institute

RUP - Rational Unified Process

SCAMPI - Standard CMMI Appraisal Method for Process Improvement

SEI - Software Engineering Institute 
SLA - Service Level Agreement

SOFTEX - Sociedade para Promoção da Excelência do Software Brasileiro

SPCP - Sistemas de Planejamento e Controle de Produção

SPICE - Software Process Improvement and Capability dEtermination

SPL - Software Product Line

TI - Tecnologia da Informação

TQM - Total Quality Management

UML - Unified Modeling Language 


\section{INTRODUÇÃO}

\subsection{Apresentação do Problema}

A projeção da demanda global e total de software sofre um grande aumento de ordem de magnitude, acionada por forças da economia global, como a emergência da China, a propulsão das fábricas de software da Índia e o aumento do papel do software na infra-estrutura social, por novos tipos de aplicativos e por novas plataformas tecnológicas como serviços de web, dispositivos móveis e aparelhos inteligentes (GREENFIELD, 2004).

O autor citado observa que o consumidor está cada vez mais exigente, valorizando atributos como qualidade, preço e prazo. Sobreviver e crescer significa saber incorporar mudanças e criar propostas ágeis e eficazes por meio de soluções que agreguem valor ao negócio, em busca de alternativas de adoção de sistemas de produção mais flexíveis.

O tema Fábrica de Software (FS) segue esta tendência, face ao intenso movimento de crescimento de demanda de software no mercado, seja em função da esperada redução de custos, da busca de maior qualidade, produtividade e padronização dos processos de desenvolvimento ou de um terreno promissor para a terceirização e exportação de serviços de software.

O conceito de FS é descrito por FERNANDES e TEIXEIRA (2004) como uma mudança de paradigma de desenvolvimento de software de forma artesanal para uma ciência. As abordagens de Engenharia de Software devem compreender métodos e ferramentas padrão, apoio automatizado para o desenvolvimento, planejamento disciplinado, análise e controle de processos, códigos e componentes reusáveis. Estas mudanças envolvem estratégias de gestão e organizacionais, concentrando-se nos processos que agreguem valor ao cliente. Conforme os autores citados uma área de desenvolvimento e manutenção de sistemas ou software é cada vez mais uma fábrica de serviços que necessita de uma visão mais orientada para a gestão de operações com foco no cliente.

COSTA (2003) aponta FS como uma proposta de solução para o outsourcing, ou seja, terceirizar alguns setores como operações "fabris". Caracteriza-se por uma estrutura complementar à organização do cliente, ampliando de forma eficaz e qualificada a capacidade de atendimento à demanda de serviços de software, levando 
em consideração fatores como gestão de pessoas, gestão organizacional, qualidade de software, de processos e produtos. Com a terceirização, todas as disciplinas de projetos de software podem ser segmentadas em uma FS, como: planejamento, levantamento de requisitos, análise e desenho, construção e testes.

A maturidade de uma organização em Engenharia de Software mede o grau de competência, técnica e gerencial, que essa organização possui para produzir software de boa qualidade, dentro de prazos e custos razoáveis e previsíveis (PAULA FILHO, 2003).

O autor citado considera que, em organizações com baixa maturidade em software, os processos são informais, e apenas existem na cabeça de seus praticantes. Um dos pontos principais para as organizações que adotam o modelo de FS é a existência de processos definidos que permitem que a organização tenha um modus operandi padronizado e reprodutível. Isto facilita a capacitação das pessoas e torna $\mathrm{o}$ funcionamento da organização menos dependente de determinados indivíduos.

Segundo o autor, entretanto, não é suficiente que os processos sejam definidos. Processos rigorosamente definidos, mas não alinhados com os objetivos da organização são entraves burocráticos e não fatores de produção. $O$ critério de verdadeiro êxito dos processos é a medida de quanto eles contribuem para que os produtos sejam entregues aos clientes e usuários com melhor qualidade, por menor custo e em prazo mais curto.

SANTOS (2002) ressalta a importância do estudo sobre processos, mostrando crescentes tendências nas organizações: processos cada vez mais interfuncionais, em razão da multiplicidade de conhecimentos necessários ao desenvolvimento de atividades nas organizações; ampla segmentação de clientes (individualização) que demanda customizações que criam complexidade aos processos; redução dos ciclos de vida dos produtos e serviços em função do crescente aumento da taxa de inovação nas organizações; globalização da competição, na qual produtos e serviços são resultados de processos que devem atender às necessidades dos clientes locais ou em diferentes eixos geográficos; integração das cadeias de suprimentos que trazem mais pressão à flexibilidade, integração e dinâmica dos processos dentro e entre organizações; valorização dos trabalhadores do conhecimento, que passam a ser um dos eixos de diferenciação das organizações, visto que diante de tanta complexidade 
a capacidade de aprendizado, explicitação e acúmulo de experiências apresenta-se como fundamental.

Esta multiplicidade e complexidade de fatores relatados estão presentes em um grande contingente de empresas produtoras de software e caracteriza-se por:

- Diversidade de projetos, produtos e serviços oferecidos acrescidos com o aumento das demandas;

- Diversidade nas áreas de domínios de negócios;

- Ambiente multidisciplinar: diferentes áreas de domínio de conhecimentos envolvidas no sistema de produção como: Engenharia de Software, Engenharia de Produção, Administração da Produção, Gestão de Projetos, Gestão do Conhecimento, Gestão de Competências, Gestão de Processos, Metodologias de Qualidade, Estrutura e Cultura Organizacional, entre outros;

- Ambiente multifuncional: processos cada vez mais interfuncionais, que exigem competências e especializações distintas em: comercialização, relacionamento e atendimento ao cliente, gestão de projetos, negócios, processos, arquitetura de software, engenharia de software, análise e design, codificação, testes, qualidade, infra-estrutura, suporte, enfim, diferentes especializações que implicam em papéis e responsabilidades específicos;

- Ambiente multiplataforma: diversidade de plataformas tecnológicas como mainframe, cliente servidor, web, sistemas integrados e sistemas distribuídos;

- Multiplicidade de tecnologias de hardware e software, associados a técnicas, ferramentas e métodos específicos que, por sua vez, são inovados com freqüência por intermédio de novos produtos lançados no acirrado e concorrente mercado de Tecnologia da Informação (TI), o que dificulta sua atualização e acompanhamento;

- Complexidade na integração e alinhamento com processos de fornecedores externos;

- Complexidade na gestão por competências dos profissionais da área de TI.

As pesquisas contemporâneas abaixo descritas mostram evidências representativas da crescente importância do estudo sobre Fábrica de Software e Processos:

- Pesquisa realizada pela Sociedade para Promoção da Excelência do Software Brasileiro (SOFTEX, 2002) em parceria com o Massachussets Institute of 
Technology (MIT), mostrou que o Brasil possui um conjunto de realidades mais do que uma identidade. Por um lado, caracteriza-se por uma forte demanda doméstica que desestimula a exportação, por uma fragmentação do mercado nacional. Por outro, o Brasil é o sétimo mercado mundial de software, concorrendo com China e Índia. Neste caso, existe uma presença importante de empresas nacionais em quase todas as áreas do mercado de software, que rivalizam em competição aberta com empresas internacionais presentes no País.

Nessa pesquisa observou-se que a maioria das empresas tem seu modelo de negócios baseado em produto, mas são os serviços que asseguram a maior fatia de sua comercialização.

No que diz respeito à capacitação de processo, embora todas as empresas analisadas tenham referido que dispõe de metodologia de desenvolvimento, a pesquisa constatou que apenas uma pequena parcela possui certificação de elevada maturidade em seu processo de desenvolvimento de software, uma lacuna importante do ponto de vista de afirmação internacional.

$\mathrm{O}$ estudo sugere áreas de desenvolvimento, potencialmente no setor financeiro e de governo. As duas importantes áreas que se destacam são Entreprise Resource Planning (ERP) para pequenas e médias empresas e Fábricas de Software. A indústria brasileira de software é reconhecida pela sua criatividade, competência e capacidade de inovação. Apesar do Brasil mostrar possuir um grande potencial de crescimento, ainda se convive com prazos e orçamentos não cumpridos e falta de qualidade nos produtos comercializados.

- Uma pesquisa conduzida pelo GARTNER (2006) e divulgada na XI Conferência Anual em São Paulo revela que, enquanto $56 \%$ das empresas mundiais colocam entre suas prioridades de negócios para 2006 fatores como crescimento da relação com os clientes, $52 \%$ de empresas brasileiras ainda têm como preocupação central a melhoria dos processos de negócios.

Um fator que reforça a importância do estudo sobre processos em organizações de TI, é o crescimento da adoção de soluções tecnológicas relacionadas a processos de negócios como o Business Process Management System (BPMS), que é a plataforma tecnológica para a realização de gestão de processos de negócios, possibilitando a 
descoberta, o desenho e o detalhamento de processos de negócio, assim como a execução, administração, supervisão e controle.

O Business Process Modeling Notation (BPMN) é uma iniciativa desenvolvida pelo grupo chamado Business Process Management Initiative (BPMI), que tem como objetivo o estabelecimento de um padrão para modelagem de processos.

Neste sentido, as organizações estão sempre em busca de maior produtividade, que pode ser conseguida via aquisição de ferramentas mais produtivas e/ou via técnicas de estudo de métodos de trabalho. O grande desafio para manter a competitividade e o foco sempre voltado ao cliente é conseguir flexibilizar a produção para a obtenção de um produto que esteja de acordo com o desejo do cliente, mantendo altos índices de produtividade e qualidade.

O aumento da escala de produção de software acarreta um crescimento significativo da complexidade de seu processo de produção. Isto ocorre em razão de dificuldades para integração e harmonização das características técnicas, funcionais, operacionais, gerenciais e estratégicas das diversas etapas do processo de desenvolvimento e manutenção de software e em diferentes plataformas tecnológicas e de negócios.

A adoção de um modelo de FS vem como uma solução para atender à crescente demanda de software, visando a divisão das atividades com a adoção de um sistema de produção mais flexível e dinâmico, facilitando a prática da terceirização. Neste contexto, faz-se necessária a criação de processos de negócios de desenvolvimento de software baseados em fluxos de produção claros e bem definidos, profissionais especializados e reuso de artefatos de software de forma produtiva, a fim de evitar desperdícios e retrabalhos.

Isto implica a definição estratégica da estrutura organizacional de FS, na organização do trabalho adequada às diferentes demandas de serviços e produtos e na integração e alinhamento dos distintos processos existentes no funcionamento da FS, procurando seguir sempre sua linha dorsal. A adoção do paradigma FS sugere novas estruturas organizacionais, na qual aparecerão processos, subprocessos e células que cortam transversalmente a estrutura funcional.

A aplicação prática da presente pesquisa foi executada em uma empresa de Tecnologia da Informação que presta serviços ao setor público. Neste cenário deparamos com outra questão: analisar, definir e estabelecer processos de FS, 
considerando a complexidade que envolve empresas do setor público. Em geral, estes ambientes possuem características em comum como: descontinuidade administrativa, provocada por eleições; constantes mudanças organizacionais; não visam lucratividade; ausência de indicadores de desempenho; tendência a "verticalização" do processo; conflitos entre o pessoal permanente e não permanente; projetos de curto prazo; descontinuidade nos projetos; projetos duplicados; e clima de desgaste, insegurança e resistência entre os funcionários de carreira ou não.

Neste cenário surgem dificuldades em conciliar os aspectos políticos, estrutura organizacional e cultura organizacional com os aspectos de negócios, operacionais e técnicos relativos à produção de software. Assim a adoção de um modelo de FS em uma organização de TI do setor público torna-se ainda mais complexa.

\subsection{Motivação}

A motivação inicial de pesquisa sobre o tema "Fábrica de Software" surgiu em 2002, pela participação da autora, do projeto denominado ElabSoft - Laboratório de Desenvolvimento de Projetos e Processos de Software do Departamento de Engenharia de Produção da Escola Politécnica da Universidade de São Paulo, constituído por um grupo de especialistas em Tecnologia da Informação (TI).

Para TRINDADE (2006), o objetivo principal do ElabSoft constituí-se em levantar, discutir, experimentar e gerir conhecimentos direta e indiretamente ligados à aplicabilidade da Engenharia de Software, mais especificamente como potencializar a produtividade no desenvolvimento de software por meio de processos otimizados, tanto de manufatura como de organização e gerenciamento da produção. Uma das linhas de pesquisa do Elabsoft refere-se à definição de uma "Fábrica de Software Modelo", cujo desenvolvimento foi iniciado pelo grupo, com o objetivo de conceituar métodos, técnicas e ferramentas relativas ao contexto fabril para software, dando ênfase à componentização.

Outra pesquisa associada ao Elabsoft, que a autora participou referiu-se ao desenvolvimento de um projeto piloto denominado Manwapp, um sistema informatizado para administração e controle de serviços externos prestados em campo por empresas de telecomunicações. 
O referido projeto usava a plataforma Internet como meio de integração e acesso dos usuários ao sistema, sendo apoiado também por tecnologias wireless. O Manwapp foi desenvolvido, com a colaboração dos participantes do grupo, por meio da metodologia Orientada a Objetos, no modelo de arquitetura de três camadas: apresentação, negócios e persistência, utilizando UML (Unified Modeling Language), Tecnologia DotNet e processo RUP (Rational Unified Process), além de um conjunto de técnicas e ferramentas de implementação.

A partir da participação nos projetos do Elabsoft, a autora iniciou o estudo do presente trabalho, que no início visava a pesquisa do reuso de componentes e processos de Software em um contexto de Fábrica de Software.

Entretanto, em outro momento surgiu a oportunidade para aplicar os conceitos de Fábrica de Software em uma empresa produtora de software em larga escala para diversos clientes simultaneamente que atende o setor público municipal, que será denominada neste trabalho como EmpresaTI.

O projeto em foco tinha como objetivo inicial o mapeamento dos principais processos de negócios, alinhados à nova estrutura organizacional da empresa, ou seja, era necessário mapear todos os processos interfuncionais, definindo claramente os links entre as áreas da empresa, os clientes, fornecedores e artefatos de entrada e saída, assim abranger, tanto os aspectos de sistemas de produção como os de Engenharia de Software e processos de terceirização.

Neste contexto, posteriormente, o projeto passou a denominar-se "Metodologia de Desenvolvimento de Sistemas e Integração" - MDSI. No projeto, a autora como funcionária regular da EmpresaTI, atuou em equipes multidisciplinares, com competências de analista de processos, analista de sistemas e, sobretudo, pesquisadora. Desta forma, aconteceu a continuidade empírica do estudo, caracterizando a metodologia de pesquisa como pesquisa-ação e, consolidando-se o objetivo principal do presente trabalho, referente a: "Como mapear, definir, reestruturar e estabelecer processos de Fábrica de Software em uma organização de TI do setor público?”. 


\subsection{Objetivos}

O presente estudo insere-se na área de Engenharia de Produção, subárea de Tecnologia da Informação, no contexto geral de Fábrica de Software e Melhoria de Processos.

O objetivo geral do trabalho referiu-se a:

- Como mapear, definir, reestruturar e estabelecer processos e conceitos de Fábrica de Software em uma organização de TI do setor público. As características de FS consideradas foram: padronização de processos, reuso de artefatos, segmentação de atividades, gestão de operações, terceirização, estrutura e cultura organizacional. A meta principal referiu-se à integração e alinhamento corporativo do processo de desenvolvimento e manutenção de software.

Os objetivos específicos foram:

- Estudar e analisar conceitos, características e processos sobre Fábrica de Software, com base na literatura, assim como pesquisar temas relacionados ao contexto da pesquisa;

- Criar, definir, e aplicar os modelos conceituais: Estrutura Organizacional de Referência de FS; Modelo Dinâmico de Referência de FS; Arquitetura de Definição de Processos para FS; Modelo de Definição de Processos; Diagrama de Representação da Modelagem dos Processos; Diagrama de Componentes Organizacionais de Análise da FS; Metodologia de Desenvolvimento de Sistemas e Integração (MDSI).

- Planejar, estruturar e executar uma pesquisa-ação concretizando os objetivos definidos;

Os dados da Tabela 1 sumarizam o contexto do projeto de pesquisa deste trabalho.

Tabela 1 - Contexto do Projeto de Pesquisa

\begin{tabular}{|l|l|}
\hline \multicolumn{1}{|c|}{ Componente } & \multicolumn{1}{c|}{ Contexto do Projeto de Pesquisa } \\
\hline Metodologia & Pesquisa-ação \\
\hline Questão do estudo & $\begin{array}{l}\text { Como mapear, definir, reestruturar e estabelecer processos de Fábrica de } \\
\text { Software em uma Organização de TI do setor público? }\end{array}$ \\
\hline Proposições & $\begin{array}{l}\text { É possível mapear, definir, reestruturar e estabelecer processos de } \\
\text { Fábrica de Software em uma organização de TI do setor público, } \\
\text { considerando aspectos, como: padronização de processos, reuso de } \\
\text { artefatos, segmentação de atividades, terceirização, estrutura e cultura } \\
\text { organizacional visando a integração e alinhamento corporativo. }\end{array}$ \\
\hline
\end{tabular}




\begin{tabular}{|c|c|}
\hline $\begin{array}{l}\text { Unidade(s) de } \\
\text { análise(s) }\end{array}$ & $\begin{array}{l}\text { - Identificação: } \\
\text { Empresa de economia mista de TI - Tecnologia da Informação de grande } \\
\text { porte, que atua no setor público, com cerca de } 700 \text { pessoas na força de } \\
\text { trabalho, denominada neste trabalho como EmpresaTI. } \\
\text { • Características Gerais: } \\
\text { Ambiente multifuncional, multidisciplinar, multiplataforma, diversidade } \\
\text { de clientes, produtos e serviços oferecidos, diversidade de infra-estrutura } \\
\text { de hardware e software, opera com processos de terceirização. } \\
\text { - Unidades de Análise: } \\
\text { - Unidade de Análise 1: } \\
\text { Estrutura Organizacional e Cultura Organizacional } \\
\text { - Unidade de Análise 2: } \\
\text { Metodologias e Processos de Desenvolvimento e Manutenção de } \\
\text { Software } \\
\text { - Unidade de Análise } 3: \\
\text { Mudanças Organizacionais }\end{array}$ \\
\hline Envolvidos na pesquisa & Pesquisadores, diretores, gerentes, analistas, técnicos e especialistas \\
\hline $\begin{array}{l}\text { Interessados nos } \\
\text { resultados }\end{array}$ & $\begin{array}{l}\text { Organizações produtoras de software, Fábricas de Software, por meio da } \\
\text { alta direção, dos empresários, diretores, gerentes, analistas, } \\
\text { desenvolvedores, técnicos e especialistas; } \\
\text { Pesquisadores das áreas de melhoria de processos de desenvolvimento de } \\
\text { software e Fábrica de Software }\end{array}$ \\
\hline
\end{tabular}

A pesquisa pretende oferecer uma contribuição de cunho empírico, no sentido de mapear, definir, reestruturar e estabelecer processos de FS alinhados ao contexto de uma organização produtora de software do setor público, considerando aspectos estratégicos, operacionais, técnicos e cultura organizacional. O objetivo para o meio acadêmico é contribuir como referência para estudos relacionados à Definição e Mapeamento de Processos de Fábrica de Software e Melhoria de Processos de Desenvolvimento e Manutenção de Software.

\subsection{Estrutura do Trabalho}

O presente trabalho está estruturado em oito capítulos, dos quais este é o Capítulo 1 que apresentou a proposta do trabalho, o contexto do problema, a motivação para este estudo, os objetivos a serem alcançados e a estrutura do trabalho.

O Capítulo 2 trata da fundamentação teórica por meio de assuntos envolvidos para base do estudo: Fábrica de Software, contribuições da Engenharia de Produção, contribuições da Engenharia de Software, reuso de software, Modelos de Melhores Práticas, Gestão de Processos, Estrutura Organizacional e Cultura Organizacional. O Capítulo 3 apresenta a metodologia de pesquisa, a estrutura e a lógica do processo de pesquisa, enfocando o método de pesquisa-ação. 
O Capítulo 4 trata da Fase Preliminar da pesquisa referente à caracterização da Empresa estudada, envolvendo seu histórico e cultura organizacional.

O Capítulo 5 descreve o Ciclo 1 da pesquisa-ação, referente à análise do contexto organizacional e ao desenvolvimento da Estrutura Organizacional de Referência de Fábrica de Software e do Modelo Dinâmico de Referência de Fábrica de Software, baseados na fundamentação teórica e pesquisa empírica.

O Capítulo 6 descreve o Ciclo 2 da pesquisa-ação, referente ao mapeamento, definição e estabelecimento dos processos, compreendendo as fases de diagnóstico, planejamento, execução, avaliação e resultados. Neste ciclo, são gerados a Arquitetura e o Modelo de Definição de Processos para FS e o Diagrama de Modelagem de Processos. Na seqüência, são descritos: a condução do projeto, a aplicação dos modelos no mapeamento dos processos e a especificação das matrizes dos elementos fundamentais para definição dos processos. No mapeamento dos processos são consideradas as visões: estratégica, funcional, tática, específica ou operacional, pontual e de execução, gerando-se o macrofluxo do Processo de Negócio da Organização, o fluxo do Processo-Padrão e os fluxos específicos dos processos da FS.

O Capítulo 7 descreve o Ciclo 3 da pesquisa-ação referente à análise do impacto e influência das mudanças organizacionais nos processos e, a revisão dos artefatos gerados no Ciclo 2, assim como mostra o Diagrama dos Componentes Organizacionais de análise da FS para o desenvolvimento da Metodologia de Desenvolvimento de Sistemas e Integração - MDSI.

O Capítulo 8 faz a análise final, conclusões do trabalho, contribuições relevantes e sugestões para trabalhos futuros.

No final são apresentados os anexos referentes aos artefatos gerados durante a pesquisa-ação, e as Referências Bibliográficas que nortearam o estudo. 


\section{FUNDAMENTAÇÃO TEÓRICA}

A fundamentação teórica foi efetuada previa e concomitantemente ao período de duração da pesquisa-ação. O estudo serviu como embasamento para a construção dos modelos, que por sua vez, serviram como guia para o monitoramento e condução da pesquisa-ação, assim como ao entendimento do complexo contexto do ambiente pesquisado, culminando na associação do estudo empírico com o teórico.

O embasamento teórico do trabalho compreendeu as seguintes áreas do conhecimento que permeiam o conceito de Fábrica de Software: Contribuições da Engenharia de Produção; Contribuições da Engenharia de Software; Reuso de Software; Modelos de Melhores Práticas; Gestão de Processos; Estruturas Organizacionais e Cultura Organizacional, descritos a seguir.

\subsection{Fábrica de Software}

O paradigma de Fábrica de Software (FS) busca a obtenção de qualidade e produtividade no desenvolvimento e manutenção de software por meio de padronização de processos, reuso de artefatos e controle do sistema de produção. Um framework de FS pode ser abordado em diferentes óticas com foco em: segmentação das atividades; desenvolvimento baseado em componentes; linhas de produção de software e terceirização. O estudo destes assuntos é descrito nas subseções a seguir.

\subsubsection{Conceito de Fábrica de Software}

O termo Fábrica de Software foi usado entre 1960 e 1970, nos Estados Unidos da América (EUA) e no Japão. CUSUMANO (1991) foi um dos principais autores a divulgar o termo, em suas pesquisas, no final da década de 1980, a respeito das práticas de desenvolvimento de software. Segundo o autor, o sucesso das FS do Japão e EUA deve-se à inclusão de um alto grau de reuso, modularização, uso de ferramentas, controle e gerenciamento dos sistemas, aumentando a qualidade e a flexibilidade. Os projetos de FS desenvolvidos mostraram que o ganho de produtividade da indústria japonesa pôde ser superado pela adoção de seus métodos de trabalho.

A distinção feita pelos japoneses já levava em conta características que, hoje, ainda são despercebidas por várias empresas que associam o termo "Fábrica" ao mero desenvolvimento de software, sem a preocupação com as padronizações que vão 
além do algoritmo exigido pela linguagem de programação ou com os aspectos associados à produção em massa e em larga escala, tais como: simplificação, integridade conceitual, aderência aos padrões, automação seletiva no processo de desenvolvimento, padronizações de tarefas e de controles, divisão do trabalho, mecanização e automatização.

Entre as empresas norte-americanas pioneiras na construção de uma Fábrica de Software, encontra-se a System Development Corporation (SDC). Seu modelo, do início da década de 1970, apresentava duas partes: uma área de controle de projetos para assegurar a qualidade e outra área, de implementação, que incluía design, construção e testes de software, ambas coordenadas por procedimentos padrões (CUSUMANO, 1991).

Este modelo era continuamente alimentado por diversos projetos e culminou no Manual de Desenvolvimento de Software SDC, fazendo com que os projetos convergissem na montagem de produtos com menos defeitos e no cumprimento de prazos estabelecidos. O modelo rapidamente influenciou as empresas norteamericanas e japonesas.

De acordo com SWANSON (1991), a literatura de sistemas de informação não contempla a expressão "Fábrica de Software", mas concentra-se em aspectos chave em relação ao conceito, tais como reuso. Mas, esse reuso não é limitado meramente às linhas de código e sim aplicado a todo um conjunto de atividades propostas pela Engenharia de Software.

Conforme o autor citado, na mudança de paradigma do desenvolvimento de software de uma forma artesanal para uma ciência, as abordagens de Engenharia de Software devem compreender: métodos e ferramentas-padrão; apoio automatizado para o desenvolvimento; planejamento disciplinado; análise e controle de processos; códigos e componentes reusáveis.

HUMPHREY (1991) define o conceito de software e seu paradigma da produção em escala, configurando-a como prática industrial e conclui que as motivações para a evolução do conceito de "software-house" para "Fábrica de Software" estão alicerçadas nas necessidades de aumento da produtividade desse tipo de produto, pela implementação de práticas de reuso de componentes, de modelos processuais, 
estabelecimento de métricas quantitativas ligadas à produção e métodos apropriados à contigüidade administrativa.

O autor citado preocupou-se também com a proximidade da gestão de negócios e estabeleceu um guia para os negócios da produção de software, segundo uma divisão por áreas de gerenciabilidade, que denomina "Princípios da Gestão de Processos de Software":

- Administração do pessoal: os profissionais são fatores críticos no processo produtivo e devem ser intimamente envolvidos em seu desenvolvimento e em sua melhoria. A gestão deve focar os defeitos de produção, não como uma forma de caracterizar erros pessoais, mas como oportunidades para a evolução do processo;

- Metodologia de processo: os processos precisam ser formalmente definidos e ter metas e elementos de mensuração estabelecidos, para que dados estatísticos possam ser colhidos e analisados, permitindo identificar problemas e determinar suas causas;

- Suporte ao processo: grupos especiais precisam ser estabelecidos para que especializações e treinamentos necessários, tanto dos profissionais de produção como de administração sejam providenciados, visando à obtenção e o bom uso do melhor ferramental em suas especificações;

- Controle do processo: práticas de gerenciamento são necessárias ao controle das mudanças, considerando que a avaliação dos períodos produtivos é conduzida para o monitoramento de efetividades e identificação de necessidades de melhoria, o que leva a procedimentos certificadores da implementação de ações corretivas, quando necessárias e, conseqüentemente, da qualidade do processo.

AAEN et al. (1997) definem FS como uma organização que provê serviços de desenvolvimento de software com alta qualidade, a baixo custo e de forma rápida, utilizando um processo bem definido, flexível e reusável, tecnologia de ponta adequada ao padrão de desenvolvimento, reuso de código, além de algumas formas de feedback sobre o andamento da atividade.

Uma das características mais importantes para a proposta de uma FS reside no fato do uso intensivo da tecnologia de objetos, na montagem de uma biblioteca de componentes e no incentivo constante para a obtenção de design patterns, 
componentes e o uso de frameworks existentes em todas as áreas do desenvolvimento de software (COSTA, 2003).

FERNANDES e TEIXEIRA (2004) apresentam Fábricas de Software como um processo estruturado, controlado e melhorado de forma contínua, considerando as abordagens da Engenharia Industrial orientadas para o atendimento a múltiplas demandas de natureza e escopo distintas, visando à geração de produtos de software, conforme os requisitos documentados dos usuários e/ou clientes, da forma mais produtiva e econômica.

Conforme citam os autores, o fundamento para estabelecer uma FS está baseado na obtenção de benefícios das linhas de produção, na qualidade de produtos, como na produtividade alcançada. Estas linhas de produção baseiam-se na definição de um processo e um fluxo que devem acompanhar cada operação do processo, além de prover as ferramentas necessárias para se obter a ação necessária. Assim, quanto mais segmentado for o processo, mais simples será cada operação, obtendo com isto uma divisão do trabalho orientada à especialização.

Os autores observam que iniciativas de implementação de melhores práticas apoiadas em modelos de qualidade, metodologias e processos de gestão, sem o entendimento da gestão de múltiplas demandas e projetos e seus requisitos, produzem resultados bem aquém do esperado.

Alguns atributos básicos de uma FS são relacionados, conforme FERNANDES e TEIXEIRA (2004), a:

- Processo definido e padrão;

- Interação controlada com o cliente;

- Solicitações de serviço padronizadas;

- Estimativas de custos e prazos;

- Controle rigoroso dos recursos envolvidos em cada demanda da fábrica;

- Controle e armazenamento em bibliotecas de itens de software;

- Controle do status e execução de todas as demandas;

- Produtos gerados de acordo com os padrões estabelecidos pela organização;

- Equipe treinada e capacitada nos processos organizacionais e produtivos;

- Controle da qualidade do produto;

- Processos de atendimento ao cliente; e 
- Métricas definidas e controle dos acordos de nível de serviço definidos com o cliente.

Os dados da Tabela 2 mostram uma compilação de estudos sobre Fábricas de Software encontrados na literatura.

Tabela 2 - Compilação de Trabalhos sobre Fábrica de Software

\begin{tabular}{|c|c|}
\hline Autor & Síntese do trabalho \\
\hline $\begin{array}{l}\text { BREMER (1968) } \\
\text { apud CASTOR } \\
(2005)\end{array}$ & $\begin{array}{l}\text { BREMER (1968) relata que a General Eletric criou uma Fábrica de Software } \\
\text { para aumentar a produtividade no desenvolvimento de sistemas, por meio da } \\
\text { utilização de ferramentas padronizadas e bancos de dados com históricos para } \\
\text { controle financeiro e gerenciamento das atividades da fábrica. }\end{array}$ \\
\hline $\begin{array}{l}\text { M. D. MCLLROY } \\
\text { (1969) apud } \\
\text { CASTOR (2005) }\end{array}$ & $\begin{array}{l}\text { MCLLROY (1969) da AT\&T propôs novos conceitos para o } \\
\text { desenvolvimento produtivo de software, baseados na reutilização sistemática } \\
\text { de código. }\end{array}$ \\
\hline $\begin{array}{l}\text { BAUER (1971) } \\
\text { apud CASTOR } \\
(2005)\end{array}$ & $\begin{array}{l}\text { BAUER (1971) propôs que "o projeto e produção de software deve ser visto } \\
\text { como uma área da Engenharia Industrial”, listando problemas de projetos de } \\
\text { software em larga escala como: divisão das tarefas em partes gerenciáveis; } \\
\text { divisão do desenvolvimento em estágios distintos; acompanhamento e } \\
\text { gerenciamento do projeto automatizado. }\end{array}$ \\
\hline $\begin{array}{l}\text { MATSUMOTO } \\
(2002)\end{array}$ & $\begin{array}{l}\text { Apresenta a Fábrica de Software da Toshiba do Japão nos anos } 1970 \text { e } 1980 \text {, } \\
\text { reutilizando módulos e fragmentos de códigos existentes em aplicações } \\
\text { diferentes, introduzindo uso de ferramentas- padrão, provendo o treinamento } \\
\text { extensivo dos profissionais. }\end{array}$ \\
\hline $\begin{array}{l}\text { CUSUMANO } \\
\text { (1991) }\end{array}$ & $\begin{array}{l}\text { Relata estudos das FS no Japão: Hitachi, Nec, Toshiba e Fugitsu e FS nos } \\
\text { Estados Unidos da América nos anos 1960, } 1970 \text { e 1980, inclusão de alto } \\
\text { grau de reuso de código, aumento da qualidade e flexibilidade. }\end{array}$ \\
\hline $\begin{array}{l}\text { CUSUMANO } \\
\text { (1991) }\end{array}$ & $\begin{array}{l}\text { Descreve a Fábrica de Software da SDC - System Development Corporation. } \\
\text { Seu modelo do início da década de } 1970 \text { apresentava duas partes: uma área } \\
\text { de controle de projetos, para assegurar a qualidade, e outra de } \\
\text { implementação, que incluía o Design, Construção e Testes de software, } \\
\text { ambas coordenadas por meio de procedimentos-padrão. }\end{array}$ \\
\hline SWANSON (1991) & $\begin{array}{l}\text { Estudo de caso da aplicação do paradigma de FS na Celite nos Estados } \\
\text { Unidos da América concentrando esforços na introdução de qualidade no } \\
\text { processo de desenvolvimento e programação. }\end{array}$ \\
\hline $\begin{array}{l}\text { JOHNSON (1991) } \\
\text { Apud CASTOR } \\
(2005)\end{array}$ & $\begin{array}{l}\text { Expôs em seu livro: "The Software Factory: managing software development } \\
\text { and maintenance", o modelo implementado na empresa Hallmarks Cards, } \\
\text { focando uma FS, sobretudo em relação aos componentes, não aos processos. }\end{array}$ \\
\hline BASILI et al. (1992) & $\begin{array}{l}\text { Modelo de Fábrica de Projetos baseado em Fábrica de Experiência representa } \\
\text { a arquitetura da fábrica em níveis de abstração, como Fábrica de Domínios e } \\
\text { Fábrica de Componentes }\end{array}$ \\
\hline $\begin{array}{l}\text { EVANS (1994) } \\
\text { Apud CASTOR } \\
(2005)\end{array}$ & $\begin{array}{l}\text { Apresenta seu modelo de FS, baseado em uma linha de montagem que } \\
\text { interage com processos de garantia da qualidade do produto, suporte } \\
\text { automatizado para o desenvolvimento e gestão do ambiente. }\end{array}$ \\
\hline COSTA (2003) & $\begin{array}{l}\text { Baseado em uma estrutura de Fábrica de Software Padrão, o trabalho propõe } \\
\text { uma padronização para a definição do serviço, o uso de métricas adequadas } \\
\text { ao ambiente de fabricação de software, contribuindo na contratação, } \\
\text { definição dos prazos e custos do serviço a ser prestado. }\end{array}$ \\
\hline $\begin{array}{l}\text { GREENFIELD e } \\
\text { SHORT (2003) }\end{array}$ & $\begin{array}{l}\text { O conceito de FS é fundamentado no desenvolvimento baseado em } \\
\text { componentes, direcionado a modelos e a linhas de produto de software que } \\
\text { caracteriza uma iniciativa de fábrica, visando a tornar a montagem de } \\
\text { aplicações mais barata pelo de reuso sistemático, possibilitando a formação } \\
\text { de cadeias de produção. }\end{array}$ \\
\hline
\end{tabular}




\begin{tabular}{|l|l|}
\hline FERNANDES e \\
TEIXEIRA (2004) & $\begin{array}{l}\text { Apresentam um framework para FS classificada em quatro tipos de fábricas: } \\
\text { Fábrica de Projetos Ampliada, Fábrica de Projetos de Software, Fábrica de } \\
\text { Projetos Físicos, Fábrica de Programas. O trabalho mostra uma visão } \\
\text { orientada para a gestão de operações de processos produtivos e gerenciais. }\end{array}$ \\
\hline TRINDADE (2006) & $\begin{array}{l}\text { O trabalho foca os papéis que desempenham o conhecimento e o duo- } \\
\text { processo ensinagem-aprendizagem para suas administrações, visando a } \\
\text { permitir estruturação e gestão de saberes, competências e habilidades em um } \\
\text { contexto de Fábrica de Software. }\end{array}$ \\
\hline FABRI (2007) & $\begin{array}{l}\text { O trabalho propõe um modelo para a criação e organização de um processo } \\
\text { fabril de produção de software, baseado no mapeamento de 11 empresas de } \\
\text { produção de software, brasileiras e japonesas com características fabris. }\end{array}$ \\
\hline
\end{tabular}
Fonte: compilada pela autora

Nos últimos trinta anos, foram realizadas várias iniciativas para a criação de FS em diferentes partes do mundo, cada uma delas adotando distintas estratégias para organização e execução de suas atividades (CASTOR, 2005).

Segundo o autor, algumas tinham o foco na adoção de processos, outras priorizavam a adoção de ferramentas de automação. Assim, o termo "Fábrica de Software" passou um tempo esquecido e, atualmente, volta a ganhar espaço em corporações de bens e serviços de informática, não mais restritas aos grandes players de mercado, mas também a empresas de médio e pequeno porte. Apesar dessa nova retomada, o número de textos sobre o assunto ainda é muito reduzido. $\mathrm{O}$ autor relaciona alguns fatores que estão causando esta retomada:

- Padrões e especificações abertas;

- Práticas no mercado mundial de pesquisas em Engenharia de Software;

- Definição e amadurecimento de padrões de qualidade;

- Evolução das ferramentas CASE (Computer Aided Software Engineering);

- Facilidade de compartilhamento de conhecimento por meio da Internet;

- Alta competitividade no mercado;

- Fácil acesso a tecnologias;

- Aumento da demanda por software;

- Baixo custo do hardware;

- Movimento do software livre;

- O movimento dowsizing iniciado na década de 1980;

- O crescente número de terceirização na área de software.

A partir de um questionário, realizado de fevereiro a julho de 2002, efetuado em 31 empresas brasileiras que se denominam "Fábricas de Software", COSTA (2003) 
verificou que embora todas defendam os conceitos reais de uma FS, poucas realmente os aplicavam de forma efetiva. O uso de padrões e métricas ou técnicas que tragam maior qualidade e produtividade aos processos de desenvolvimento de software ainda são muito falados, porém, pouco praticados.

$\mathrm{O}$ autor constatou que na realidade existem estruturas organizadas em células específicas de desenvolvimento de software que se especializam e trabalham para um determinado cliente durante muito tempo, o que foge dos conceitos de uma FS dentro das propostas internacionais, sobretudo indianas, japonesas e norte-americanas.

Segundo TEIXEIRA (2006) os serviços fornecidos pelas FS do Brasil normalmente escalam em níveis como: prestação e consultoria, análise e modelagem de processos de negócio. Evidência disso é a proporção média no quadro de pessoal das FS, cuja parcela de profissionais dedicados exclusivamente à codificação de programas é reduzida, comparada a outros países onde se apostou na oferta de outsourcing de programação de software. Para o autor, a grande oportunidade de crescimento para as FS brasileiras está no mercado interno. Na competição, tanto doméstica como internacional, ele constata a necessidade de diferenciação por especialização em verticais de negócios que ofereçam aos clientes um valor maior do que o código.

\subsubsection{Frameworks organizacionais de Fábricas de Software}

Segundo BASILI et al. (1992), objetos de software e seus relacionamentos incorporam um grande volume de experiências e atividades de desenvolvimento passados. É este reuso da experiência que necessita ser totalmente incorporado ao processo de produção de software.

Os autores propõem um framework organizacional orientado ao reuso, como é mostrado na Figura 1, definindo duas estruturas: uma organização orientada ao projeto e outra denominada Fábrica de Experiência.

A Fábrica de Experiência é uma abordagem para monitorar e analisar os projetos desenvolvidos, desenvolver e empacotar as práticas de reuso de diferentes tipos de experiências que a organização possui como conhecimentos, processos, ferramentas e produtos, visando sempre ao reuso desses componentes de software.

A arquitetura da Fábrica de Experiência é representada em dois níveis de abstração: a Fábrica de Domínio, que é o gerenciamento do conhecimento por domínio de reuso, 
e a Fábrica de Componentes, que produz e manipula uma coleção de artefatos a serem fornecidos para a Fábrica de Projetos.

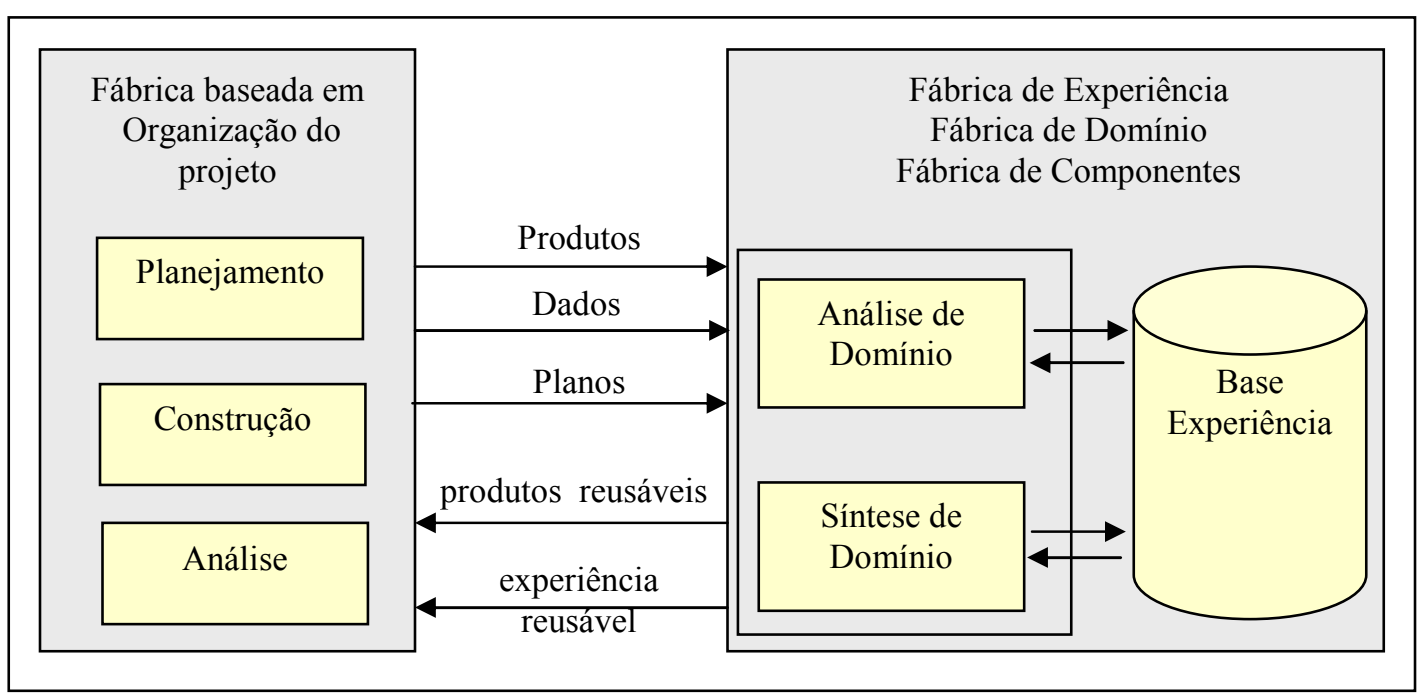

Figura 1 - Fábrica de Experiência

Fonte: BASILI et al. (1992)

A Engenharia de Software Baseada em Componentes (CBSE - Component-Based Software Engineering) é uma engenharia que enfatiza o projeto e a construção de sistemas baseados em computador, usando componentes de software reusáveis.

O modelo de desenvolvimento de software mostrado por PRESSMAN (2002) infere em um escopo de Fábrica de Componentes de Software, cujos processos de Engenharia de Domínio correm em paralelo com os da Engenharia de Software, reusando modelos de domínio, modelos estruturais e bibliotecas de componentes, conforme mostrado na Figura 2.

Para o autor, com o reuso sistemático, torna-se necessário criar processos de Engenharia de Domínio, como parte do processo de desenvolvimento, independente da Engenharia de Software. Em qualquer modelo de reuso, na Engenharia de Domínio, o produto principal é constituído de ativos reusáveis, a serem utilizados na construção de sistemas, e na Engenharia de Software, o produto é o próprio sistema de software. A Engenharia de Domínio cria um modelo de domínio de aplicação, que é usado como base para analisar os requisitos do usuário no curso da Engenharia de Software.

Uma arquitetura de software genérica (e os correspondentes pontos estruturais) fornece a entrada para o projeto da aplicação. Finalmente, depois de terem sido adquiridos, selecionados de bibliotecas existentes, ou construídos (como parte da 
Engenharia de Domínio), os componentes reusáveis são colocados à disposição dos engenheiros de software durante o Desenvolvimento Baseado em Componentes (DBC) (PRESSMAN, 2002).

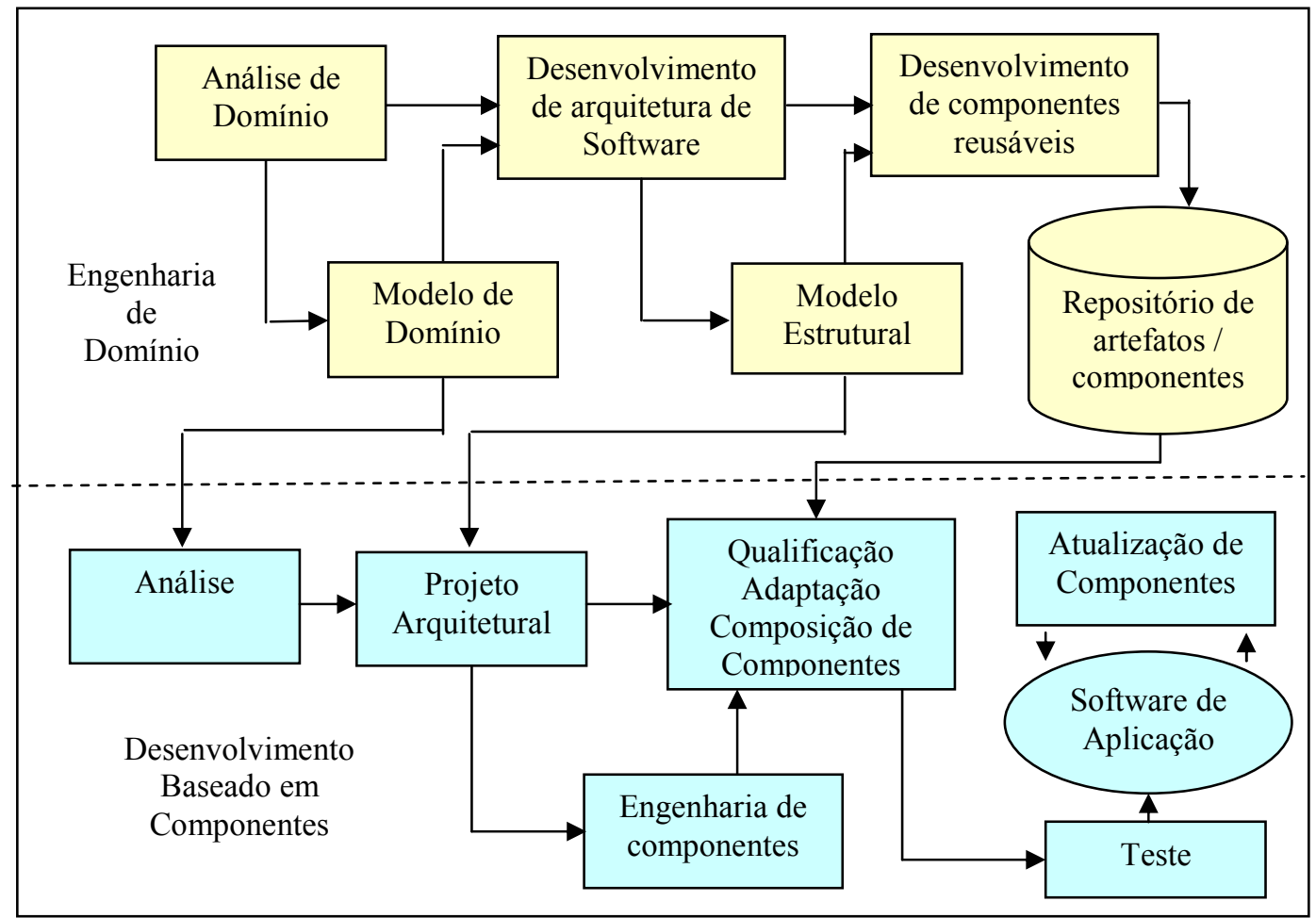

Figura 2 - Engenharia de Software Baseada em Componentes Fonte: PRESSMAN (2002)

FERNANDES e TEIXEIRA (2004) apresentam um framework para FS classificado em quatro tipos de fábricas, de acordo com seu escopo de atuação ao longo das fases de desenvolvimento de um projeto de software, conforme mostrado na Figura 3.

A Fábrica de Programas tem por objetivo principal codificar e testar programas de computador. No seu processo produtivo, engloba praticamente as fases de construção e testes unitários.

A Fábrica de Projetos atua com um pouco mais de abrangência no processo de produção, englobando fases, como: projeto conceitual, especificação lógica, projeto detalhado da solução, realização de testes de integração e de aceitação. Dependendo da interface com o cliente, a fábrica pode se caracterizar por projetos de software ou projetos físicos, porém, seus requisitos e características básicas são muito semelhantes. 


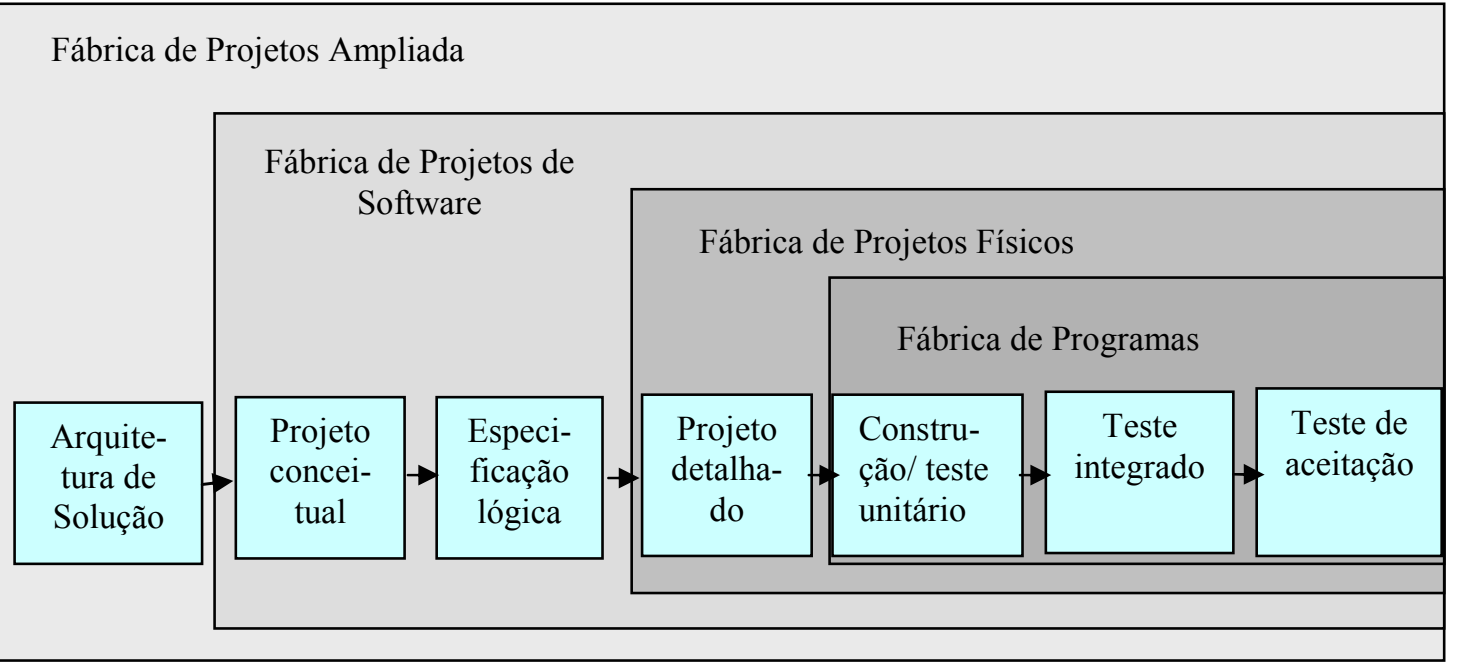

Figura 3 - Fábrica de Software

Fonte: FERNANDES e TEIXEIRA (2004)

A Fábrica de Projetos Ampliada abrange a arquitetura da solução, ou seja, um estágio anterior à conceituação do software que envolve: implantações de processos, hardware, serviços e equipamentos de rede, telecomunicações, etc.

\subsubsection{Linha de Produto de Software}

Uma linha de produto de software ou Software Product Line (SPL) é um conjunto de sistemas que usa software intensivamente, compartilhando um conjunto de características comuns e gerenciadas, que satisfazem as necessidades de um segmento particular de mercado ou missão, que são desenvolvidos baseados em um conjunto comum de ativos principais e de uma forma preestabelecida (CLEMENTS e NORTHROP, 2002).

Nesta definição, segundo os autores, alguns termos representam as características mais importantes de uma linha de produto: conjunto comum de ativos, forma preestabelecida e segmento particular de mercado ou missão.

- Conjunto comum de ativos ou artefatos: os ativos são a essência da linha de produto e correspondem a um conjunto de elementos customizáveis, utilizados na construção dos softwares produzidos (produtos). Entre os ativos estão, por exemplo: componentes de software, modelos de documentos utilizados no processo (artefatos), design-patterns utilizados pela equipe de desenvolvimento, documentação dos requisitos comuns à família de produtos, a arquitetura da linha de produtos (que será a base da arquitetura de cada produto gerado), cronogramas, etc. Dentre estes 
elementos, a arquitetura é o elemento-chave e, normalmente, é estudada à parte dos outros ativos.

- Forma preestabelecida: o processo de produção de software por intermédio de uma linha de produto é realizado por planos de produção que são definidos para cada software (produto) que será produzido pela linha. Ao definir um plano de produção, que dará origem a um novo produto, deve-se relacionar quais ativos farão parte desse produto e, assim, estabelecer um vínculo com os processos anexos de cada ativo usado.

Os processos anexos são pequenos processos de utilização contidos em cada ativo e que definem o que o ativo faz, qual sua flexibilidade, qual a técnica de configuração do ativo. Esta natureza preestabelecida de funcionamento do processo produtivo da linha de produto garante o ganho de tempo e confiabilidade no desenvolvimento dos produtos.

- Segmento particular ou missão: muitas vezes, chamado de domínio, refere-se ao corpo de conhecimento ou à área de especialização em que a linha de produto atua. $\mathrm{O}$ domínio está diretamente relacionado com o conjunto de funcionalidades correlacionadas que os produtos da linha pretendem atender. Como a flexibilidade dos ativos é limitada, o modelo exige uma delimitação de um segmento de atuação. Sem essa delimitação, o escopo da linha de produto poderia ser muito abrangente o que tornaria muito custoso criar e manter o conjunto comum de ativos.

Conforme DURSCKI et al. (2004), o processo do SPL sugere dividir o produto em pequenas partes, mais compreensíveis e gerenciáveis (ativos); possuir especificações claras e sem ambigüidades para produção / montagem (forma preestabelecida) e atender a um domínio específico (segmento particular ou missão) para que, como em uma linha de montagem da indústria tradicional, cada novo produto seja um reuso de partes de produtos construídos anteriormente, pertencentes à mesma família e, de preferência, com um mínimo de esforço adicional de construção.

O SPL tem por objetivo criar uma manufatura de software nos mesmos moldes de uma linha de montagem de automóveis, o que vem resolver a questão da Fábrica de Componentes de Software. Este conceito começa a ser adotado à medida que as novas plataformas de ambientes distribuídos se disseminam de forma generalizada e surgem novas ferramentas de apoio ao desenvolvimento. 
Observa-se que o conceito de linha de produto de software está alinhado ao processo de desenvolvimento de uma FS, sugerindo um processo de fabricação automatizado, baseado em componentes preestabelecidos, conforme o tipo ou domínio do produto.

\subsubsection{Terceirização e Fábricas de Software}

O potencial de terceirização em TI na área de desenvolvimento e manutenção de sistemas concentra-se no desenho da solução e na construção ou programação de sistemas. Para o desenho da solução é necessário conhecer os processos de negócios, neste caso é preciso ter critérios para selecionar quais atividades terceirizar, se estes são considerados estratégicos ou não à empresa. Já a construção ou programação de sistemas, é um procedimento que envolve conhecimento técnico e habilidades, motivo pelo qual a terceirização acontece mais facilmente nesta área, a qual já é citada como commoditie.

HUMPHREY (1989) considera que um dos aspectos fundamentais para a garantia da qualidade de software de terceiros é o processo de rever e auditar as soluções apresentadas pelos fornecedores, de acordo com procedimentos e padrões aplicáveis e definidos. Isto ocorre de forma minuciosa, avaliando a existência de desvios com relação aos requisitos e padrões especificados e contratados e que garantam desempenho e objetividade a seus resultados.

Esta questão tem sido alvo de constantes preocupações e ações de melhoria, tendo como foco principal o estabelecimento de processos metodológicos de desenvolvimento e manutenção de software de terceiros. A relação clientefornecedor de muitas empresas, além de estar embasada nesses modelos, encontra-se regulada através de acordos de níveis de serviço (SLA - Service Level Agreement) e, indicadores de projetos e processos que permitem uma transparência maior às partes envolvidas.

O amadurecimento dos processos tanto da contratada como da contratante é fator importante para assegurar resultados de sucesso. A garantia do processo de software descreve o conjunto de resultados esperados que podem ser atingidos quando se segue o processo de software estabelecido.

\subsubsection{Considerações}

As principais características encontradas nos conceitos relacionados à Fábrica de Software referem-se às: técnicas, conceitos e práticas industriais; reuso de artefatos; 
padronização de processos; ferramentas automatizadas; controle e garantia da qualidade; gestão de projetos; gestão de processos; gestão da produção; métricas de qualidade e produtividade; segmentação do trabalho; e, mais recentemente, estão relacionados aos conceitos de: componentização; frameworks; padrões; arquiteturas; linhas de produtos de software; terceirização e gestão de operações.

Uma Fábrica de Software pressupõe linhas de produção diferenciadas, com processos bem planejados e definidos para cada tipo de produto ou serviço oferecido, clara definição das atribuições das áreas funcionais, identificação de papéis e responsabilidades, criação de repositórios de reuso de artefatos, forte aplicação das práticas de Engenharia de Software, Gestão de Operações, Gestão de Projetos e Gestão de Processos.

Com o movimento de terceirização, as empresas que prestam serviços de terceirização de desenvolvimento e manutenção de software passaram a denominarse "Fábricas de Software", embora muitas não sigam os conceitos originais das propostas das empresas japonesas e norte-americanas. Comumente o termo "Fábrica de Software" é encontrado associado à terceirização de codificação (programação ou implementação ou construção) de software, por esta área ser a mais freqüente e facilmente terceirizada.

No contexto deste trabalho, o conceito de FS é usado para a organização cujo negócio-fim é a produção e fornecimento de software, ou seja, a FS cobre o ciclo inteiro de desenvolvimento e manutenção de software englobando todas as áreas e processos ligados à produção de software, incluindo os processos de terceirização.

CASTOR (2005) cita que com a constante evolução da Engenharia de Software e das tecnologias envolvidas no desenvolvimento de sistemas, as FS poderão vir a ser uma realidade cada vez mais presente no mercado e tornar-se cada vez mais efetivas dentro de seu objetivo de produzir software de qualidade, em pouco tempo e com baixo custo. Como resultado, espera-se em todo mercado mundial um crescimento ainda maior na adoção do modelo de Fábrica de Software para o desenvolvimento de sistemas.

\subsection{Contribuições da Engenharia de Produção}

Com a adoção do paradigma de Fábrica de Software, os modelos industriais começaram a ser referenciados nas estruturas corporativas das empresas de TI. A 
diversidade dos cenários de negócios, combinadas com a crescente necessidade de integração dos diversos ambientes tecnológicos, migraram as restrições de produtividade do domínio da tecnologia para o controle operacional.

Desta forma, torna-se importante a junção de diversificadas áreas de domínios do conhecimento como a Engenharia de Produção, Administração, Gestão de Processos, Qualidade e Engenharia de Software, para permitir o gerenciamento da complexidade desses ambientes, garantir a execução dos serviços das empresas de TI e, obter a agilidade organizacional almejada. Nas próximas subseções são estudadas disciplinas da Engenharia de Produção que permeiam o conceito de Fábrica de Software.

\subsubsection{Conceitos da Engenharia de Produção}

A definição clássica da Engenharia de Produção adotada tanto pelo American Institute of Industrial Engineering (A.I.I.E.) como pela Associação Brasileira de Engenharia de Produção (ABEPRO, 2007) diz: "Compete à Engenharia de Produção o projeto, a implantação, a melhoria e a manutenção de sistemas produtivos integrados, envolvendo homens, materiais e equipamentos, especificar, prever e avaliar os resultados obtidos destes sistemas, recorrendo a conhecimentos especializados da matemática, física, ciências sociais, conjuntamente com os princípios e métodos de análise e projeto da engenharia".

Em CONTADOR et al. (1997) é descrita a palestra proferida por LEME sobre Engenharia de Produção em 1965, em que conceitua: "Uma primeira classificação dos campos de atividade dentro da produção decorre da resposta às perguntas: o que, como, quando, quanto, com que e onde produzir. Uma segunda classificação corresponde às fases: planejamento, execução ou controle da produção. Dentro desta concepção existe um grande paralelismo entre os engenheiros de produto, processo e produção. Aos três cabe a tarefa de desenvolvimento e de projeto. O primeiro desenvolve e projeta o produto; o segundo, o processo; o último, o sistema. $\mathrm{Na}$ produção integram-se os três projetos: o produto, respondendo "o que fazer"; o do processo respondendo "como fazer", e o do sistema, indicando as formas de programação, supervisão e controle. Cabe à alta administração o planejamento geral da empresa, em suas diversas modalidades. Fazem parte deste planejamento geral a escolha da linha de produtos, a fixação da capacidade produtiva da empresa dentro de cada linha, o estabelecimento da política de pessoal, a programação dos 
investimentos, a escolha da forma de distribuição do produto. Este planejamento fixa os objetivos que servirão de base aos planos da administração média” (LEME, 1965). DAVIS et al. (2003) conceituam Administração da Produção com base na perspectiva corporativa, como sendo o gerenciamento dos recursos diretos que são necessários para obtenção dos produtos e serviços de uma organização. O mercado consumidor - os clientes dos bens e serviços da empresa - dá forma à estratégia corporativa da empresa. Esta estratégia é apoiada na missão corporativa e reflete como a empresa planeja usar todos os seus recursos e funções (marketing, finanças, produção, etc.) para obter vantagem competitiva. A partir de uma perspectiva operacional, os autores conceituam Administração da Produção como um conjunto de componentes, cuja função está concentrada na conversão de um número de insumos em algum resultado desejado. Esta conversão é denominada "processo de transformação", que costuma ser tratada como núcleo técnico, especialmente em organizações de manufatura. Os autores citados ressaltam que está cada vez mais difícil diferenciar entre serviços e manufatura. Conseqüentemente, a abordagem atual sugere que a vasta maioria dos produtos seja constituída, tanto dos componentes de bens como de serviços, e que ambos os elementos precisam ser abordados juntos, a fim de que a empresa seja bem-sucedida.

FERNANDES e TEIXEIRA (2004) consideram que uma estratégia de operações pode ser caracterizada como um padrão coerente de grande quantidade de decisões individuais, que afeta a habilidade da empresa obter vantagem competitiva. Dada à complexidade da função "operações”, os autores classificam tais decisões em áreas de decisão estratégicas que se caracterizam como famílias de problemas-afim, como mostradas na Tabela 3 .

Tabela 3 - Áreas de Decisão em Operações - Manufatura x Serviços

\begin{tabular}{|l|l|l|}
\hline \multicolumn{1}{|c|}{ Área de Decisão } & \multicolumn{1}{c|}{ Manufatura } & \multicolumn{1}{c|}{ Serviços } \\
\hline Projeto de Produtos e & Definir o pacote (produto e serviços de & Definir o pacote de \\
Serviços & apoio), assim como projetar o processo & serviços em termos de: \\
& que irá gerar o produto e decidir sobre a & instalações de apoio, bens \\
& tecnologia do produto. & $\begin{array}{l}\text { físicos facilitadores, } \\
\text { serviços explícitos e }\end{array}$ \\
& & implícitos, assim como \\
& & definir o processo de \\
& & entrega do serviço \\
\hline
\end{tabular}




\begin{tabular}{|c|c|c|}
\hline $\begin{array}{l}\text { Projeto da Rede de } \\
\text { Operações Produtivas }\end{array}$ & $\begin{array}{l}\text { Projetar a cadeia de fornecimento e de } \\
\text { distribuição; decidir sobre: o grau de } \\
\text { verticalização, localização e tamanho da } \\
\text { operação. }\end{array}$ & Idem. \\
\hline Projeto do Arranjo Físico & $\begin{array}{l}\text { Decidir sobre o tipo de arranjo físico em } \\
\text { função do processo, detalhar os recursos } \\
\text { necessários. }\end{array}$ & Idem. \\
\hline Tecnologia do Processo & $\begin{array}{l}\text { Decidir sobre a tecnologia de: } \\
\text { processamento de materiais, } \\
\text { processamento de informação, } \\
\text { processamento do consumidor e nível de } \\
\text { integração. }\end{array}$ & Idem. \\
\hline $\begin{array}{l}\text { Projeto e Organização do } \\
\text { Trabalho }\end{array}$ & $\begin{array}{l}\text { Decidir sobre: habilidades da força de } \\
\text { trabalho, projeto de tarefas, aspectos } \\
\text { ergonômicos, aspectos comportamentais } \\
\text { e de gestão da força de trabalho. }\end{array}$ & Idem. \\
\hline $\begin{array}{l}\text { Planejamento e Controle da } \\
\text { Capacidade Produtiva }\end{array}$ & $\begin{array}{l}\text { Decidir sobre: a capacidade do sistema } \\
\text { de operação, políticas de capacidade, } \\
\text { abordagem de planejamento e controle. }\end{array}$ & Idem. \\
\hline $\begin{array}{l}\text { Planejamento e Controle de } \\
\text { Estoque }\end{array}$ & $\begin{array}{l}\text { Decidir sobre: volume de suprimento, } \\
\text { tempo de colocação de pedidos, sistema } \\
\text { de controle e análise de estoque. }\end{array}$ & $\begin{array}{l}\text { Aplicam-se a certos tipos } \\
\text { de serviços, cujos bens } \\
\text { facilitadores e instalações } \\
\text { são componentes } \\
\text { fundamentais no pacote } \\
\text { de serviços. }\end{array}$ \\
\hline $\begin{array}{l}\text { Planejamento e Controle da } \\
\text { Cadeia de Suprimentos }\end{array}$ & $\begin{array}{l}\text { Decidir sobre: compras e políticas de } \\
\text { desenvolvimento de fornecedores, gestão } \\
\text { de distribuição física, logística, tipos de } \\
\text { relacionamento com a cadeia. }\end{array}$ & Idem. \\
\hline $\begin{array}{l}\text { Material Requirements } \\
\text { Planning }\end{array}$ & $\begin{array}{l}\text { Decidir sobre planos de capacidade de } \\
\text { recursos. }\end{array}$ & $\begin{array}{l}\text { Idem, inclusive para as } \\
\text { operações de mão-de-obra } \\
\text { intensiva. }\end{array}$ \\
\hline $\begin{array}{l}\text { Planejamento e Controle da } \\
\text { Qualidade }\end{array}$ & Decidir sobre o sistema da Qualidade. & Idem. \\
\hline Melhoramento da Produção & $\begin{array}{l}\text { Decidir sobre indicadores de } \\
\text { desempenho. }\end{array}$ & Idem. \\
\hline $\begin{array}{l}\text { Prevenção e Recuperação de } \\
\text { Falhas }\end{array}$ & $\begin{array}{l}\text { Decidir sobre: indicadores e tratamento } \\
\text { de falhas, melhoria do processo. }\end{array}$ & Idem. \\
\hline Administração da Qualidade & $\begin{array}{l}\text { Decidir sobre: abordagem da gestão da } \\
\text { qualidade, sistemas da qualidade, } \\
\text { mecanismos de melhoria contínua. }\end{array}$ & Idem. \\
\hline
\end{tabular}

Fonte: FERNANDES e TEIXEIRA (2004)

\subsubsection{Processos de Produção}

De acordo com DAVENPORT (1994), processo é um conjunto de atividades que devem ser executadas para atender a um cliente. É uma estrutura específica de atividades localizadas no tempo e no espaço, com um começo, um fim, entradas e saídas claramente identificadas. Exige uma acentuada ênfase na maneira como o trabalho é feito na organização, em contraste com a ênfase relacionada com o produto, que se centra no que é o produto. 
O autor cita que a atenção crescente para com o projeto, visando à industrialização, é prova de que as empresas reconhecem a importância da engenharia no processo de fabricação, bem como do produto. $\mathrm{O}$ autor cita que dois influentes executivos dos setores de engenharia e pesquisa, da IBM e da GE, pronunciaram: "A fase de projeto do ciclo de desenvolvimento tem se concentrado tradicionalmente nas características e desempenho do produto e não no processo pelos quais é fabricado. Projetamos um produto primeiro, e depois nos incumbimos da tarefa de fazê-lo. Não obstante, o custo e a qualidade finais do produto são inseparáveis da maneira pela qual é feito. Se o produto pode ser feito com facilidade, seus custos serão baixos e sua qualidade alta"

Para DAVENPORT (1994), a maneira de projetar o processo que produz o produto ou serviço terá um impacto significativo na habilidade da produção ao atender às necessidades de seus consumidores. Um processo implantado no local errado, ou com pessoal insuficiente, ou com um arranjo físico confuso ou desordenado, ou com tecnologia inadequada, ou com pessoal incapaz, não pode satisfazer consumidores, porque não se pode ter desempenho eficiente ou eficaz.

Por isso, o projeto, tanto de produtos e serviços como de processo afetará os objetivos de desempenho da produção. A adoção de processos dotados de uma estrutura clara pode ter várias de suas dimensões medidas. Esses processos podem ser medidos pelo tempo e custo de sua execução. Suas entradas e saídas podem ser avaliadas em termos de utilidade, coerência, variabilidade, ausência de defeitos e numerosos fatores. Estas medidas tornam-se os critérios para a avaliação do valor da inovação e para o estabelecimento de programas de melhoria constante.

\subsubsection{Sistemas de Produção}

SLACK et al. (1996) definem que, em geral, as classes de atividades que se aplicam a todos os tipos de produção, não importa como as fronteiras funcionais foram definidas, incluem:

- Entender os objetivos estratégicos da produção;

- Desenvolver uma estratégia de produção para a organização;

- Desenhar produtos, serviços e processos de produção;

- Planejar e controlar a produção; e

- Melhorar o desempenho da produção. 
HAX e CANDEA (1984) classificam o fluxo de produção em três classes: produção em massa, produção intermitente e produção unitária.

- Na produção em massa, tem-se uma linha de produção dedicada à produção em larga escala de um mesmo produto. Tanto as operações como o fluxo de materiais é bastante previsível, sendo o ritmo de produção definido pela velocidade da linha.

- Na produção unitária, a gerência da produção assemelha-se à gerência de projetos. O processo produtivo está direcionado para produção de um único ou poucos produtos simultaneamente. As atividades e o fluxo de produção são bastante diversificados e variáveis ao longo do tempo.

- Entre estes dois extremos situa-se a produção intermitente ou em lotes. Nesse caso, o volume de produção não justifica a implantação de uma linha dedicada (produção em massa) e, tampouco, a organização da produção semelhante à produção unitária (gerência de projetos). A produção ocorre em lotes de diferentes produtos que compartilham os mesmos recursos. O sistema de produção deve ser flexível o bastante para permitir mudanças de produtos ou lotes sem perda de eficiência.

Assim, as atividades de produção são caracterizadas por ordens de produção, em que se especificam quantidades, operações (roteiros de produção) e materiais necessários. Dada a intermitência do fluxo, surge o problema de seqüenciamento das ordens nos centros de produção e a necessidade de controlar o fluxo de materiais e o uso de outros recursos (humano, ferramentas, etc.) para manutenção do fluxo de produção.

Outro mecanismo para classificação dos sistemas de produção é identificar e diferenciar os sistemas produtivos entre os direcionados a estoque ou a ordens/ comendas. Essa classificação representa a forma de interação dos sistemas produtivos com os clientes, ou seja, o nível de interferência que o cliente tem no produto final. PIRES (1995) cita que o primeiro grupo engloba os sistemas nos quais a venda do produto, geralmente, é feita após sua produção, enquanto o segundo grupo engloba aqueles em que ela é feita antes da produção. $\mathrm{O}$ autor apresenta quatro tipos básicos dessa classificação:

- Produção para Estoque (MTS - Make to Stock): caracteriza os sistemas que produzem produtos padronizados, baseados em previsões de demanda. Nesse caso, nenhum produto é customizado, porque o pedido é feito com base no estoque de produtos acabados. Isso significa que a interação dos clientes com o projeto é muito 
pequena ou inexistente. Os sistemas MTS têm como principal vantagem a rapidez na entrega dos produtos, mas os custos com estoques tendem a ser grandes e os clientes não têm como expressar suas necessidades a respeito dos produtos. Nesses sistemas, os ciclos de vida dos produtos tendem a ser relativamente longos e previsíveis.

- Montagem sob Encomenda (ATO - Assemble to Order): caracteriza os sistemas em que os subconjuntos, grandes componentes e materiais diversos são armazenados até o recebimento dos pedidos dos clientes contendo as especificações dos produtos finais. A interação dos clientes com o projeto do produto é limitada. Nos sistemas ATO, as entregas dos produtos tendem a ser de médio prazo e as incertezas da demanda (quanto ao mix e volume dos produtos) são gerenciadas por meio de um excesso no dimensionamento dos estoques de subconjuntos e capacidades das áreas de montagem.

- Produção sob Encomenda (MTO - Make to Order): o projeto básico pode ser desenvolvido apoiado nos contatos iniciais com o cliente, mas a etapa de produção só se inicia após o recebimento formal do pedido. A interação com o cliente costuma ser extensiva e o produto está sujeito a algumas modificações mesmo durante a fase de produção. Num sistema MTO, os produtos, no qual, não são um de cada tipo, porque usualmente os produtos são projetados a partir de especificações básicas. Os tempos de entrega tendem a ser de médio a longo prazos e as listas são únicas para cada produto.

- Engenharia sob Encomenda (ETO - Engineering to Order): é praticamente uma extensão do MTO, com o projeto do produto sendo feito quase que totalmente baseado nas especificações do cliente. Os produtos são bastante customizados e o nível de interação com o cliente é muito grande.

\subsubsection{Planejamento e Controle de Produção}

SLACK et al. (1996) definem Planejamento e Controle de Produção (PCP) como sendo a atividade de se decidir sobre o melhor emprego dos recursos de produção, assegurando a execução do que foi previsto. Os autores definem planejamento como a atividade que garante que a produção ocorra eficazmente e produza produtos e serviços como devido. Isto requer que os recursos estejam disponíveis na quantidade adequada, no momento adequado e no nível de qualidade adequado. 
Conforme CORRÊA e GIANESI (1997), os Sistemas de Planejamento e Controle de Produção (SPCP) são o "coração" dos processos produtivos e a "cola" que mantém os vários recursos produtivos juntos, trabalhando como um sistema integrado e coeso, e não trabalhando apenas como um conjunto desconexo de elementos.

Eles têm o objetivo básico de planejar e controlar o processo de manufatura em todos os seus níveis, incluindo os materiais, os equipamentos, as pessoas, os fornecedores e os distribuidores. Por meio do SPCP, a organização garante que as suas decisões operacionais sobre o que, quando, quanto e com o que produzir e comprar sejam adequados às suas necessidades estratégicas que, por sua vez, são ditadas por seus objetivos estratégicos corporativos e pelo seu mercado.

Para PIRES (1995), por concepção o PCP trata de atividades altamente independentes que sempre requerem uma abordagem sistêmica em sua execução. Isso significa que, em um nível de complexidade variável, as atividades descritas, a seguir, e representadas na Figura 4, sempre se farão necessárias.

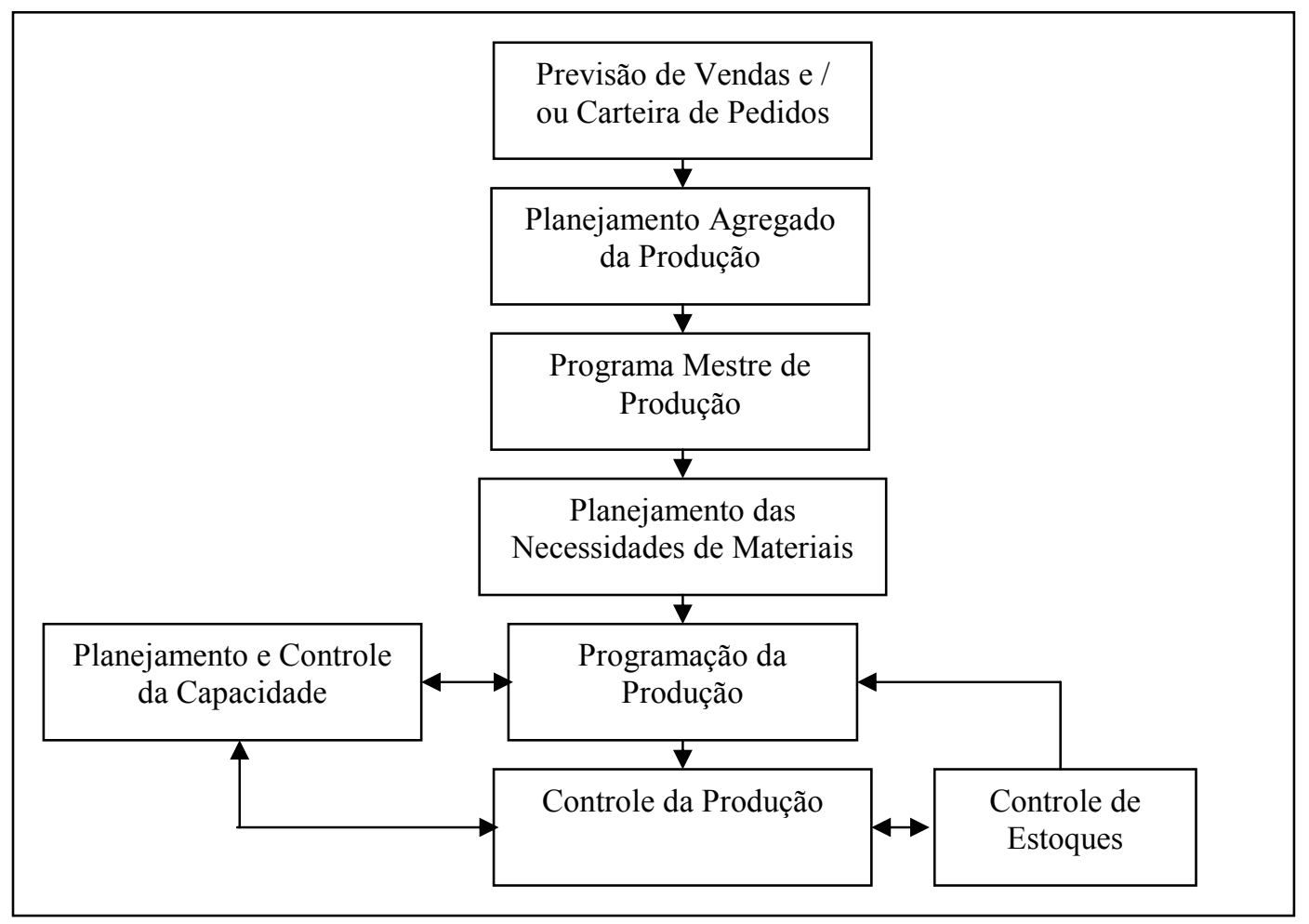

Figura 4 - Atividades básicas do Planejamento e Controle da Produção Fonte: PIRES (1995)

- Previsão de vendas e / ou carteira de pedidos: o planejamento praticamente se inicia com os dados fornecidos pela área de vendas. Normalmente, esses dados dizem respeito ao que produzir, em quais quantidades e em que prazo. 
- Planejamento agregado da produção: consiste no estabelecimento dos níveis gerais de produção e capacidade para um período de médio a longo prazo. Nesse nível de planejamento, uma macrocomparação da carga de trabalho com a capacidade permite antecipar a tomada de decisões, tais como novos investimentos.

- Programa mestre de produção: consiste em um referencial básico para a produção, estabelecendo quando e em que quantidade cada produto deverá ser produzido dentro de um determinado horizonte de planejamento. Na elaboração desse programa, as restrições impostas pela capacidade são verificadas em um nível macro, ou seja, geralmente é a etapa onde verificações mais detalhadas da capacidade podem nivelar a produção por restrições organizacionais e/ou econômicas.

- Planejamento das necessidades de materiais: calcula as chamadas necessidades líquidas para cada produto ou componente a ser produzido que são calculadas com base nas necessidades brutas vindas da lista de materiais, pelas exigências impostas pelo programa mestre e pelas informações do controle de estoques (itens em estoque e itens em processo de fabricação / compras).

- Controle de estoques: trata basicamente do controle sobre todos os itens fabricados, comprados e utilizados pela indústria para produção de seus produtos. O controle de estoques visa a trabalhar com dois objetivos aparentemente conflitantes: minimizar os investimentos em estoques e maximizar os níveis de atendimento aos clientes e à produção da indústria.

- Programação da produção: consiste em determinar os prazos de entrega para os itens definidos, respectivamente como fabricados e comprados. Para os itens fabricados, muitas vezes são definidos também o centro produtivo e a seqüência das operações a serem realizadas. As restrições a essa tarefa são impostas pela capacidade disponível do centro produtivo, para o período em questão, bem como pelas exigências tecnológicas colocadas nos roteiros de produção.

- Planejamento e controle da capacidade: estipula quais devem ser os níveis de produção máximos que os centros produtivos devem ter em um certo horizonte de planejamento. Cuida das providências para que a capacidade planejada seja realizada e das informações a serem utilizadas por outras atividades do PCP.

- Controle da produção: consiste em acompanhar a fabricação e compra dos itens planejados (programados), com o objetivo de que os prazos sejam cumpridos. O 
controle da produção costuma também atuar colhendo dados importantes para o sistema de custos, tomando decisões típicas de chão de fábrica (como mudanças de prioridades, necessidade de horas extras, etc.) e alimentando informações ao controle dos estoques.

Para CONTADOR e CONTADOR (1997), as atividades do PCP, podem ser divididas em quatro fases, que são hierarquizadas no sentido de que a fase seguinte seja iniciada após a implementação das decisões tomadas na fase anterior. Assim, a abordagem hierárquica considera diferentes horizontes de planejamento: longo, médio, curto e curtíssimos prazos (Tabela 4).

Tabela 4 - Processo de Decisão no Planejamento da Produção

\begin{tabular}{|l|l|l|l|}
\hline \multicolumn{1}{|c|}{ Horizonte } & \multicolumn{1}{|c|}{ Entradas } & \multicolumn{1}{c|}{ Funções do PCP } & \multicolumn{1}{c|}{ Saídas } \\
\hline Longo Prazo & $\begin{array}{l}\text { Pesquisa de Mercado } \\
\text { Previsões de longo prazo }\end{array}$ & $\begin{array}{l}\text { Planejamento de } \\
\text { recurso } \\
\text { COMO PRODUZIR }\end{array}$ & $\begin{array}{l}\text { Linhas de produtos } \\
\text { Processos de } \\
\text { fabricação } \\
\text { Políticas de } \\
\text { atendimento ao cliente }\end{array}$ \\
\hline Médio Prazo & $\begin{array}{l}\text { Previsões de demandas } \\
\text { de médio prazo } \\
\text { Planos de emprego da } \\
\text { mão-de-obra }\end{array}$ & $\begin{array}{l}\text { Plano de produção } \\
\text { O QUE É QUANTO } \\
\text { PRODUZIR }\end{array}$ & $\begin{array}{l}\text { Necessidades de } \\
\text { materiais } \\
\text { Planos de estocagem } \\
\text { Planos de entrega } \\
\text { Níveis de força de } \\
\text { trabalho }\end{array}$ \\
\hline Curto Prazo & $\begin{array}{l}\text { Prazos de entrega } \\
\text { Prioridades de } \\
\text { atendimento }\end{array}$ & $\begin{array}{l}\text { Programação da } \\
\text { produção } \\
\text { QUANDO } \\
\text { PRODUZIR }\end{array}$ & $\begin{array}{l}\text { Ordens de fabricação } \\
\text { Tamanhos de lote } \\
\text { Utilização de horas } \\
\text { extras } \\
\text { Reserva de material }\end{array}$ \\
\hline Curtíssimo Prazo & $\begin{array}{l}\text { Ordens de fabricação } \\
\text { Critérios de } \\
\text { seqüenciamento }\end{array}$ & $\begin{array}{l}\text { Liberação da produção } \\
\text { ONDE E QUEM } \\
\text { PRODUZIR }\end{array}$ & $\begin{array}{l}\text { Seqüência de tarefas } \\
\text { Requisição de recursos } \\
\text { Designação de tarefas } \\
\text { Coleta de dados para } \\
\text { controle }\end{array}$ \\
\hline
\end{tabular}

Fonte: adaptado de CONTADOR e CONTADOR (1997)

Embora esta divisão seja relativa, pois depende das características dos sistemas de produção, é uma tentativa de tratar as decisões de maneira apropriada em nível de incertezas e importância de cada etapa de planejamento.

Conforme citam CONTADOR e CONTADOR (1997), controle de produção é a ação destinada a evitar que uma atividade ou produto se desvie das condições preestabelecidas. Para efetuar um controle, é necessário que se tenha previamente estabelecido um padrão de comparação, com um plano, uma meta, um prazo, um 
consumo, um montante de recursos, uma despesa, uma especificação de produto, etc. e, realizado o que foi previsto (atividade ou produto). O controle em si consiste em:

- Obter informações sobre o que foi realizado e sempre que possível, informações quantificadas e na mesma unidade de medida do padrão de comparação;

- Comparar o realizado com o previsto (padrão);

- Tomar providências quando o realizado não coincidir com o previsto, por meio ou da correção dos fatos para que se aproximem dos preestabelecidos ou do replanejamento das condições (estabelecimento de novo padrão de comparação).

Dentre as atribuições da liberação da produção está a coleta de informações para controle da produção. Um apontador ou o próprio operário anota na ordem de operação a quantidade produzida, a data e a hora de início e fim do trabalho; outros empregados fazem anotações nas respectivas ordens sobre o que efetivamente foi realizado. Estas ordens são encaminhadas ao PCP, para que proceda aos controles. Os controles de produção mais freqüentes são de:

- Prazo (datas e término);

- Quantidade, produzida e refugada;

- Eficiência do operário, da máquina e do material;

- Horas produtivas e de horas paradas, com respectivas causas (da máquina e do operário);

- Horas-extras e respectiva justificativa;

- Despesas e de custo;

- Produtividade.

Feita a comparação do previsto com o realizado, o PCP emite relatórios aos setores da empresa para que providências sejam tomadas com o objetivo de corrigir falhas e desvios. Os relatórios devem ser hierarquizados, isto é, cada setor administrativo deve receber somente as informações que afetam seu campo decisório, adequadamente agregadas para que os administradores não percam tempo em detalhes pouco úteis à sua ação. A hierarquização dos relatórios pode obedecer ao seguinte critério para:

- A alta administração, informações agregadas a respeito do desempenho da fábrica como um todo e de cada departamento; 
- A gerência de departamento, informações agregadas sobre o desempenho do departamento e de cada setor administrativo imediatamente subordinado;

- O supervisor de produção, informações a respeito do desempenho de cada turno de produção e sobre exceções individuais;

- O encarregado de produção, informações sobre o desempenho de cada operário em cada operação.

\subsubsection{Organização do Trabalho}

ZARIFIAN (2001) define três tipos de organização do trabalho: equipes semiautônomas, organização em rede e organização por projeto, e sugere uma organização que resulte em uma mutação dos três tipos de arranjos.

- A constituição de equipe semi-autônoma, é um tipo de organização do trabalho que pode estimular a competência individual, com base na competência coletiva: o compartilhar competências, de um lado, e a opção pela responsabilidade de equipe, de outro, provocam de alguma forma o desenvolvimento singular de cada competência individual, mas dentro de limites da ocupação considerada. No entanto, essa organização do trabalho possui várias limitações:

- Corre o risco, caso confinada em si mesma, de levar a uma visão corporativa de trabalho, cada célula cuidando apenas de seu próprio resultado e de suas próprias obrigações, sem se sentir solidária com as outras equipes;

- Leva a uma segmentação de competências. A empresa pode conseguir melhorar os desempenhos pontuais das equipes sem conseguir produzir uma visão de conjunto desse desempenho e, por conseguinte, podem ocorrer muitas disfunções e perdas de eficácia no nível das interações entre equipes;

- Encerra as diferentes ocupações em si mesmas, embora uma maior parcela dos problemas e eventos importantes toque várias ocupações ao mesmo tempo e precise de sua ocupação.

- A organização em rede é muito flexível e pode ter diversas configurações, duas delas são a organização por processo e a organização por linha de produto. Em qualquer dos casos, o princípio de organização é o mesmo: células (equipes) diferentes são articuladas em uma mesma rede de trabalho, direcionada para determinada categoria de clientela, enfatiza-se a responsabilidade de cada equipe em face do resultado conjunto. Esta organização tem por objetivo estimular as interações 
entre equipes e possibilitar ganhos em termos de desempenho, graças à estruturação sistemática de uma comunicação interequipes e interocupações.

No entanto, pode existir uma considerável ambigüidade na natureza da rede: trata-se realmente de uma rede de cooperação ou trata-se, sobretudo, de uma rede de pressão e controle sobre equipes de assalariados. Não existe nenhuma resposta automática a esta questão: as empresas podem promover essas novidades em termos realmente inovadores ou podem se contentar em reproduzir os antigos esquemas.

A organização em rede, a priori, é muito útil para estimular as comunicações intercompreensivas no seio da organização, também comporta algumas limitações e dificuldades:

- Corre o risco de tornar os objetivos das equipes muito abstratos e distantes de seu limite imediato de atuação;

- Corre o risco de estimular as tensões e divergências entre diferentes ocupações e limitar os esforços de aprofundamento profissional de cada uma delas, se o sentido da co-responsabilidade não estiver suficientemente consolidado; e

- Pode limitar a autonomia das equipes, em virtude da intensificação da pressão proveniente da rede.

- A organização por projeto possui uma origem diferente das anteriores. Foi desenvolvida, fundamentalmente, no ambiente de concepção (escritórios de estudos e de métodos, centros de pesquisa-desenvolvimento) para estimular e acelerar os processos de inovação. Seu princípio é simples: trata-se de reunir uma equipe multiocupacional em torno de um projeto de inovação, com objetivos precisos e por um período determinado (que vai do começo do projeto a seu fim). Trata-se, então, por definição de uma organização temporária. As pessoas trabalham juntas em um projeto preciso e por um período limitado. A grande vantagem desse tipo de organização é fazer convergir as competências e o investimento subjetivo dos membros do projeto. Os assalariados apropriam-se de "seu projeto" e, na medida que sabem o que fazem e por que o fazem. Podem aplicar muita energia e entusiasmo nele, mantendo um grande domínio sobre a organização interna do projeto (mas pouco poder sobre suas finalidades externas). Outra vantagem desse tipo de organização é estimular a comunicação interocupações, na medida que todas as ocupações envolvidas pelo projeto encontram-se diretamente presentes ou 
representadas na equipe e sejam levadas a se ocuparem continuamente de problemas comuns.

O próprio projeto pode ser visto como um "macroevento", conduzido de maneira “comunicacional”. Nessa maneira de conduzir um projeto, o quinhão de inovação e de criatividade é, em principio, grande. No entanto, essa organização tem alguns inconvenientes:

- Por definição é finita: o que é feito depois do término do projeto com os membros das equipes do projeto?

- É possível que seja mais utilizada em um sentido de aceleração do fluxo de inovação (de acordo com a antiga concepção do trabalho industrial de tipo fordista) do que como um meio de estímulo das diferentes opções de inovação;

- Coloca-se a questão de saber como os projetos de inovação "entram" no funcionamento ordinário da empresa. Por exemplo, como após o desenvolvimento de um novo produto, este é lançado na fábrica e assumido por ela. Em outras palavras, como o regime de inovação cruza-se com o regime de exploração usual das unidades de fabricação.

- A idéia que começa a aflorar é a de reunir estas três mutações organizacionais: organização por equipes semi-autonômas, organização em rede e organização por projeto em um mesmo funcionamento, tentando-se utilizar as qualidades de cada uma delas e limitar seus respectivos defeitos. Com base na análise destas formas de trabalho, o autor propõe uma caracterização de organização do trabalho baseada em uma organização celular em rede, animada por projetos (ZARIFIAN, 2001).

Os três modelos organizacionais podem ser novamente aplicados quando são colocados na perspectiva da produção do serviço. O conceito de "serviço" não modifica necessariamente a forma de organização, pelo contrário, confere-lhe outra justificativa e sentido. A produção de serviço, conceito que reúne práticas que visam e têm por conseqüência gerar efeitos úteis aos destinatários do serviço, representam uma referência significante unificadora, que pode perpassar pelas diversas esferas de trabalho. Quer no nível da célula, da rede ou do projeto, o serviço dá sentido à unidade, à convergência e à utilidade coletiva das ações profissionais.

Outro modelo de organização do trabalho por equipe multifuncional corresponde aos conceitos de Engenharia Simultânea. 
Segundo PRASAD (1997), Engenharia Simultânea é uma abordagem sistemática para o desenvolvimento integrado e paralelo do projeto de um produto e os processos relacionados, incluindo, manufatura e suporte. Esta filosofia toma como base a sinergia entre seus agentes que devem trabalhar em equipes multifuncionais, formadas por pessoas de diversas áreas da empresa. A equipe deve crescer e diminuir ao longo de sua existência, mantendo sempre um mesmo núcleo de pessoas, que acompanha o desenvolvimento. Durante algumas atividades, devem fazer parte da equipe: clientes e fornecedores, quando se trabalhar no conceito de cadeia de suprimentos, conforme a posição da empresa dentro desta cadeia.

Todo o trabalho dessa equipe deve ser suportado por recursos, métodos e técnicas integradas. Deve-se sempre enfatizar que o foco do trabalho deve estar concentrado nas necessidades do cliente. É importante ressaltar que todos os elementos da empresa envolvidos nessa definição de Engenharia Simultânea (atividades, informação, organização e recursos) devem ser considerados no modelo do processo de desenvolvimento de produtos. A organização multifuncional e matricial das organizações, características herdadas da Engenharia Simultânea, permite às empresas as alocações pontuais de seus profissionais, otimizando seus trabalhos e planejando melhor as atividades necessárias à execução de projetos.

\subsubsection{Gestão por Competências}

FLEURY e FLEURY (2000), ao mostrarem a gestão de pessoas para a formação de competências, apresentam uma cronologia que parte da introdução do taylorismofordismo (início do século XX) e chega à abordagem sociotécnica (década de 1960), sobre a qual a organização da produção observa a combinação de conhecimentos e habilidades técnicas e sociais, como a semente da competência desejada. Nesse sentido, estende-se até a análise do modelo japonês (década de 1980), mostrando particularidades desta transformação que, baseada em fatores como mobilização, participação, aprendizado e comprometimento, produz uma visão estratégica da empresa muito mais abrangente do que no modelo sociotécnico. Para os autores, a gestão estratégica dos recursos humanos permite à organização planejar e dominar a formação de competências.

“A competência profissional é uma combinação de conhecimentos, de saber-fazer, de experiências e comportamentos que se exerce em um contexto preciso. Ela é 
constatada quando de sua utilização em situação profissional, a partir da qual é passível de validação. Compete então à empresa identificá-la, avaliá-la, validá-la e fazê-la evoluir" (ZARIFIAN, 2001).

Essa definição indica claramente a mudança radical que é preciso operar no tocante ao modelo do posto de trabalho. A competência é, realmente, a competência de um indivíduo (e não a qualificação de um emprego), manifesta-se e é avaliada quando de sua utilização profissional (na relação prática do indivíduo com a situação profissional), logo, a maneira como ele enfrenta essa situação está no âmago da competência. A competência só se manifesta na atividade prática, é dessa atividade que poderá ocorrer à avaliação das competências nela utilizadas.

ZARIFIAN (2001) analisa três mutações principais, ocorridas no mundo do trabalho, que justificam a emergência do modelo de competências para gestão das organizações:

- Evento é aquilo que ocorre de forma imprevista, não programada, vindo a perturbar o desenrolar normal do sistema de produção, ultrapassando a capacidade rotineira de assegurar sua auto-regulação; isto implica que a competência não pode estar contida nas predefinições da tarefa, fazendo com que as pessoas precisem estar sempre mobilizando recursos para resolver novas situações;

- A noção de comunicação, que implica a necessidade das pessoas compreenderem o outro e a si mesmas para partilharem objetivos e normas organizacionais;

- A noção de serviços: noção de atender um cliente externo ou interno à organização precisa ser central e presente em todas as atividades.

O trabalho não se configura mais apenas como o conjunto de tarefas associadas descritivamente ao cargo, mas torna-se o prolongamento direto da competência que o indivíduo mobiliza em face de uma situação profissional cada vez mais mutável e complexa. Essa complexidade de situações torna o imprevisto cada vez mais quotidiano e até rotineiro.

A definição multifuncional de competência de ZARIFIAN (2001) é alimentada por três aspectos: a tomada de iniciativa e de responsabilidade do indivíduo; a inteligência prática das situações, que se apóia sobre os conhecimentos adquiridos e 
os transforma; e a faculdade de mobilizar redes de atores em torno das mesmas situações, co-responsabilidade e partilha do que está em jogo em cada situação.

No modelo de organização do trabalho por equipes multifuncionais, todos contribuem à produção de um mesmo serviço, reconhecido como significativamente útil por um cliente ou usuário. Logo, capaz de transformar positivamente as condições de atividade desse destinatário. A competência é, por conseguinte, "apropriada" na organização, ao mesmo tempo em que pode encaminhar-se subjetivamente e com conhecimento de causa, para a produção do serviço.

Para SLACK et al. (1996), o enriquecimento do trabalho é uma evolução sobre o enriquecimento de cargos, pois acrescenta a seu caráter de racionalização em prol da minimização de pressões, maior domínio e crescente autonomia para a tomada de decisão, mesmo que isso acarrete maior responsabilidade. $\mathrm{O}$ alargamento do trabalho traduz aumento de tarefas de mesmo tipo, pelo aumento de volume de serviços relativos aos afazeres englobados.

\subsubsection{Considerações}

Em uma Fábrica de Software "o que fazer" concentra-se nas categorias e linhas de produtos e serviços oferecidos, de acordo com as demandas dos clientes, que podem estar em diferentes domínios de aplicações de negócios, implicando a utilização de diversificados ambientes tecnológicos.

O "como fazer" baseia-se nas metodologias de desenvolvimento de sistemas associado aos modelos de ciclos de vida do sistema, utilizando-se de técnicas, ferramentas e métodos de Engenharia de Software podendo ser guiados por Modelos de Melhores Práticas e Normas de Referência de Qualidade existentes no mercado de TI.

O sistema de produção da FS pauta-se nas contribuições da Engenharia de Produção, como as formas de programação, supervisão e controle do processo de desenvolvimento e manutenção de sistemas de software. Em uma FS, o sistema de produção surge de uma forma híbrida unitária, intermitente, ou sob encomenda, o que aumenta a complexidade do entendimento de seu sistema de produção.

Com o aumento da complexidade do ambiente de TI, os principais problemas dos sistemas de produção de software estão associados a fatores como: atendimento por demanda com curto prazo de entrega; projetos sem visão sistêmica; processos não 
definidos ou quando definidos não são seguidos por falhas na gestão, planejamento e controle; insuficiência ou obsolescência de ferramentas; processos operacionais $a d$ hoc; recursos mal utilizados, etc.

Outro fator primordial a ser considerado no contexto da FS é a preocupação com a Gestão por Competências, dada a característica singular dos profissionais da área de TI, que podem atuar em diferentes áreas de domínios de conhecimentos e especializações.

Este conjunto de fatores acarreta dificuldades e problemas nos sistemas de desenvolvimento e manutenção de software de forma geral, na gestão de operações, gestão dos projetos, gestão dos processos, nas atividades de planejamento e controle de produção e dificuldades na integração das atividades interfuncionais e terceirizadas, gerando altos riscos na produtividade, qualidade final do produto e na satisfação dos clientes e usuários.

\subsection{Contribuições da Engenharia de Software}

A Engenharia de Software (ES) é uma disciplina da engenharia, com o objetivo de desenvolver sistemas de software com boa relação custo-benefício. À medida que a capacidade de produzir software aumenta, também cresce a complexidade dos sistemas de software requeridos. Neste contexto a cada dia surgem novas técnicas, métodos e ferramentas que auxiliam os profissionais de TI a executarem melhor as atividades envolvidas no desenvolvimento de software. Nas próximas subseções são mostrados os temas associados da Engenharia de Software.

\subsubsection{Conceitos de Engenharia de Software}

SOMMERVILLE (2003) conceitua Engenharia de Software como uma disciplina da engenharia que se ocupa de todos os aspectos da produção de software, desde os estágios iniciais de especificação do sistema até sua manutenção, depois que o mesmo entrou em operação.

PRESSMAN (2002) descreve ES como uma tecnologia em camadas e como qualquer abordagem em engenharia, deve apoiar-se em um compromisso organizacional com a qualidade. As camadas compreendem processos, métodos e ferramentas para o desenvolvimento de software.

- O fundamento da ES é a camada de processo. O processo de ES é o link que mantém unidas as camadas de tecnologia e permite o desenvolvimento racional e 
oportuno do software. As áreas-chave de processo formam a base para o controle gerencial de projetos de software e estabelecem o contexto no qual os métodos técnicos são aplicados, os produtos de trabalho (modelos, documentos, dados, relatórios, formulários, etc.) são produzidos, os marcos são estabelecidos, a qualidade é assegurada e as modificações são geridas.

- Os métodos fornecem a técnica de como fazer para construir o software. Os métodos incluem um amplo conjunto de tarefas que abrange análise de requisitos, projeto, construção, manutenção e testes. Métodos de ES repousam em um conjunto de princípios básicos, que regem cada área de tecnologia e incluem atividades de modelagem e outras técnicas descritivas.

- Ferramentas são o conjunto de software que proporcionam apoio automatizado ou semi-automatizado aos processos e aos métodos.

\subsubsection{Processos de Software}

HUMPHREY (1989) define processo de software como o conjunto de tarefas de Engenharia de Software necessárias para transformar os requisitos dos usuários em software.

Para PAULK et al. (1994), um ambiente de desenvolvimento de software inicia-se com uma sólida definição do processo que inclui atividades, usualmente denominadas como fases, tarefas ou passos, e o que será produzido em cada uma dessas atividades. O processo especifica a ordenação das atividades, que podem ser seqüenciais, concorrentes ou paralelas, e todas reunidas definem a base da execução do desenvolvimento.

Para PAULA FILHO (2003), a ES se preocupa com o software como um produto. Normalmente o desenvolvimento de um software é feito dentro de um projeto. Um projeto ou geração de um produto representa a execução de um processo. Quando um processo é bem definido, terá subdivisões que permitem avaliar o progresso de um projeto e corrigir seus rumos quando ocorrerem problemas. Essas subdivisões são chamadas de fases, atividades ou iterações. As subdivisões devem ser terminadas por marcos, isto é, pontos que representam estados significativos do projeto. Geralmente, os marcos são associados a resultados concretos: documentos, modelos ou porções do produto.

SOMMERVILLE (2003) classifica os processos em quatro tipos: 
- Processos informais: são aqueles em que não há um modelo estritamente definido. O processo a ser utilizado é escolhido pela equipe de desenvolvimento;

- Processos gerenciados: são processos em que há um modelo definido de processo implantado, são utilizados para orientar o processo de desenvolvimento;

- Processos metódicos: são processos em que se utiliza algum método de desenvolvimento definido;

- Processo de melhoria: são os processos que têm objetivos de melhorias inerentes.

Os processos do desenvolvimento de software que apresentam maior interesse, segundo PFLEEGER e ATLEE (2006), são:

- Requisitos: descrição das necessidades do usuário, transformação em especificações funcionais e não funcionais e determinação dos vários componentes do software a serem desenvolvidos: escopo, entidades envolvidas, funcionalidades, padrões de usabilidade e regras de aceitação;

- Projeto: estruturação da forma com a qual o software estará resolvendo cada uma das especificações formuladas, contemplando o código computacional (artefatos), o tratamento de dados e a interface homem-máquina;

- Codificação: transformação das especificações em linguagem computacional, criando os artefatos especificados no projeto;

- Testes: eliminação dos erros e falhas encontrados no código e no conjunto do software no qual cada artefato estará presente. Os testes envolvem as atividades de validação (presença de todos os requisitos) e verificação (funcionamento correto de cada componente);

- Integração: adequação de todos os novos artefatos no conjunto do software, garantindo o perfeito funcionamento. Assim como a integração do teste envolve a validação e a verificação de todos os requisitos;

- Instalação: disponibilização do software no ambiente produtivo com o usuário;

- Aceitação: manifestação do grau de satisfação do cliente com o software;

- Manutenção: correção dos erros surgidos após a entrega para o usuário.

\subsubsection{Modelos de Processos de Software}

Um modelo de processo de software é uma descrição simplificada ou uma representação abstrata de um processo de software, que é apresentada a partir de uma perspectiva específica. Alguns exemplos dos tipos de modelos de processo de 
software que podem ser produzidos são: modelos de workflow, modelos de fluxo de dados, modelo de ação, etc. (SOMMERVILLE, 2003).

PRESSMAN (2002) denomina modelos da estrutura dos processos classificando-as em etapas denominadas ciclos de vida. Os modelos de ciclo de vida do software podem ocorrer em seqüência ou sobrepostas e executadas interativamente, dependendo do modelo adotado para a construção do software. Podem ser decompostas em unidades menores, como etapas, atividades ou tarefas, a fim de permitir um maior controle e visibilidade da execução do projeto de software.

Os modelos de ciclo de vida de software mais comumente citados na literatura são:

- Cascata: é um modelo de desenvolvimento bem definido, no qual os processos são executados de forma seqüencial. SOMMERVILLE (2003) cita que os principais estágios do modelo cascata retratam as atividades de desenvolvimento fundamentais, que são: análise e definição de requisitos; projeto de sistemas e de software; implementação e teste de unidades; integração e teste de sistemas; operação e manutenção;

- Espiral: representa o processo de software como uma seqüência de atividades. Cada loop na espiral representa uma fase do processo de software. O modelo espiral permite a criação de software de forma interativa, ou seja, seqüencial e em blocos;

- Evolucionário: tem como base a idéia de desenvolver uma implementação inicial, expor o resultado, e fazer seu aprimoramento por meio de muitas versões, até que um sistema adequado tenha sido desenvolvido. SOMMERVILLE (2003) considera dois tipos de desenvolvimento evolucionário: Desenvolvimento Exploratório, em que o objetivo do processo é trabalhar em conjunto com o cliente, explorando na prática seus requisitos e, posteriormente, entregar o sistema final. O sistema evolui com o acréscimo de novas características, à medida que elas são propostas pelo cliente. E Protótipos Descartáveis, cujo objetivo do desenvolvimento evolutivo é compreender os requisitos do cliente e, a partir disso, desenvolver a definição de requisitos para o sistema. $\mathrm{O}$ protótipo concentra-se em fazer experimentos com partes dos requisitos que estejam mal compreendidos; 
- Orientado ao Reuso: segundo SOMMERVILLE (2003) essa abordagem tem como base a existência de um número significativo de componentes reusáveis. $\mathrm{O}$ processo de desenvolvimento de sistemas se concentra na integração desses componentes, em vez de proceder ao desenvolvimento a partir do zero;

- Iterativo e Incremental: apresentado na próxima secção por meio do RUP Processo Unificado da Rational;

- Metodologias Ágeis: será apresentada na seqüência com foco no XP - Extreme Programming.

\subsubsection{RUP - Processo Unificado da Rational}

Para KRUTCHEN e KROLL (2003), o RUP - Rational Unified Process, embora sugira um processo, pode ser considerado como:

- Uma abordagem de desenvolvimento de software que é iterativa, centrada na arquitetura e dirigida por casos de uso, ou seja, levantamento de requisitos baseados na visão do usuário;

- Um processo de Engenharia de Software bem definido e bem estruturado, claramente define quem é o responsável, como as coisas são feitas e quando fazêlas;

- Um produto-processo que fornece um framework de processo customizável para a Engenharia de Software.

A Figura 5 ilustra como o RUP está organizado e estruturado em fases e disciplinas, bem como a alocação e a utilização de recursos é feita durante o ciclo de vida do projeto de desenvolvimento de software.

O RUP (2003) apresenta duas dimensões: a primeira é a estática que representa a estrutura estática do processo, descrevendo como seus elementos são agrupados logicamente em disciplinas. Disciplinas são agrupamentos lógicos de papéis, atividades, artefatos e outros guias para a descrição de um processo, são representadas por um fluxo de trabalho; a segunda dimensão é a dinâmica, representada pelo tempo: expressa o processo por meio de ciclos, decompostos em fases, que são divididas em iterações com marcos de conclusão.

O processo de desenvolvimento de software do RUP é iterativo, no qual uma iteração incorpora um conjunto de atividades em modelagem de negócios, requisitos, análise e projeto, implementação, testes e implantação, em várias proporções, dependendo 
de onde a iteração esteja localizada no ciclo de desenvolvimento. Os principais benefícios da abordagem iterativa são a identificação e o tratamento dos principais riscos do projeto em tempo hábil.

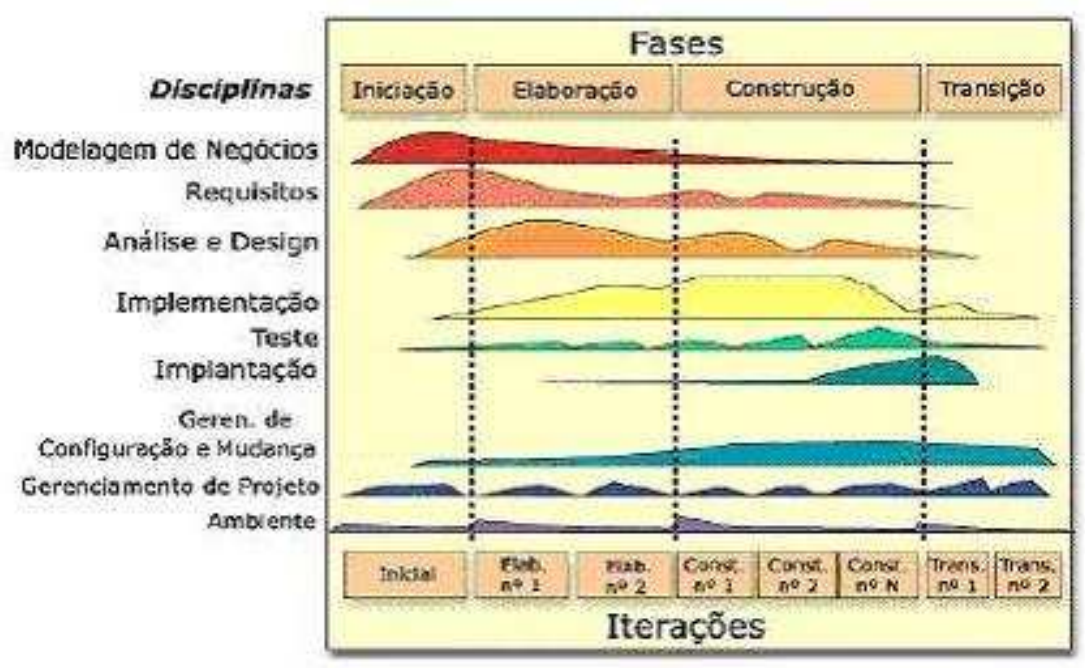

Figura 5 - Ciclos do RUP - Rational Unified Process Fonte: RUP (2003)

De acordo com BOOCH et al. (1999), o desenvolvimento de software é complexo e pode durar muitos meses ou até mesmo anos. Em razão disso, é melhor dividir o trabalho em pequenas partes ou miniprojetos. Cada um é uma interação que resulta em um incremento do produto de software que está sendo desenvolvido. Cada iteração refere-se aos passos, dentro de um fluxo de trabalho, que deve ser seguido para gerar o incremento definido.

Os processos dinâmicos do RUP indicam as fases representadas pela dimensão de tempo entre duas maiores marcas (milestones) de processos, durante a qual um conjunto bem definido de objetivos é encontrado, artefatos são completados, e a decisão é tomada no sentido de ir para a próxima fase, "milestone", que pode ser definida como eventos organizados no final de cada fase de desenvolvimento para fornecer visibilidade a seus problemas, sincronizar o gerenciamento, perspectivas de engenharia e verificar que os objetivos de cada fase foram obtidos. Abaixo um resumo de cada fase:

\section{Iniciação}

- Estabelecer o escopo do projeto;

- Selecionar os casos de uso críticos do negócio;

- Buscar ao menos uma arquitetura candidata; 
- Elaborar cronograma e estimativas de custos do projeto;

- Estimar os riscos do projeto;

- Preparar o ambiente de apoio ao projeto.

\section{Elaboração}

- Assegurar que a arquitetura, os requisitos e os planos estejam estáveis para prover o resto do projeto;

- Resolver os riscos de arquitetura do projeto;

- Produzir um protótipo;

- Demonstrar que a arquitetura suportará os requisitos;

- Estabelecer um ambiente de apoio para o projeto.

\section{Construção}

- Minimizar os custos de desenvolvimento;

- Atingir qualidade de forma rápida e prática;

- Obter versões utilizáveis o quanto antes;

- Completar análise, design e implementação;

- Assegurar-se de que o usuário está pronto para a entrega;

- Buscar paralelismo nas atividades de desenvolvimento.

\section{Transição}

- Realizar beta teste para validar o produto;

- Executar teste paralelo com sistemas legados;

- Converter base de dados existentes;

- Treinar usuários;

- Resolver problemas de implantação.

KRUTCHTEN e KROLL (2003) definem "Disciplina", que representa a dimensão estática do processo, como uma coleção de atividades relacionadas que estão ligadas à maior área de interesse dentro do processo em geral. Uma disciplina especifica todas as atividades e quais papéis podem executar para produzir um determinado conjunto de artefatos (documentos, especificações, protótipos, relatórios, etc.). Este pode ser interpretado como o conjunto de processos e fluxos de trabalho da Engenharia de Software, necessários à geração dos produtos do projeto, chamados de artefatos pelo RUP. 
As disciplinas compõem: modelagem de negócios, requisitos, análise e design, implementação, testes, implantação, gerenciamento de configuração e mudança, gerenciamento de projeto e ambiente.

O RUP usa um padrão visual apoiado na Unified Modeling Language (UML) e possui três elementos-chave: casos de uso, arquitetura e desenvolvimento iterativo e incremental.

Para ALMEIDA (2004), colocar o modelo RUP em prática é preciso adotar um processo multidimensional composto de ciclos, fases, disciplinas, fluxos de trabalho, análise de riscos, controle de qualidade, gerenciamento de projeto e controle de configuração.

\subsubsection{Metodologias Ágeis}

Segundo LARMAN (2007) métodos de desenvolvimento ágil usualmente aplicam desenvolvimento iterativo e evolutivo de tempo limitado, empregam planejamento adaptativo, promovem entrega, incrementam e incluem valores e práticas que encorajam agilidade, reposta rápida e flexível à modificação.

O termo "Metodologias Ágeis" tornou-se popular, em 2001, quando especialistas em processos de desenvolvimento de software representando os métodos ágeis estabeleceram princípios comuns compartilhados por todos esses métodos. Foram criados a Aliança Ágil e o estabelecimento do "Manifesto Ágil". Os conceitos-chave do "Manifesto Ágil" (AGILE MANIFESTO, 2005) são:

- Indivíduos e interações em lugar de processos e ferramentas;

- Software executável em lugar de documentação;

- Colaboração do cliente em lugar de negociação de contratos;

- Respostas rápidas a mudanças em lugar de seguir planos.

O "Manifesto Ágil" não rejeita os processos e ferramentas, a documentação, a negociação de contratos ou o planejamento, mas simplesmente mostra que eles têm importância secundária quando comparados com os indivíduos e interações, com o software estar executável, com a colaboração do cliente e as respostas rápidas a mudanças e alterações. Estes conceitos aproximam-se melhor com a forma que pequenas e médias organizações trabalham e respondem a mudanças. Entre as metodologias ágeis, uma das mais conhecidas é Extreme Programming - XP.

XP baseia-se nas doze práticas (BECK, 1999), descritas a seguir: 
Planejamento: consiste em decidir o que é necessário ser feito e o que pode ser adiado no projeto. XP baseia-se em requisitos atuais ao desenvolvimento de software, não em requisitos futuros. Além disso, procura evitar os problemas de relacionamento entre a área de negócios e a área de desenvolvimento. As duas áreas devem cooperar para o sucesso do projeto e cada uma deve focar em partes específicas do projeto. Desta forma, enquanto a área de negócios deve decidir sobre o escopo, a composição das versões e as datas de entrega, os desenvolvedores devem decidir sobre as estimativas de prazo, o processo de desenvolvimento e o cronograma detalhado, para que o software seja entregue nas datas especificadas.

Entregas freqüentes: visam à construção de um software simples. Conforme os requisitos surgem, há a atualização do software. Cada versão entregue deve ter o menor tamanho possível, contendo os requisitos de maior valor para o negócio. Idealmente devem ser entregues versões a cada mês ou no máximo a cada dois meses, aumentando a possibilidade de feedback rápido do cliente. Isto evita surpresas caso o software seja entregue após muito tempo e melhora as avaliações do cliente, aumentando a probabilidade do software final estar de acordo com os requisitos do cliente.

Metáfora: são as descrições de um software sem a utilização de termos técnicos, com o intuito de guiar o desenvolvimento do software.

Projeto simples: o programa desenvolvido com XP deve ser o mais simples possível e satisfazer os requisitos atuais, sem a preocupação de requisitos futuros. Eventuais requisitos futuros devem ser adicionados assim que eles realmente existirem.

Testes: XP focaliza a validação do projeto durante todo o processo de desenvolvimento. Os programadores desenvolvem o software criando primeiramente os testes.

Programação em pares: a implementação do código é feita em dupla, ou seja, dois desenvolvedores trabalham em um único computador. O desenvolvedor que está com o controle do teclado e do mouse implementa o código, enquanto o outro observa continuamente o trabalho que está sendo feito, procurando identificar erros sintáticos e semânticos e pensando estrategicamente em como melhorar o código que está sendo implementado. Esses papéis podem e devem ser alterados continuamente. 
Uma grande vantagem da programação em dupla é a possibilidade dos desenvolvedores estarem continuamente aprendendo um com o outro.

Refatoração: focaliza o aperfeiçoamento do projeto do software e está presente em todo o desenvolvimento. A refatoração deve ser feita apenas quando é necessário, ou seja, quando um desenvolvedor da dupla, ou os dois percebe ser possível simplificar o módulo atual sem perder nenhuma funcionalidade.

Propriedade coletiva: o código do projeto pertence a todos os membros da equipe. Isto significa que qualquer pessoa percebe que pode adicionar valor a um código, mesmo que ele próprio não o tenha desenvolvido, pode fazê-lo, desde que faça a bateria de testes necessária. Isto é possível porque XP todos são responsáveis pelo software inteiro. Uma grande vantagem desta prática é que, caso um membro da equipe deixe o projeto antes do fim, a equipe consegue continuar o projeto com poucas dificuldades, pois todos conhecem todas as partes do software, mesmo que não seja de forma detalhada.

Integração contínua: é a prática de interagir e construir o sistema de software várias vezes por dia, mantendo os programadores em sintonia, além de possibilitar processos rápidos. Integrar apenas um conjunto de modificações de cada vez é uma prática que funciona bem, porque fica óbvio quem deve fazer as correções quando os testes falham é a última equipe que integrou o código novo ao software. Esta prática é facilitada com o uso de apenas uma máquina de integração, que deve ter livre acesso a todos os membros da equipe.

40 horas de trabalho semanal: XP assume que não se deve fazer horas extras constantemente. Caso seja necessário trabalhar mais de 40 horas pela segunda semana consecutiva, existe um problema sério no projeto que deve ser resolvido não com aumento de horas trabalhadas, mas, com melhor planejamento, por exemplo. Esta prática procura ratificar o foco nas pessoas e não em processos e planejamentos. Caso seja necessário, os planos devem ser alterados, ao invés de sobrecarregar as pessoas.

Cliente presente: é fundamental a participação do cliente durante todo o desenvolvimento do projeto. O cliente deve estar sempre disponível para sanar todas as dúvidas de requisitos, evitando atrasos e até mesmo construções erradas. Uma 
idéia interessante é manter o cliente como parte integrante da equipe de desenvolvimento.

Código padrão: padronização na arquitetura do código, para que este possa ser compartilhado entre todos os programadores.

\subsubsection{Considerações}

Muitas vezes na ES existe uma confusão entre modelos de processos de desenvolvimento e modelos da estrutura dos processos dos projetos de software. Nos modelos de processos de desenvolvimento, não há uma identificação da seqüência das diferentes atividades, tarefas que serão executadas, os processos não são ordenados no tempo. Simplesmente, estes modelos indicam quais processos poderão ser executados. Já os modelos da estrutura dos processos, indicam a seqüência que as atividades e tarefas dos processos de desenvolvimento e manutenção deverão seguir, classificando-as em etapas denominadas ciclos de vida (PRESSMAN, 2002).

Este trabalho tem como objetivo definir modelos da estrutura dos processos com base no mapeamento, definição, reestruturação e estabelecimento dos processos de desenvolvimento e manutenção de software em uma organização de TI do setor público, considerando as características de uma FS. Adiante é possível ver o projeto que realiza este objetivo denominado "Metodologia de Desenvolvimento de Sistemas e Integração - MDSI”. A definição da MDSI usa nomenclatura e conceitos do RUP, abordando intensamente os processos, técnicas, ferramentas e métodos estipulados na Engenharia de Software.

\subsection{Reuso de Software}

Um dos principais objetivos enfatizados no contexto de uma FS é o reuso de software, termo abrangente, que incorpora uma série de disciplinas inter-relacionadas como: Gestão do Conhecimento; Análise de Domínio; Linha de Produtos de Software; Arquitetura de Software; Desenvolvimento Baseado em Componentes (DBC); Orientação a Objetos; padrões; frameworks e ferramentas para suporte ao reuso. Verifica-se que existe uma confluência de áreas caminhando em direção à produção em larga escala e, automatizada de software, o que também vai de encontro ao paradigma de FS. Nesta sessão, é feito um estudo desses conceitos procurando agrupá-los e relacioná-los. 


\subsubsection{Gestão do Conhecimento}

Especificamente na área de software, o conhecimento é produzido e utilizado durante seu desenvolvimento. Em muitos casos, o conhecimento está disperso nas atividades de cada pessoa ou em documentos armazenados em vários lugares e mídias; no entanto, para a vantagem competitiva, o conhecimento não pode estar no nível do indivíduo ou disperso em lugares desconhecidos.

NONAKA e TAKEUCHI (1997) distinguem os dois tipos de conhecimento: o explícito, que é o conhecimento formal contido nos manuais e nas normas das organizações e pode facilmente ser processado por um computador, e o tácito ou implícito, obtido pela experiência, que sendo de natureza intuitiva e subjetiva, dificulta o processamento e a transmissão. Os autores acreditam que o conhecimento acumulado, se amplamente compartilhado dentro da organização, forma uma base de conhecimento organizacional que abastece a inovação, aperfeiçoamento e melhorias contínuas.

Para DAVENPORT e PRUSAK (1998), o conhecimento tem origem e é aplicado na mente dos conhecedores. Nas empresas, ele costuma estar embutido não só em documentos e repositórios, mas também em rotinas, processos, práticas e normas organizacionais. O conhecimento deriva da informação da mesma forma que a informação deriva de dados. TEIXEIRA (2000) distingue "dado", como valor sem significado; "informação", como dado com significado e "conhecimento", como informação estruturada e contextualizada. Para o autor, o conhecimento é o elemento habilitador da decisão.

OLIVEIRA JR (1999) entende por Gestão do Conhecimento o processo de identificar, desenvolver, disseminar, atualizar e proteger o conhecimento estrategicamente relevante à empresa seja com base nos esforços internos à organização ou a partir de processos que extrapolam suas fronteiras.

\subsubsection{Engenharia de Domínio}

Uma das áreas ligadas diretamente à organização do conhecimento é definida como Engenharia de Domínio, em que se identifica e organiza o conhecimento sobre o domínio do problema, visando a entendê-lo e representá-lo por modelos de domínio criados com base na análise de domínio, na qual a aquisição de conhecimento ocorre mais intensamente. 
PRIETO-DIAZ e ARANGO (1991) citam que o trabalho da Análise de Domínio é baseado em dois pontos principais: a especificação para um domínio das informações reusáveis, como identificar, obter e representar as informações dentro de um domínio; a coesão e estabilidade dos problemas de domínio. A coesão na representação dos conhecimentos de um domínio torna possível a captura do conhecimento necessário para a solução de diversos problemas, sob a forma de um conjunto finito e pequeno de descrições reusáveis. A estabilidade torna possível a amortização do custo da captura e a representação da informação por meio de seu reuso durante longos períodos e em diversas situações e lugares.

O domínio é um conceito-chave no reuso sistemático, que pode ser definido como uma área de aplicação ou, mais formalmente, como conjunto de sistemas que compartilham as decisões de projeto. Portanto, o domínio é o contexto e o escopo em que se realiza o reuso; e chama-se de Engenharia de Domínio (ED) ao conjunto de atividades de análise e implementação deste domínio (FRAKES e ISODA, 1994).

Os métodos de ED propostos na literatura mostram que existem basicamente três etapas principais:

- Análise de domínio: determina os requisitos comuns de uma família de aplicações com o objetivo de identificar as oportunidades de reuso;

- Projeto de domínio: utiliza os resultados da análise do domínio para identificar e generalizar soluções para os requisitos comuns, por meio da especificação de uma arquitetura de software do domínio. As oportunidades de reuso identificadas na análise do domínio são refinadas de forma a especificar as restrições do projeto;

- Implementação do domínio: transforma as oportunidades de reuso e soluções do projeto em um modelo de implementação, que inclui serviços como: a identificação, reengenharia e/ou construção e manutenção de componentes reusáveis que suportem esses requisitos e soluções de projeto.

Para WERNER e BRAGA (2005), em todas as fases da ED, devem existir produtos específicos a serem disponibilizados:

- Na fase de Análise de Domínio, devem ser produzidas reapresentações que capturem o contexto e a abrangência do domínio, explicitando abrangência com outros domínios; 
- O projeto de domínio deve disponibilizar modelos que especifiquem a estrutura arquitetural a ser seguida pelas aplicações do domínio. As representações geradas devem prover modelos arquiteturais que auxiliem na especificação de arquiteturas específicas para cada aplicação. Podem-se ter vários modelos arquiteturais para um único modelo;

- A fase de implementação do domínio deve produzir componentes de implementação que especifiquem as principais funcionalidades encontradas em aplicações do domínio. Esses componentes devem estar em conformidade com o modelo de abstração da fase de análise e com os modelos arquiteturais da fase de projeto, de forma que possam cooperar entre si para implementar todas as funcionalidades para uma dada aplicação.

Trabalhos gerados sobre Análise de Domínio mostram que as principais linhas de pesquisa referem-se à utilização de arquiteturas específicas para o domínio, abordagem baseada em conhecimento para apoiar o reuso, enfoque no apoio ao entendimento do problema e o uso de definição formal para a documentação. Os dados da Tabela 5 mostram uma compilação de pesquisas sobre Modelos de Engenharia de Domínio, conforme descritos em WERNER e BRAGA (2005).

Tabela 5- Trabalhos sobre Engenharia de Domínio

\begin{tabular}{|l|l|}
\hline \multicolumn{1}{|c|}{ Autor } & \multicolumn{1}{c|}{ Descrição do Trabalho } \\
\hline COHEN, 1994 & $\begin{array}{l}\text { FODA (Feature Oriented Domain Analysis) - propõe o uso de features } \\
\text { características do domínio que sejam visíveis para o usuário. Descrevem } \\
\text { sobretudo a modelagem de estudos de caso na fase de análise, dando } \\
\text { enfase à modelagem funcional. }\end{array}$ \\
\hline $\begin{array}{l}\text { Simos, 1996 apud } \\
\text { Werner e Braga (2005) }\end{array}$ & $\begin{array}{l}\text { ODM (Organizations Domain Modeling) - Framework para criação de } \\
\text { métodos de Engenharia de Domínio particularizados, de acordo com as } \\
\text { necessidades das organizações. Possui um enfoque gerencial do processo } \\
\text { de reuso. }\end{array}$ \\
\hline GOMMA et al., 1996 & $\begin{array}{l}\text { Método proposto por GOMMA e KERSCHBERG incorporado a um } \\
\text { ciclo de vida evolutivo do domínio. Utiliza a orientação a objetos em } \\
\text { seus modelos, sobretudo de análise. }\end{array}$ \\
\hline $\begin{array}{l}\text { Kang, 1998 apud } \\
\text { Werner e Braga (2005) }\end{array}$ & $\begin{array}{l}\text { Feature-Oriented Reuse Method (FORM) - O método é mais voltado } \\
\text { para o detalhamento de como desenvolver componentes por meio das } \\
\text { features identificadas. Para isso, usa técnicas como templates, geração } \\
\text { automática de código, parametrização, entre outras. }\end{array}$ \\
\hline $\begin{array}{l}\text { Jacobson, Griss, } \\
\text { Jonhson (1997) apud } \\
\text { Werner e Braga (2005) }\end{array}$ & $\begin{array}{l}\text { Reuse-Driven Software Engineering Business (RSEB) - É um método } \\
\text { baseado no reuso. Os autores partem da abordagem OO para a criação de } \\
\text { um método com características de DBC - Desenvolvimento Baseado em } \\
\text { Componentes }\end{array}$ \\
\hline $\begin{array}{l}\text { Griss, Favaro e } \\
\text { D’Alessandro (1998) }\end{array}$ & $\begin{array}{l}\text { Processo definido e detalhado para a Engenharia de Domínio, mostrando } \\
\text { modelo de features, casos de uso e seus desdobramentos. Utiliza } \\
\text { abordagens de Engenharia de Software, como padrões e frameworks. }\end{array}$ \\
\hline
\end{tabular}




\begin{tabular}{|l|l|}
\hline \multicolumn{1}{|c|}{ Autor } & \multicolumn{1}{c|}{ Descrição do Trabalho } \\
\hline $\begin{array}{l}\text { D’Souza e Wills (1998) } \\
\text { apud Werner e Braga } \\
(2005)\end{array}$ & $\begin{array}{l}\text { Catalysis é um método de DBC (Desenvolvimento Baseado em } \\
\text { Componentes) detalhado, que cobre todas as fases do desenvolvimento } \\
\text { de um componente a ser utilizado no desenvolvimento de uma dada } \\
\text { aplicação, desde a especificação até sua implementação, usando padrões } \\
\text { e frameworks. }\end{array}$ \\
\hline Atkinson et al. (2000) & $\begin{array}{l}\text { O método Kobra identifica duas atividades principais: a parte de linhas } \\
\text { de produto e a parte da Engenharia da Aplicação, que é a instanciação do } \\
\text { framework genérico criado nas etapas anteriores. }\end{array}$ \\
\hline $\begin{array}{l}\text { Cheesman e Daniels } \\
(2000)\end{array}$ & $\begin{array}{l}\text { Ė um trabalho de extensão da UML para apoiar o DBC. O processo é } \\
\text { uma modificação do RUP para atender aspectos específicos de DBC. Não } \\
\text { existe um modelo de reuso de componentes em uma aplicação. }\end{array}$ \\
\hline
\end{tabular}

Fonte: compilada de WERNER e BRAGA (2005)

\subsubsection{Conceito e Classificação do Reuso de Software}

Para garantir a qualidade de seus produtos, uma Fábrica de Software está assentada em pilares como: processos definidos, metodologias consistentes e artefatos reusáveis. Estes artefatos são agrupados e reusados a cada novo projeto, eliminando retrabalhos. Dessa forma, se ganha tempo e maior flexibilidade no processo de desenvolvimento a um custo significativamente menor.

JACOBSON et al. (1997) definem o reuso de software como: "o uso futuro ou uso repetitivo de um artefato de software". O reuso sistemático é a criação, gerenciamento, suporte e reaproveitamento propositado de artefatos, que são produtos ou subprodutos do processo de desenvolvimento de software.

Os artefatos reusáveis incluem elementos tangíveis (código, projeto, algoritmo, planos de testes, documentação, etc.) e elementos intangíveis (conhecimento e metodologias) (LIN, 1998).

BASILI et al. (1992) citam que um dos problemas de reuso é a inabilidade de reconhecer qual experiência é apropriada para o reuso e integrar as atividades de reuso no processo de desenvolvimento de software. Isso implica uma mudança cultural significativa na indústria de software para uma estrutura de projeto centrada em idéias e experiências de desenvolvedores de projetos, gerando um repositório de reuso permanente da corporação, o que envolve investimentos iniciais altos, dificultando sua implementação.

CHENG (1994) cita razões técnicas e não técnicas para as dificuldades apresentadas para a adoção do reuso. As razões não técnicas referem-se à:

- A maioria das organizações não oferece recompensa para quem reusa software; 
- O desafio intelectual do profissional de software, que busca solucionar um problema interessante de seu próprio jeito;

- Incentivos econômicos tendem a trabalhar contra o reuso de software. Muitos produtores não estão dispostos a desenvolver metodologias que produzam componentes reusáveis, pois eles próprios seriam dispensados no futuro;

- Em qualquer projeto, o gerente não está disposto a gastar qualquer esforço que não esteja diretamente ligado ao projeto.

As razões técnicas referem-se aos seguintes fatores:

- Falta de ferramentas de suporte ao reuso. Reuso requer planejamento quando um componente é originalmente definido e implementado;

- Falta de padronização para representar os componentes de software;

- Falta de bibliotecas de componentes de software;

- Falta de ferramentas de pesquisa e recuperação de componentes.

DUSINSK e KATWIJK (1995) apresentam quatro dimensões a serem consideradas nos processos de reuso: 1) identificar os artefatos reusáveis (procurar, selecionar, entender, adaptar); 2) domínio dos conhecimentos a serem aplicados para encontrar os itens reusáveis; 3) engenharia de reuso: adaptação, integração e desenvolvimento dos artefatos de reuso; 4) conhecimento necessário para construir sistemas baseados em reuso, identificar as mudanças a serem inseridas no processo de desenvolvimento para um reuso sistemático.

\section{Classificações do Reuso de Software}

Os estudos por meio de métodos de Análise de Domínio podem identificar a classificação dos reusáveis, de acordo com sua funcionalidade (FRAKES e ISODA, 1994).

Vários autores classificaram o reuso de software por meio de domínios diferentes, conforme mostrados a seguir.

CUSUMANO (1992) lista potenciais artefatos reusáveis na fase de desenvolvimento de software, mostra que o reuso torna-se cada vez mais efetivo quando praticado sistematicamente (Tabela 6).

Tabela 6 - Artefatos reusáveis no desenvolvimento de software

\begin{tabular}{|l|l|}
\hline $\begin{array}{c}\text { Fases do desenvolvimento } \\
\text { de software }\end{array}$ & Artefatos reusáveis \\
\hline Requisitos & Requisitos, especificações, estudos do negócio, modelo de custos \\
\hline
\end{tabular}




\begin{tabular}{|l|l|}
\hline $\begin{array}{c}\text { Fases do desenvolvimento } \\
\text { de software }\end{array}$ & \multicolumn{1}{c|}{ Artefatos reusáveis } \\
\hline Análise & Modelo do projeto, histórico, simulação de sistemas \\
\hline Projeto & $\begin{array}{l}\text { Projetos, padrões, frameworks, relatórios do consumidor, histórico dos } \\
\text { custos de reengenharia, simulação de projetos }\end{array}$ \\
\hline Desenvolvimento & $\begin{array}{l}\text { Módulos de códigos, manuais do programador, manuais de operação, } \\
\text { casos de testes unitários, simulação de códigos, programas de } \\
\text { treinamento de operação }\end{array}$ \\
\hline Integração e Testes & $\begin{array}{l}\text { Planos de testes do sistema, casos e procedimentos, detalhes da } \\
\text { simulação de interfaces }\end{array}$ \\
\hline Manutenção & $\begin{array}{l}\text { Problemas e dificuldades reportadas, planos de testes de regressão, } \\
\text { procedimentos }\end{array}$ \\
\hline
\end{tabular}

$$
\text { Fonte: CUSUMANO (1992) }
$$

PRIETO-DIAZ (1993) apresenta uma classificação do reuso, dividindo os tipos de reuso sob seis facetas: pela substância, escopo, modo, técnica, intenção e produto, conforme mostrado na Tabela 7.

Tabela 7 - Classificação do reuso

\begin{tabular}{|l|l|l|l|l|l|}
\hline \multicolumn{1}{|c|}{ Substância } & \multicolumn{1}{|c|}{ Escopo } & \multicolumn{1}{c|}{ Modo } & \multicolumn{1}{c|}{ Técnica } & \multicolumn{1}{c|}{ Intenção } & \multicolumn{1}{c|}{ Produto } \\
\hline $\begin{array}{l}\text { Idéias, } \\
\text { conceitos. }\end{array}$ & Vertical & $\begin{array}{l}\text { Planejado, } \\
\text { sistemático }\end{array}$ & Composicional & $\begin{array}{l}\text { Caixa preta } \\
\text { sem } \\
\text { modificação }\end{array}$ & Códigos fontes \\
\hline $\begin{array}{l}\text { Artefatos, } \\
\text { componentes }\end{array}$ & Horizontal & $\begin{array}{l}\text { Ad-hoc, } \\
\text { oportunista. }\end{array}$ & Gerativo & $\begin{array}{l}\text { Caixa branca, } \\
\text { com } \\
\text { modificação. }\end{array}$ & Projetos \\
\hline $\begin{array}{l}\text { Procedimentos, } \\
\text { habilidades. }\end{array}$ & & & & & Especificações \\
\hline & & & & & Objetos \\
\hline & & & & & Textos \\
\hline & & & & & Arquiteturas \\
\hline
\end{tabular}

Fonte: PRIETO-DIAZ (1993)

- Faceta substância: define a essência do item a ser reusado:

- Idéias, conceitos: tipo de reuso que envolve conceitos formais, tais como: soluções gerais para uma classe de problemas;

- Artefatos, componentes: componentes de software;

- Procedimentos e habilidades.

- Faceta escopo: define a forma e a extensão do reuso:

- Vertical: diz respeito ao reuso de software dentro do mesmo domínio ou área de aplicação;

- Horizontal: componentes genéricos podem ser reutilizados em diferentes aplicações em diferentes domínios.

- Faceta Modo: define como o reuso é conduzido: 
- Planejado, sistemático: reuso utilizando-se de práticas formais, procedimentos e documentos-padrão;

- $A d-h o c$, oportunista: prática informal. O reuso é conduzido individualmente e não de modo corporativo.

- Faceta Técnica: define qual a abordagem utilizada para implementar o reuso:

- Composicional: os elementos teoricamente não são alterados quando são reusados;

- Gerativo: os componentes reusados não são facilmente identificáveis, como entidades concretas, geralmente, são padrões.

- Faceta intenção: define como os elementos serão reusados.

- Caixa Branca: são elementos reusáveis que podem ser modificados e adaptados. A principal dificuldade neste tipo de reuso é o controle das mudanças dos reusáveis, que precisam ser mais formalizados (muitas vezes por parametrizações).

- Caixa Preta: o reuso do tipo caixa preta é aquela em que não ocorrem modificações no reusável. Os reusáveis são encapsulados e as suas funcionalidades são acessadas por meio de interfaces padronizadas. As principais dificuldades são definir o domínio das funcionalidades e os impactos no desempenho. Esta idéia converge aos conceitos de componentes de software. $\mathrm{Na}$ abordagem caixa preta, torna-se necessário um adaptador externo, encapsulando o reusável e suas interfaces ou pelas interfaces específicas.

- Faceta Produto: define que tipo de produtos que serão reusados:

- Código fonte: forma mais comum de reuso de software;

- Projeto: qualquer informação de projeto de software;

- Especificação: Qualquer representação de alto nível de um sistema de software que pode ser reusado;

- Objetos: são métodos, ferramentas e ambientes para criação de objetos;

- Textos: qualquer documento necessário ou gerado na construção de sistemas de software;

- Arquiteturas: refere-se a arquiteturas de software específicas no domínio, nos quais os componentes de software são integrados. 
LIN (1998) mostra o escopo do reuso no domínio de uma empresa (Tabela 8).

Tabela 8 - Escopo do Reuso

\begin{tabular}{|l|l|}
\hline Tipo de Reuso & \multicolumn{1}{c|}{ Descrição } \\
\hline Pessoal & $\begin{array}{l}\text { Praticado individualmente pelo profissional de software. Uma biblioteca de rotinas } \\
\text { pessoal é incrementada constantemente para uso pessoal. Cada indivíduo é } \\
\text { responsável por produzir e manter seus próprios produtos de trabalho. }\end{array}$ \\
\hline Intraprojeto & $\begin{array}{l}\text { Reuso do projeto - freqüentemente são designados um ou mais profissionais para } \\
\text { criar os produtos reusáveis de trabalho (em geral uma biblioteca de funções) para } \\
\text { que outros membros do projeto possam usá-los. }\end{array}$ \\
\hline Interprojeto & $\begin{array}{l}\text { Prática de reuso em múltiplos projetos. O reuso, neste nível, necessita de } \\
\text { coordenação e organização dos vários grupos participantes. }\end{array}$ \\
\hline Empresa & $\begin{array}{l}\text { Reuso de mesmo domínio de empresas. O reuso requer suporte e coordenação dos } \\
\text { múltiplos níveis de gerenciamento das múltiplas organizações. }\end{array}$ \\
\hline Interempresas & $\begin{array}{l}\text { Reuso por meio de empresas, incluindo, práticas de reuso de diferentes } \\
\text { companhias }\end{array}$ \\
\hline
\end{tabular}
Fonte: LIN (1998)

SOMMERVILLE (2003) identifica aproximações de reuso de software em sistemas aplicativos, componentes, objetos e níveis funcionais (Tabela 9).

Tabela 9 - Artefatos reusáveis no desenvolvimento de software

\begin{tabular}{|l|l|}
\hline \multicolumn{1}{|c|}{ Artefatos reusáveis } & \multicolumn{1}{c|}{ Descrição } \\
\hline $\begin{array}{l}\text { DBC- Desenvolvimento } \\
\text { Baseado em Componentes }\end{array}$ & $\begin{array}{l}\text { Os sistemas são desenvolvidos integrando componentes em } \\
\text { conformidade com uma estrutura de modelo de componentes. }\end{array}$ \\
\hline Frameworks de aplicação & $\begin{array}{l}\text { Coleções de classes abstratas e concretas que podem ser adaptadas e } \\
\text { estendidas para criar sistemas aplicativos. }\end{array}$ \\
\hline $\begin{array}{l}\text { Reuso de produtos COTS } \\
\text { (Commercial off-the-shelf) }\end{array}$ & $\begin{array}{l}\text { Sistemas são desenvolvidos para integrar sistemas aplicativos } \\
\text { existentes. Como a funcionalidade oferecida por esses sistemas é } \\
\text { muito mais ampla do que a dos componentes, o potencial de retorno } \\
\text { do reuso aumenta. }\end{array}$ \\
\hline $\begin{array}{l}\text { Desenvolvimento de } \\
\text { componentes para reuso }\end{array}$ & $\begin{array}{l}\text { Componentes compartilhados. Os projetistas de componentes } \\
\text { reusáveis devem encontrar um equilíbrio entre a generalidade e a } \\
\text { facilidade de compreensão. }\end{array}$ \\
\hline $\begin{array}{l}\text { Famílias de aplicações ou } \\
\text { linha de produtos }\end{array}$ & $\begin{array}{l}\text { Um tipo de aplicação é adaptado de diferentes formas a clientes } \\
\text { diferentes. }\end{array}$ \\
\hline Padrões de Projeto & $\begin{array}{l}\text { Abstrações genéricas que ocorrem nas aplicações são representadas } \\
\text { como design patterns que mostram objetos e interações abstratas e } \\
\text { concretas. }\end{array}$ \\
\hline
\end{tabular}

Fonte: SOMMERVILLE (2003)

AMBLER (2004) mostra categorias de reuso, tendo como base o RUP (Tabela 10).

Tabela 10 - Categorias de reuso baseados no RUP

\begin{tabular}{|l|l|}
\hline $\begin{array}{c}\text { Categoria de } \\
\text { reuso }\end{array}$ & \multicolumn{1}{c|}{ Descrição } \\
\hline Arquitetura & $\begin{array}{l}\text { O reuso e/ou desenvolvimento dos componentes técnicos e de negócios e serviços } \\
\text { são descritos em um modelo de arquitetura empresarial. }\end{array}$ \\
\hline Artefato & $\begin{array}{l}\text { Casos de uso, documentos-padrão, guias e procedimentos de modelos de domínios } \\
\text { específicos. }\end{array}$ \\
\hline Código & Reuso de código fonte, incluindo o uso de web services. \\
\hline Componente & Reuso de componentes encapsulados. \\
\hline Framework & Reuso de coleções de classes. \\
\hline
\end{tabular}




\begin{tabular}{|l|l|}
\hline $\begin{array}{c}\text { Categoria de } \\
\text { reuso }\end{array}$ & \multicolumn{1}{c|}{ Descrição } \\
\hline Herança & Reuso de herança de classes existentes. \\
\hline Padrões & Reuso de padrões para resolver problemas comuns. \\
\hline Template & $\begin{array}{l}\text { Reuso de uma lista de layouts comuns para desenvolver artefatos - documentos, } \\
\text { modelos e código fonte. }\end{array}$ \\
\hline
\end{tabular}

Fonte: AMBLER (2004)

\subsubsection{Frameworks}

Um framework de software é uma arquitetura reusável que fornece comportamento e estrutura genérica para uma família de abstrações de software (APPLETON, 2000). Um “framework" é um projeto de um conjunto de objetos que colabora entre si para execução de um conjunto de responsabilidades e reusa análise, projeto e código. Reusa análise, porque descreve os tipos de objetos importantes e como um problema maior pode ser dividido em problemas menores. Reusa projeto, porque contém algoritmos abstratos e descreve a interface que o programador deve implementar e as restrições a serem satisfeitas pela implementação. Reusa código, porque torna mais fácil desenvolver uma biblioteca de componentes compatíveis e porque a implementação de novos componentes pode herdar grande parte de seu código das superclasses abstratas. Embora todos os tipos de reuso sejam importantes, os de análise e projeto são os que mais compensam a longo prazo (JOHNSON, 1998).

Um dos maiores benefícios de utilizar frameworks é que permite um nível maior de reuso de código e projeto pela obtenção de diretrizes de arquitetura e de infraestrutura e também da especialidade do domínio e do reuso de funções implementadas em um determinado domínio.

FAYAD e SCHIMIDT (1997) classificam os frameworks em três grupos:

- Frameworks de infra-estrutura: Estes framewoks simplificam o desenvolvimento da infra-estrutura de sistemas portáveis e eficientes, como por exemplo, os sistemas operacionais, sistemas de comunicação, interfaces com o usuário e ferramentas de processamento de linguagem;

- Frameworks de integração de "middleware": são usados para integrar aplicações e componentes distribuídos. São projetados para melhorar a habilidade de desenvolvedores em modularizar, reusar e estender sua infra-estrutura de software para funcionar com mais facilidade em um ambiente distribuído;

- Frameworks de aplicação empresarial: estão voltados a domínios de aplicação mais amplos e são as pedras fundamentais para atividades de negócios das 
empresas, como por exemplo, sistema de telecomunicações, aviação, manufatura e Engenharia Financeira.

\subsubsection{Padrões}

A idéia de padrões de software originalmente foi embasada no conceito de padrões de ALEXANDER et al. (1977), ao definirem que cada padrão descreve um problema que ocorre diversas vezes no ambiente, então, apresenta o núcleo da solução para esse problema, de forma que possa utilizar essa solução várias vezes sem empregá-la do mesmo modo duas vezes.

Um padrão descreve uma solução para um problema que ocorre com freqüência durante o desenvolvimento de software, podendo ser considerado como um par "problema / solução". Esses pares podem ser agrupados em famílias de problemas e soluções similares, e cada família exibe um padrão, tanto de problema como de solução (BUSCHMANN et al., 1998).

Um padrão é um conjunto de informações instrutivas que possui um nome e capta a estrutura essencial e o raciocínio de uma família de soluções comprovadamente bemsucedidas para um problema repetido que ocorre sob um determinado contexto e um conjunto de repercussões. (APPLETON, 2000)

$\mathrm{Na}$ Engenharia de Software, desenvolvedores têm tentado encontrar padrões que venham ao encontro dos planos, algoritmos, estruturas de dados e idiomas aprendidos no passado. Projetistas familiarizados com certos padrões podem aplicálos imediatamente a problemas de projeto, sem precisar redescobrí-los (GAMMA et al., 1995).

Um dos primeiros trabalhos estabelecendo padrões foi o de COAD (1992), que descreve sete padrões de análise. Em 1993, GAMMA et al. (1995) e outros introduziram os primeiros de seus 23 padrões de projeto.

Padrões de software abrangem diferentes níveis de abstração, podendo, portanto ser classificados em diversas categorias de modo a facilitar sua recuperação e uso, porém essa classificação não é rigorosa. MALDONADO et al. (2000) relacionam diferentes categorias de padrões:

- Padrões de processo: definem soluções aos problemas encontrados nos processos envolvidos na Engenharia de Software: desenvolvimento, controle de configuração, testes, etc.; 
- Padrões arquiteturais: expressam o esquema ou organização estrutural fundamental de sistemas de software ou hardware;

- Padrões de padrão: são os que descrevem como um padrão deve ser escrito, ou seja, padronizam a forma com que os padrões são apresentados aos usuários;

- Padrões de análise: descrevem soluções para problemas de análise de sistemas, embutindo conhecimento sobre o domínio de aplicações específicas;

- Padrões de projeto: definem soluções para problemas de projeto de software e ensinam os projetistas a padronizarem o modo como desenvolvem;

- Padrões de interface: definem soluções para problemas comuns no projeto da interface de sistemas;

- Padrões de programação: descrevem soluções de programação particulares de uma determinada linguagem ou regras gerais de estilos de programação;

- Padrões de persistência: descrevem soluções para problemas de armazenamento de informações em arquivos ou banco de dados;

- Padrões de teste: fornecem diretrizes para auxiliar os testadores na avaliação da qualidade do produto;

- Padrões para hipertexto: descrevem soluções para problemas encontrados no projeto de hipertextos; e

- Padrões para hipermídia: descrevem soluções para problemas encontrados no desenvolvimento de aplicações hipermídia.

Os padrões de projeto são abstrações de alto nível, que documentam soluções bemsucedidas de projeto. Eles são fundamentais para o reuso de projeto no desenvolvimento orientado a objetos. Uma descrição-padrão deve incluir um nome de padrão, uma descrição de problema e de solução, uma declaração dos resultados e os componentes de uso do padrão. SOMMERVILLE (2003).

Para a utilização destes padrões, deve-se pensar em maneiras de agrupar os padrões existentes, segundo algum critério, de forma a facilitar sua recuperação e reuso. Isso pode ser feito por meio de coleções de padrões, catálogo de padrões, sistemas de padrões ou linguagem de padrões.

\subsubsection{Componentes de Software}

Conforme aponta SZYPERSKI (1998), os componentes de software são módulos binários, de produção, aquisição e implantação independentes, que interagem entre si 
para formar um sistema funcional. Um componente é uma unidade de composição com interfaces contratualmente especificadas e dependências de contexto explícitas. Componentes podem ser desenvolvidos utilizando o paradigma de orientação a objetos, isto é, como estruturas de classes inter-relacionadas, com visibilidade externa limitada, porém, no caso geral, componente não depende de tecnologia de implementação. Assim, qualquer artefato de software pode ser considerado um componente, desde que possua uma interface definida.

Segundo BARROCA et. al. (2005), as interfaces podem ser classificadas em dois tipos: interfaces fornecidas e interfaces requeridas. A primeira define os serviços oferecidos pelo componente por meio de operações. A segunda define os serviços que o componente necessita de outros componentes.

Em geral, os componentes são classificados em:

- Componentes de interface homem-máquina: componentes que implementam elementos de uma interface gráfica (Graphical User Interface - GUI);

- Componentes de infra-estrutura: componentes de suporte ao uso dos recursos de infra-estrutura, como base de dados e rede; e

- Componentes de negócios: componentes que encapsulam a lógica e os dados do negócio.

O desenvolvimento de software orientado a componentes é uma das principais abordagens que promove o reuso de artefatos de alta granularidade, com a capacidade de promover reuso de projeto e código. Nesta abordagem uma aplicação é constituída com base em um conjunto de módulos (componentes) interligados.

\subsubsection{Arquitetura de Software}

A definição de arquitetura apresentada por SHAW e GARLAND (1996) cita que a Arquitetura de Software define o que é o sistema em termos de componentes computacionais e os relacionamentos entre estes componentes. A visão sobre um software pode se ater a diferentes níveis de abstração. Distintas técnicas de modelagem produzem descrições de um software em diferentes níveis de sua escala de abstração. A arquitetura representa o mais elevado grau de abstração. Define um software em termos de um conjunto de artefatos e de conexões entre esses artefatos. Conforme os autores citados, a Arquitetura de Software surgiu como uma evolução natural das abstrações de projeto, na busca de novas formas de construir sistemas de 
software maiores e mais complexos. A Arquitetura de Software busca formas de descrever organizações de sistemas de software existentes, com vista a promover o reuso de experiência de projeto, possibilitando a escolha da forma de organização mais adequada para um sistema de software a se desenvolver.

Uma proposta de visões em Arquitetura de Software descrito por KRUCHTEN (1995) atende aos seguintes propósitos:

- Abordar a organização lógica do sistema;

- Organizar suas funcionalidades;

- Abordar os aspectos de concorrência; e

- Descrever a distribuição física do software na plataforma utilizada.

O modelo de arquitetura 4+1 de KRUCHTEN (1995) mostra cinco visões: lógica, processo, desenvolvimento, implementação e casos de uso.

- A visão lógica tem seu foco nos requisitos funcionais, seus componentes são objetos e funções do domínio da aplicação e apresenta relacionamentos de associação, dependência, composição e herança;

- A visão de processos tem seu foco em requisitos de qualidade, como desempenho e confiabilidade, seus componentes são processos e linhas de execução e os relacionamentos que apresenta são de concorrência, dependência, comunicação, etc.;

- A visão de desenvolvimento tem o foco no processo de desenvolvimento, seus componentes são unidades de código e programas, e os relacionamentos são de exportação e importação;

- A visão física está focada em requisitos de qualidade. Seus componentes são pacotes de instalação e processadores, e os relacionamentos que apresenta são de comunicação e dependência; e

- A visão de casos de uso é a descrição de uma arquitetura organizada em torno destas quatro visões, ilustradas por alguns casos de uso ou cenários, que se tornam uma quinta visão (modelo $4+1$ ).

\subsubsection{Reuso de Processos}

FIORINI (2001) define reuso de processos como o uso de um modelo de processo na criação de outro processo. HOLLENBACH e FRAKES (1996) utilizam o modelo 
3Cs: conceito, conteúdo e contexto que descreve o ambiente necessário aplicado para o reuso de componentes de software para organizar os dados do processo:

- Conceito - semântica: uma especificação informal da informação geral do processo, descrição do cliente e a descrição da interface;

- Conteúdo - implementação: inclui a descrição dos procedimentos do processo, utilizando a representação gráfica e textual; e

- Contexto - uma descrição sobre o domínio, a organização e o projeto no qual o processo está inserido e será executado, além do custo, benefício e riscos do processo.

Para os autores, a finalidade de uma metodologia para definição de processos é criar processos reusáveis, tais que projetos dentro de uma organização possam adaptá-los a um custo efetivo a seus requisitos. O ciclo de vida para a descrição dos processos segue os seguintes passos:

- Definir o processo reusável e garantir que eles possam ser reusados;

- Desenvolver treinamento para o processo reusável;

- Adaptar o processo reusável ao projeto;

- Executar o processo no projeto, acompanhar a garantia da qualidade e efetuar medições; e

- Refinar o processo baseado nas medições e nos passos anteriores, o processo deve ser avaliado para verificar se atingiu seus objetivos ou não.

\subsubsection{Considerações}

A fim de melhorar o processo de desenvolvimento e manutenção de software, é essencial que a FS melhore a maneira como administra o conhecimento existente com base nas experiências adquiridas de novos experimentos. O reuso de software é essencial para a obtenção de grandes retornos pela redução de custos, prazos e esforços e, sobretudo, para o atendimento ao aumento da demanda de software. Porém, segundo BARROCA et al., os maiores obstáculos são de natureza gerencial, econômica e técnica e, para que o reuso de software se torne um fato, o ciclo de vida deve ser adaptado para incluir atividades como a análise de domínio. 
Conforme BASILI et al. (1992), as metas prioritárias para o crescimento da qualidade e produtividade são: melhorar a eficácia dos processos, reduzir o volume de re-trabalho e reusar os produtos gerados no ciclo de vida.

PRIETO-DIAZ e ARANGO (1991) apontam três fatores que auxiliam a solucionar problemas de reuso: análise e engenharia de domínio, reuso de processos e megaprogramação. Os autores comentam que a comunidade verifica a possibilidade de criar coleções de processos reusáveis que possam ser conectados para instanciar processos novos e mais complexos. Também salientam que o reuso de processos é um meio de reusar experiências práticas e conhecimentos.

\subsection{Modelos de Melhores Práticas e Normas de Qualidade}

O mercado de TI vem buscando cada vez mais o apoio em modelos de referência para o gerenciamento, controle e desenvolvimento de projetos de software. Embora existam muitos e variados modelos, cada qual com suas particularidades, forças e fraquezas. Alguns modelos vêm se destacando, cada qual procurando enfatizar aspectos específicos relacionados aos projetos de desenvolvimento de software focando, sobretudo os princípios da qualidade. Os modelos estudados neste trabalho são:

- Norma ISO 9001-2000 - Sistemas de Gestão da Qualidade - Requisitos;

- Norma ISO/IEC 9126 - Qualidade do Produto de Software;

- Norma ISO/IEC 12207 - Processos do Ciclo de Vida do Software;

- CMMI - Modelo Integrado de Capacidade de Maturidade;

- PMBOK - Processos de Gestão de Projetos; e

- ITIL - Biblioteca de Infra-Estrutura de Tecnologia da Informação.

A seguir, será feita uma explanação sobre estes modelos, não estando no escopo do trabalho o detalhamento de cada processo definido nos modelos. O objetivo principal deste estudo é servir como guia para identificar e analisar os processos que compõem os modelos de definição de processos da FS, assim como relacioná-los ao contexto organizacional da Empresa estudada na pesquisa-ação.

\subsubsection{Norma ISO 9001:2000 - Sistemas de Gestão da Qualidade - Requisitos}

A ISO 9001:2000 é uma evolução do conjunto de normas ISO 9000 estabelecido no início da década de 1990. A ISO 9001:2000 aplica-se tanto a empresas ou atividades 
de serviços, como de manufatura, e é orientada para sistemas de qualidade que têm por objetivo a geração de produtos e/ou serviços, de acordo com os requisitos dos clientes. Neste sentido, abrange todo o ciclo de vida de um produto ou serviço, desde sua concepção até sua desmobilização.

A norma aplica totalmente os princípios da Gestão da Qualidade Total, usando fortemente o ciclo de DEMING, ou seja, PDCA - Plan-Do-Check-Act. Os requisitos da norma ISO 9001:2000 foram reorganizados nas seguintes abordagens de processos:

- Sistema de Gestão de Qualidade: sistema geral de gestão de qualidade;

- Requisitos de Documentação: política da qualidade documentada, manual da qualidade, procedimentos documentados, registros de documentos;

- Responsabilidade da Gestão: comprometimento, foco no cliente, diretivas, planejamento e comunicação;

- Gestão de Recursos: recursos humanos, infra-estrutura e ambiente de trabalho;

- Realização do Produto: planejamento, processos relativos a clientes, projeto, compras, operações de produção e serviços e controle dos recursos de monitoração e medição;

- Medição, Análise e Aperfeiçoamento: monitoração e medição, controle da conformidade ou não-conformidade de produtos, análise de dados e aperfeiçoamentos.

O modelo pode ser aplicado a qualquer tipo de operação ou negócio que resulte em um produto ou serviço. No caso específico da área de TI, pode-se aplicá-lo a operações de desenvolvimento de sistemas, de suporte, de infra-estrutura e sucessivamente. Segundo FERNANDES e TEIXEIRA (2004), esta norma pode ser combinada perfeitamente com o CMMI, PMBOK e outros modelos voltados para processos de TI em geral.

Esta norma é passível de certificação por parte de uma entidade credenciada, geralmente uma empresa de auditoria de sistemas da qualidade. A certificação tem reconhecimento mútuo, ou seja, por várias entidades credenciadoras no Brasil e em outros países. Neste caso, a auditoria é caracterizada como a terceira parte, pois é a organização postulante que deve contratar a entidade que irá realizar a auditoria. 
O sistema de qualidade recebe uma auditoria de manutenção a cada seis meses e, ao final de três anos, a organização deve passar por uma nova certificação de revalidação. Nesta auditoria de revalidação, espera-se que tenha havido progresso na melhoria contínua do sistema da qualidade.

\subsubsection{Norma ISO/IEC 9126 - Qualidade do Produto de Software}

A ISO/IEC 9126 (1991) trata da avaliação do produto de software, do ponto de vista de suas características de qualidade. A norma é aplicável para quem faz aquisição e/ou desenvolvimento de software de usuários, assim como para quem fornece suporte, manutenção ou realiza auditoria de software.

A norma sugere sua aplicação nas seguintes situações:

- Definir os requisitos de qualidade do software;

- Avaliar especificações de software para verificar se satisfazem os requisitos de qualidade durante o desenvolvimento;

- Descrever características e atributos do software desenvolvido, antes de ser entregue;

- Avaliar o software antes da aceitação.

A norma sugere a avaliação dos atributos da qualidade do software relacionados à Funcionalidade, Confiabilidade, Usabilidade, Eficiência, Manutenibilidade e Portabilidade.

- Funcionalidade: conjunto de atributos que satisfazem necessidades implícitas e explícitas: adequabilidade, exatidão, interoperabilidade, conformidade e segurança;

- Confiabilidade: conjunto de atributos relacionados à capacidade do software de manter seu nível de desempenho, conforme as condições estabelecidas por um período de tempo estabelecido: maturidade, tolerância às falhas e capacidade de recuperação;

- Usabilidade: conjunto de atributos relacionados ao esforço para usar o software ou na avaliação individual de tal uso, por um ou mais usuários: facilidade de entendimento, facilidade de aprendizagem e de operação;

- Eficiência: conjunto de atributos que dizem respeito à relação entre o nível de desempenho do software e a quantidade de recursos usada, sob condições estabelecidas: comportamento do tempo e recursos; 
- Manutenibilidade: conjunto de atributos relacionados ao esforço necessário para realizar modificações especificadas: facilidade de análise, mudança, testes e estabilidade; e

- Portabilidade: conjunto de atributos do software relacionados à habilidade de ser transferido de um ambiente para outro: capacidade de adaptação, facilidade de instalação, nível de conformidade e facilidade de substituição.

Na FS, a ISO/IEC 9126 pode ser aplicada para avaliação e aceitação de softwareproduto ou software desenvolvido ou adquirido pela empresa, conforme os requisitos estabelecidos para cada uma das características de qualidade esperadas. Da mesma forma, esta norma pode auxiliar na especificação de condições de teste de aceitação ou do processo de avaliação de software que a empresa adquire ou possui.

\subsubsection{Norma ISO/IEC 12207 - Ciclo de Vida do Software}

Os conceitos sobre processos existentes na norma de qualidade NBR ISO/IEC 12.207 (1998) identificam mais amplamente os processos envolvidos em uma organização desenvolvedora de software como mostrado na Figura 6.

A norma organiza as atividades do ciclo de vida de um software em três grandes fases:

- Processos fundamentais - conjunto de atividades técnicas que envolve desde a aquisição até a manutenção de um software;

- Processos de apoio - conjunto de atividades de apoio aos processos fundamentais para garantia da qualidade do software;

- Processos organizacionais - conjunto de atividades relativas à infra-estrutura dos processos fundamentais e gerência dos projetos.

Para o mapeamento dos processos da FS, a adoção do entendimento desta norma auxilia na padronização da terminologia, no entendimento do conteúdo de cada processo, na simplificação da estrutura de cada um deles, na alta coesão dos processos de desenvolvimento de software e no baixo acoplamento entre si.

Entretanto, a norma deixa para a organização definir 'como' os processos serão executados, conservando, dessa forma, a flexibilidade para que as organizações a implementem, de acordo com sua cultura e tecnologia empregada. 


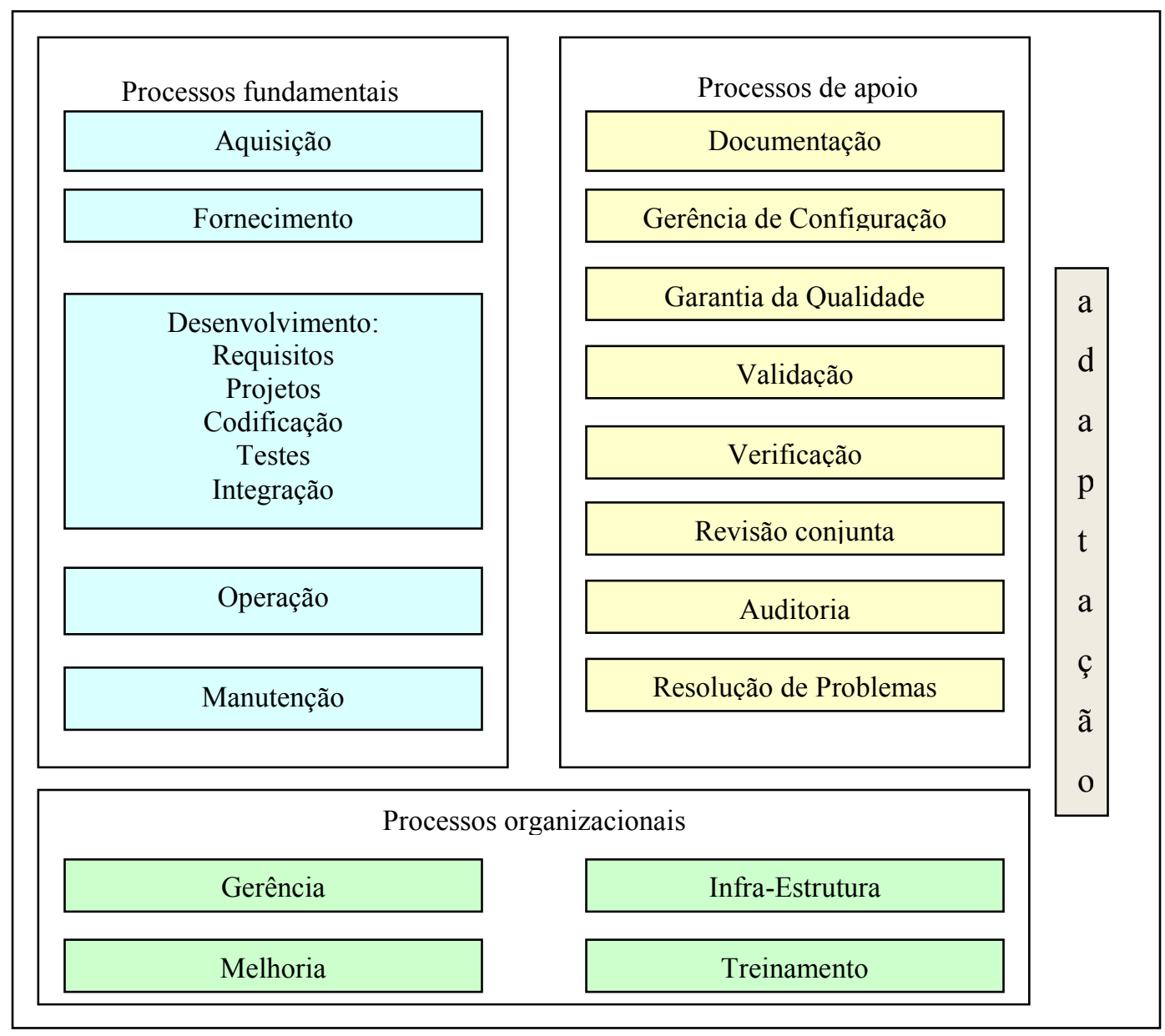

Figura 6 - ISO/IEC 12207 - Processos do Ciclo de Vida do Software Fonte: ISO/IEC 12207 (1998)

\subsubsection{CMMI - Modelo Integrado da Maturidade da Capacidade}

O Modelo CMMI (2005) - Capability Maturity Model Integration, é uma evolução do SW-CMM - Software Capability Maturity Model, definido no SEI (Software Engineering Institute), a pedido do Departamento de Defesa dos Estados Unidos da América. O CMMI foi criado para integrar os diversos modelos CMM (Capability Maturity Model), que atendem às várias atividades relacionadas ao desenvolvimento de software e avalia o nível de maturidade do processo de desenvolvimento de software de uma empresa (CHRISSIS et al., 2007).

Existem dois tipos de representação no CMMI: em estágios e contínua. A representação em estágios trata do nível de maturidade da organização como um todo, contendo cinco níveis de maturidade: inicial, gerenciado, definido, gerenciado quantitativamente e em otimização. Cada nível é constituído por um conjunto de áreas de processos, compostas por objetivos específicos e genéricos. Cada objetivo 
específico pode ser composto por um conjunto de práticas específicas. A representação contínua permite que uma organização selecione uma área de processo específica e melhore com relação a esta área (CHRISSIS et al., 2007).

A representação contínua usa níveis de capacidade para caracterizar a melhoria relacionada a uma determinada área de processo (WEBER, 2004). A Figura 7 apresenta os níveis de maturidade da versão CMMI-SE/SW (CMMI-Software Engineering and SoftWare), além do foco das áreas-chave de processo a eles associados.

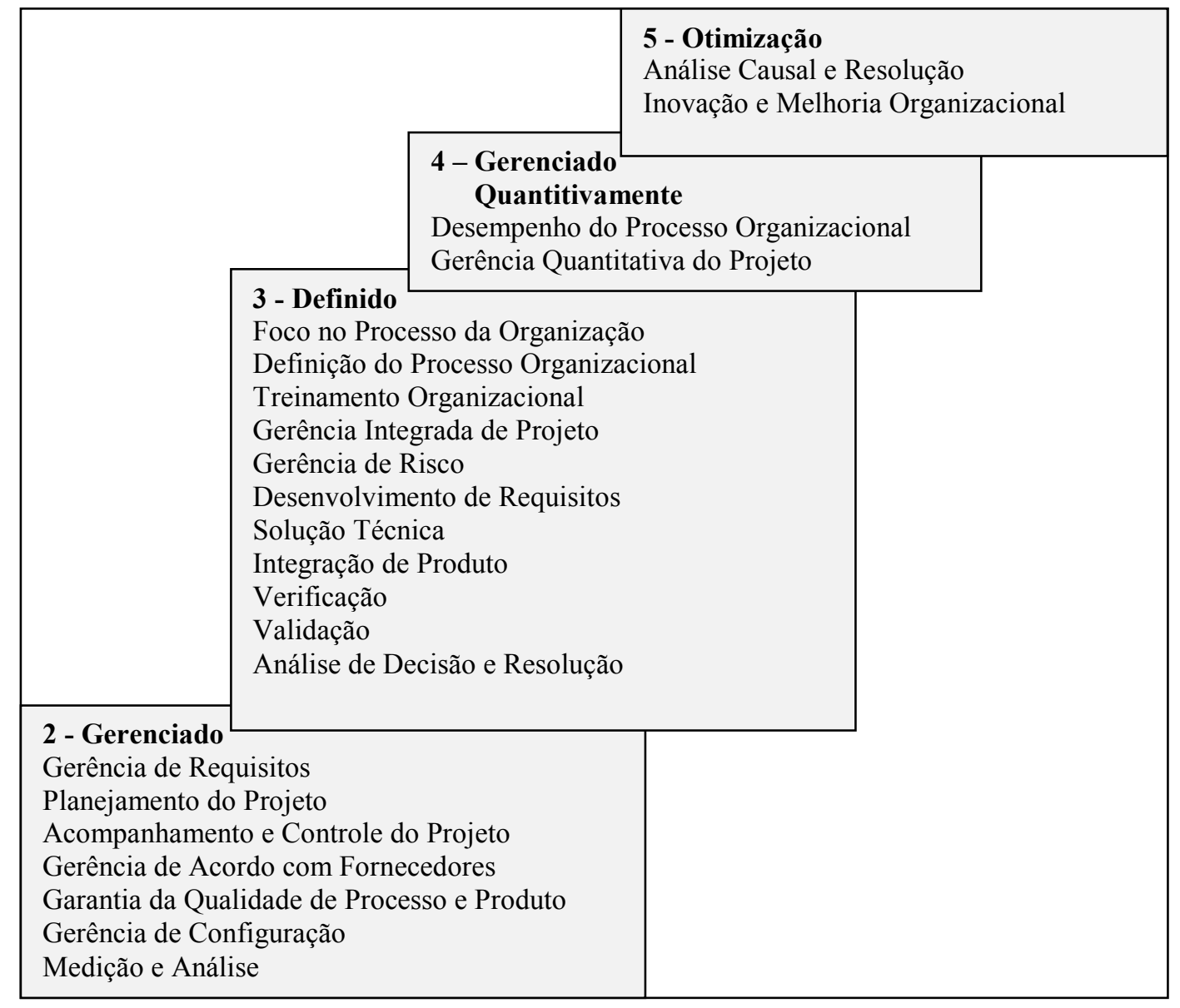

Figura 7 - Níveis de maturidade do CMMI Fonte: CMMI-SE/SW (2005)

O CMMI fornece um modelo de avaliação rigoroso, chamado SCAMPI - Standard CMMI Appraisal Method for Process Improvement. Uma avaliação SCAMPI é dividida em três fases: planejamento inicial e preparação; avaliação local; relato de resultados. Uma avaliação SCAMPI deve ser liderada por um avaliador treinado e autorizado pelo SEI. 
Segundo FIORINI et al. (1998), no CMM uma das ênfases dos processos de certificação é verificar se o que é realizado (processo) está documentado e, se o que está documentado corresponde ao processo que é realizado. Portanto, a definição de processos de software é fundamental, para que isso seja comprovado e atinja níveis mais elevados de maturidade. A partir do nível 3, a ênfase em questões relacionadas com a definição de processos é bem maior, iniciando com a definição de um conceito fundamental: o Processo de Software Padrão da organização. Em uma organização, diversos projetos podem coexistir possuindo características específicas. Mas é importante que exista um processo básico que guie o estabelecimento de um processo comum na organização.

\subsubsection{PMBOK - Modelo de Processos de Gestão de Projetos}

Uma importante referência à gerência de projetos é o Modelo PMBOK (2004) Guide Project Management Body of Knowledge, ou Guia do "Corpo" de Conhecimento em Gestão de Projetos, compilado pela expertise do PMI - Project Management Institute. O PMBOK divide as práticas de gestão de projetos em processos e agrupa-os em nove áreas de conhecimento:

- Gerência da Integração do Projeto;

- Gerência do Escopo do Projeto;

- Gerência do Tempo do Projeto;

- Gerência do Custo do Projeto;

- Gerência da Qualidade do Projeto;

- Gerência dos Recursos Humanos do Projeto;

- Gerência das Comunicações do Projeto;

- Gerência dos Riscos do Projeto;

- Gerência das Aquisições do Projeto.

Cada processo englobado em uma área de conhecimento possui três componentes: entradas; ferramentas e técnicas; e saídas. Desta forma, mostra-se o que deve ser feito, quais são as premissas e os resultados da tarefa.

- As entradas são informações e documentos resultantes do processo origem;

- Ferramentas e técnicas fornecem mecanismos e recursos que devem ser aplicados às entradas para gerar as saídas; e 
- As saídas são informações e documentos resultantes do tratamento realizado nas entradas.

No PMBOK (2004), cita-se que os processos são classificados em duas categorias:

- Processos orientados ao gerenciamento do projeto: relacionam-se com a descrição, a organização, o controle, o acompanhamento e a conclusão do projeto; e

- Processos orientados aos produtos do projeto: relacionam-se com a especificação e a elaboração dos produtos do projeto. Os processos orientados aos produtos são definidos, de acordo com a visibilidade e o nível de controle que se deseja ter no projeto e variam conforme a área de aplicação do projeto.

O fluxo de atividades da gerência de projetos segue cinco grupos de processos, conforme a Figura 8.

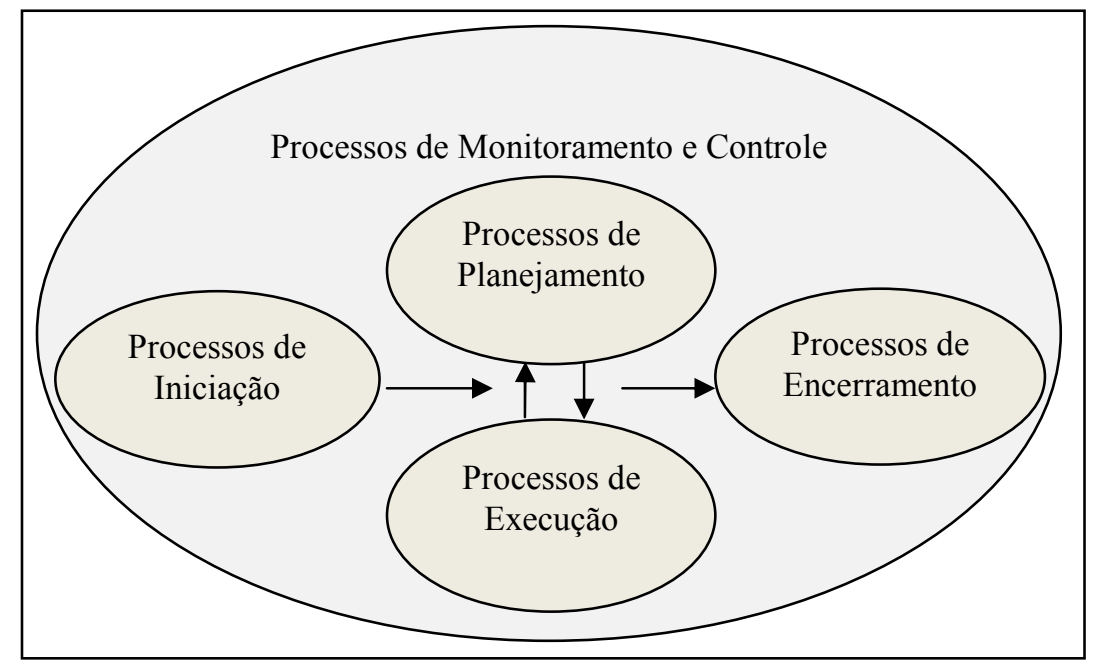

Figura 8 - Grupos de Processos do PMBOK Fonte: PMBOK (2004)

1. Processo de iniciação: refere-se à autorização do projeto ou fase do projeto;

2. Processo de planejamento: refere-se à definição e refinamento dos objetivos e seleção da melhor das alternativas de ação para alcançar os objetivos que o projeto estiver comprometido em atender;

3. Processo de execução: preocupa-se em coordenar pessoas e outros recursos para realizar o plano;

4. Processo de monitoramento e controle: assegura que os objetivos do projeto sejam atingidos, por meio da monitoração regular de seu progresso, para identificação de 
variações do plano, possibilitando, assim, que ações corretivas sejam tomadas quando necessárias;

5. Processo de encerramento: formaliza a aceitação do projeto e seu encerramento.

O PMBOK (2004) utiliza conceitos da Engenharia Simultânea, propondo que um projeto deve ser executado de forma multifuncional, pela alocação matricial de pessoas, de acordo com o tempo definido (fases dos projetos) e da especialização técnico-profissional de cada pessoa.

Por se tratar de um trabalho genérico, várias empresas têm utilizado o PMBOK como metodologia para melhorar o gerenciamento e integração de recursos. $\mathrm{O}$ conhecimento e as práticas descritos no PMBOK não são necessariamente aplicados em sua totalidade em todos os projetos na área de desenvolvimento de software.

Comparando o Modelo CMMI com o PMBOK, observa-se que ambos estão baseados fortemente em processos; enquanto o CMMI foca no processo de projetos relacionados a software, o PMBOK reúne experiências e práticas para qualquer tipo de projeto.

\subsubsection{ITIL - Biblioteca de Infra-Estrutura de Tecnologia da Informação}

O Information Tecnology Infrastructure Library (ITIL, 2005) foi desenvolvido em 1983, por agências do governo inglês, para avaliar as operações de TI das empresas que contratava. ITIL define processos e atividades em suporte aos serviços de TI. Os serviços de TI referem-se a um conjunto de funções relacionadas, fornecidas por sistemas de TI que suportam uma ou mais áreas de negócios, conforme mostrado na Figura 9.

Este serviço pode ser composto de hardware, software e componentes de comunicação, mas é percebido como uma entidade coerente e auto-suficiente.

A visão de gerenciamento de serviços e o acordo mútuo que apresentam "onde queremos estar" devem ser formulados em conjunto pelas áreas de negócio e TI, em benefício dos objetivos de negócio. Esta visão deve conter todos os aspectos do programa que inclui pessoas, processos e tecnologias. Uma boa declaração de visão serve a quatro propósitos importantes: 


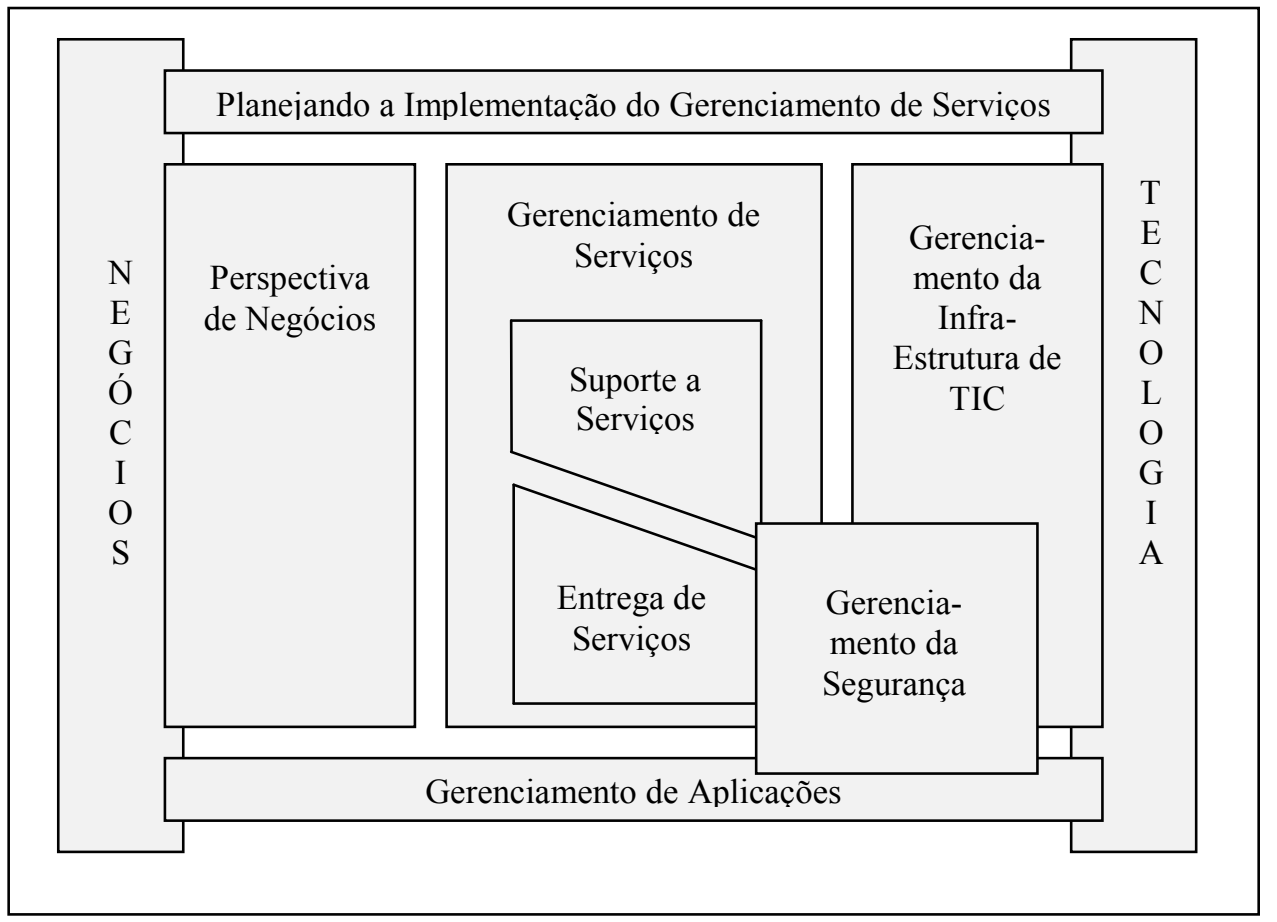

Figura 9 - Áreas e Escopo do Modelo ITIL

Fonte: ITIL (2005)

- Direciona claramente o programa;

- Motiva as pessoas a tomarem ações na direção correta;

- Coordena a visão de várias pessoas distintas; e

- Representa a visão dos gestores seniores.

Os núcleos de áreas funcionais do ITIL são: suporte a serviços relacionados com o usuário final e as gerências de entrega de serviços, relacionadas com cliente pagante, conforme são detalhados nos dados da Tabela 11.

Tabela 11- Núcleos das áreas funcionais do ITIL

\begin{tabular}{|l|l|}
\hline \multicolumn{1}{|c|}{ GERÊENIA } & \multicolumn{1}{c|}{ DEFINIÇÃO } \\
\hline $\begin{array}{l}\text { Gerência de Acordo } \\
\text { de Nível de } \\
\text { Serviços }\end{array}$ & $\begin{array}{l}\text { Elaboração e monitoração do acordo de nível de serviços prestados pela } \\
\text { Empresa, assinado entre Empresa e cliente. Este acordo contempla } \\
\text { disponibilidade de máquinas referentes aos serviços prestados, fluxo de } \\
\text { execução dos processos, indicadores de qualidade, métricas e tabela } \\
\text { Balanced ScoredCard com resultados finais. }\end{array}$ \\
\hline $\begin{array}{l}\text { Gerência de } \\
\text { Configuração }\end{array}$ & $\begin{array}{l}\text { Responsável pela contabilização de todos os recursos de TI na empresa e } \\
\text { seus serviços, fornecer informações precisas sobre configurações e } \\
\text { documentação para reportar todos os outros processos de gerenciamento de } \\
\text { serviços, além de proporcionar uma base sólida às demais disciplinas do } \\
\text { ITIL, sobretudo para mudanças, incidentes, problemas e liberações. }\end{array}$ \\
\hline
\end{tabular}




\begin{tabular}{|c|c|}
\hline GERÊNCIA & DEFINIÇÃO \\
\hline $\begin{array}{l}\text { Gerência de } \\
\text { Capacidade e } \\
\text { Disponibilidade }\end{array}$ & $\begin{array}{l}\text { Garantir a existência da capacidade de TIC, determinar as demandas do } \\
\text { negócio, previsões de cargas de trabalho, a execução e o planejamento de } \\
\text { recursos de TIC, aperfeiçoar a capacidade de infra-estrutura para entrega } \\
\text { do nível de responsabilidade a um custo efetivo. }\end{array}$ \\
\hline $\begin{array}{l}\text { Gerência de } \\
\text { Mudanças }\end{array}$ & $\begin{array}{l}\text { Assegurar que procedimentos e métodos padronizados sejam usados } \\
\text { eficientemente para o atendimento de todas as mudanças requeridas na } \\
\text { infra-estrutura de TIC, de maneira a minimizar o impacto adverso na } \\
\text { qualidade e disponibilidade dos serviços Analisar, coordenar, liberar ou } \\
\text { vetar a execução das solicitações de serviços no ambiente da infra- } \\
\text { estrutura. Registrar e armazenar informações das alterações em banco de } \\
\text { dados, visando a referências futuras. Realizar reuniões para liberação de } \\
\text { serviços considerados críticos. }\end{array}$ \\
\hline Service Desk & $\begin{array}{l}\text { Fornecer um ponto central estratégico de contato para clientes, em um } \\
\text { ponto único de contato operacional para o tratamento de incidentes até a } \\
\text { resolução. O Service Desk é responsável por receber chamados de } \\
\text { clientes/usuários por abrir, registrar e encaminhar e, finalmente, } \\
\text { encerrar estes chamados, empregando os mecanismos proporcionados pelo } \\
\text { Gerenciamento de Incidentes. }\end{array}$ \\
\hline $\begin{array}{l}\text { Gerência de } \\
\text { Incidentes }\end{array}$ & $\begin{array}{l}\text { Monitorar o ambiente de TI, no sentido de obedecer aos níveis de serviço } \\
\text { prédeterminados e escalar corretamente os incidentes, dentro do processo } \\
\text { de entrega do serviço, à medida que eles apareçam. O Gerenciamento de } \\
\text { Incidentes possui a responsabilidade de solucionar incidentes o mais rápido } \\
\text { possível e garantir que o serviço do usuário esteja disponível o mais } \\
\text { rápido. }\end{array}$ \\
\hline $\begin{array}{l}\text { Gerência de } \\
\text { Liberações }\end{array}$ & $\begin{array}{l}\text { Apresentar uma visão completa de uma mudança em um serviço de TI e } \\
\text { assegurar que todos os aspectos de uma liberação (técnicos ou não } \\
\text { técnicos) sejam considerados. Engloba o planejamento, design, construção, } \\
\text { configuração e testes de software e hardware para criar um conjunto de } \\
\text { componentes de uma liberação para um ambiente de produção. Garantir } \\
\text { um mínimo de impacto de implantação de liberação no ambiente de } \\
\text { produção. }\end{array}$ \\
\hline $\begin{array}{l}\text { Gerência de } \\
\text { Problemas }\end{array}$ & $\begin{array}{l}\text { Minimizar o impacto adverso nos negócios causados por incidentes e } \\
\text { problemas provocados por erros na infra-estrutura de TI e prevenir a } \\
\text { recorrência de incidentes relacionados a esses erros. Busca obter a causa } \\
\text { do erro e iniciar ações para removê-lo. Ao mesmo tempo, o processo é } \\
\text { reativo (respondendo a Incidentes repassados a ele pelo Service Desk) e } \\
\text { proativo, identificando erros conhecidos e solucionando problemas antes } \\
\text { que ocorra um incidente relacionado a ele. }\end{array}$ \\
\hline
\end{tabular}
Fonte: ITIL (2005)

\subsubsection{Considerações}

A principal característica dos Modelos de Melhores Práticas é visar a melhoria de processos de software, fornecendo diretrizes de "o que" deve ser feito; a forma de implementação, “o como fazer", sendo responsabilidade da empresa que deseja implantar o modelo e/ou buscar sua certificação.

Neste trabalho, os Modelos de Melhores Práticas são usados como guias para auxiliar a análise e mapeamento geral dos processos, identificando os processos-chave existentes na FS, assim como oferecer uma sugestão de utilização customizada e integrada desses Modelos no âmbito da FS. Os fluxos dos processos mapeados 
servem como sustentação ou instrumentos de trabalho para uma futura adoção ou certificação de Modelos de Melhores Práticas. Assim como estes Modelos servem como um importante guia auxiliar para o mapeamento e análise dos processos.

\subsection{Gestão por Processos}

Uma FS segue um modelo de empresa produtiva, organizada e controlada como qualquer outra organização industrial se, transformada em um ambiente de trabalho baseado em processos corporativos. Os processos são definidos sob duas premissas fundamentais: elevar o desempenho operacional e, incorporar controles que agreguem confiabilidade e qualidade nos trabalhos realizados. Assim é fundamental desdobrar, mapear e padronizar cada processo da cadeia de valor. As FS que obtiverem maior maturidade no gerenciamento das disciplinas que suportem toda a cadeia de serviços de software, conseguirão antecipar oportunidades e implementar novas tecnologias combinadas com as novas frentes de negócios.

\subsubsection{Conceito de Gestão por Processos}

A Reengenharia de Processos de Negócio, como nova abordagem de gestão e otimização do desempenho das organizações, aparece cerca de 50 anos após os Modelos precursores como: a Teoria Sistêmica (paradigma em meados do século XX); o JIT (Just in Time) nos anos 70; a Automation Systems Integration; CIM (Computer Integrated Manufacturing); Reestructuring, TQM (Total Quality Management) todos nos anos 80, e o Downsizing no início dos anos 90 (MONTEIRO, 2004).

Parte do sucesso que as empresas japonesas tiveram com relação às suas concorrentes americanas nas décadas de 1980 e 1990, decorreu do fato de terem implementado a Gestão por Processos, muito antes das empresas ocidentais entenderem a que o assunto se referia. O papel de destaque dado ao gerenciamento de processos na cultura corporativa japonesa garantiu que, em diversas ocasiões, muitas empresas desse país tenham desenvolvido processos rápidos e eficientes em áreas-chave, como o desenvolvimento de produtos, logística, vendas e comercialização.

ALVARENGA NETTO (2006) realizou levantamento da literatura sobre a conceituação da organização por processos. Foram pesquisadas 98 referências bibliográficas, nas quais puderam ser identificadas 55 propostas conceituais sobre 
Gestão por Processos. Do estudo, foram constatadas diversas propostas de conceituação sobre as iniciativas de melhorar a competitividade com base em processo, o que elas parecem ter em comum, é a consideração de valor para os clientes e o cruzamento das fronteiras organizacionais. Desta forma, o autor adota o termo Gestão por Processos por parecer mais amplo, incluindo concepção, planejamento e organização abrangendo processos administrativos, de apoio, serviços e tratamento de informações, incluindo, o relacionamento além das fronteiras departamentais, propondo a seguinte conceituação: “Gestão por processos é o enfoque sistêmico de projetar e melhorar continuamente os processos organizacionais, por pessoas potencializadas e trabalhando em equipe, combinando capacidades tecnológicas emergentes e sob uma postura filosófica para a qualidade, objetivando a entrega do valor ao cliente".

\subsubsection{Processos Empresariais}

Segundo MONTEIRO (2004), uma empresa, tendo como pressuposto seu objetivo, ou sua visão, desenha uma estratégia de funcionamento que integra e articula, um conjunto de componentes para produzir os tipos de produtos e/ou serviços a que se propõe. Estes componentes mostrados na Figura 10 referem-se a:

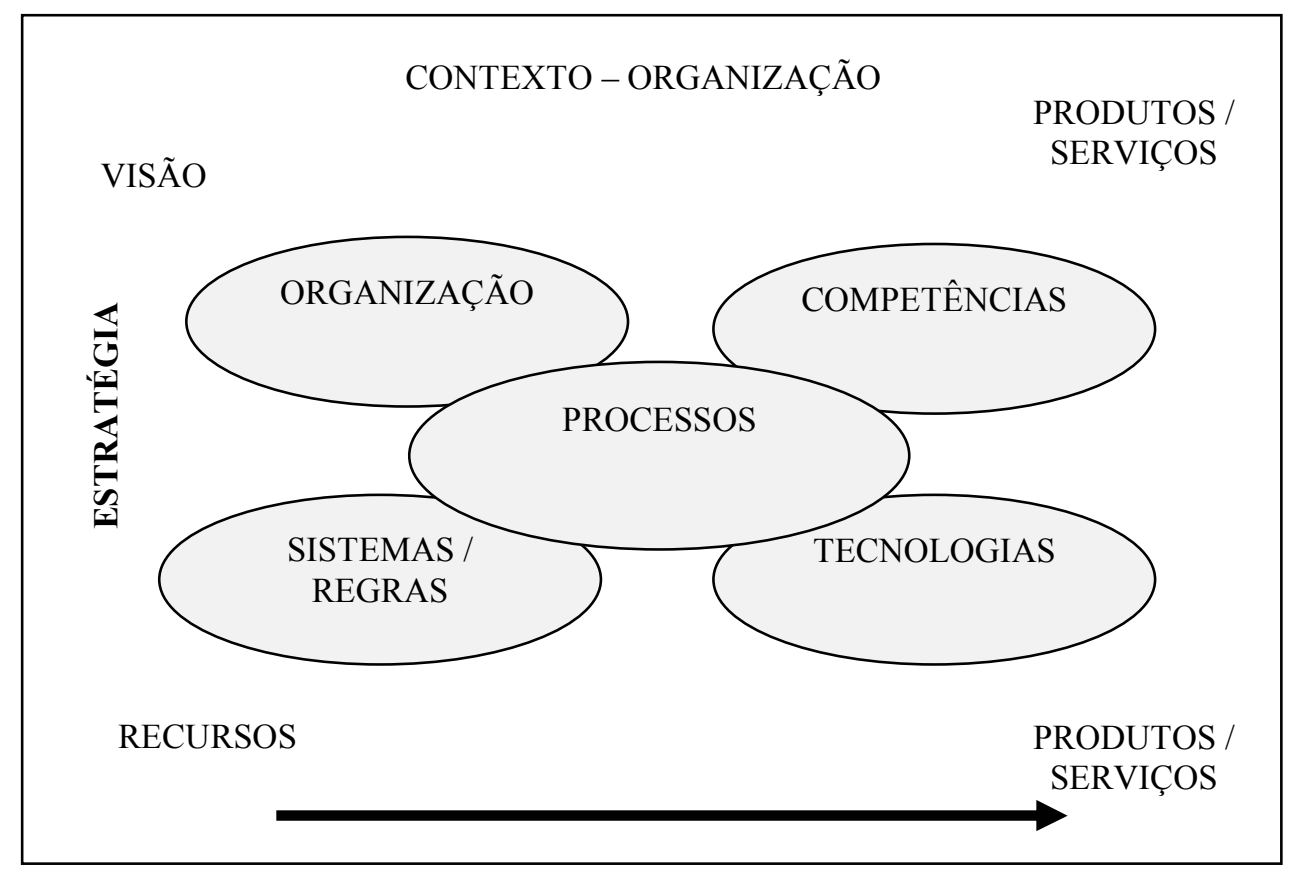

Figura 10 - Componentes da Estratégia de Funcionamento de uma Organização Fonte: adaptado de MONTEIRO (2004) 
- Organização: que engloba a cultura (história, crenças, referências, comportamentos, políticas, etc.) da organização, os modelos de estrutura (objetivos, responsabilidades e atribuições), modelos de gestão e de liderança em exercício;

- Competências: que constituem o conjunto dos conhecimentos, saberes, capacidades e habilidades que a organização tem disponível em seu quadro de profissionais para a execução dos diversos processos de negócios;

- Sistemas e Regras: que a entidade precisa obedecer ou cumprir;

- Processos de Negócios: que desenvolvem e executam os produtos e serviços (finais ou intermediários) aos clientes, internos ou externos à organização, aplicando ou cumprindo sistemas e regras;

- Tecnologias: que são as técnicas e ferramentas que viabilizam e/ou agilizam os processos, no cumprimento dos sistemas e na aplicação das regras para a produção dos produtos e/ou serviços finais ou intermediários.

Para GONÇALVES (2000), não existe um produto ou serviço oferecido por uma empresa sem um processo empresarial. Da mesma forma, não faz sentido existir um processo empresarial que não ofereça um produto ou serviço. Olhando de outra maneira, os processos empresariais são atividades coordenadas que envolvem pessoas, procedimentos e tecnologia. Por outro lado, algumas vezes, as atividades essenciais (aquelas que são críticas para que sejam atingidos os objetivos da empresa) podem ser chamadas de processos. Elas envolvem um conjunto de atividades operacionais, diversos níveis organizacionais e práticas gerenciais.

HARRINGTON (1993) cita que é interessante separar os processos de produção dos bens e serviços oferecidos dos demais processos que ocorrem na empresa: os processos relacionados com a gestão da empresa e os de apoio aos processos produtivos. Os processos utilizam os recursos da organização para oferecer resultados objetivos a seus clientes.

Uma compilação sobre os tipos de processos, realizada por GONÇALVES (2000) mostra três categorias básicas de processos empresariais:

- Processos de negócio (ou de cliente): são os que caracterizam a atuação da empresa e são suportados por outros processos internos, resultando no produto ou serviço que é recebido por um cliente externo. Os processos de negócios são 
ligados à essência do funcionamento da organização. Eles são típicos da empresa em que operam e são muito diferentes de uma organização para outra. Eles têm o suporte dos sistemas desenvolvidos ao longo de décadas de desafios e aperfeiçoamento;

- Processos organizacionais ou de integração organizacional: são centralizados na organização e viabilizam o funcionamento coordenado dos vários subsistemas da organização em busca de seu desempenho geral, garantindo o suporte adequado aos processos de negócio. Os processos organizacionais, geralmente, produzem resultados imperceptíveis para os clientes externos, mas são essenciais para a gestão efetiva do negócio; e

- Processos gerenciais: são focalizados nos gerentes e em suas relações e incluem as ações de medição e ajuste do desempenho da organização. Os processos gerenciais incluem as ações que os gerentes devem realizar para dar suporte aos demais processos de negócio. A avaliação da qualidade do atendimento aos pedidos dos clientes é um processo gerencial típico em diversas organizações.

GONÇALVES (2000) cita com relação à capacidade de geração de valor para o cliente, que os processos podem ser primários, quando incluem as atividades que geram valor ao cliente, ou de suporte, que são os conjuntos de atividades que garantem o apoio necessário ao funcionamento adequado dos processos primários. É importante notar que os processos primários são os de negócio e que os processos organizacionais e os gerenciais, de acordo com essa definição, são processos de suporte.

De maneira geral, os processos nas empresas podem ser internos (quando tem início, são executados e terminam dentro da mesma empresa) ou externos. Os processos podem, também, ser inter ou intra-organizacionais (quando envolvem diversas empresas diferentes para sua realização). Os processos empresariais podem também ser horizontais e verticais, dependendo de sua orientação básica com relação à estrutura organizacional da empresa.

Para o autor citado, a primeira característica importante dos processos é a interfuncionalidade. Embora alguns processos sejam inteiramente realizados dentro de uma unidade funcional, a maioria dos processos importantes das empresas (especialmente os processos de negócio) atravessa as fronteiras das áreas funcionais. 
Por isso, são conhecidos como processos transversais, transorganizacionais (crossorganizational), interfuncionais ou interdepartamentais. Também são conhecidos como processos horizontais já que se desenvolvem ortogonalmente à estrutura vertical típica das organizações estruturadas funcionalmente. Enquanto os times verticais correspondem aos componentes funcionais, geográficos e de produto da empresa, como é o caso da equipe de vendas, os times horizontais correspondem às pessoas que trabalham nos processos transorganizacionais, como por exemplo, o processo de atendimento de pedidos de clientes.

A segunda característica importante dos processos de negócio é o fato de que eles têm clientes. O conceito de processo empresarial associa-se à idéia de cadeia de valor, com a definição de fluxos de valor: uma coleção de atividades que envolve a empresa de ponta a ponta, com o propósito de entregar um resultado a um cliente ou usuário final. Esse cliente, ao qual o resultado deve ser entregue, pode ser interno ou externo à organização. Nesse sentido, a empresa é uma coleção de fluxos de valor voltada à satisfação das expectativas de um determinado grupo de clientes.

A centralização das empresas em seus processos levará a desenhos organizacionais muito diferentes dos que se conhece atualmente. O primeiro estágio, não é apenas previsível, mas já está sendo adotado em muitas empresas, é o de redistribuir os recursos humanos e técnicos das empresas ao longo dos processos de negócios (GONÇALVES, 1997).

As parcerias e as redes de empresas estão surgindo como um segundo estágio desse movimento de reforma conceitual. Dessa forma, nem todos os recursos essenciais para a operação da empresa encontram-se dentro da empresa ou pertencem a ela.

Para o autor citado, o emprego de conceito de processos na estruturação das empresas também leva ao desenvolvimento da função do "dono do processo", cujas atribuições essenciais são: garantir o andamento adequado ao fluxo do processo, a facilitação do relacionamento dos recursos aplicados ao processo, a avaliação do funcionamento da empresa da perspectiva do processo e o aperfeiçoamento do funcionamento do processo.

Uma vez que os processos empresariais e as atividades funcionais são ortogonais; em muitas situações, as pessoas são membros de equipes funcionais e de equipes de processos ao mesmo tempo. Essa forma atenuada de estrutura matricial apresenta 
várias das dificuldades características deste tipo de estrutura, especialmente, a duplicidade de comando e o conflito do emprego dos recursos da organização.

Outra conseqüência da adoção da estrutura organizacional por processos é que não há sentido em se falar em centralização ou descentralização administrativa, já que as decisões são tomadas por grupos de trabalho no local organizacional em que são necessárias. Como unidade central no desenho de organizações modernas, os processos enfrentam a crescente concorrência do conceito de network.

Segundo o autor entre todas as tecnologias empregadas nas empresas, a Tecnologia de Informação (TI) tem importância especial para a abordagem de processos. Além de sua utilização na automatização de tarefas e na própria execução dos processos, pode ser empregada em diversas atividades de apoio e gestão desses processos: na visualização do processo, na automatização do que é interessante automatizar na execução e na gestão do processo, na sincronização das atividades, na coordenação dos esforços, na comunicação dos dados e na monitoração automática do desempenho, etc. As empresas têm investido na aplicação de TI em seus processos mais importantes, de negócio ou não, exatamente para poderem aperfeiçoar os seus desempenhos.

HAMMER (2002) relaciona ações a serem executadas para criar uma empresa voltada a processos:

- Tornar-se obcecado pelos processos completos que criam valor para os clientes;

- Garantir que todos compreendam os processos e o respectivo papel na sua execução;

- Nomear proprietários de processos entre os gerentes seniores, para mensurar, gerenciar e melhorar os processos;

- Desenvolver uma empresa orientada para processo, alinhando instalações, remuneração e estruturas em torno de processos;

- Promover uma cultura de trabalho em equipe e de responsabilidade compartilhada;

- Constituir um conselho de processos, para evitar que os silos funcionais sejam substituídos por fossas processuais;

- Gerenciar todas as atividades como processos, para melhorar a empresa; e

- Converter os processos em estilo de vida. 


\subsubsection{Engenharia de Processos}

SANTOS (2002) define que a Engenharia de Processos de Negócios (EPN) está amparada por quadros-conceituais ligados à Engenharia de Produção (EP). Tem como finalidade explicitar, analisar e aprimorar processos e, assim, promover o desenvolvimento da gestão e operacionalização das organizações.

Segundo o autor, a EPN possibilita o entendimento de como o trabalho é realizado, particularmente, no que se refere aos fluxos horizontais ou transversais de atividades e informações em um dado ambiente empresarial.

A EPN complementa ou substitui a visão funcional habitualmente compartilhada nas organizações. Esta compreensão vai além do entendimento do fluxo de etapas de um processo, pois busca representar como as unidades organizacionais se integram, por meio de suas interfaces, com o objetivo de gerar resultados compartilhados por toda a organização. Estes resultados são norteados pela intenção de agregar valor a seus clientes. Desdobrados desta orientação, seus objetivos são o planejamento, projeto, estruturação e avaliação de processos. Esses objetivos devem ser aplicados para suportar a implementação de estratégias organizacionais e para assegurar a coordenação entre as atividades da organização. O principal alvo da EPN é a coordenação das fronteiras organizacionais.

$\mathrm{Na}$ área de TI, PAULA FILHO (2003) apresenta um fluxo denominado Engenharia de Processos, com os seguintes objetivos:

- Estabelecer responsabilidades pela melhoria de processos de software da organização;

- Aferir, desenvolver, manter e melhorar os processos de software da organização;

- Desenvolver e manter um patrimônio de processos da organização que colete a experiência dos projetos realizados, de forma a contribuir para a melhoria constante dos processos;

- Facilitar o uso do patrimônio dos processos da organização e comunicar seus resultados importantes aos membros das equipes de projetos; e

- Desenvolver novos processos de software, sempre que necessários.

Conforme o autor citado, o patrimônio de processos da organização tipicamente consta dos seguintes itens:

- A descrição do processo-padrão da organização; 
- As descrições dos processos personalizados da organização;

- Padrões de produto e processo;

- Exemplos, gabaritos e listas de conferência de artefatos;

- Sítios de suporte e outros recursos de comunicação interna; e

- Base de dados históricos.

\subsubsection{Modelagem de Processos}

A Modelagem de Processos de Negócios é uma atividade corporativa que produz modelos de recursos, de fluxos de informação e das operações dos negócios que ocorrem na empresa. Um dos principais objetivos buscados na construção da especificação de uma organização é o de melhor entendê-la, procurando identificar problemas e procurar soluções que melhorem o desempenho organizacional, tal como aumentar a velocidade das tarefas, reduzir custos e melhorar a qualidade dos serviços. Os métodos de modelagem a serem utilizados para representar os processos organizacionais precisam relacionar a estrutura das informações e dos processos com os negócios e objetivos organizacionais (HUHNS et al., 1992).

VERNADAT (1996) apresenta os seguintes princípios de modelagem de processos: separação de focos para reduzir a complexidade; decomposição funcional; modularidade; generalidades do modelo; reuso; separação do comportamento e funcionalidade; descasamento entre processos e recursos; conformidade; visualização do modelo; simplicidade versus adequação; gestão da complexidade; rigor na representação; separação de dados e controle.

Para ERIKSSON e PENKER (2000), a modelagem dos processos identifica:

- Quais atividades são necessárias para caracterizar um processo;

- Quando atividades são executadas, e qual a ordem de execução;

- Por que as atividades são executadas, qual o objetivo do processo;

- Como as atividades são executadas;

- Quais os recursos consumidos e produzidos;

- Como as atividades devem ser executadas;

- Quem controla os processos;

- Como o processo está relacionado com a organização;

- Como os processos se relacionam com outros processos; e 
- Que sistemas de informação suportam os processos.

A modelagem de processos tem como objetivos principais (CURTIS et al., 1992):

- Facilitar a comunicação e compreensão entre as pessoas: a mesma representação do modelo pode ser compartilhada por todo o grupo de desenvolvimento;

- Facilitar o aperfeiçoamento do processo: por meio de um modelo, é possível analisar o processo e descobrir pontos onde ele pode ser melhorado;

- Reuso: os processos não necessitam ser modelados todas as vezes que forem realizados. Suas descrições precisam ser armazenadas e reusadas quando necessário;

- Suportar gerência do processo: tendo um processo definido, é possível realizar estimativas e planejamento;

- Prover orientação automatizada do processo: um processo definido permite que ferramentas automatizem algumas partes do modelo e orientem os usuários no andamento do processo; e

- Suportar execução automatizada: um ambiente automatizado pode controlar o comportamento do processo definido, coletar métrica e reforçar as regras para garantir a integridade do processo.

\section{Modelos de Representação de Processos}

A modelagem de processos funciona como planos, em que as atividades estão descritas em conjunto e vinculadas a um diagrama que define papéis e objetivos. Nos modelos visuais tem-se um acréscimo de conhecimento sobre o negócio em sua totalidade, o que possibilita o aperfeiçoamento e melhoria contínua no fluxo de atividades.

HARRIGNTON (1993) define fluxograma, diagramação lógica ou fluxo como modelos para descrever graficamente um processo existente ou um novo processo proposto, usando símbolos simples, linhas e palavras, de forma a apresentar graficamente as atividades e a seqüência no processo. Segundo o autor, bons fluxogramas destacam as áreas em que procedimentos confusos afetam a qualidade e a produtividade, além de facilitar as comunicações entre as áreas problemáticas, em função da capacidade de esclarecer processos complexos. 
Durante o mapeamento do processo, há um aumento da compressão do problema, e as respostas às perguntas tornam-se mais aparentes, o que possibilita a correta modelagem desses processos.

ERIKSSON e PENKER (2000) criaram um conjunto de estereótipos para a modelagem dos processos de negócios usando extensões da UML (Unifield Modeling Language). Desta forma a modelagem do processo de negócio suporta o projeto de software na medida em que facilita a abstração dos procedimentos que regem o negócio. Como o Modelo de Processo de Negócio contempla um âmbito maior que o sistema proposto no projeto, permite ao analista identificar claramente o que está no âmbito desse sistema bem como o que será implementado.

\section{Ferramentas de Modelagem de Processos}

Para executar a modelagem do processo existem no mercado diversas ferramentas informatizadas, como por exemplo, o ARIS Toolset da IDS (SCHEER, 1998), o VISIO (VISIO, 2000) da Microsoft, o EA - Enterprise Architecture da Sparks Systems (SPARKS, 2000). Estas ferramentas trabalham com diversos modelos capazes de representar visões da estrutura organizacional, dos processos, das funções, dos dados e de outros elementos referentes aos processos de negócios da organização.

\subsubsection{BPMN - Notação de Modelagem de Processos de Negócios}

Business Process Modeling Notation (BPMN, 2006), é um padrão para modelagem de processos, criado pelo Business Process Management Initiative (BPMI, 2006), que foi incorporado pelo Object Management Group (OMG), após a fusão entre estas entidades, ocorrida em 2005.

A intenção do BPMN é estabelecer-se como padrão para o BPM (Business Process Management) pelas seguintes razões: 1) ter como objetivo oferecer uma notação de fácil entendimento para todos os envolvidos com processos. Assim, tanto usuários de negócios como profissionais de TI conseguem facilmente ler um modelo de processos em BPMN. Desta forma, o BPMN torna-se, na prática, uma ferramenta que cria uma língua comum entre as áreas de negócios e TI, reduzindo a distância existente entre elas; 2) o BPMN foi dotado de uma série de recursos que tornam possível a modelagem de processos extremamente complexos. O uso de tais recursos é opcional e, assim, o modelo pode ser construído apenas com os elementos mais 
simples, para facilitar a leitura. Ao utilizar estes recursos, pode-se chegar a um nível bastante refinado do comportamento do processo, agregando várias informações técnicas, e permitindo o mapeamento automático para padrões de execução de processos, como o BPEL (Business Process Execution Language). Assim, conseguese uma transição natural da modelagem para a execução dos processos; 3) O BPMN define um único tipo de diagrama, chamado de Business Process Diagram (BPD). Neste diagrama, como ilustrado no exemplo da Figura 11, são dispostos os diversos elementos que formam o BPMN.

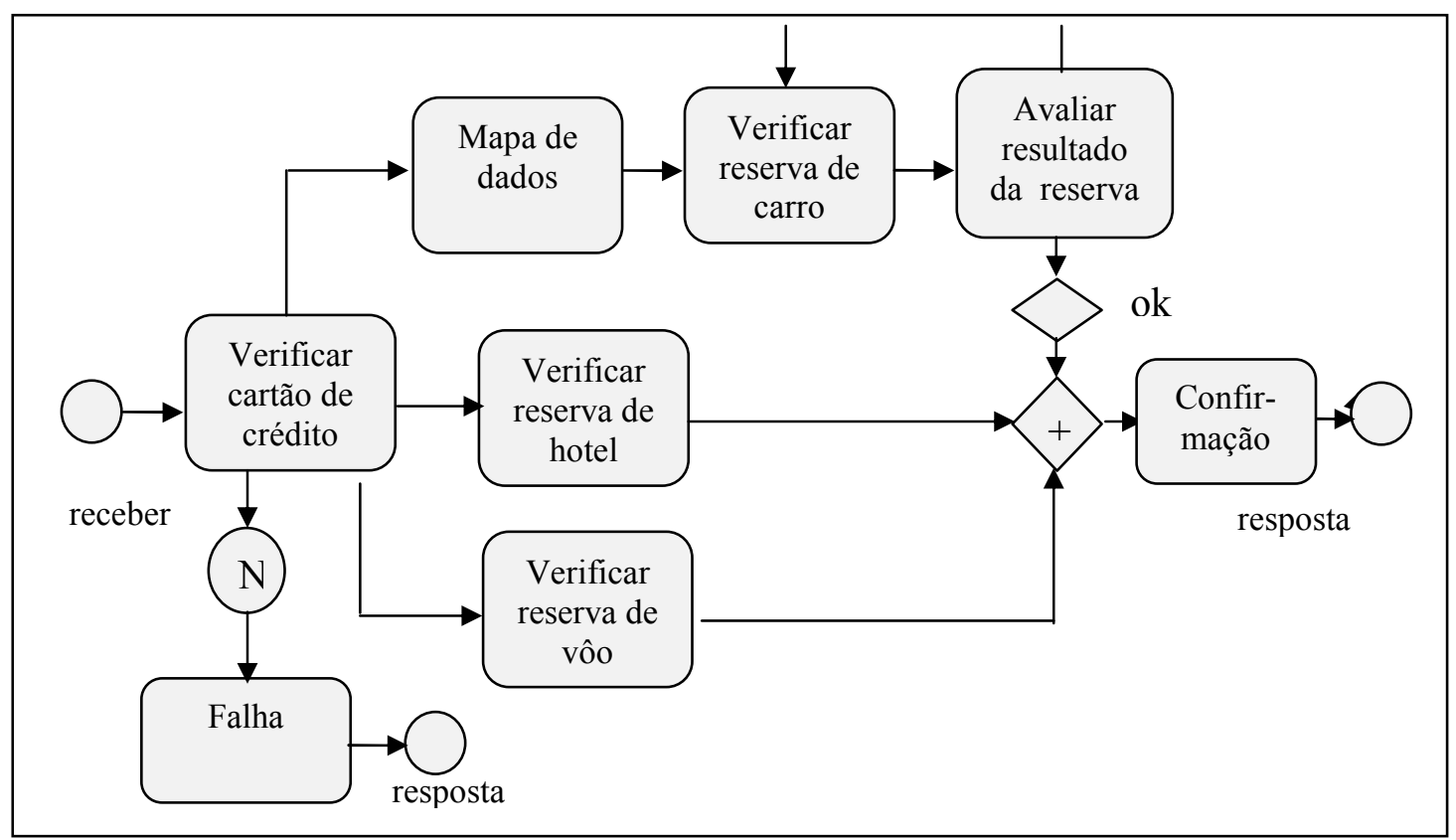

Figura 11 - Exemplo de Diagrama BPMN- Business Process Modeling Notation

O BPMN possui diversos elementos; os básicos são apenas quatro: atividades, eventos, gateways (decisões) e sequence flows (rotas). Com apenas estes quatro elementos, é possível construir modelos bastante expressivos de processos, fazendo com que o BPMN seja efetivamente fácil de aprender e simples de utilizar.

À medida que se coleta mais dados sobre o processo a ser modelado, é possível utilizar as diversas variações desses elementos, cada uma com uma semântica precisa (por exemplo, eventos baseados em tempo). Pode-se também adicionar novos elementos que enriqueçam a semântica do processo.

Um modelo BPMN permite representar os seguintes conceitos:

- Processos, subprocessos e atividades;

- Loops, instanciação múltipla de atividades e transações de compensação; 
- Eventos de início, de fim e intermediários no processo (ex.: um processo pode ser iniciado a partir do evento "e-mail vindo do cliente");

- Decisões, paralelismo e sincronização de processos;

- Organizações, departamentos e papéis que participam do processo;

- Trocas de mensagens entre organizações participantes do processo; e

- Objetos de dados que tramitam ao longo do processo.

\subsubsection{Considerações}

O principal objetivo deste trabalho refere-se à modelagem, definição, reestruturação e estabelecimento de processos aderentes às características de uma Fábrica de Software em uma organização produtora de software do setor público. Para isso, foi definida uma Arquitetura de Definição de Processos para FS, baseando-se nos conceitos de Gestão por Processos, Engenharia de Processos, Técnicas e Ferramentas de Modelagem de Processos. As ferramentas usadas na Modelagem dos Processos foram o Visio e o EA (Enterprise Architecture) e, a técnica usada para a representação dos fluxos foi baseada no Modelo de Processos de Negócios de ERIKSSON e PENKER (2000).

Conforme cita HAMMER (1998), na literatura sobre concepções organizacionais ganha destaque a "Organização por Processos", que evidencia a definição de arquitetura de processos como hierarquicamente superior à arquitetura de sistemas e, por isso, precisa contar com novas competências a serem adquiridas e desenvolvidas pelas organizações. A figura do "process owner" (dono de processo) adquire poder e autoridade compatíveis com os da cúpula das hierarquias funcionais. Este movimento caminha para a chamada "Gestão por Processos".

\subsection{Estruturas Organizacionais}

A estrutura organizacional é definida pela alta direção, de acordo com a estratégia de negócios da organização. A estrutura de uma organização pode ser definida como resultado de um processo, pela qual a autoridade é distribuída. As atividades, desde os níveis mais baixo até a alta administração, são especificadas e um sistema de comunicação é delineado, permitindo que as pessoas realizem as atividades e exerçam a autoridade que lhes compete para atingir os objetivos organizacionais (VASCONCELLOS, 1989). 


\subsubsection{Estrutura Funcional e por Projeto}

No PMBOK (2004) é descrito que a estrutura da organização executora freqüentemente restringe a disponibilidade ou as condições sob as quais os recursos tornam-se disponíveis para o projeto. As estruturas das organizações podem apresentar um amplo espectro de estruturas, da funcional à projetizada, com uma variedade de combinação entre elas. A clássica organização com estrutura funcional é uma hierarquia em que cada funcionário tem um superior bem definido.

Os membros da equipe são agrupados por especialidades, tais como: produção, marketing, engenharia e contabilidade em um primeiro nível, com a engenharia ainda subdividida em organismos funcionais que suportam o negócio das grandes organizações como, por exemplo, mecânica e elétrica.

As organizações com estrutura funcional também têm projetos, mas o escopo percebido do projeto está limitado às fronteiras da função. Por exemplo, quando o desenvolvimento de um novo produto é empreendido em uma organização com estrutura funcional pura, a fase de design é normalmente chamada de "projeto de design" e só inclui o pessoal do departamento de engenharia. Se questões sobre manufatura vêm à tona, elas sobem na estrutura hierárquica até a chefia do departamento que consulta a chefia do departamento de manufatura. A chefia do departamento de engenharia, então, transmite as respostas, descendo na estrutura hierárquica até o gerente de projeto de engenharia.

Do outro lado do espectro, encontra-se a organização com estrutura projetizada. Nesta organização, os membros das equipes com freqüência trabalham juntos, em um mesmo local físico. Neste tipo de estrutura, a maioria dos recursos da organização está envolvida em projetos e os gerentes de projeto têm grande autoridade e independência.

Normalmente, organizações com estrutura projetizada possuem unidades organizacionais denominadas departamentos. Entretanto, estes departamentos ou se reportam direto ao gerente de projeto, ou fornecem serviços de suporte aos diversos projetos existentes.

\subsubsection{Estrutura Matricial}

O PMBOK (2004) refere que uma organização com estrutura matricial é uma mistura com característica funcional e projetizada. As estruturas matriciais fracas mantêm 
muitas características da organização com estrutura funcional e o papel do gerente de projeto é mais o de um coordenador ou despachante do que de um gerente propriamente dito. De modo similar, as estruturas matriciais fortes têm muitas características da organização com estrutura projetizada - gerentes de projeto, com considerável autoridade, dedicados ao projeto e pessoal administrativo, alocado em tempo integral ao projeto.

Quando duas ou mais formas de estrutura são utilizadas simultaneamente sobre os membros de uma organização, a estrutura resultante chama-se matricial (Figura 12).

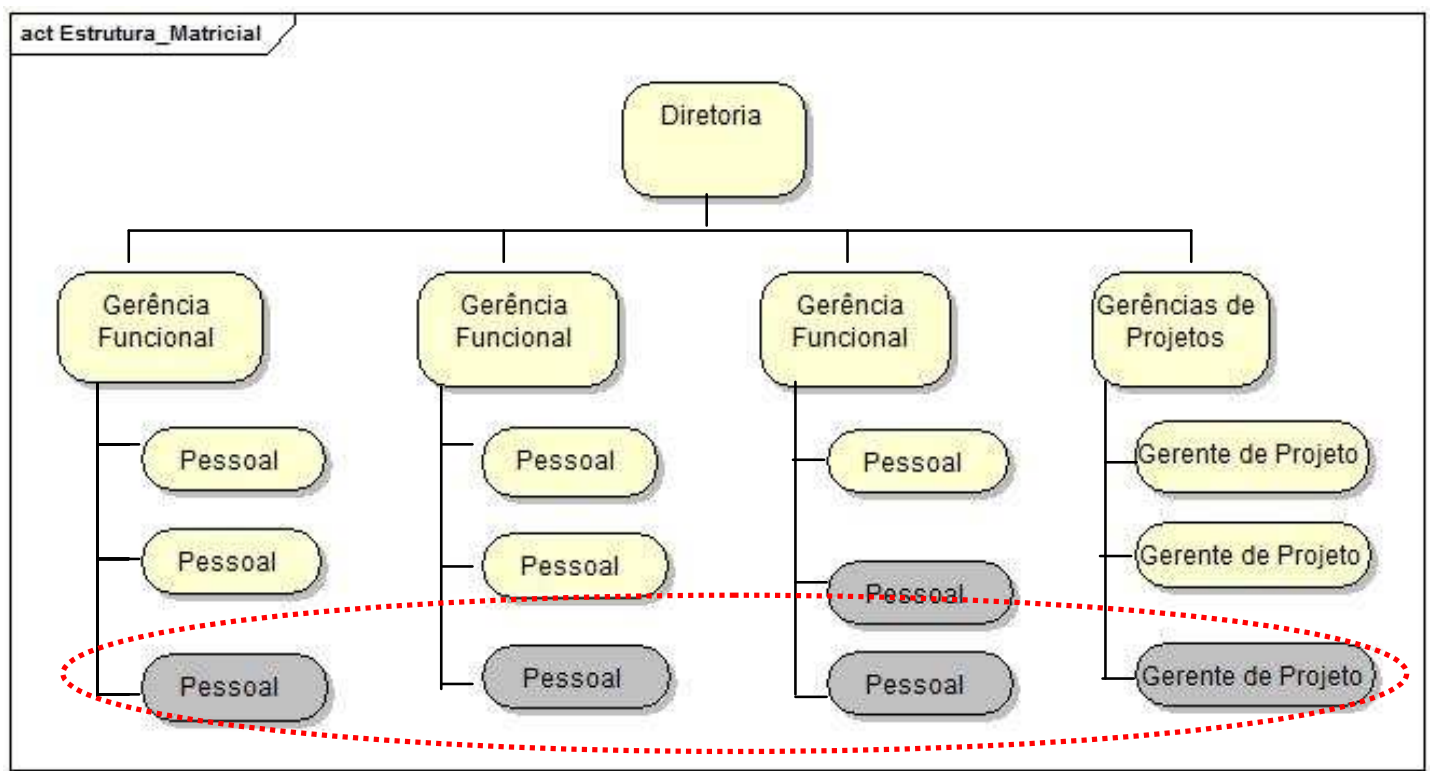

Figura 12 - Estrutura Matricial Fonte: PMBOK (2004)

Um aspecto particular da estrutura matricial é a dupla ou múltipla subordinação. Um determinado especialista responde simultaneamente a um gerente funcional e a um gerente de projetos, por exemplo (VASCONCELLOS, 1989).

Neste modelo, o especialista tem compromissos funcionais em seu departamento, e ao mesmo tempo, está envolvido em um ou mais projetos. Cada área oferece, por meio de seus especialistas, determinada contribuição para a realização dos projetos. Enquanto a organização funcional favorece a especialização e o acúmulo de conhecimentos, a organização por projetos favorece a orientação para algum tipo de resultado ou problema a ser resolvido. A solução de problemas práticos depende cada vez mais da colaboração de um maior número de especializações. A execução de 
projetos multidisciplinares só pode ser bem-sucedida com a necessária adaptação da estrutura administrativa para este tipo de atividade (VASCONCELLOS, 1989).

O principal ponto forte da departamentalização funcional é agrupar especialistas, o que minimiza o número necessário deles, ao mesmo tempo, em que permite o compartilhamento dos recursos especializados entre os diversos produtos. Seu principal ponto fraco é a dificuldade de coordenação das tarefas dos diversos especialistas funcionais, de modo que as atividades sejam concluídas dentro de orçamentos e prazos.

A estrutura matricial tenta aproveitar os pontos fortes da estrutura funcional e projetizada e evitar suas desvantagens. O ponto forte da estrutura matricial está em sua capacidade de facilitar a coordenação quando a organização realiza uma multiplicidade de tarefas complexas e independentes.

Conforme VASCONCELLOS (1989), as características estruturais destas organizações são:

- Baixo nível de formalização;

- Utilização de formas avançadas de departamentalização;

- Multiplicidade de comando;

- Diversificação elevada; e

- Comunicação horizontal e diagonal.

MINTZBERG (2003) distingue dois tipos de estruturas matriciais: uma forma permanente, em que as interdependências permanecem mais ou menos estáveis e, como resultado, o mesmo sucede com as unidades e seus funcionários; e uma forma mutante, ajustada ao trabalho com projetos, em que as interdependências, as unidades de mercado e seus funcionários estão em freqüente mudança.

A estrutura matricial mutante é utilizada nos trabalhos com projetos, em que os outputs mudam com freqüência. Nestes casos, a organização opera como um conjunto de equipes de projeto (na verdade, unidades temporárias baseadas no mercado), cujos membros procedem dos departamentos funcionais e atendem a vários propósitos internos. Essa estrutura é matricial porque os líderes de projetos assumem posição ao lado dos gerentes funcionais, cujo poder é compartilhado igualmente entre eles. 
Para CHIAVENATO (1999), o desenho matricial permite satisfazer duas necessidades da organização: especialização e coordenação. Por outro lado, o autor apresenta algumas limitações. Embora muito utilizada pelas grandes organizações, como meio de trazer a inovação e a flexibilidade, a estrutura em matriz viola a unidade de comando e introduz conflitos inevitáveis de duplicidade de supervisão, enfraquecendo a cadeia de comando e a coordenação lateral. O desenho matricial impõe uma nova cultura organizacional, uma nova mentalidade e um novo tipo de comportamento à organização.

\subsubsection{Considerações}

Neste trabalho, a Empresa estudada pertence ao setor público e, desta forma, está sujeita a constantes mudanças na estrutura organizacional causando grandes impactos nos processos estratégicos e operacionais. A pesquisa-ação realizada neste estudo motivou-se por ocasião de uma mudança na estrutura organizacional de um modelo verticalizado para um modelo matricial.

Segundo VASCONCELLOS (1989) a estrutura matricial apresenta as vantagens da estrutura por projetos, na qual existe um responsável pelo conjunto das tarefas: o gerente de projeto, indivíduo que tem a visão de todo o projeto, integrando as várias áreas funcionais. Ao mesmo tempo, a estrutura matricial apresenta as vantagens da estrutura funcional, onde o aperfeiçoamento dos indivíduos é favorecido pela existência, em cada área, de um elemento com elevada qualificação técnica: o gerente funcional. Este indivíduo tem também a função de melhor alocar os recursos humanos e materiais sob sua responsabilidade.

A estrutura matricial apresenta inegáveis pontos fortes quando temos que assegurar o sucesso de projetos que envolvem várias áreas técnicas, em termo do cumprimento de orçamentos e prazos e, ao mesmo tempo, evitar capacidade ociosa na utilização de recursos humanos e materiais.

\subsection{Cultura Organizacional}

A Cultura Organizacional é definida como: "um conjunto de valores e pressupostos básicos expressos em elementos simbólicos que, em sua capacidade de ordenar, atribuir significações, construir a identidade organizacional, tanto agem como elemento de comunicação e consenso como ocultam e instrumentalizam as relações de dominação" (FLEURY e FISHER, 1996). Assim é ressaltado o fato de, quanto 
mais forte for uma cultura mais difícil ser sua mudança em função de determinados valores encontrarem-se arraigados nas pessoas.

PIRES e MACEDO (2006) descrevem a cultura como um dos pontos-chave na compreensão das ações humanas, funcionando como um padrão coletivo que identifica os grupos, suas maneiras de perceber, pensar, sentir e agir. Assim, mais do que um conjunto de regras, de hábitos e artefatos; cultura significa construção de significados partilhados pelo conjunto de pessoas pertencentes a um mesmo grupo social.

Os autores descrevem que a cultura, com a construção do significado social e normativo, possibilita que um grupo se fortaleça ou se desintegre. A cultura expressa os valores e as crenças que os membros desse grupo partilham. Tais valores manifestam-se por meio de símbolos, como: mitos, rituais, histórias, lendas e uma linguagem especializada, orientando os indivíduos de uma referida cultura na forma de pensar, agir e tomar decisões.

\subsubsection{Características das Organizações Públicas}

PIRES e MACEDO (2006) afirmam que as organizações públicas são mais vulneráveis à interferência do poder político, pois são geridas pelo poder público. Elas, também, têm a missão de prestar serviços à sociedade. Esta prestação de serviços está, habitualmente, em contradição com a limitação dos recursos recebidos por elas. Quando há recursos disponíveis, eles tendem a depender da decisão política e das flutuações da capacidade econômica do Estado. Segundo os autores, as organizações públicas mantêm as mesmas características básicas das demais organizações, acrescidas, entretanto, de algumas especificidades como: apego às regras e rotinas, supervalorização da hierarquia, paternalismo nas relações, apego ao poder, entre outras.

Estas diferenças são importantes na definição dos processos internos, na relação com inovações e mudança, na formação dos valores e crenças organizacionais e políticas de recursos humanos. Os autores constatam que as organizações públicas são sistemas complexos em razão do alto índice de burocracia estatal, já que seus dirigentes são responsáveis perante uma autoridade externa pela organização pública, gerando, assim, uma tendência para centralizar as decisões. 
De acordo com CARBONE (2000) no Brasil, os trabalhadores de organizações públicas necessitam possuir habilidades diplomáticas em suas relações de trabalho, para não provocarem divergências com a administração dos gestores. Nas organizações públicas brasileiras, as relações de estima e os jogos de influência são os verdadeiros indicadores de poder.

PIRES e MACEDO (2006) observam que, de um lado, tem-se a burocracia em seu sentido corporativo, centralizadora e, portanto, contrária às mudanças na organização e nas formas de operar do aparelho do Estado; e de outro, as forças inovadoras que, não raramente encontram muita dificuldade para implementar de maneira efetiva projetos de reforma. Essas forças inovadoras buscam introduzir nas organizações públicas, uma cultura de flexibilidade e de gestão empreendedora que permita às organizações públicas atuarem de forma eficiente em um mundo de rápidas transformações.

Segundo CARBONE (2000), as características das organizações públicas que dificultam sua mudança são as seguintes:

- Burocratização: excessivo controle de procedimentos, gerando uma administração engessada, complicada e desfocada das necessidades do país e do contribuinte;

- Autoritarismo/centralização: excessiva verticalização da estrutura hierárquica e centralização do processo decisório;

- Aversão aos empreendedores: ausência de comportamento empreendedor para modificar e se opor ao modelo de produção vigente;

- Paternalismo: alto controle da movimentação de pessoal e da distribuição de empregos, cargos e comissões, dentro da lógica dos interesses políticos dominantes;

- Levar vantagem: constante promoção da punição àqueles indivíduos injustos, obtendo vantagens dos negócios do Estado; e

- Reformismo: desconsideração dos avanços conquistados, descontinuidade administrativa, perda de tecnologia e desconfiança generalizada. Corporativismo como obstáculo à mudança e mecanismo de proteção à tecnocracia.

Um ponto fundamental a ser considerado no planejamento e na gestão pública, é a presença de dois corpos funcionais com características distintas: um permanente e 
outro não permanente. O corpo permanente é formado pelos trabalhadores de carreira, cujos objetivos e cultura foram formados no seio da organização, e o não permanente é composto por administradores políticos que seguem objetivos externos e mais amplos aos da organização. Entre eles, o conflito é acentuado pela substituição dos trabalhadores não permanentes, que mudam a cada novo mandato (MARTELANE, 1991).

LIMA (2005) salienta a diferença das organizações públicas das empresas privadas. As empresas privadas estão sempre atentas a resultados e melhorias de seu desempenho, pois sabem que sua sobrevivência depende disso. Para o governo, isso nem sempre se aplica, pois ele não sairá do mercado. O fracasso do governo não é o rendimento, mas, a reeleição ou a possibilidade de reeleger seu sucessor.

As reeleições acabam por eleger os que agradam uma parte da sociedade ou um conjunto de grupos de interesse e não segundo as competências de suas gestões nos serviços públicos. Assim, a política resume-se à subjetividade ou à ideologia e não aos indicadores de efetivo desempenho na gestão pública.

Ressalta-se que os indicadores de desempenho no serviço público são praticamente inexistentes, comprovando que os resultados são por diversas vezes negligenciados. A respeito das organizações públicas da área de TI, em palestra proferida sobre a TI na reforma do Estado, SAUR (1996) cita que os sistemas governamentais de informação desenvolvidos pelas empresas públicas federais, estaduais e municipais de Informática, até então, não estavam totalmente engajadas com o verdadeiro compromisso com o cidadão comum. O "dono" do sistema acabava não sendo a sociedade, mas, o núcleo burocrático que encomendava a aplicação para seu uso, segundo suas necessidades operacionais. O autor referindo-se a TI na Reforma do Estado acrescenta que as empresas públicas necessitam ser capazes de efetivamente ajudar o Aparelho do Estado em atender às novas demandas do cliente-cidadão.

\subsubsection{Considerações}

É imprescindível a abordagem do assunto Cultura Organizacional, sobretudo em organizações do setor público. Observa-se que características do setor público como: rotatividade de lideranças, alto índice de mudanças, descontinuidade nos projetos, conflitos de interesses, corporativismo e verticalização do processo, exercem uma forte influência nos processos estratégicos atingindo diretamente nos processos 
operacionais da organização, e em conseqüência nos produtos gerados e entregues ao usuário final, ou seja, ao cliente-cidadão.

GUIMARÃES (2000) afirma que "no setor público, o desafio que se coloca para a nova administração pública é como transformar estruturas burocráticas, hierarquizadas e que tendem a um processo de insulamento, em organizações flexíveis e empreendedoras".

O autor cita que esta transformação só é possível quando ocorrer uma ruptura com os modelos tradicionais e a administração dos recursos públicos e introduzir-se uma nova cultura de gestão.

\subsection{Fundamentação Teórica - Considerações Finais}

A fundamentação teórica do trabalho compreendeu o estudo de disciplinas que permeiam o conceito e a complexidade dos ambientes de Fábrica de Software (FS), assim como o estudo sobre características de organizações públicas. A Figura 13 mostra uma síntese da organização da fundamentação teórica, objetivos, temas e principais autores relacionados.

\begin{tabular}{|c|c|}
\hline $\begin{array}{c}\text { Compreender } \\
\text { Conceitose } \\
\text { Frameworks de FS }\end{array}$ & $\begin{array}{l}\text { - Fábrica de Sw (Basili, Cusumano, Humphrey, Greenfield, Fernandes e Teixeira, Costa) } \\
\text { - Engenharia de Sw (Pressman, Paula Filho, Sommerville, Humphrey, Kruchten) } \\
\text { - Reuso de Sw (Prieto-Diaz, Fiorini, Werner, Gamma, Lin, Dusinsk, Cusumano, Barroca) } \\
\text { - Engenharia de Produção (Contador, Davis, Pires, Zarifian, Slack, Mintzberg) } \\
\text { - Estruturas Organizacionais (Vasconcellos, Chiavenato, Davenport, PMBOK) }\end{array}$ \\
\hline $\begin{array}{c}\text { Compreender o } \\
\text { funcionamento de } \\
\text { FS e MDS }\end{array}$ & $\begin{array}{l}\text { - Metodologias de Desenvolvimento de SW (Pressman, Sommerville, Booch, Shaw, } \\
\text { Kruchten, Beck, Fiorini) } \\
\text { - Gestão do Conhecimento (Nonaka e Takeuti, Davenport e Prusak) } \\
\text { - Gestão por Processos (Davenport, Hammer, Harrington, Cameira, Gonçalves, Alvarenga, } \\
\text { Eriksson e Penker) } \\
\text { - Gestão de Projetos (PMBOK) } \\
\text { - Gestão por Competências (Zarifian, Fleury e Fleury, Slack) } \\
\text { - Modelos de Mellhcres Práticas (ISO/IEC12207, ISO/IEC } 9126, \text { CMMI, RUP, PMBOK, ITIL) }\end{array}$ \\
\hline $\begin{array}{l}\text { Compreender } \\
\text { Organizações } \\
\text { Públicas de TI }\end{array}$ & $\begin{array}{l}\text { - Cultura Organizacional (Fleury e Fisher, Pires e Macedo) } \\
\text { - Organizações Públicas (Pires e Macedo, Lima, Schall, Bragança) }\end{array}$ \\
\hline $\begin{array}{c}\text { Definição da } \\
\text { Metodologia de } \\
\text { Pesquisa }\end{array}$ & $\begin{array}{l}\text { - Conceitos, Métodos, Metodologias (Yin, Nakano e Fleury, Thiollent) } \\
\text { - Pesquisa-Ação (Thiollent, Coughlan e Coghlan, Miguel) }\end{array}$ \\
\hline
\end{tabular}

Figura 13 - Síntese da Fundamentação Teórica

A definição da metodologia de pesquisa será descrita no próximo capítulo. 


\section{METODOLOGIA DE PESQUISA}

Este capítulo contém uma revisão de metodologias de pesquisa aplicadas na Engenharia de Produção e apresenta a abordagem metodológica da presente pesquisa, caracterizada como Pesquisa-Ação (PA). Mostra as decisões estratégicas necessárias tomadas para o desenvolvimento e delineamento do projeto de pesquisa para a resolução da questão principal deste trabalho: "Como mapear, definir, reestruturar e estabelecer processos de FS em uma organização de TI do setor público?”.

\subsection{Conceitos}

THIOLLENT (2004) distingue método e metodologia de pesquisa: o método fica em um primeiro nível em que é feita uma efetiva abordagem da situação investigada com métodos e técnicas particulares aplicados na captação da informação social, enquanto a metodologia é um meta-nível, sendo uma instância de reflexão do primeiro nível. Seu objetivo consiste em analisar as características dos vários métodos disponíveis, avaliar suas capacidades, potencialidades, limitações ou distorções e criticar os pressupostos ou implicações de sua utilização. A metodologia é considerada como modo de conduzir a pesquisa, no processo de investigação, tomar decisões oportunas, selecionar conceitos, hipóteses, técnicas e dados adequados.

Para BRYMAN (1989), a metodologia de pesquisa possui duas abordagens: a qualitativa e a quantitativa. A pesquisa qualitativa está na ênfase dada ao objeto em estudo, seja indivíduo, organização ou processo. Está voltada mais à compreensão dos fatos, e a pesquisa quantitativa é impulsionada por um conjunto de questões previamente definidas (extraídas da teoria e literatura), e está mais voltada à mensuração do fenômeno.

Conforme citam NAKANO e FLEURY (1996), as abordagens de pesquisa orientadas para a Engenharia de Produção são de cunho quantitativo quando se referem a temas técnicos das engenharias ou, de cunho qualitativo, quando o tema está associado às ciências sociais.

Estes autores realizaram um estudo a respeito dos principais métodos de pesquisa aplicados à Engenharia de Produção (EP). Atentam que apesar da aparente simplicidade da classificação, nem sempre parece possível uma distinção tão clara. 
Na prática da pesquisa, encontram-se diversas situações em que há superposição de conceitos. Os principais métodos de pesquisa na EP são caracterizados nos dados da Tabela 12, e os três métodos mais comuns de pesquisa qualitativa são: o estudo de caso, a pesquisa-ação e a pesquisa participante.

Tabela 12 - Principais Métodos de Pesquisa na EP

\begin{tabular}{|l|l|l|l|}
\hline \multicolumn{1}{|c|}{$\begin{array}{c}\text { Método de } \\
\text { Pesquisa }\end{array}$} & \multicolumn{1}{|c|}{ Descrição } & $\begin{array}{l}\text { Abordagem } \\
\text { principal }\end{array}$ & Instrumentos \\
\hline Experimental & $\begin{array}{l}\text { Teste das hipóteses de um experimento } \\
\text { controlado }\end{array}$ & Quantitativa & Experimentos \\
\hline Survey & $\begin{array}{l}\text { Coleta de dados por entrevista ou } \\
\text { questionário. A análise dos dados exige } \\
\text { tratamento estatístico }\end{array}$ & Quantitativa & Questionários \\
\hline $\begin{array}{l}\text { Pesquisa } \\
\text { participante }\end{array}$ & $\begin{array}{l}\text { Baseada em metodologia de observação } \\
\text { participante }\end{array}$ & Qualitativa & $\begin{array}{l}\text { Observação } \\
\text { direta }\end{array}$ \\
\hline Pesquisa-ação & $\begin{array}{l}\text { É realizada juntamente com uma ação ou } \\
\text { resolução de um problema, e onde os } \\
\text { pesquisadores desempenham um papel ativo } \\
\text { dessa resolução. }\end{array}$ & Qualitativa & $\begin{array}{l}\text { Observação e } \\
\text { participação } \\
\text { direta }\end{array}$ \\
\hline Estudo de caso & $\begin{array}{l}\text { Documenta e analisa a atividades de uma } \\
\text { organização ou de um pequeno grupo dentro } \\
\text { dela. A unidade de análise é a organização } \\
\text { como um todo, um departamento ou uma } \\
\text { área }\end{array}$ & Qualitativa & $\begin{array}{l}\text { Entrevistas e } \\
\text { outras fontes }\end{array}$ \\
\hline
\end{tabular}

Fonte: Baseado em NAKANO e FLEURY (1996)

YIN (2001) conceitua o estudo de caso como um método de pesquisa para responder questões do tipo "como" e "por que", ou seja, refere-se a ligações operacionais que necessitam serem traçadas ao longo do tempo.

O estudo de caso é uma investigação empírica que pesquisa um fenômeno contemporâneo dentro de um contexto da vida real, especialmente, quando os limites entre o fenômeno e o contexto não estão claramente definidos. Utiliza múltiplas fontes de informação: documentação, registros com arquivos, observação direta, observação participante e artefatos físicos. $\mathrm{O}$ autor cita que o método de estudo de caso pode ser de caso único e de casos múltiplos, em que é prevista uma lógica de replicação, com duas possibilidades: replicação literal de resultados similares e replicação teórica de resultados contraditórios.

Segundo o autor, para o estudo de caso o desenvolvimento da teoria como parte da fase de projeto é essencial, caso o propósito decorrente do estudo de caso seja determinar ou testar a teoria. O projeto completo incorpora uma 'teoria' do que está sendo estudada. As idéias expostas darão cada vez mais conta das questões, proposições, unidades de análise, ligações lógicas dos dados às proposições e 
critérios de interpretação das descobertas. Por essa razão, é essencial que se desenvolva uma teoria antes que se faça a coleta dos dados de qualquer estudo de caso.

Para YIN (2001), um projeto de pesquisa é a seqüência lógica que conecta os dados empíricos às questões de pesquisa iniciais do estudo e, em última análise, suas conclusões. $\mathrm{O}$ autor relaciona cinco componentes do projeto de pesquisa:

- A questão do estudo, ou seja, o núcleo da pesquisa. Envolve as perguntas que deverão ser respondidas depois de concluído o trabalho, em que surgirão as conclusões sobre a análise realizada;

- As proposições, que representam afirmações teóricas criadas inicialmente no trabalho de pesquisa, a fim de agir como um guia na análise do que está sendo estudado;

- As unidades de análise devem guardar direta correlação com as perguntas básicas da pesquisa, já que são elas que indicam o objetivo do trabalho;

- A lógica que une os dados às proposições. $\mathrm{O}$ autor sugere como a estruturação dos dados em um padrão de adequação que facilite a análise pontual e contribua com a visão global do fenômeno;

- Os critérios para se interpretar as descobertas. Segundo o autor não há maneira adequada para o estabelecimento dos critérios para a interpretação das descobertas, pois envolve a subjetividade para a análise de cada caso.

\subsection{Pesquisa-Ação}

THIOLLENT (2004) cita que a pesquisa participante e a pesquisa-ação são muito semelhantes. Toda pesquisa-ação é do tipo participativo: a participação das pessoas implicadas nos problemas investigados é absolutamente necessária. O ponto de distinção está no fato de que a pesquisa participativa não inclui necessariamente uma ação planejada.

De acordo com o autor a Pesquisa-Ação (PA) teve sua origem na década de 1940, apresentada como um método apropriado para conhecer e intervir nas organizações, complementando as outras técnicas de pesquisa organizacional existentes até então: diagnóstico, aplicação de questionários, entrevistas e estudos de caso.

$\mathrm{O}$ autor conceitua PA como um tipo de pesquisa social com base empírica que é concebida e realizada em estreita associação com uma ação ou com a resolução de 
um problema coletivo, nos quais os pesquisadores e participantes representativos da situação ou do problema estão envolvidos de modo cooperativo ou participativo. Além disso, é preciso que a ação seja uma ação não trivial, o que quer dizer uma ação problemática merecendo investigação para ser elaborada ou conduzida.

Segue uma compilação das principais características da PA, segundo THIOLLENT (2004):

- Há uma ampla e explícita interação entre pesquisador e pessoas implicadas na situação investigada;

- Desta interação, resulta a ordem de prioridade dos problemas a serem pesquisados e das soluções a serem encaminhadas sob forma de ação concreta;

- O objetivo de investigação não é constituído pelas pessoas e sim pela situação social e pelos problemas de diferentes naturezas encontrados nesta situação;

- O objetivo da PA consiste em resolver ou, pelo menos, esclarecer os problemas da situação observada;

- Durante o processo, há um acompanhamento das decisões, das ações e de toda atividade intencional dos atores da situação;

- A pesquisa não se limita a uma forma de ação, pretende-se aumentar o conhecimento ou o 'nível de consciência' das pessoas e grupos considerados;

- O planejamento de uma PA é muito flexível e, contrária a outros tipos de pesquisa não é composta de uma série de fases rigidamente ordenadas e limitadas aos aspectos acadêmicos e burocráticos da maioria das pesquisas convencionais. $\mathrm{Na} \mathrm{PA}$, o planejamento das ações é realizado pelos atores sociais, podendo ser o pesquisador um animador ou um participante ativo;

- Embora a PA privilegie o lado empírico, a abordagem nunca deixa de colocar as questões relativas aos quadros de referência teórica, sem os quais a pesquisa empírica não faria sentido. A linha seguida pela PA é atentar às exigências teóricas e práticas para equacionar problemas relevantes dentro da situação social;

- Na PA, é possível estudar dinamicamente os problemas, decisões, ações, negociações, conflitos e tomadas de consciência que ocorrem entre os agentes durante o processo de transformação da situação. Da observação e avaliação 
dessas ações, e pela evidência dos obstáculos encontrados no caminho, há um ganho de informação a ser captado e restituído como ganho de conhecimento;

- Do ponto de vista científico, a PA é uma proposta metodológica e técnica que oferece subsídios para organizar a pesquisa social aplicada sem os excessos da postura convencional em nível da observação, processamento de dados, experimentação, etc. Com ela, introduz-se maior flexibilidade na concepção e aplicação dos meios de investigação concreta.

\subsubsection{Ciclos da Pesquisa-Ação}

COUGHLAN e COGHLAN (2002) para a implementação de uma PA, propõem um modelo de condução da PA que compreende três fases principais: uma preliminar, um ciclo de condução e uma meta-fase, como é mostrado na Figura 14.

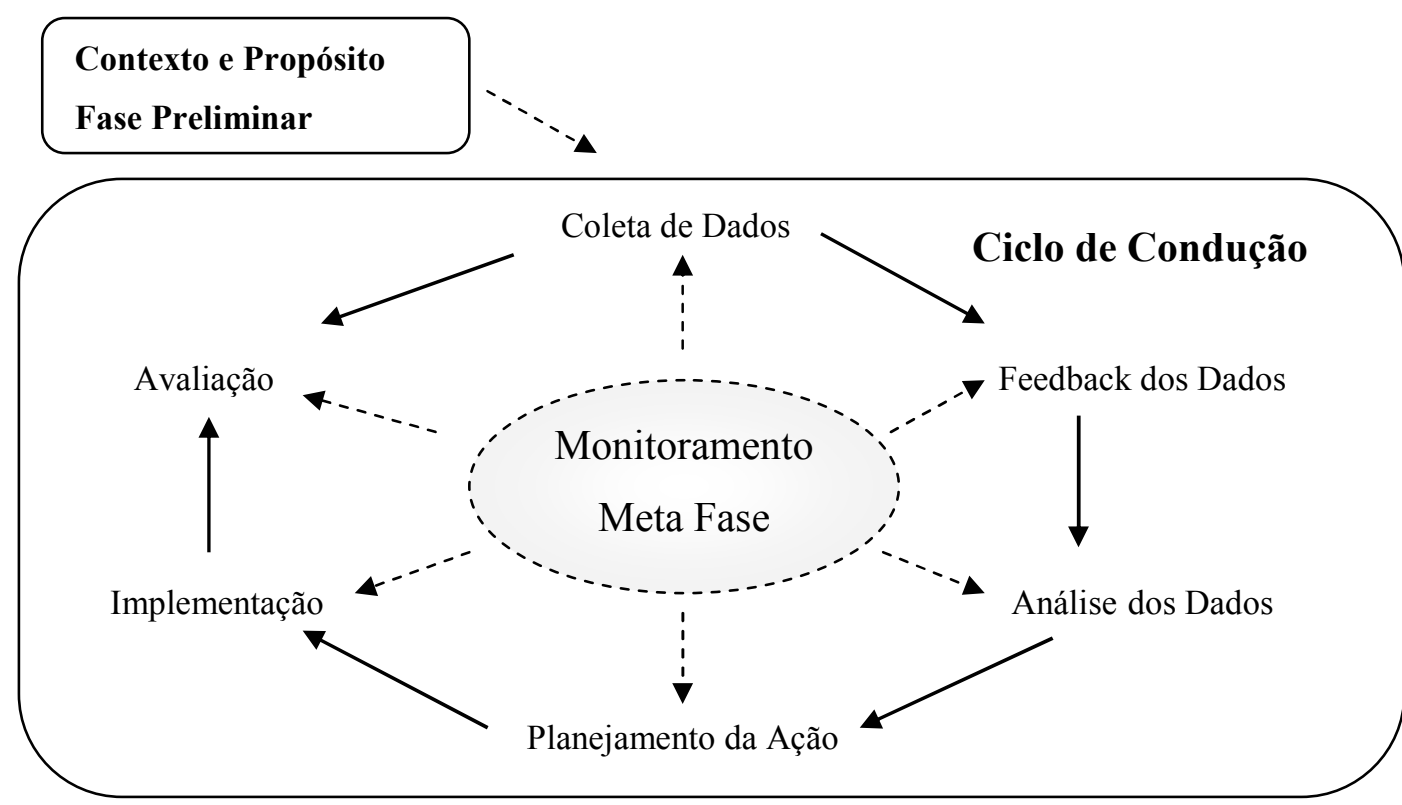

Figura 14 - Ciclos da Pesquisa-Ação Fonte: COUGHLAN e COGHLAN (2002)

- A fase preliminar visa ao entendimento sobre o contexto onde a pesquisa será realizada, assim como o propósito da condução do trabalho. Esta fase envolve ainda o estabelecimento das justificativas para a ação requerida e para a pesquisa.

- O ciclo de condução compreende seis passos: inicia com a coleta dos dados, feedback dos dados, análise dos dados, planejamento da ação, implementação da ação e avaliação dos dados, retornando para a nova coleta dos dados (caso necessário), fechando então o ciclo. 
- A meta-fase ou monitoramento compreende uma verificação de cada um dos seis passos anteriores, no sentido de identificar qual é o aprendizado gerado na condução da PA, ou seja, mostra os resultados. Esse monitoramento deve estar presente de diferentes maneiras, conforme cada passo do ciclo de condução. Do lado organizacional, pode haver o estabelecimento de um grupo diretivo durante a condução da PA, nesse caso, com maior interesse nos resultados práticos da PA. Por outro lado, o pesquisador deve estar interessado não só na operação do projeto, mas também no monitoramento dos processos de aprendizagem que levará, em última instância, a contribuição teórica desse tipo de desenvolvimento empírico.

MIGUEL (2005) realizou uma síntese dos seis passos do ciclo de condução da PA com base em COUGHLAN e COGHLAN (2002), conforme são mostrados nos dados da Tabela 13.

Tabela 13 - Seis Passos do Ciclo de Condução a partir de COUGHLAN E COGHLAN

\begin{tabular}{|c|c|c|}
\hline Fase & Descrição & Meios \\
\hline Coleta de Dados & $\begin{array}{l}\text { Dados são gerados por meio do } \\
\text { envolvimento com o processo } \\
\text { organizacional }\end{array}$ & $\begin{array}{l}\text { Dados qualitativos: observação } \\
\text { direta, discussões, entrevistas } \\
\text { Dados quantitativos: relatórios, } \\
\text { registros operacionais }\end{array}$ \\
\hline Feedback dos Dados & $\begin{array}{l}\text { Os dados são retornados para a } \\
\text { organização visando } \\
\text { disponibilizá-los para análise }\end{array}$ & $\begin{array}{l}\text { Relatórios elaborados pelo } \\
\text { pesquisador, reuniões de feedback }\end{array}$ \\
\hline Análise dos Dados & $\begin{array}{l}\text { Análise conjunta realizada pelo } \\
\text { pesquisador e membros } \\
\text { envolvidos (por exemplo, } \\
\text { membros dos times de trabalho) }\end{array}$ & $\begin{array}{l}\text { Ferramentas e critérios de análise } \\
\text { que necessitam estar relacionados } \\
\text { aos propósitos da pesquisa e da } \\
\text { intervenção }\end{array}$ \\
\hline Planejamento da Ação & $\begin{array}{l}\text { Atividade conjunta que estabelece } \\
\text { o que vai ser feito e com que } \\
\text { prazo }\end{array}$ & $\begin{array}{l}\text { Responder questões do tipo: o que } \\
\text { necessita ser alterado e em que } \\
\text { parte da organização? Qual o } \\
\text { apoio necessário? Como o } \\
\text { comprometimento pode ser } \\
\text { obtido? Como superar as } \\
\text { resistências? }\end{array}$ \\
\hline Implementação da Ação & $\begin{array}{l}\text { A ação estabelecida é então } \\
\text { implementada visando promover } \\
\text { as mudanças planejadas }\end{array}$ & $\begin{array}{l}\text { Ferramentas estabelecidas para } \\
\text { executar a implantação em } \\
\text { colaboração com os envolvidos }\end{array}$ \\
\hline Avaliação & $\begin{array}{l}\text { Reflexão dos resultados esperados } \\
\text { ou não decorrentes da } \\
\text { implementação da ação }\end{array}$ & $\begin{array}{l}\text { Revisão do processo visando } \\
\text { avaliar os resultados, incluindo } \\
\text { melhorias para o ciclo seguinte }\end{array}$ \\
\hline
\end{tabular}
Fonte: MIGUEL(2005)

\subsection{Caracterização da Pesquisa}

THIOLLENT (2004) refere que em um contexto organizacional, a ação considerada visa com freqüência resolver problemas de ordem aparentemente mais técnica, como 
no caso deste trabalho, mapear, definir, reestruturar e introduzir metodologias de desenvolvimento e manutenção de sistemas na EmpresaTI, considerando características obtidas dos conceitos de Fábrica de Software.

Segundo o autor, por trás de problemas desta natureza há sempre uma série de condicionantes sociais a serem evidenciados pela investigação. $\mathrm{Na} \mathrm{PA}$, os pesquisadores desempenham um papel ativo no equacionamento dos problemas encontrados, no acompanhamento e na avaliação das ações desencadeadas em função dos problemas. A ênfase da PA pode ser dada a um dos três aspectos: resolução de problemas, tomada de consciência ou produção de conhecimento.

Muitas vezes, a PA só consegue alcançar um ou outro desses três aspectos. Com amadurecimento metodológico, a PA, quando bem conduzida poderá vir a alcançálos simultaneamente, este é o objetivo desejado para a finalização deste trabalho. Nesse sentido, a presente pesquisa pretende oferecer uma contribuição de cunho empírico, associada a uma contribuição teórica no sentido de geração de conhecimento do contexto estudado.

Os dados da Tabela 14 mostram as principais características associadas à $\mathrm{PA}$, de acordo com COUGHLAN e COGHLAN (2002) colocando o respectivo relacionamento com as características da presente pesquisa.

Tabela 14 - Características da Presente Pesquisa

\begin{tabular}{|l|l|}
\hline $\begin{array}{l}\text { Principais Características } \\
\text { da Pesquisa-Ação }\end{array}$ & \multicolumn{1}{c|}{ Características da Presente Pesquisa } \\
\hline $\begin{array}{l}\text { O pesquisador toma a ação } \\
\text { não é mero observador) }\end{array}$ & $\begin{array}{l}\text { A pesquisadora como funcionária regular da EmpresaTI, com } \\
\text { competências de analista de sistemas e processos, atuou com } \\
\text { participação ativa na condução do mapeamento, definição e } \\
\text { estabelecimento dos processos de desenvolvimento e manutenção } \\
\text { de sistemas alinhados à nova estrutura organizacional da Empresa }\end{array}$ \\
\hline $\begin{array}{l}\text { A pesquisa envolve dois } \\
\text { objetivos: solucionar um } \\
\text { problema e contribuir para a } \\
\text { ciência. }\end{array}$ & $\begin{array}{l}\text { O trabalho envolve a solução de um problema que objetiva a } \\
\text { investigação de forma adaptada ao contexto e cultura da } \\
\text { organização. As contribuições empírica e teórica esperadas } \\
\text { referem-se à melhoria dos processos organizacionais e operacionais } \\
\text { da empresa, assim como captar e registrar as experiências } \\
\text { cientificamente relevantes. }\end{array}$ \\
\hline $\begin{array}{l}\text { A pesquisa-ação é interativa } \\
\text { cooperação e interatividade } \\
\text { entre os envolvidos) }\end{array}$ & $\begin{array}{l}\text { A pesquisa desenvolvida obteve a contribuição e interação dos } \\
\text { profissionais das áreas da organização diretamente envolvidas no } \\
\text { processo de desenvolvimento e manutenção de sistemas, compondo } \\
\text { grupos multidisciplinares de trabalho, por meio de ações } \\
\text { planejadas. Houve a utilização do saber dos pesquisadores e } \\
\text { especialistas e das experiências concretas dos participantes, para } \\
\text { solução do problema, assim como para captação dos dados } \\
\text { compilados para a Tese. }\end{array}$ \\
\hline A pesquisa-ação objetiva & Este trabalho proporcionou um entendimento abrangente do \\
\hline
\end{tabular}




\begin{tabular}{|c|c|}
\hline $\begin{array}{c}\text { Principais Características } \\
\text { da Pesquisa-Ação }\end{array}$ & Características da Presente Pesquisa \\
\hline $\begin{array}{l}\text { desenvolver um } \\
\text { entendimento holístico }\end{array}$ & $\begin{array}{l}\text { problema. Sob o ponto de vista teórico, disponibilizou um amplo } \\
\text { estudo da literatura. Sob o ponto de vista empírico ofereceu } \\
\text { condições de compreender a complexidade do ambiente } \\
\text { organizacional, desde a visão estratégica até a visão operacional e } \\
\text { técnica. O entendimento holístico envolveu a compreensão do } \\
\text { contexto no qual a pesquisa foi conduzida e a ligação entre o } \\
\text { teórico e o empírico. }\end{array}$ \\
\hline $\begin{array}{l}\text { A pesquisa-ação é } \\
\text { fundamentalmente } \\
\text { relacionada à mudança }\end{array}$ & $\begin{array}{l}\text { A pesquisa-ação realizou-se por ocasião do processo de mudança } \\
\text { da estrutura organizacional da empresa, que ocasionou várias } \\
\text { reestruturações, sendo uma delas a redefinição e o estabelecimento } \\
\text { de uma Metodologia de Desenvolvimento de Sistemas e Integração } \\
\text { alinhada à nova estrutura organizacional. }\end{array}$ \\
\hline $\begin{array}{l}\text { A pesquisa-ação pode incluir } \\
\text { todos os tipos de métodos de } \\
\text { coleta de dados (técnicas } \\
\text { quantitativas e qualitativas) }\end{array}$ & $\begin{array}{l}\text { Os métodos de coleta de dados usados foram efetuados por meio de } \\
\text { e-mails, reuniões, investigação de documentos, observações, dados } \\
\text { de palestras, relatórios de gap-analysis, entrevistas com analistas, } \\
\text { técnicos, especialistas, gerentes e pesquisadores. }\end{array}$ \\
\hline $\begin{array}{l}\text { A pesquisa-ação requer um } \\
\text { pré-entendimento (do } \\
\text { ambiente organizacional, das } \\
\text { condições, da estrutura e } \\
\text { dinâmica das operações, } \\
\text { etc.) }\end{array}$ & $\begin{array}{l}\text { Para a condução da pesquisa-ação inicialmente houve a necessidade } \\
\text { de uma fase preliminar referente ao estudo do histórico da empresa, } \\
\text { cultura organizacional e contexto organizacional anteriores e atuais } \\
\text { da empresa. }\end{array}$ \\
\hline $\begin{array}{l}\text { A pesquisa-ação deve ser } \\
\text { conduzida em tempo real } \\
\text { (um estudo de caso vivo) }\end{array}$ & $\begin{array}{l}\text { A pesquisa-ação deste trabalho compreendeu um período de } 24 \\
\text { meses (de janeiro de } 2006 \text { a dezembro de } 2007 \text { ). Durante a } \\
\text { condução da pesquisa e elaboração dos modelos, houve a captação } \\
\text { dos dados e eventos relevantes para a redação da Tese. }\end{array}$ \\
\hline $\begin{array}{l}\text { A pesquisa-ação requer } \\
\text { critérios de qualidade } \\
\text { próprios para sua avaliação. }\end{array}$ & $\begin{array}{l}\text { Os critérios de avaliação da qualidade da pesquisa-ação foram } \\
\text { embasados nos objetivos evidenciados por THIOLLENT (2004): } \\
\text { resolução de problema; tomada de consciência e produção de } \\
\text { conhecimento. } \\
\text { Com foco nesses objetivos, da observação e avaliação das ações e } \\
\text { também pela evidência dos obstáculos encontrados no caminho, } \\
\text { houve ganho de informação captado e restituído como ganho de } \\
\text { conhecimento. }\end{array}$ \\
\hline
\end{tabular}

Fonte: Baseado em COUGHLAN e COGHLAN (2002)

Como foram mostradas na tabela acima, as características desejáveis para a condução da PA podem ser consideradas como atendidas pela presente pesquisa.

Como visto anteriormente os objetivos deste trabalho referem-se a:

Objetivo geral:

- Como mapear, definir, reestruturar e estabelecer processos e conceitos de Fábrica de Software em uma organização de TI do setor público. As características de FS consideradas são: padronização de processos, reuso de artefatos, segmentação de atividades, gestão de operações, terceirização, estrutura e cultura organizacional. A meta principal refere-se à integração e alinhamento corporativo do processo de desenvolvimento e manutenção de software. 
Para atingir o objetivo geral, são estabelecidos os seguintes objetivos específicos:

- Estudar conceitos, características e processos sobre Fábrica de Software, com base na literatura, assim como pesquisar disciplinas ou temas relacionados ao contexto da pesquisa;

- Definir e propor os modelos conceituais: Estrutura Organizacional de Referência de FS; Modelo Dinâmico de Referência de FS; Arquitetura de Definição de Processos para FS; Modelo de Definição de Processos; Diagrama de Representação da Modelagem dos Processos; Diagrama de Componentes Organizacionais de Análise da FS; Metodologia de Desenvolvimento de Sistemas e Integração (MDSI);

- Verificar a aplicabilidade dos modelos em uma pesquisa-ação, concretizando os objetivos definidos.

Para concretizar esses objetivos, a PA deste trabalho foi organizada por meio de uma adaptação dos ciclos descritos por COUGHLAN e COGHLAN (2002) compreendendo:

- A fase preliminar que visa ao entendimento do contexto geral da organização;

- Três ciclos de desenvolvimento com cinco fases cada um compreendendo: diagnóstico, referente ao levantamento, feedback e análise dos dados; planejamento; execução; avaliação; e resultados do monitoramento. Os ciclos de desenvolvimento da PA são mostrados nos dados da Tabela 15.

Tabela 15 - Ciclos e Fases da Pesquisa-Ação

\begin{tabular}{|c|c|c|}
\hline \multicolumn{3}{|r|}{ CICLOS E FASES DA PESQUISA-AÇÃO } \\
\hline \multicolumn{3}{|c|}{ Fase Preliminar: Estudo do Contexto Organizacional } \\
\hline Fase & Componente & Descrição \\
\hline \multirow[t]{2}{*}{ Inicio } & \multirow[t]{2}{*}{ Fase Preliminar } & $\begin{array}{l}\text { Contexto Conceitual: } \\
\text { Fundamentação teórica para entendimento do contexto do problema } \\
\text { envolvendo as seguintes disciplinas relacionadas: } \\
\text { Fábricas de Software; Contribuições da Engenharia de Software; } \\
\text { Reuso de Software; Contribuições da Engenharia de Produção; } \\
\text { Gestão de Processos; Gestão de Projetos; Modelos de Melhores } \\
\text { Práticas; Estruturas organizacionais; Cultura Organizacional }\end{array}$ \\
\hline & & $\begin{array}{l}\text { Contexto Empírico: } \\
\text { - } \quad \text { Histórico da Empresa; } \\
\text { - } \quad \text { Análise da cultura organizacional. }\end{array}$ \\
\hline \multicolumn{3}{|c|}{ Ciclo 1: Análise da Estrutura Organizacional } \\
\hline Fase & Componente & Descrição \\
\hline 1 & Diagnóstico & $\begin{array}{l}\text { Levantamento e análise do cenário vigente. } \\
\text { Levantamento e análise das estruturas organizacionais anteriores e } \\
\text { atuais. } \\
\text { Levantamento e análise das atribuições das áreas funcionais. }\end{array}$ \\
\hline
\end{tabular}




\begin{tabular}{|c|c|c|}
\hline 2 & Planejamento & $\begin{array}{l}\text { Elaboração do Modelo de Referência de FS. } \\
\text { Elaboração do Modelo Dinâmico de Referência de FS }\end{array}$ \\
\hline 3 & Execução & $\begin{array}{l}\text { Construção de Modelos: } \\
\text { - } \quad \text { Criação e definição do Modelo de Referência de FS. } \\
\text { - Criação e definição do Modelo Dinâmico de Referência de FS. }\end{array}$ \\
\hline 4 & Avaliação & Avaliação das Estruturas Organizacionais \\
\hline 5 & Resultados & $\begin{array}{l}\text { Captação e processamento de resultados e lições aprendidas } \\
\text { relacionando o empírico ao teórico trazendo ganhos de conhecimento }\end{array}$ \\
\hline \multicolumn{3}{|c|}{ Ciclo 2: Mapeamento, Definição e Estabelecimento dos Processos } \\
\hline Fase & Componente & Descriçãa \\
\hline 1 & Diagnóstico & $\begin{array}{l}\text { Levantamento e análise das formas de trabalho e metodologias de } \\
\text { desenvolvimento de sistemas anteriores e atual. } \\
\text { Levantamento e análise das categorias de processos. }\end{array}$ \\
\hline 2 & Planejamento & $\begin{array}{l}\text { Elaboração dos mapeamentos dos processos: } \\
\text { - Macrofluxo do Processo de Negócio da Empresa; } \\
\text { - Fluxos: processo-padrão, manutenção evolutiva, adaptativa, } \\
\quad \text { corretiva, Abend. } \\
\text { Reuniões de validação dos fluxos com os gerentes das áreas } \\
\text { envolvidas. } \\
\text { Reuniões de revisão e validação dos artefatos e templates com } \\
\text { pessoal das áreas técnicas. }\end{array}$ \\
\hline 3 & Execução & $\begin{array}{l}\text { Construção de Modelos: } \\
\text { - } \quad \text { Definição da Arquitetura de Definição de Processos para FS; } \\
\text { - } \quad \text { Definição do Modelo de Definição de Processos para FS; } \\
\text { Definição das Matrizes para Definição dos Processos: } \\
\text { - Matriz de artefatos e templates; } \\
\text { - Matriz de Atividades Integrada; } \\
\text { - Matriz de ferramentas, técnicas e métodos. } \\
\text { Execução dos mapeamentos dos processos aplicando os Modelos: } \\
\text { - Visão estratégica - Macrofluxo dos Processos de Negócio; } \\
\text { - Visão funcional - Fluxo dos Processos das áreas funcionais; } \\
\text { - Visão tática - Fluxo do Processo-Padrão; } \\
\text { - Visão operacional - Fluxo dos Processos Específicos; } \\
\text { Validação pontual - Fluxos dos Processos-Chave e/ou reusáveis. } \\
\text { envolvidas. } \\
\text { Validação de artefatos e templates com representantes das áreas } \\
\text { técnicas. } \\
\text { Reunião de validação final com a Diretoria de Desenvolvimento e } \\
\text { gerentes envolvidos. } \\
\text { Elaboração da Documentação do Projeto. }\end{array}$ \\
\hline 4 & Avaliação & Revisão e avaliação do Ciclo 2: diagnósticos e soluções \\
\hline 5 & Resultados & $\begin{array}{l}\text { Captação e processamento de resultados e lições aprendidas } \\
\text { relacionando o empírico ao teórico trazendo ganhos de conhecimento }\end{array}$ \\
\hline \multicolumn{3}{|c|}{ Ciclo 3: Análise do Impacto das Mudanças Organizacionais nos Processos } \\
\hline Fase & Componente & Descrição \\
\hline 1 & Diagnóstico & $\begin{array}{l}\text { Levantamento e análise do impacto das novas mudanças } \\
\text { organizacionais nos processos de negócios. } \\
\text { Análise da influência da Cultura Organizacional }\end{array}$ \\
\hline 2 & Planejamento & $\begin{array}{l}\text { Revisão e atualização dos mapeamentos efetuados no Ciclo } 2 . \\
\text { Revisão e atualização dos artefatos e documentações geradas no } \\
\text { Ciclo } 2 .\end{array}$ \\
\hline
\end{tabular}




\begin{tabular}{|l|l|l|}
\hline 3 & Execução & Execução do novo ciclo de revisão e validação dos fluxos mapeados \\
\hline 4 & Avaliação & Avaliação da Mudança Organizacional x Cultura Organizacional \\
\hline 5 & Resultados & $\begin{array}{l}\text { Captação e processamento de resultados e lições aprendidas } \\
\text { relacionando o empírico ao teórico trazendo ganhos de conhecimento }\end{array}$ \\
\hline
\end{tabular}
Fonte: elaborada pela autora

A Figura 15 apresenta os ciclos de desenvolvimento, segundo o método de PA, mostrando a concatenação teórica das disciplinas relacionadas à PA, bem como os Modelos e artefatos gerados na pesquisa.

As questões relativas aos quadros de referência teórica, sem os quais a pesquisa empírica não faria sentido, são colocadas especialmente durante a criação dos Modelos desenvolvidos com o objetivo de atentar às exigências teóricas e práticas, a fim de embasar e equacionar os problemas relevantes dentro da situação estudada.

A condução e o detalhamento dos ciclos da pesquisa são descritos nos próximos capítulos. 


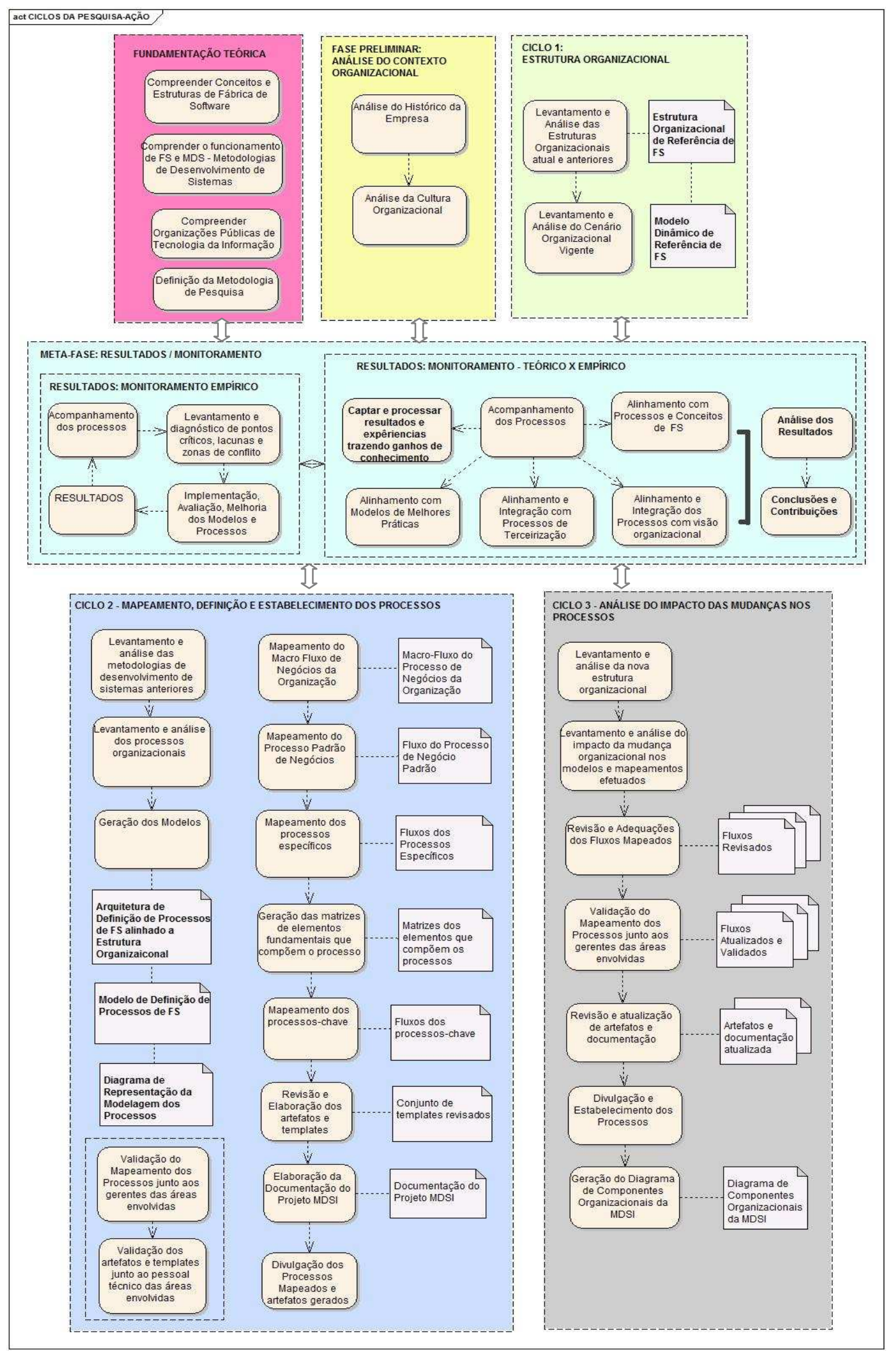

Figura 15 - Fluxo dos Ciclos da Pesquisa-Ação Fonte: elaborada pela autora 


\section{FASE PRELIMINAR - CARACTERIZAÇÃO DA EMPRESA}

Neste trabalho, a empresa pesquisada é denominada EmpresaTI. Por se tratar de uma empresa do setor público a EmpresaTI está sujeita a constantes mudanças organizacionais. A Pesquisa-Ação (PA) realizada motivou-se em decorrência de relevantes mudanças na estrutura organizacional da EmpresaTI.

A (PA) está associada a um processo de mudança que é sempre crítico, ela contribui levando os atores envolvidos a encontrar as respostas a seus próprios problemas, comprometendo-se com a mudança e aprendendo com ela.

As mudanças organizacionais são definidas como mudanças revolucionárias e mudanças graduais, que podem ser geradas, a partir de problemas no ambiente externo à organização ou por problemas internos (FLEURY e FISHER, 1996).

As autoras citadas explicam que a mudança revolucionária é aquela em que "os novos valores são antagônicos aos anteriores, gerando um processo radical de destruição dos elementos simbólicos, de redefinição completa das práticas organizacionais". A mudança gradual se dá quando "novos valores propostos são complementares aos existentes, ampliando leques de alternativas existentes para a solução de problemas".

No segundo semestre de 2005, um novo modelo de atendimento da EmpresaTI foi definido por Decreto, instituído pelo CMI - Conselho Municipal de Informática (CMI, 2005), órgão normativo, elaborador e regulador da política de informática da Prefeitura. Em razão desse novo Modelo de Atendimento, ocorreram relevantes mudanças na organização, algumas delas podendo ser consideradas como mudanças revolucionárias.

Esse modelo visava à modernização da empresa e uma maior integração entre as várias áreas do governo municipal, isto implicava crescente demanda de serviços de organização e informática para atender às exigências dos cidadãos quanto aos serviços públicos.

Os principais objetivos do novo modelo de atendimento da empresa visavam ao alinhamento com a Prefeitura e suas prioridades; gestão por resultados; transparência; mudança nos sistemas de custos e preços; busca de novos clientes e produtos; garantir o menor custo e benefício à Prefeitura Municipal nas despesas de TI, com objetivo de redução de custos; mudanças na forma de contratação com 
níveis de serviço; planejamento e controle da produção; integração dos sistemas; terceirização; flexibilidade no atendimento à crescente demanda de pedidos dos clientes, visando cada vez mais ao foco no cliente, adequando os serviços, necessidades e possibilidades de cada cliente.

Uma das reestruturações ocorridas decorrentes do novo modelo foi relativa à mudança na Estrutura Organizacional da empresa, inferindo em um Modelo Matricial. Em conseqüência deste fato, no início de 2006, foi solicitada pela alta direção uma série de projetos que faziam parte do planejamento estratégico anual da empresa. Um desses projetos referia-se ao desenvolvimento, adequação e implantação da Metodologia de Desenvolvimento de Sistemas.

O projeto tinha como objetivo inicial o mapeamento dos principais processos de negócios, alinhados à nova estrutura organizacional da empresa, ou seja, fazia-se necessário mapear todos os processos interfuncionais, definindo claramente os links entre as áreas da empresa, definindo clientes, fornecedores e artefatos de entrada e saída, abrangendo tanto os aspectos de sistemas de produção como os de Engenharia de Software e processos de terceirização.

Neste contexto, posteriormente, o projeto passou a denominar-se "Metodologia de Desenvolvimento de Sistemas e Integração" (MDSI). No projeto, a autora, como funcionária regular da EmpresaTI, atuou com competências de analista de processos, analista de sistemas e, sobretudo, pesquisadora, atuando junto a diferentes equipes multidisciplinares.

Desta forma, apresenta-se a questão empírica principal abordada pela presente pesquisa, na qual tanto a pesquisadora como os membros da instituição envolvidos no projeto estavam interessados em desenvolver uma solução ao problema exposto de forma adaptada ao novo contexto e cultura existente na organização.

A proposição referente à contribuição acadêmica refere-se à avaliação, ganhos de conhecimento e resolução da seguinte questão: "É possível mapear, definir, reestruturar e estabelecer processos de FS em uma organização de TI do setor público".

Na próxima seção é apresentado o contexto organizacional da EmpresaTI retratando seu histórico e as principais características pertinentes à sua cultura organizacional. 


\subsection{Histórico da Empresa}

A EmpresaTI é uma Empresa de Tecnologia da Informação e Comunicação, de economia mista, de grande porte, prestadora de serviços e produtora de software, com cerca de 700 funcionários, que atende ao setor público municipal.

A EmpresaTI foi criada em 1971 para que funcionasse como apoio técnico à Administração Municipal, atuando também com serviços de "bureau". Em 1974, contava com o computador IBM/370, na época com maior capacidade de armazenamento e terminais remotos instalados nos locais de trabalho (PMSP, 2005). Na década de 1980, ampliaram-se os recursos de hardware, software, tecnologia de banco de dados e rede de teleprocessamento e iniciou-se a microinformatização da Prefeitura e da EmpresaTI, tornando possível a ampliação do desenvolvimento de sistemas e aumento da demanda de serviços.

As intenções da companhia, em concordância com a política da Prefeitura, na época, eram: a utilização da informática para a democratização da informação; atualização tecnológica do parque de equipamentos; realização de intenso programa de reciclagem e capacitação técnica, visando à assimilação das novas tecnologias disponíveis; disseminação da microinformática na Prefeitura Municipal; criação da área de competência em tecnologia de ponta, com a função de captar, absorver e disseminar as profundas, rápidas e constantes inovações no setor.

Nos anos de 1990, a empresa implantou a estrutura da Rede Municipal de Informática (RMI), tornando-se a pioneira na utilização de sistema aberto de comunicação de dados no Brasil. A RMI inaugurou um novo modelo tecnológico para a informatização do município, que teve como principal característica o processamento e a comunicação de dados distribuídos, em substituição ao modelo centralizado incompatível com a complexidade e necessidades da cidade. Até então, grande parte dos grandes projetos da empresa era desenvolvida em plataforma alta ou mainframe. Nos anos seguintes, iniciou o desenvolvimento de sistemas em baixa plataforma e sistemas voltados para ambiente web, além da integração dos diferentes ambientes tecnológicos com o objetivo de criação de sistemas distribuídos e corporativos.

Atualmente, a EmpresaTI tem como função principal a execução de serviços de tratamento de informações e comunicações para a Prefeitura Municipal, 
caracterizando-se como uma empresa fornecedora de soluções informatizadas para a administração pública. Seus clientes são as Secretarias do Município, diversas entidades da administração indireta, como autarquias hospitalares, Instituto de Previdência, Emurb, Transportes, Câmara Municipal, entre outras.

Os sistemas desenvolvidos estão dirigidos, sobretudo para automação da gestão pública, aplicações para as áreas de finanças, educação, saúde, assistência social, habitação, transporte, cultura, geoprocessamento e outras, além do acompanhamento de diversificados processos administrativos.

O sistema de desenvolvimento e manutenção caracteriza-se por atendimentos sob encomenda ou demanda para vários clientes, simultaneamente em diferentes domínios de aplicação de negócios. A natureza diversa desses clientes exige da empresa a manutenção de um complexo ambiente de desenvolvimento.

A empresa possui uma série diversificada de projetos em diferentes plataformas tecnológicas, como mainframe, cliente servidor, baixa plataforma, web, sistemas integrados e sistemas distribuídos, usando grande variedade de ferramentas e técnicas.

A empresa atende às demandas que contemplam as seguintes fases de desenvolvimento de sistemas: modelagem de processos, proposta de projeto novo, planejamento de projeto, levantamento de requisitos, especificação técnica, construção, testes, homologação, manutenções diversas, atividades ligadas a projetos terceirizados como aquisição, internalização e auditoria além do planejamento, prospecção e execução de diversificados serviços de TI.

Outras municipalidades procuram a empresa para dela receberem orientação, treinamento, consultoria e assessoria para projetos específicos, intercâmbio de sistemas, implantação e processamento de sistemas especialistas. Existe também a possibilidade de aquisição descentralizada de bens e serviços de informática por meio de fornecedores externos, o que implica a definição de processos para terceirização e internalização de sistemas.

Além da prestação de serviços em desenvolvimento e manutenção de software, a EmpresaTI possui um forte segmento na área de Infra-Estrutura e Data-Center, oferecendo serviços como: Service-Desk, Command-Center, Backup e Gerenciamento de Discos, Gerenciamento de Servidores e Desk-Tops entre outros. 
Seguindo este movimento, a EmpresaTI tem investido na melhoria de atendimento e no fortalecimento de seu modelo de gestão, priorizando cada vez mais o empreendedorismo e a inovação, a fim de alinhar suas diretrizes à tendência mundial da área.

Desta forma, o corpo diretivo da EmpresaTI definiu a Missão ou razão de ser da empresa como: "Prover à Prefeitura do Município informações e soluções integradas em Tecnologia da Informação e Comunicação com agilidade, qualidade, segurança e preço justo, para melhoria da gestão pública em benefício da sociedade”, e a definição da Visão da empresa como: "Ser referência em soluções de Tecnologia da Informação e Comunicação para a administração pública, essenciais ao alcance de resultados da Prefeitura do Município”.

Neste contexto, a adoção de práticas para a padronização, organização, integração, alinhamento e controle dos processos de negócios no âmbito técnico e gerencial, alinhado ao modelo organizacional estratégico da empresa torna-se fundamental para o aumento da produtividade e qualidade dos produtos entregues aos clientes.

Este histórico compõe o quadro retratado no cenário encontrado na evolução das empresas de TI desde os anos de 1960.

Para LAURINDO e ROTONDARO (2006), o papel desempenhado pela TI vem evoluindo significativamente ao longo do tempo. Nos anos de 1960, predominava o processamento em batch (em lotes) em mainframe. Na segunda era, surge o teleprocessamento, ainda baseado em mainframe; a terceira é marcada pelos microcomputadores; na quarta e última é a disseminação de redes, em particular a Internet.

Segundo os autores, no que se refere aos impactos nos processos, na primeira era visava-se à simples automação de processos bem estruturados. Na segunda, começava a haver mudança numa forma como os processos corporativos eram executados; na terceira, passou a existir um foco nos processos baseados em aplicações distribuídas, mas integradas e, na quarta era, os processos interorganizacionais passaram a ser o principal objeto de mudanças, o que torna cada vez mais complexa a Gestão da TI. 


\subsection{Levantamento e Análise da Cultura Organizacional}

Por se tratar de uma empresa que atende o setor público, a EmpresaTI sofre uma grande rotatividade do quadro funcional, sobretudo do corpo diretivo, gerências e assessorias, ocasionadas pelas mudanças de governo, ocorridas de quatro em quatro anos, ou até mesmo de dois em dois anos, trazendo novas políticas e/ou novos modelos organizacionais, de acordo com o planejamento estratégico vigente da empresa alinhado com o novo governo.

No decorrer do tempo, graças ao legado das constantes mudanças ocorridas, a empresa foi perdendo sua identidade. A direção teve como missão recuperar a boa imagem da empresa perante seus clientes e motivar e capacitar os funcionários para dar sustentabilidade aos conhecimentos existentes e acompanhar os movimentos de inovação do mercado de TI.

Em empresas do setor público, a questão da cultura organizacional mostra-se mais complexa que as demais empresas em razão da vulnerabilidade de exposição a estas constantes mudanças organizacionais ocasionadas por mudanças de governo, agravando-se pelos aspectos políticos envolvidos. Em empresas públicas da área de TI, a complexidade aumenta mais ainda, necessitando conciliar os aspectos estratégicos, técnicos, culturais e políticos. Essas mudanças podem ocasionar grandes impactos nos processos de negócios da organização, trazendo riscos na produtividade e na qualidade dos serviços e produtos entregues aos clientes, usuários e cidadãos além, de muitas vezes, gerar um clima de desgaste, insatisfação, hostilidade, insegurança e resistência entre os funcionários de carreira ou não.

SCHALL (1997) apud PIRES e MACEDO (2006) cita que a descontinuidade administrativa é um dos pontos que mais diferenciam a organização pública da privada, conferindo às organizações públicas características específicas, que também podem ser aplicadas à realidade brasileira, como:

- Projetos de curto prazo: cada governo só privilegia projetos que possa concluir em seu mandato, para ter retorno político;

- Duplicação de projetos: cada novo governo inicia novos projetos, muitas vezes, quase idênticos, reivindicando a autoria para si; 
- Conflitos de objetivos: conflito entre os objetivos do corpo permanente e do não permanente, o que pode gerar pouco empenho em relação aos procedimentos que vão contra interesses corporativos. Ciência de que a chefia logo será substituída;

- Administração transitória: administração feita por indivíduos, muitas vezes, com pouco conhecimento da história e da cultura da organização. Predomínio de critérios políticos em detrimento da capacidade técnica ou administrativa dos nomeados.

Em um artigo sobre a EmpresaTI, BRAGANÇA et al. (2003) relatam que a empresa compartilha com fornecedores similares do setor público, de problemas sérios oriundos em grande parte do próprio processo de mudanças e evolução da TI na área. Dentre os problemas em comum, os autores citam:

- Os profissionais transformam-se de "analistas de sistemas" para "analistas dos sistemas" gerados e a eles dedicam-se com exclusividade, tornando-se especialistas em determinados "sistemas". Tal situação inviabiliza uma estrutura horizontal, pois esta pressupõe a alocação dos técnicos em tarefas temporárias;

- O domínio de determinados segmentos inclusive no de negócio, cria no cliente uma falsa sensação de estabilidade. Como só um determinado técnico domina o assunto há muitos anos e presta o serviço de modo eficiente, com a solicitação de uma demanda, recebe-se a designação da equipe;

- A verticalização do processo por muito tempo forma um contingente enorme de técnicos ponta-a-ponta, impedindo a especialização. Não há disponibilidade de projetistas suficientes para $\mathrm{o}$ atendimento nem de programadores para $\mathrm{o}$ desenvolvimento;

- Normalmente, os sistemas têm suas funcionalidades básicas desenvolvidas e entram em manutenção sem seguir um plano de versionamento.

Para BRAGANÇA et al. (2003), as discussões sobre a função da informática pública vêm tornando progressivamente mais claros os caminhos para a modernização do processo de informatização. Mais ainda tem demonstrado como fator fundamental de sucesso, a democratização da informação.

Para a realização desta modernização da TI no setor público é imprescindível que mudanças aconteçam. SLACK et al. (1996) consideram: uma vez que a prioridade de melhoramento tenha sido determinada, ações precisam considerar a abordagem ou 
estratégia que ela deseja levar adiante para o processo de mudança. Uma das razões principais para a mudança é a busca pela flexibilidade organizacional, que corresponde à capacidade de reação das organizações frente aos sobressaltos impostos pelos movimentos de inovação. 


\section{CICLO 1 - ESTRUTURA ORGANIZACIONAL}

Pelo esforço de priorizar o atendimento ao cliente, no decorrer do tempo, a EmpresaTI buscou atender solicitações de demandas de serviços associados a um complexo ambiente de desenvolvimento. O cenário vigente mostra grande parte de sua operação em manutenção de sistemas legados em mainframe e plataforma baixa, grande demanda de serviços de desenvolvimento de projetos novos em plataforma baixa, web e distribuída, além de projetos de integração e terceirização de sistemas.

\subsection{Fase 1 - Diagnóstico}

A seguir os dados listados foram obtidos baseados na análise e levantamentos efetuados em pesquisas internas, documentações, observações, relatórios de gap analysis, reuniões e questionamentos diretos com gerentes e técnicos, e mostram o retrato do contexto geral da EmpresaTI no momento da mudança organizacional:

- Diversidade de plataformas tecnológicas de hardware, software e ferramentas;

- Diversidade de áreas de domínios de aplicações de negócios;

- Diversidade de solicitações de serviços e produtos;

- Diversidade de especializações técnicas;

- Atendimento por demanda para vários clientes simultaneamente;

- Grande parte dos serviços prestados pela empresa refere-se a serviços de manutenção de sistemas;

- Aumento crescente da demanda de projetos novos e de manutenção, tanto interno como externos;

- Pessoal insuficiente para cobrir novas demandas de serviços, necessitando a contratação de Fábricas de Software externas;

- Internalização de projetos terceirizados;

- Processos de desenvolvimento e manutenção não padronizados;

- Documentação defícitária;

- Gestão do conhecimento desagregada;

- O conhecimento dos negócios, tecnologia e processos se concentra em grande parte nas pessoas (conhecimentos implícitos);

- Grande parcela de profissionais técnicos qualificados;

- Ampla e diversificada série de projetos de sistemas desenvolvidos e implantados; 
- Robustez na área de Infra-Estrutura e Data-Center; e

- Iniciativas de adoção de Modelos de Melhores Práticas como PMBOK, ITIL, ISO 9126, ISO 17779, ISO 9001 e CMMI.

Visto que a mudança na estrutura organizacional afeta diretamente os processos operacionais e, baseado no contexto apresentado, a definição de uma metodologia para promover a padronização e organização dos processos de desenvolvimento e manutenção de sistemas, e a gestão do conhecimento torna-se extremamente necessária.

\subsubsection{Análise das Estruturas Organizacionais}

O primeiro ciclo desta pesquisa, visa a compreender as estruturas organizacionais já adotadas na EmpresaTI. Desta forma, esta fase da PA compreende o levantamento de dados e a análise da estrutura organizacional vigente e das estruturas organizacionais anteriormente existentes na EmpresaTI.

\section{Estrutura Organizacional 1}

Conforme referem BRAGANÇA et al. (2003), o processo de desenvolvimento de sistemas informatizados da EmpresaTI, tinha como atribuição, todo o processo de atendimento aos órgãos da Prefeitura, o que incluía desde o levantamento da demanda, viabilização administrativa dos projetos, desenvolvimento ou apoio para contratações externas e, neste caso, internalização das tecnologias envolvidas, implantação e operação das soluções solicitadas. Para tal, contavam com pessoal especializado no desenvolvimento de sistemas: analistas de negócio, de sistemas, programadores e outros.

Os autores observam que essa "verticalização" era responsável por boa parte da dificuldade de integração e reutilização das soluções, causando redundância e retrabalho. Após a identificação da demanda, pertinente ao escopo de cada departamento de atendimento e da viabilização administrativa de cada projeto, os analistas de sistemas deveriam dar início ao processo de concepção, desenho e documentação da solução, para que pudesse ser encaminhado à programação, que só então, trataria do desenvolvimento.

Entretanto em razão de necessidades, sempre urgentes, de implantação dessas soluções, nem todo o processo era respeitado. Normalmente, o próprio analista de 
negócio encarregava-se de todas as etapas, da concepção ao desenvolvimento e dos testes à implantação.

Segundo os autores, este desvio acarretou a "personalização" da mecânica, ou seja, o domínio técnico dos requisitos e dos produtos gerados que deveriam permanecer no âmbito corporativo, acabaram se tornando "propriedade" do(s) trabalhador(es) envolvidos.

Esta "dependência personalizada" pode, no curto prazo, render aparentes bons frutos, como a sensação de satisfação imediata do cliente, advinda do domínio sobre os assuntos e da dedicação dos analistas. Mas, a médio e longo prazo, este modelo acarretou conseqüências sérias: altos custos de manutenção, ausência de padrões, impossibilidade de aplicação de medidas de produtividade, corporativismo, vícios técnicos, enfim, uma lista de "distorções técnicas" que, levadas ao extremo, podem comprometer todo o processo.

\section{Estrutura Organizacional 2}

Em 2002, um decreto regulamentado pelo Conselho Municipal de Informática (CMI), instituía a possibilidade da aquisição descentralizada de bens e serviços de informática por meio de fornecedores externos, por parte da Administração Municipal. O fato evidenciou a necessidade de modernização e mudanças dos processos de aquisição, desenvolvimento e manutenção de software estabelecido há décadas na Empresa. Na ocasião, foi proposto pela área de Desenvolvimento e Tecnologia da EmpresaTI um conjunto de conceitos de arquitetura de software, sob a forma de diretrizes tecnológicas, o que culminou em sua publicação pelo CMI (CMI, 2002), no Diário Oficial do Município.

$\mathrm{Na}$ época, um novo modelo organizacional, mostrado na Figura 16 foi proposto. De acordo com BRAGANÇA et al. (2003), este modelo era composto de quatro departamentos de atendimento responsáveis pelo trabalho com os clientes e usuários, cada um respondendo por um grupo de assuntos: gestão administrativa, gestão tributária e financeira, gestão urbana e gestão de projetos sociais, observando suas necessidades, propostas e solicitações, transformando-as em projetos a serem desenvolvidos pelo Departamento de Desenvolvimento de Sistemas, ou externamente, quando necessário. 


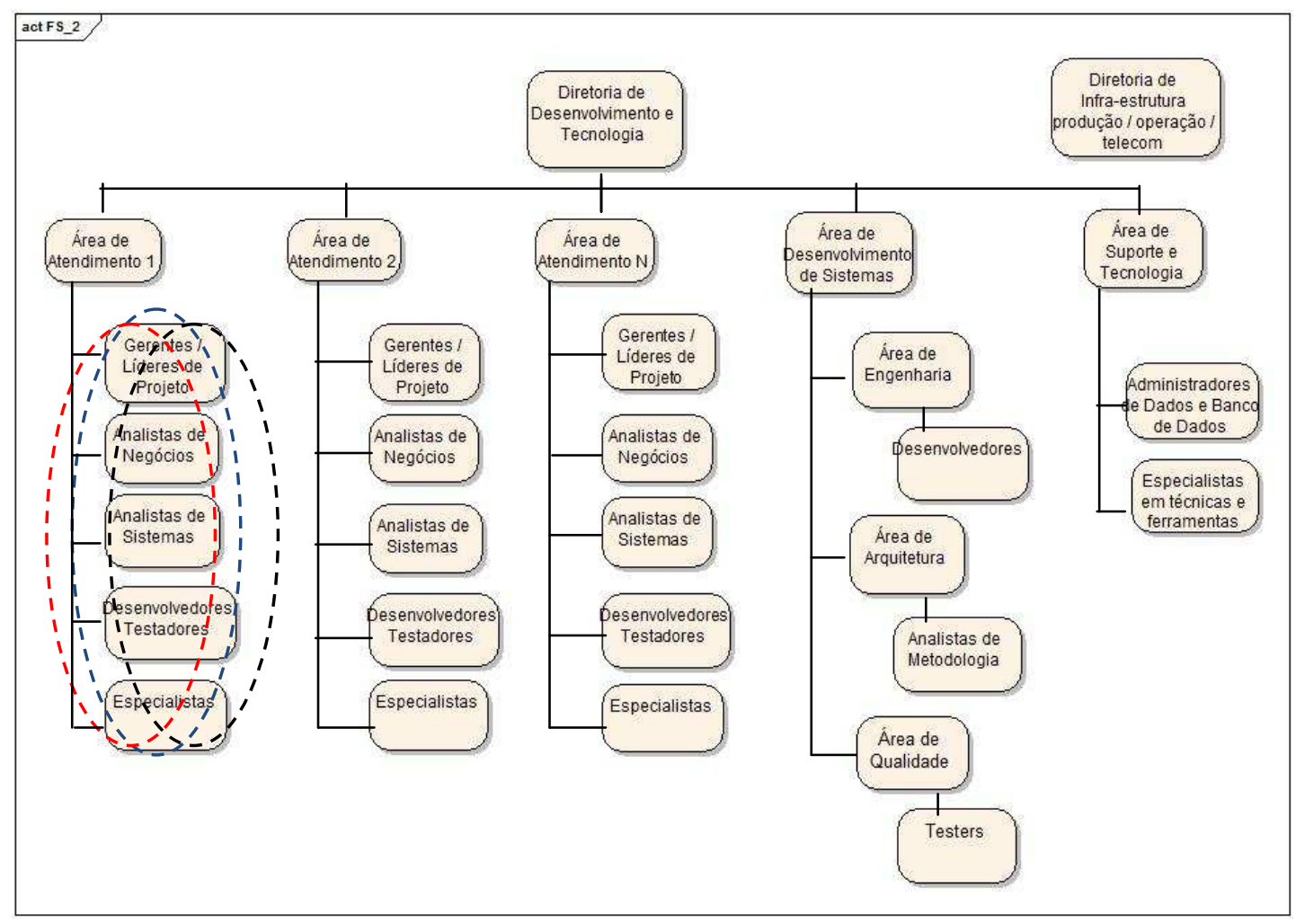

Figura 16 - Estrutura Organizacional da EmpresaTI - Projetizada

O Departamento de Desenvolvimento de Sistemas contava com duas áreas: uma área de Suporte e Tecnologia, responsável por manter o planejamento global do atendimento, atuar na prospecção de novas tecnologias, prover suporte e gerenciar a infra-estrutura de desenvolvimento; e a outra, de Desenvolvimento de Sistemas, composta de três divisões: Divisão de Arquitetura, responsável por prover padrões e estilos, validar a arquitetura dos sistemas; Divisão de Engenharia, responsável por manter o repositório de funcionalidades, desenvolver componentes, serviços, funcionalidades e interfaces, além de gerenciar o desenvolvimento; Divisão de Controle de Qualidade dos Sistemas, responsável por emitir planos de testes internos e externos, desenvolver e utilizar ferramentas de testes, executar testes internos, controlar a execução dos testes externos e emitir relatórios de qualidade.

\section{Estrutura Organizacional 3}

Em 2005, definiu-se um novo modelo de atendimento da EmpresaTI, em decorrência de diretrizes estabelecidas por Decreto, instituído pelo CMI (CMI, 2005). Este modelo visava a modernização da empresa e uma maior integração entre as várias áreas do Governo Municipal, o que implicava uma crescente demanda de serviços de 
organização e informática para atender às exigências dos cidadãos quanto aos serviços públicos.

Os principais objetivos do novo modelo de atendimento da empresa visavam ao: alinhamento com a Prefeitura e suas prioridades; gestão por resultados; transparência; mudança nos sistemas de custos e preços; busca de novos clientes e produtos; garantir o menor custo e benefício para a Prefeitura nas despesas de TI, com objetivo de redução de custos; mudanças na forma de contratação, com níveis de serviço; planejamento e controle da produção; integração dos sistemas; terceirização; flexibilidade no atendimento à crescente demanda de pedidos dos clientes, visando a cada vez mais o foco no cliente, adequando os serviços, necessidades e possibilidades de cada cliente.

Este novo modelo de atendimento implicou a principal mudança ocorrida na Empresa referente à estrutura organizacional, que inferiu em um Modelo Matricial, conforme mostrado na Figura 17.

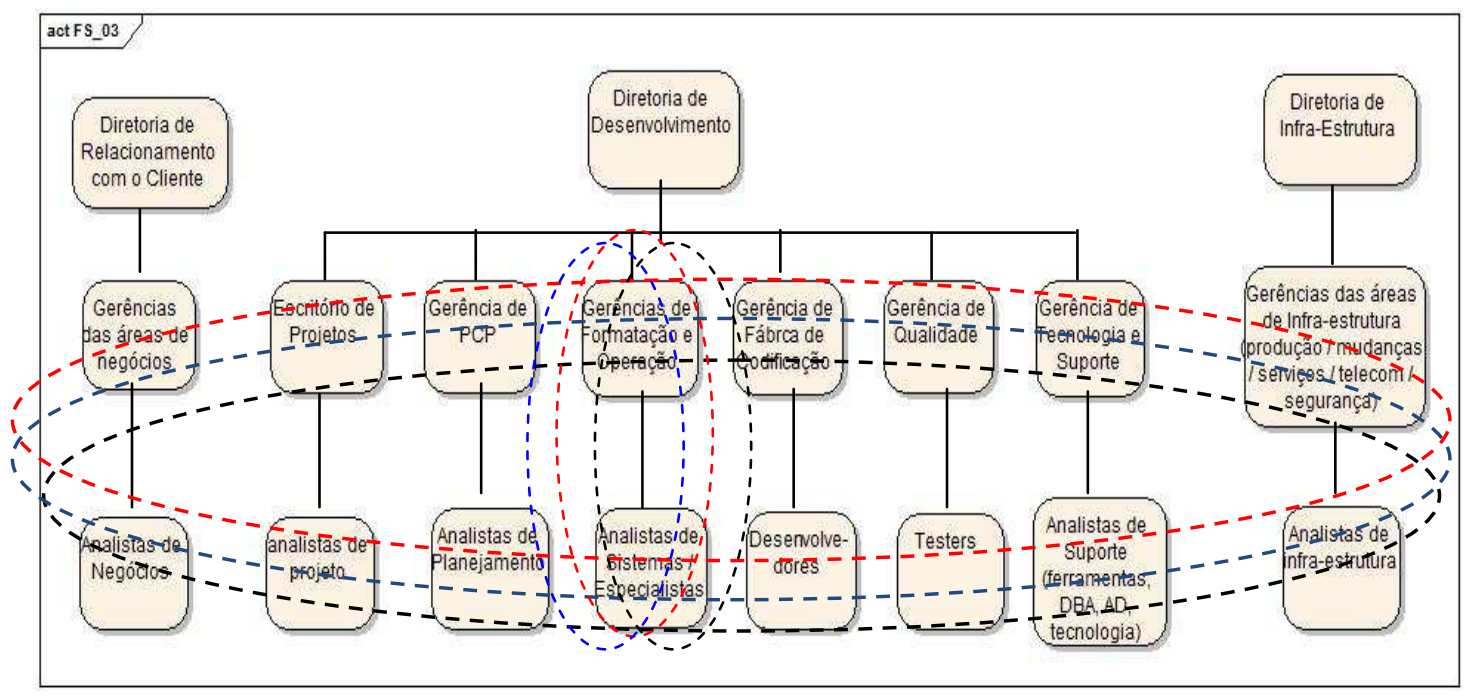

Figura 17 - Estrutura Organizacional da EmpresaTI - Matricial

As principais unidades organizacionais criadas nos âmbitos das diretorias e gerências envolvidas no processo de desenvolvimento e manutenção de software, ou seja, áreas diretamente ligadas ao negócio-fim da empresa constituíam-se de: 1) Diretoria de Relacionamento com o cliente, separada por áreas que atendem grupos de clientes em diferentes domínios de negócios; 2) Diretoria de Desenvolvimento, composta de: área de Análise e Design, denominada na empresa como área de Formatação e Operação; área de Codificação, denominada na empresa como Fábrica de Software; 
área de Testes de Qualidade; área de Tecnologia; área de Planejamento e Controle de Produção (PCP); Escritório de Projetos e Grandes Projetos; 3) Diretoria de InfraEstrutura, composta das áreas de: Mudanças, Produção, Serviços, Segurança, Telecomunicações e Rede.

Neste modelo, o principal ponto forte da departamentalização funcional é agrupar especialistas, o que minimiza o número necessário deles, ao mesmo tempo em que permite o compartilhamento dos recursos especializados entre os diversos projetos. Seu principal ponto fraco é a dificuldade de coordenação das tarefas dos diversos especialistas funcionais, de modo que as atividades sejam concluídas dentro dos orçamentos e prazos devidos.

\subsection{Fase 2 - Planejamento}

Uma vez analisadas as estruturas organizacionais adotadas na EmpresaTI, o objetivo desta fase concentrou-se em planejar um Modelo de Referência de Fábrica de Software compatível com a nova estrutura organizacional da EmpresaTI (Estrutura Organizacional 3), com foco nas principais características de Fábricas de Software encontradas na literatura, como padronização de processos, reuso de artefatos de software, divisão do trabalho, gestão de operações e terceirização.

O Modelo de Referência de FS serviu como guia de condução para o mapeamento dos processos abrangendo, tanto os aspectos de Engenharia de Produção como os aspectos de Engenharia de Software.

\subsection{Fase 3 - Execução: Construção dos Modelos}

Os produtos desenvolvidos nesta fase ficaram estabelecidos como:

- Definição da Estrutura Organizacional de Referência de FS, baseado nas estruturas analisadas da EmpresaTI e em conceitos teóricos sobre Fábricas de Software;

- Definição do Modelo Dinâmico de Referência de FS adequada à Estrutura Organizacional de Referência de FS.

\subsubsection{Estrutura Organizacional de Referência de FS}

A Estrutura Organizacional de Referência de FS foi concebida com base em um Modelo Matricial, definindo as áreas funcionais agrupadas em especializações, de 
acordo com os segmentos dos principais processos-chave relativos ao desenvolvimento de software.

Com base nos conceitos do modelo matricial, da observação empírica da Estrutura Organizacional 3, e da fundamentação teórica, definiu-se a Estrutura Organizacional de Referência de FS mostrada na Figura 18.

As principais idéias adotadas para a definição da Estrutura de FS pautaram-se nos conceitos de Fábrica de Software dos autores analisados na Seção 2.1 citados, a seguir:

CUSUMANO (1991) - Fábricas de Software do Japão: dá ênfase ao reuso, modularização, controle e gerenciamento de projetos e processos.

BASILI et al. (1992) - Fábrica de Experiências para reuso: o modelo sugere diferentes artefatos e experiências que podem ser usados em todo o processo de desenvolvimento e manutenção de software.

PRESSMAN (2002) - Engenharia de Software Baseada em Componentes: o modelo alimenta o processo de desenvolvimento, de acordo com a análise de domínio efetuada, gerando artefatos e componentes reusáveis utilizados durante o processo de desenvolvimento de software.

FERNANDES e TEIXEIRA (2004) - O modelo de FS segue a idéia da divisão do trabalho orientado à especialização proposta pelos autores, como a Fábrica de Projetos Ampliada, Fábrica de Projetos, a Fábrica de Projetos Físicos e a Fábrica de Programas.

KRUCHTEN e KROLL (2003) - A estruturação da FS usa como Guia de Referência o processo de desenvolvimento de software do RUP - Rational Unified Process, que contempla o desenvolvimento iterativo, gerenciamento de requisitos, arquiteturas baseadas em componentes, modelagem visual, verificação contínua da qualidade e controle de mudanças no software. A nomenclatura e os conceitos da dimensão estática do RUP referentes aos conceitos de disciplina são usados para denominar as áreas funcionais da FS, enquanto a dimensão dinâmica está diretamente associada ao mapeamento e definição dos processos de desenvolvimento e manutenção de software da FS. 


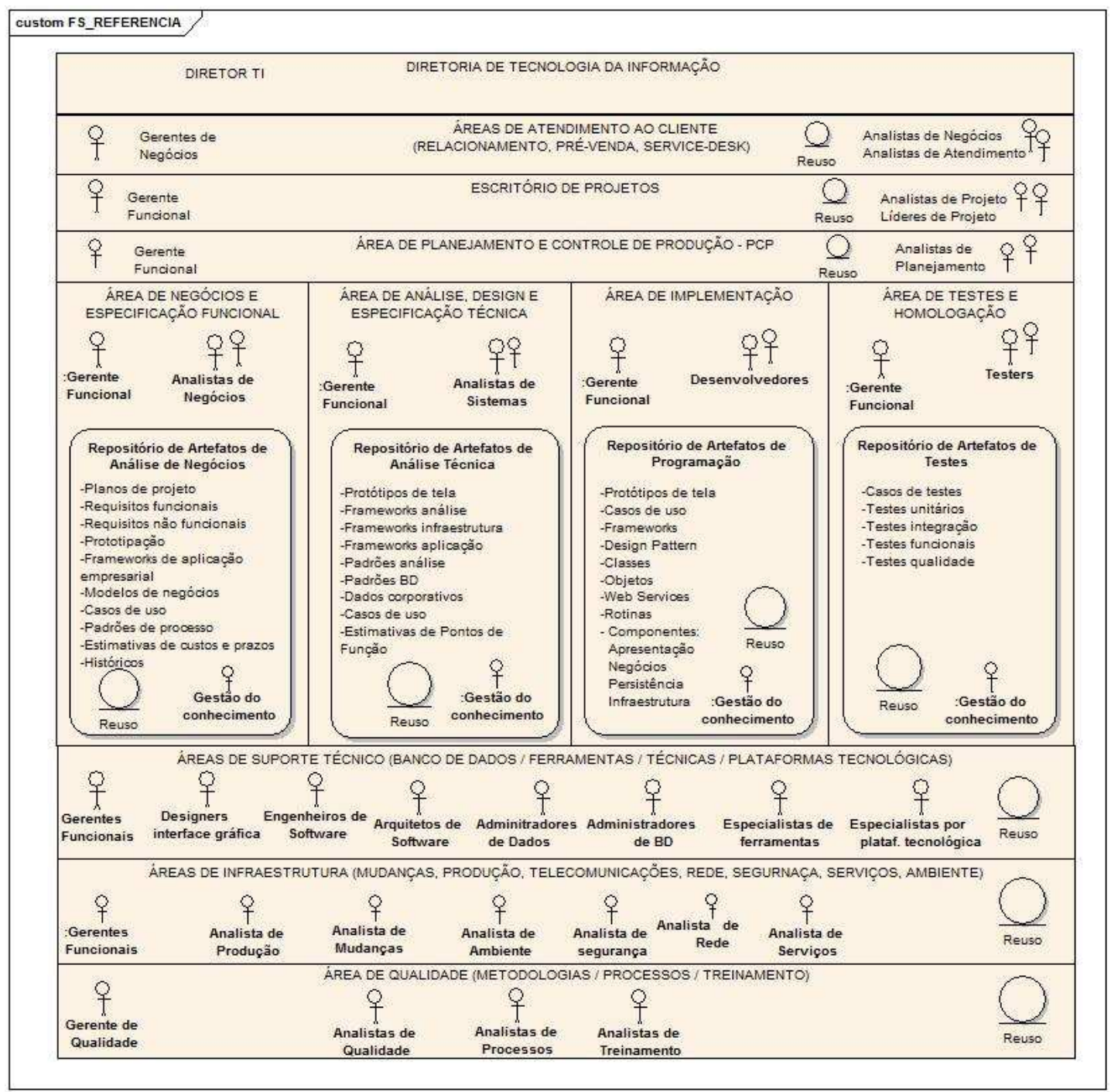

Figura 18 - Estrutura Organizacional de Referência de Fábrica de Software Fonte: elaborada pela autora

Os repositórios de artefatos de reuso, representados na Figura 18, simbolizam as bases de experiências, de acordo com as idéias de BASILI et al. (1992) e PRESSMAN (2002), que incentivam a cultura do reuso para estabelecer a gestão do conhecimento e garantir a uniformidade e integração no âmbito da Fábrica de Software. Os repositórios de reuso comportam artefatos como frameworks, padrões, componentes, arquiteturas e artefatos e processos reusáveis, de acordo com os estudos efetuados na Seção 2.4.

Em relação ao modelo matricial, VASCONCELLOS (1989) aponta que, neste modelo, o especialista tem compromissos funcionais em seu departamento e, ao mesmo tempo, está envolvido em um ou mais projetos. Cada área oferece, por meio 
de seus especialistas, determinada contribuição para a realização dos projetos. Assim, enquanto a organização funcional e as áreas de suporte favorecem a especialização e a acumulação e disseminação de conhecimentos, a organização por projetos favorece a orientação para algum tipo de resultado ou problema a ser resolvido.

De maneira resumida, a estrutura organizacional da FS possui áreas com as seguintes funções: a área de Atendimento ao Cliente negocia e especifica as necessidades da área usuária. A área de Planejamento e Controle de Produção aloca os recursos a serem utilizados, controla e distribui as ordens de serviços. O Escritório de Projetos define e orienta o uso de metodologias de gestão de projetos e efetua controle da carteira de projetos. A área de Negócios faz a visão do negócio, modelagem dos processos, e o levantamento e especificação de regras de negócios, requisitos funcionais e não funcionais. A área de Análise e Design faz a especificação técnica, arquitetura, integração e montagem do sistema. A área de Implementação codifica os módulos, programas e componentes da aplicação. A área de Testes homologa o produto final verificando se atende às especificações exigidas. A área de Suporte Técnico dá apoio às áreas de desenvolvimento, por meio de especialistas. A área de Infra-Estrutura fornece e mantém o ambiente tecnológico necessário para o desenvolvimento, homologação e implantação das aplicações. A área de Qualidade é responsável pelo acompanhamento dos processos, metodologias de desenvolvimento de software e garantia da qualidade.

A seguir, são apresentadas as descrições das atribuições de cada área funcional da FS.

\section{1. Área de Atendimento ao Cliente, Pré-Venda e Service-Desk}

O objetivo do Atendimento ao Cliente é negociar e caracterizar a solicitação da forma mais completa possível, definindo um documento Visão e Escopo do Projeto que contemple: plano de comunicação, risco, qualidade, custos, prazos e escopo do projeto (RUP, 2003).

A área de Pré-Venda é responsável pelo relacionamento com o cliente, comercialização e marketing dos produtos oferecidos, bem como captar os anseios do cliente.

O Service Desk é a unidade que centraliza e atende usuários e clientes em relação a reclamações, sugestões e solicitações de modificações e manutenções em sistemas 
existentes e serviços, direcionando as mesmas aos responsáveis, de acordo com os processos estabelecidos.

\section{Escritório de Projetos}

Segundo o PMBOK (2004), um Escritório de Projetos (Project Management Office PMO) é uma unidade organizacional que centraliza e coordena o gerenciamento de projetos sob seu domínio. Um PMO também pode ser chamado de "escritório de gerenciamento de programas", "escritório de gerenciamento de projetos", "suporte às práticas de projeto" ou "escritório de programas".

O PMO concentra-se no planejamento, na priorização e na execução coordenada de projetos e subprojetos, vinculados aos objetivos gerais de negócios da matriz ou do cliente. Supervisiona o gerenciamento de projetos, programas ou uma combinação dos dois, coordenam e gerenciam projetos relacionados.

Os PMO podem operar de modo contínuo, desde o fornecimento de funções de apoio ao gerenciamento de projetos na forma de treinamento, software, políticas padronizadas e procedimentos, até o gerenciamento direto real e a responsabilidade pela realização dos objetivos do projeto.

Assim um PMO específico pode receber uma autoridade delegada para atuar como parte interessada integral e um importante tocador de decisões durante o estágio de iniciação de cada projeto, pode ter autoridade para fazer recomendações ou pode encerrar projetos para manter a consistência dos objetivos de negócios. Além disso, pode estar envolvido na seleção, gerenciamento e realocação, se necessário, do pessoal compartilhado do projeto e, quando possível, do pessoal dedicado do projeto.

\section{3. Área de Planejamento e Controle de Produção (PCP)}

As principais tarefas da área de PCP de uma Fábrica de Software são:

- Elaborar o plano de produção da Fábrica de Software;

- Encaminhar as ordens de serviço para a produção;

- Determinar cancelamentos e suspensões de ordens de serviço;

- Controlar a execução das ordens de serviço;

- Determinar a necessidade de horas extras dos recursos humanos;

- Avaliar desvios das estimativas do planejamento, registrar essa informação e disponibilizar para o planejamento e para a gestão da demanda; 
- Reprogramar o plano da produção quando há atrasos na execução das ordens de serviços; e

- Autorizar início de execução de ordens de serviço. (FERNANDES e TEIXEIRA, 2004)

\section{4. Área de Negócios e Especificação Funcional}

Faz parte desta área a modelagem de processos de negócios do cliente, que consiste em entender a estrutura e a dinâmica da organização à qual o software será entregue; identificar problemas correntes na organização e possíveis aperfeiçoamentos; assegurar que o cliente, o usuário final e os desenvolvedores possuam a mesma compreensão da empresa ou organização; produzir os requisitos de software necessários para suportar os objetivos da organização (KRUCHTEN, 2003).

Segundo o autor citado o levantamento de requisitos funcionais e não funcionais comumente realizados por analistas de negócios, consiste em estabelecer e manter o consentimento entre clientes e stakeholders sobre o que o software deve fazer; fornecer uma melhor compreensão dos requisitos aos arquitetos e desenvolvedores de software; definir os limites do software; fornecer as bases para o planejamento das iterações, estimativa de custo e tempo de desenvolvimento; definir as interfaces do software com base nas necessidades e objetivos dos usuários.

\section{5. Área de Análise e Design}

KRUCHTEN (2003) relaciona as seguintes atividades para esta área ou disciplina:

- Transformar os requisitos dentro de um design do que será o software;

- Desenvolver uma arquitetura para o software; e

- Adaptar o design para aspectos de desempenho.

A especificação técnica, comumente realizada por analistas de sistemas, com os especialistas da área de suporte técnico, como AD's (Administradores de Dados), DBA's (Administradores de Banco de Dados), arquitetos de software, engenheiros de software, analistas de infra-estrutura e especialistas de ferramentas e plataformas tecnológicas envolvem as atividades:

- Análise, modelagem e arquitetura do sistema, usando diagramas UML como: diagramas de casos de uso, classes, componentes, seqüência, atividades voltados para ambientes em baixa plataforma. Para ambientes em mainframe, os 
diagramas comumente referem-se à análise estruturada ou essencial, como diagramas de contexto, diagramas de fluxos de dados (DFD's) e fluxogramas;

- Prototipação de telas, relatórios e documentos (com o apoio de designers de interface gráfica);

- Especificação do sistema e programas ou casos de uso;

- Análise de reuso de artefatos de software (com o apoio de analistas de domínio);

- Modelagem lógica e física de dados, gerando o Modelo Entidade Relacionamento (MER) e o Dicionário de Dados (com o apoio de administradores de dados (AD's) e administradores de banco de dados (DBA's); e

- Análise de Pontos de Função (APF) (com o apoio de especialistas em cálculo de Pontos de Função).

\section{6. Área de Implementação ou Codificação}

KRUCHTEN (2003) relaciona as seguintes atividades para a área ou disciplina de implementação:

- Preparar a organização do código em termos de implementação de subsistemas, organizados em camadas (layers);

- Implementar classes e objetos em termos de componentes (código fonte, binários, executáveis, etc), de acordo com a análise orientada a objetos. Para sistemas em mainframe, implementar os programas ou rotinas de acordo com a análise estruturada ou essencial;

- Testar os componentes desenvolvidos como unidades; e

- Integrar os resultados obtidos por desenvolvedores individuais (ou em equipes) em um sistema executável.

\section{7. Área de Testes e Homologação}

KRUCHTEN (2003) relaciona as seguintes atividades para a área ou disciplina de testes:

- Verificar a interação entre os objetos;

- Verificar a integração de todos os componentes de software;

- Verificar se todos os requisitos foram implementados corretamente;

- Verificar os defeitos e assegurar que eles sejam tratados antes da entrega do software. 
O produto é testado de uma forma integrada (analista de negócios, analista de sistemas, clientes, stakeholders), identificando possíveis erros antes da entrega do produto final.

Ao final dos testes, o produto é homologado e empacotado de acordo com os padrões estabelecidos, sendo instalado nos servidores e ativado em produção. Durante algum tempo, uma equipe de suporte ao cliente estará ativa até que o sistema fique estável.

\section{8. Área de Suporte Técnico}

A área de Suporte Técnico é composta de profissionais para atividades de apoio ou especialistas em diferentes expertises, com o objetivo de prover o auxílio nas atividades de desenvolvimento de software. A participação do suporte dos especialistas é essencial para incentivar a padronização e reuso de artefatos, métodos, técnicas e ferramentas. As atividades de suporte podem compreender:

- Modelagem de Dados e criação de Banco de Dados (AD's - Administradores de Dados e DBA's - Administradores de Banco de Dados);

- Análise de Pontos de Função ou Pontos de Casos de Uso (especialista de APF ou $\mathrm{UCP})$;

- Padrões para Prototipação de interfaces gráficas (designers de interface, analistas de multimídia);

- Frameworks ou arquiteturas de sistemas e programas (arquitetos de software); e

- Especialistas de ferramentas por plataforma tecnológica (mainframe, plataforma baixa, cliente servidor, web, sistemas integrados, sistemas distribuídos).

\section{9. Área de Infra- Estrutura, Ambiente e Produção}

A área de Infra-Estrutura é responsável pelo suporte em relação a todos os recursos de hardware, software e serviços necessários à execução dos processos de produção. No RUP (2003), a disciplina denominada “Ambiente" é definida com os objetivos:

- Manter o foco nas atividades necessárias para configurar o processo para o projeto;

- Descrever as atividades requeridas para desenvolver as diretrizes básicas para suporte ao projeto; e

- Fornecer para a organização de desenvolvimento de software, o ambiente de processos e ferramentas que suportarão a equipe de desenvolvimento, homologação e instalação do software. 
A área de Infra-Estrutura pode compreender as unidades: gestão de mudanças, gestão de produção, gestão de telecomunicações, rede, segurança e gestão de serviços. Segundo o ITIL (2005), a gestão de mudanças tem como objetivo controlar todas as mudanças que possam causar impacto na habilidade da área de TI em entregar serviços, por meio de um processo único e centralizado de aprovação, programação e controle de mudanças, para assegurar que a infra-estrutura de TI permaneça alinhada aos requisitos dos negócios com o menor risco possível.

Segundo FERNANDES e TEIXEIRA (2004), a Gestão da Configuração deve controlar as versões dos itens de software de cada ordem de serviço e componentes reusáveis que possam ser utilizados por todas as ordens de serviço. Itens de software são programas de computador, ordens de serviço, documentos de especificação lógica e física de projetos, procedimentos documentados, planos de projetos, etc.

KRUCHTEN (2003) relaciona as seguintes atividades para a disciplina de Gestão de Mudança e Configuração:

- Identificar itens de configuração;

- Restringir configurações para os itens identificados;

- Auditar as alterações feitas nos itens identificados; e

- Definir e gerenciar as alterações dos itens identificados.

\section{0. Área de Qualidade}

A área de Qualidade está voltada à qualidade do processo, tendo como atribuições: customização do processo organizacional para os projetos; orientação das equipes; avaliação periódica do uso do processo customizado; levantamento e acompanhamento da resolução de não conformidades e conflitos; levantamentos de oportunidades de melhorias técnicas e de processos; coleta de medidas e disponibilização das medições.

\subsubsection{Modelo Dinâmico de Referência de FS}

Segundo FERNANDES e TEIXEIRA (2004), a abordagem de trabalho em equipe é fundamental para a qualidade da operação de software, devendo ter mais intensidade, no contexto de desenvolvimento e manutenção. Na organização do trabalho, o principal desafio está na gestão do conhecimento: transformar o conhecimento tácito em explícito, ou seja, disseminar e documentar o conhecimento (relacionados a negócios, técnicas, metodologias, processos, hardware, software, etc.). Segundo os 
autores, a indisponibilidade desse tipo de conhecimento é um dos fatores de maior impacto na produtividade e flexibilidade de uma operação de software.

Nesta parte do trabalho, é proposto um modelo de funcionamento, embasado no entendimento dos tipos de organização do trabalho existente em uma FS. Com base no modelo de organização do trabalho por equipes multifuncionais, Engenharia Simultânea e no contexto da Estrutura Organizacional de Referência de FS, que infere em um modelo matricial, é proposto o Modelo Dinâmico de Referência de FS mostrado na Figura 19.

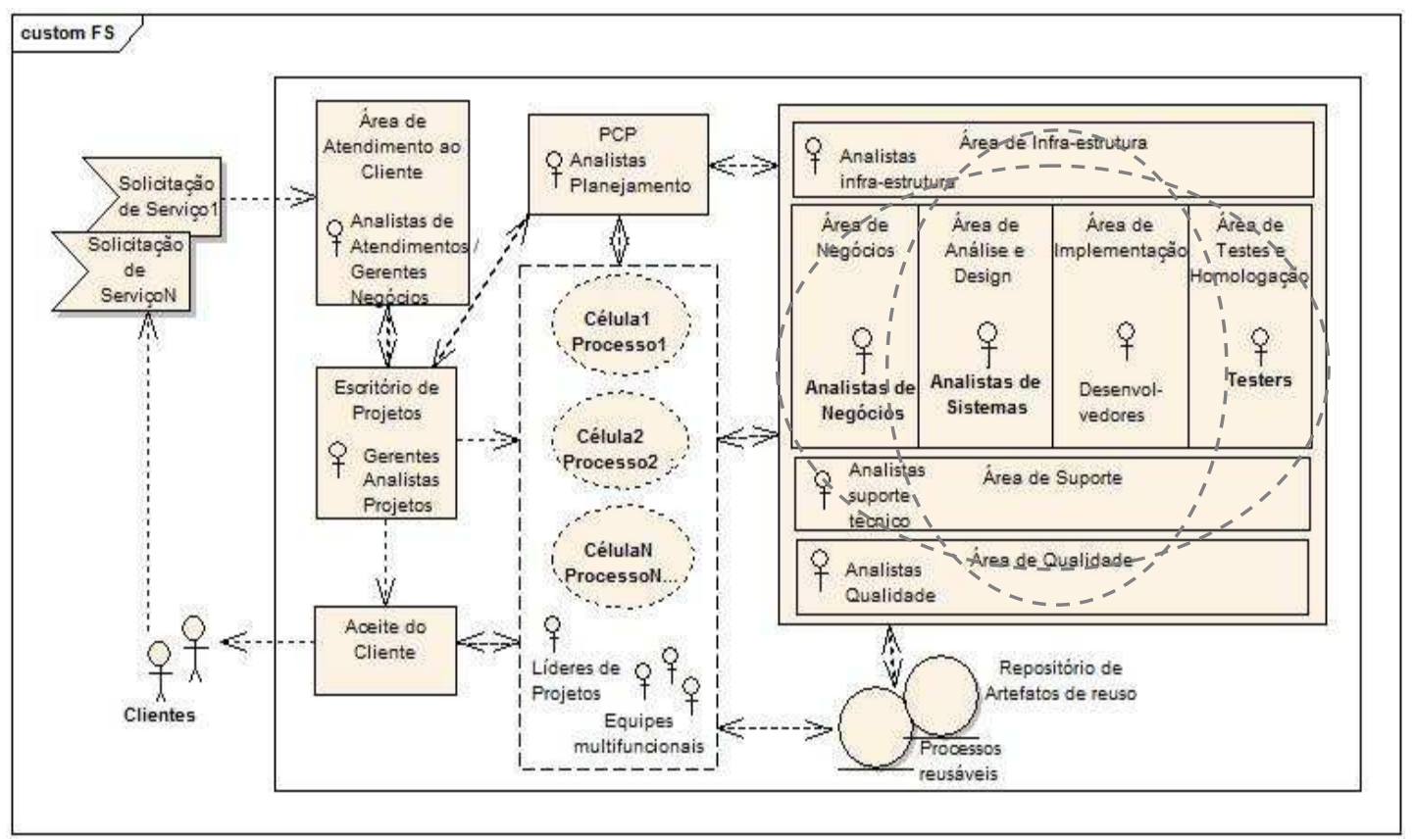

Figura 19- Modelo Dinâmico de Referência para Fábrica de Software Fonte: elaborada pela autora

De forma sintetizada, para o funcionamento da FS, é proposto o seguinte fluxo: os analistas de atendimento ao cliente elaboram um documento relativo à demanda do serviço com acompanhamento do Escritório de Projetos. A Ordem de Serviço (OS) é encaminhada para a área de Planejamento e Controle de Produção (PCP) onde é efetuado o registro desta solicitação. O PCP, com os gerentes das áreas funcionais envolvidas, aloca os recursos necessários, analisando a disponibilidade e adequação dos perfis de competências dos profissionais.

A alocação dos recursos pode ser de uma equipe multifuncional ou de um profissional específico, dependendo da categoria de serviço solicitado. Para o desenvolvimento de projetos novos, em geral, segue-se o fluxo do Processo-Padrão 
de Desenvolvimento, ou seja, forma-se a célula (equipe) de trabalho com analistas de negócios que fazem a visão e escopo do projeto, a modelagem dos processos de negócios e o levantamento de regras de negócios, requisitos funcionais e não funcionais. Analistas de sistemas responsáveis pela arquitetura e modelagem do sistema, classes, dados e as especificações técnicas dos casos de uso, programas, módulos ou componentes. Desenvolvedores responsáveis pela codificação das aplicações e testes unitários. Testers que executam testes integrados de qualidade para homologação do produto final, tendo como guia as especificações, casos de testes e planos de testes.

Se forem detectados erros, as equipes de análise e desenvolvimento irão saná-los, reiniciando o ciclo de testes. Ao final do processo, com a aprovação do cliente, o sistema está homologado e liberado para implantação no ambiente de produção, permitindo a realização de um piloto até sua completa estabilização. Em seguida, efetiva-se a entrada do sistema em produção, acompanhado da documentação e treinamento com todos os aspectos de operação e administração do sistema. $\mathrm{Na}$ conclusão do trabalho, os recursos são retornados às suas unidades de origem.

O tamanho ou grau de complexidade da demanda solicitada pelo cliente categoriza o tipo de solicitação de serviço e, conseqüentemente, a organização do trabalho associado ao fluxo do processo correspondente. O Modelo proposto reflete a organização do trabalho para projetos que justifiquem a formação de uma célula de trabalho multifuncional. Neste caso, adéqua-se a projetos complexos, médios, grandes ou novos. Como estes tipos de projetos, normalmente são os mais completos, ou seja, englobam todas as fases do ciclo de vida do software, adotou-se a denominação "Modelo Dinâmico de Referência de FS".

No caso de manutenções de sistemas legados, por exemplo, existe a tendência do trabalho ficar a cargo de um analista especialista do sistema; desta forma, não há necessidade de criação de células de trabalho. Assim, o PCP direciona o trabalho ao recurso competente específico.

\subsection{Fase 4 - Avaliação}

A avaliação da Estrutura Organizacional 1, mostra como ponto crítico principal a verticalização da estrutura, o que dificultava a integração e reuso de soluções, causando redundância e retrabalho. Normalmente um único analista era responsável 
por todas as etapas do processo, isto é o domínio técnico e de negócios tornava-se propriedade do "analista do sistema", em lugar de permanecer no âmbito corporativo.

A avaliação da Estrutura Organizacional 2 mostra uma estrutura mais flexível, voltada à organização do trabalho por equipes de projetos, apoiada por áreas de suporte ao desenvolvimento. O diferencial desta estrutura estava no departamento de desenvolvimento de sistemas, composta entre outras da área de Arquitetura que oferecia suporte à metodologia de desenvolvimento de sistemas; área de Engenharia, responsável pela codificação e repositório de componentes; e a área de Testes de qualidade do produto.

A Estrutura Organizacional 3 infere em um modelo matricial, mostra o agrupamento de especialistas e funções que permite obter o estabelecimento da gestão do conhecimento técnico e de negócios, facilitando o compartilhamento dos recursos especializados e permitindo a geração dos repositórios de reuso de artefatos, componentes e processos de forma mais organizada e controlada. Esta estrutura serviu como base para a criação da Estrutura Organizacional de Referência de FS e o Modelo Dinâmico de Referência de FS.

\subsection{Fase 5 - Resultados}

A Estrutura Organizacional 3, assim como a Estrutura Organizacional de Referência de FS, baseadas no Modelo Matricial possibilitam criar ambientes com as seguintes características:

- Facilidade na padronização e uniformização dos processos e serviços;

- Facilidade na criação de padrões, frameworks, reuso de artefatos e sistemas corporativos por meio de áreas e processos especializados;

- Melhorias no controle, acompanhamento e medição de processos e produtos;

- Flexibilidade e democratização no aproveitamento dos recursos; e

- Flexibilidade e melhoria nas atividades de terceirização.

No entanto, existem desafios a serem enfrentados como:

- Os profissionais precisam ter mais competências, capacitação e flexibilidade;

- Maior complexidade na gestão de projetos e integração dos processos interfuncionais;

- Conflito entre as áreas funcionais e duplicidade de supervisão; e 
- Os resultados são alcançados de médio a longo prazos.

$\mathrm{Na}$ transição da Estrutura Organizacional 2 para o novo modelo - Estrutura Organizacional 3, os seguintes pontos foram identificados como fatores importantes a serem considerados para efetivar concretamente a mudança:

- Capacitação gerencial e técnica;

- Mudança da cultura organizacional;

- Eficiência e eficácia operacional;

- Gestão de operações;

- Gestão do conhecimento;

- Inovação tecnológica; e

- Apoio e patrocínio da alta direção.

No Modelo Dinâmico de Referência de FS, observa-se que o modelo matricial permite organizar o trabalho em equipes agrupadas por projetos, o que facilita a gestão do projeto. Como um projeto tem começo, meio e fim, esta forma de trabalho pode ser caracterizada como uma estrutura matricial mutante, cujos recursos são devolvidos às áreas funcionais ao término do trabalho. No caso de manutenção de sistemas de software, pode-se trabalhar com uma estrutura matricial permanente, em que as interdependências permanecem mais ou menos estáveis. 


\section{CICLO 2 - MAPEAMENTO, DEFINIÇÃO E ESTABELECIMENTO DOS PROCESSOS}

O Ciclo 2 representa o cerne da PA e abrangeu o período de janeiro de 2006 a dezembro de 2006. Este ciclo busca a definição de processos corporativos e funcionais, de forma a garantir que toda a estrutura operacional da EmpresaTI esteja baseada em modelos de trabalho, e formalização dos processos, e não em ilhas isoladas de organização. A adoção de padrões corporativos garante que uma determinada inovação ou aperfeiçoamento metodológico seja aplicado em todas as unidades operacionais, viabilizando a melhoria contínua ao longo prazo.

\subsection{Fase 1 - Diagnóstico}

Neste ciclo inicialmente foram efetuados o levantamento e a análise do histórico das metodologias de desenvolvimento de sistemas anteriormente adotadas na EmpresaTI, a fim de entender suas principais características e os problemas enfrentados. Este levantamento realizou-se com base nas entrevistas, dados de documentações e observações.

\subsubsection{Análise das Metodologias de Desenvolvimento de Sistemas}

\section{Metodologia 1}

A metodologia de desenvolvimento de sistemas existente por volta do ano de 1995, denominada MDSP, tinha as seguintes características: metodologia estruturada; orientada a projetos; ciclo de vida cascata e espiral; documentação tradicional. Foi implementada pelo apoio de uma empresa externa de consultoria, com acompanhamento de projetos piloto e vingou durante o tempo em que os sistemas e os ambientes tecnológicos ainda se mantinham estáveis. Em razão das constantes mudanças tanto internas como externas e pelo rápido avanço tecnológico, a metodologia no decorrer do tempo descaracterizou-se.

\section{Metodologia 2}

Em 2002, foi proposto pela área de Desenvolvimento e Tecnologia da EmpresaTI com o CMI - Conselho Municipal de Informática, um conjunto de conceitos de arquitetura de software, sob a forma de diretrizes tecnológicas, o que culminou em sua publicação, estabelecida por Decreto (CMI, 2002), no Diário Oficial do Município. Conseqüentemente, foi criada uma metodologia de desenvolvimento de sistemas denominada DGSI - Disciplina de Gestão de Soluções Informatizadas. Esta 
metodologia pregava um conjunto de referências técnicas para orientar os processos de fabricação de software, baseada na MSF (Microsoft Solutions Framework), PMBOK, RUP e CMM; orientada a projetos; modelo de equipe que estabelecia o plano de trabalho; modelo de processo que determinava as fases do projeto; referências para processos de terceirização; vasta documentação em UML, e com suporte de uma área denominada Divisão de Arquitetura. Na época adotava-se a Estrutura Organizacional 2 (Seção 5.1.1), e ainda permaneciam os focos de trabalho, em que a inteligência e o conhecimento dos negócios e a tecnologia concentravam-se nas pessoas.

Embora esta metodologia tenha sido consistente e abrangente, em razão da dissolução da área responsável, provocada por mudanças organizacionais no ano de 2005, ela foi descontinuada.

\section{Metodologia 3}

A partir do $2^{\circ}$ semestre de 2005 , ocorreram relevantes mudanças na estrutura organizacional da EmpresaTI. Na ocasião, um Comitê de Tecnologia, formado por analistas e assessores da área de desenvolvimento, iniciou a concepção de uma nova Metodologia de Desenvolvimento de Sistemas (MDS), considerando a metodologia anterior DGSI. A MDS contemplava um workflow único do processo, para projeto de sistema novo, considerando a interface de todas as áreas funcionais envolvidas e artefatos e templates baseados em UML, Metodologia Estruturada e Orientada a Objetos. Em razão de novas mudanças na estrutura organizacional e novas regras de negócios, o Comitê extinguiu-se, e por não haver uma área específica ou um grupo permanente de suporte à metodologia, esta foi interrompida.

\section{Metodologia 4}

No início de 2006 a autora deste trabalho, como funcionária regular da EmpresaTI, atuava na Gerência de Análise e Design (Estrutura Organizacional 3 - Seção 5.1.1), e com mais uma analista de Metodologia eram as responsáveis por revisar os artefatos e templates; atualizar o workflow; dar suporte ao desenvolvimento e dar continuidade à Metodologia MDS anteriormente interrompida.

Em junho de 2006, foi solicitada pela alta direção da empresa uma série de projetos que faziam parte do escopo do planejamento estratégico anual. Um desses projetos referia-se ao desenvolvimento, adequação e implantação da Metodologia de 
Desenvolvimento de Sistemas, desta vez, formando um grupo de trabalho multidisciplinar para o desenvolvimento do projeto. Tinha como objetivo o mapeamento dos principais processos de negócios, alinhados à nova estrutura organizacional da EmpresaTI (Estrutura Organizacional 3), ou seja, fazia-se necessário mapear todos os processos interfuncionais, definindo claramente os links entre as áreas da EmpresaTI, definindo clientes, fornecedores e artefatos de entrada e saída, abrangendo tanto os aspectos de sistemas de produção como os de Engenharia de Software e processos de terceirização devidamente adaptados ao ambiente e cultura da organização. Neste contexto, posteriormente o projeto passou a denominar-se "Metodologia de Desenvolvimento de Sistemas e Integração" - MDSI. No projeto, a autora atuou na área de Racionalização de Processos com competências de analista de processos, analista de sistemas e, sobretudo pesquisadora, executando o projeto com as equipes multidisciplinares, constituindo-se no objeto principal de pesquisa deste trabalho, com a permissão e apoio da alta-direção vigente na época.

\subsection{Fase 2 - Planejamento}

O projeto MDSI - Metodologia de Desenvolvimento de Sistemas e Integração obteve o apoio da Diretoria de Desenvolvimento e a participação das áreas: Racionalização de Processos; Tecnologia; Relacionamento; Análise e Design; Fábrica (Codificação); Testes do Produto; Escritório de Projetos; Planejamento e Controle; e a Diretoria de Infra-Estrutura com as gerências de Produção, Mudanças e Rede.

Para o desenvolvimento e execução do projeto, foi constituído um grupo de trabalho fixo com quatro profissionais: um assessor e uma analista da área de tecnologia, um analista da área de processos e a autora do presente trabalho.

No decorrer do projeto foram formados grupos multidisciplinares de trabalho temporários e rotativos com profissionais das áreas envolvidas, assim como foram realizadas reuniões para validação dos fluxos com cada um dos gerentes das áreas envolvidas.

O cronograma de planejamento do Projeto MDSI ficou estabelecido para o período de julho de 2006 a dezembro de 2006 e englobou as seguintes fases e atividades:

- Levantamento e análise das:

- Atribuições de cada gerência envolvida;

- Papéis e responsabilidades; 
- Atividades que compõem os processos;

- Artefatos e templates;

- Técnicas e ferramentas;

- Normas e regras;

- Ações para a análise e diagnósticos nos processos:

- Identificar e priorizar os problemas;

- Identificar e priorizar as causas;

- Identificar e priorizar soluções;

- Desenvolver soluções;

- Elaboração do mapeamento dos fluxos:

- Proposta de Projeto, Projeto Novo e Projeto de Melhorias;

- Manutenção Evolutiva, Adaptativa;

- Manutenção Emergencial: Corretiva e Abend (Abnormal End).

- Integração entre as áreas funcionais;

- Integração com a Metodologia de Gestão de Projetos (baseada no PMBOK);

- Integração com processos da Infra-Estrutura (com processos do ITIL);

- Integração com o Planejamento e Controle de Produção;

- Integração com processos de terceirização;

- Validação dos fluxos junto às gerências envolvidas;

- Revisão e definição dos artefatos e templates junto ao pessoal técnico;

- Elaboração do Manual de utilização e Documentação da MDSI; e

- Publicação, Divulgação e Instituição da MDSI.

As etapas que compõem o planejamento para o mapeamento e definição de processos apoiaram-se no conceito de definição de processos de SLACK et al. (1996), que compreendem as seguintes atividades:

- Estudo do método de trabalho atual: registro do método atual de execução do trabalho, exame sistemático do trabalho, desenvolvimento de um novo método com base nas críticas surgidas;

- Projeto do trabalho: alocação do trabalho para cada pessoa na organização, definição do grau de autonomia e responsabilidade, especificação da seqüência e local de realização do trabalho; 
- Divisão do trabalho: divisão de uma determinada tarefa em tantas partes quantas sejam convenientes para que cada indivíduo a execute de forma correta e eficaz. Para tanto, leva em consideração a especialização e competências das pessoas, as práticas de reuso e, também, o melhor aproveitamento dos recursos;

- Design do processo: definição do fluxo das atividades do processo, considerando as regras de precedência e dependência e gerando o fluxo específico.

A Figura 20 mostra a seqüência de atividades para o mapeamento e definição dos processos.

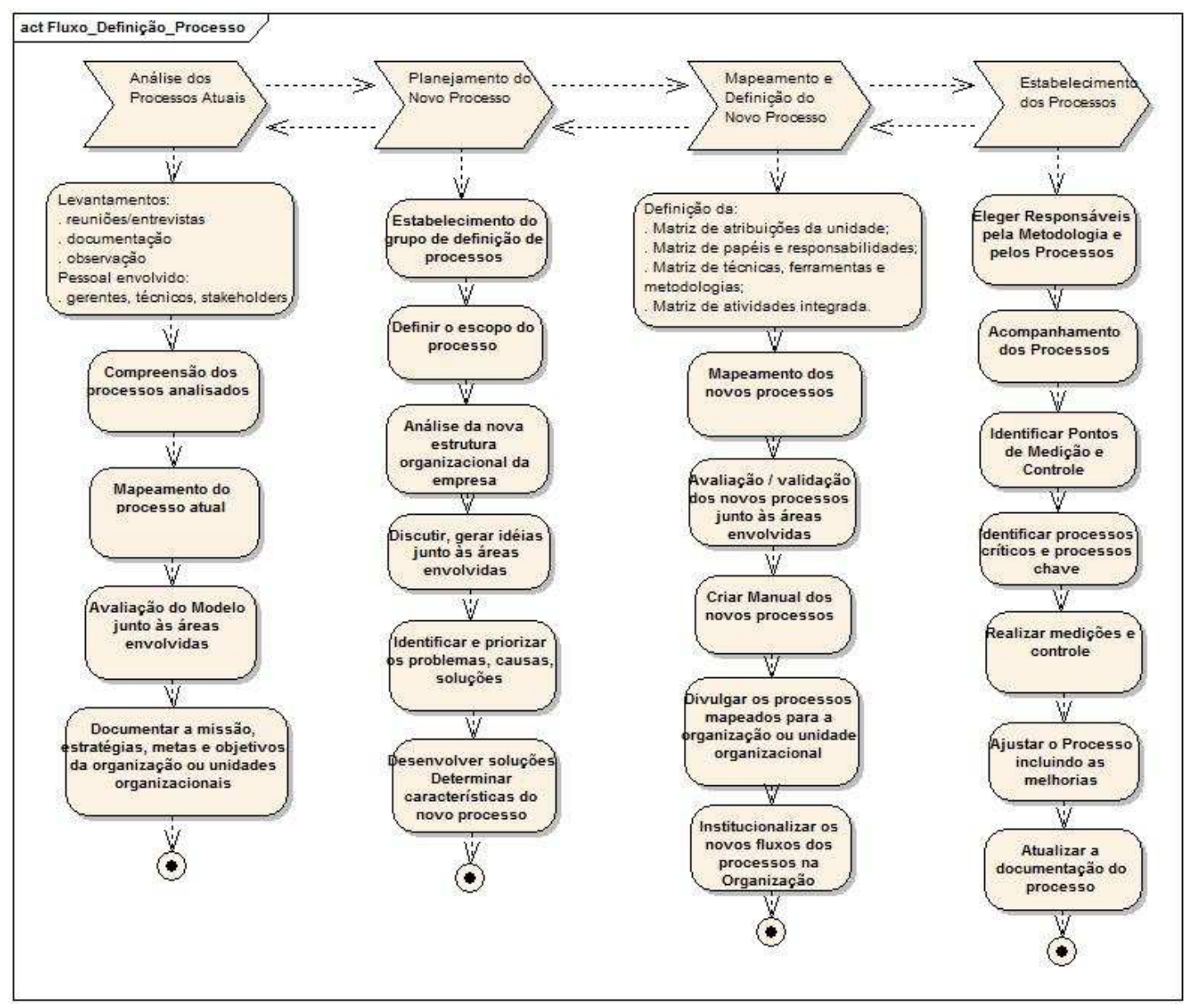

Figura 20 - Fluxo de Definição de Processos

Fonte: baseado em SLACK et al. (1996)

Conforme pontua VERNADAT (1996), o escopo da modelagem de empresas, é basicamente definido pelas respostas às perguntas "o quê", "como", "quando", "quem" e "onde". Respondendo "o que é" ou "o que deve ser feito", são descritos os aspectos funcionais da empresa. "O que" refere-se também ao aspecto informacional, ou seja, quais dados são usados ou produzidos e qual seu relacionamento. "Como" e 
"quando" referem-se aos aspectos do comportamento dinâmico do sistema, integrando ao modelo o importante aspecto do tempo. Por fim, deve-se responder “quem” é responsável por quais funções, conferindo uma dimensão organizacional ao modelo, mas também qualificando o local no qual as funções são executadas.

O Modelo de Processos de Negócio de uma organização representa a forma como os processos são executados na vida real, pois representa a visão do processo atual, denominado as-is, em contraponto com o modelo to-be, que reflete alterações futuras aos processos, implementáveis ou não, que resultam da análise dos processos de negócio em processos de TQM - Total Quality Management (DAVENPORT, 1994). O modelo de processos de negócio as-is é uma representação abstrata da organização no presente, incluindo sua estrutura, seu relacionamento com o exterior, seus fluxos de trabalho, sistemas de informação e as máquinas que suportam a execução dos processos.

O modelo de processos de negócio as-is tem como objetivos gerais:

- Servir de base para melhoria dos processos;

- Servir de base para inovação dos processos;

- Servir de ponto de partida para construção de uma arquitetura de sistemas de informação;

- Servir de ponto de partida para captura de requisitos para o desenvolvimento de sistemas de informação;

- Servir como repositório de conhecimento comum da organização.

O repositório de conhecimento sobre o processo mapeado pode trazer as seguintes vantagens:

- Aumentar o conhecimento do que cada um faz, como parte do todo organizacional;

- Facilitar a comunicação por permitir focar "o ponto de vista certo";

- Tornar toda a organização explícita;

- Servir como base para instituir normas e modelos de qualidade;

- Servir como base documental para a gestão da qualidade;

- Definir objetivos para todos os processos;

- Clarear quem são os atores dos processos pela identificação do relacionamento fornecedor / cliente; 
- Identificar a contribuição dos recursos envolvidos; e

- Clarear quais fatores internos ou externos influenciam o processo.

\subsection{Fase 3.1 - Execução: Construção dos Modelos}

Esta fase trata da construção dos Modelos para Definição dos Processos da FS. Para um melhor entendimento dos processos, foi feito um estudo sobre como analisar, mapear e definir os processos organizacionais de FS, sob diferentes visões, o que originou a Arquitetura de Definição de Processos, o Modelo de Definição de Processos, e o Diagrama de Representação para Modelagem dos Processos.

GONÇALVES (2000) ressalta que "as empresas são grandes coleções de processos". Para o autor, a definição dos processos na empresa é essencialmente dinâmica, mudando com o tempo. Novos componentes vão sendo adicionados e outros adaptados à medida que o ambiente muda, a empresa cresce e o conhecimento especializado desenvolve-se. O funcionamento do processo precisa, então, ser adaptado, de modo que possa se adequar à nova situação.

Esta constatação justifica a importância do conhecimento detalhado de todos os elementos necessários ao entendimento e mapeamento dos processos, na tentativa de adequá-los estrategicamente às mudanças organizacionais. A seguir é mostrado o entendimento desta "coleção de processos" por meio de diferentes abordagens de análise dos processos.

\section{Visão Funcional $x$ Visão por Processos}

Conhecer os processos de uma organização significa conhecer como os produtos e serviços são planejados, produzidos e entregues. Segundo CAMEIRA e CAULLIRAUX (2000), um ponto importante no mapeamento de processos refere-se à questão da visão funcional (visão vertical) versus a visão por processos (horizontal). A visão horizontal possibilita a quebra de barreiras funcionais, permitindo tratar processualmente os fluxos de informações, promovendo um encadeamento das funções de uma empresa e realizando o link das atividades em relação aos processos (Figura 21).

Conforme DAVENPORT e PRUSAK (1998), um dos fatores relevantes que se deve ter em mente quando se realizam processos de levantamento e modelagem de processos, é o entendimento dos fluxos transversais de informação. 


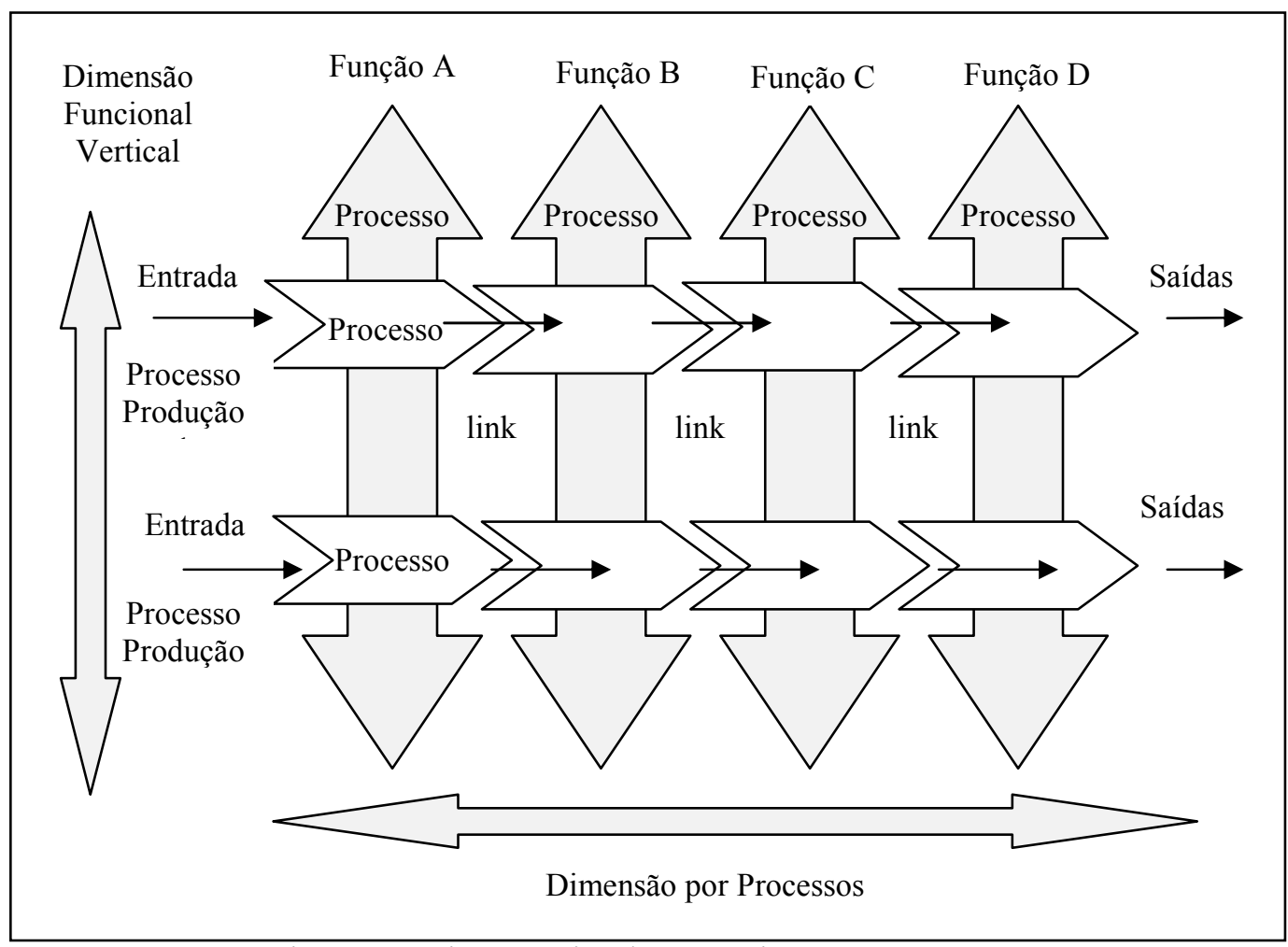

Figura 21 - Visão Funcional versus Visão por Processos

Fonte: adaptado de FIORINI (1998)

Segundo FIORINI et al. (1998), no gerenciamento com uma visão funcional, cada pessoa vê apenas sua parte no processo. Existe pouca comunicação entre os envolvidos no processo, fazendo com que as ligações (links) entre uma parte e outra do processo sejam ignoradas, limitando-se apenas a uma troca de produtos. Entretanto, geralmente, nessas ligações concentra-se a maior parte dos problemas relacionados à

otimização do processo. Outra decorrência dessa visão são os conflitos comuns com relação à priorização de funções ou áreas. $\mathrm{Na}$ visão por processos, estes são definidos e discutidos por todos os envolvidos; por exemplo, clientes e fornecedores internos, numa tentativa de melhorar as ligações, retiram o que não agrega valor ao negócio.

Dessa forma, todos os envolvidos passam a ter uma visão única de como o processo "flui" na organização; entendem por que o trabalho de cada um é importante no que se refere aos objetivos do processo e melhoram a comunicação. Todos os participantes passam a falar a linguagem do processo estabelecido, melhorando o relacionamento cliente/fornecedor interno. Ressalta-se que, a partir da definição do processo, é possível definir-se medições e coletar dados de execução. Isto dá 
visibilidade aos gerentes e técnicos sobre o andamento do projeto e dos processos por ele utilizados. Uma vez definido os processos e estabelecido o treinamento, o processo fluirá por si só, sem depender de pessoas-chave, ou seja, quando uma pessoa sai, outra poderá assumir seu lugar, guiando-se por este processo.

\section{Visão Top-Down x Visão Bottom-Up}

Outra abordagem de mapeamento de processos é a lógica top-down e bottom-up. Conforme CAMEIRA e CAULLIRAUX (2000) na lógica top-down o levantamento e a modelagem são realizados com base na cúpula estratégica, da alta gerência ou dos principais gerentes de cada área, gerando-se os macros processos principais e, depois, detalhando-se os processos que os compõem, descendo-se na estrutura hierárquica da organização.

$\mathrm{Na}$ lógica bottom-up, o levantamento dos processos, subprocessos e links ocorrem com os gerentes e principais conhecedores dos processos em cada área, sendo cada processo validado com todos os integrantes. Esta visão permite que todos os processos operacionais, internos a cada instância organizacional, sejam mapeados e que todos os integrantes da organização possam se localizar facilmente nesses processos. Nessa lógica, a dificuldade é compatibilizar os inúmeros links detectados entre unidades distintas.

\section{Níveis de Granularidade dos Processos}

A partir do nível 3 do CMMI, a ênfase em questões relacionadas com a definição de processos é bem maior, iniciando com a definição de um conceito fundamental: o Processo de Software Padrão da Organização.

FIORINI et al. (1998) mostram uma classificação dos conceitos de processos em níveis de granularidade do processo de software e sua aplicabilidade, conforme a Figura 22.

No nível arquitetônico, o processo é descrito em termos da arquitetura do Processo de Software Padrão da organização. Fornece uma descrição de alto nível (visão), dando ênfase à ordenação, às interdependências e a outros relacionamentos (internos e externos) do processo de negócios da organização. 


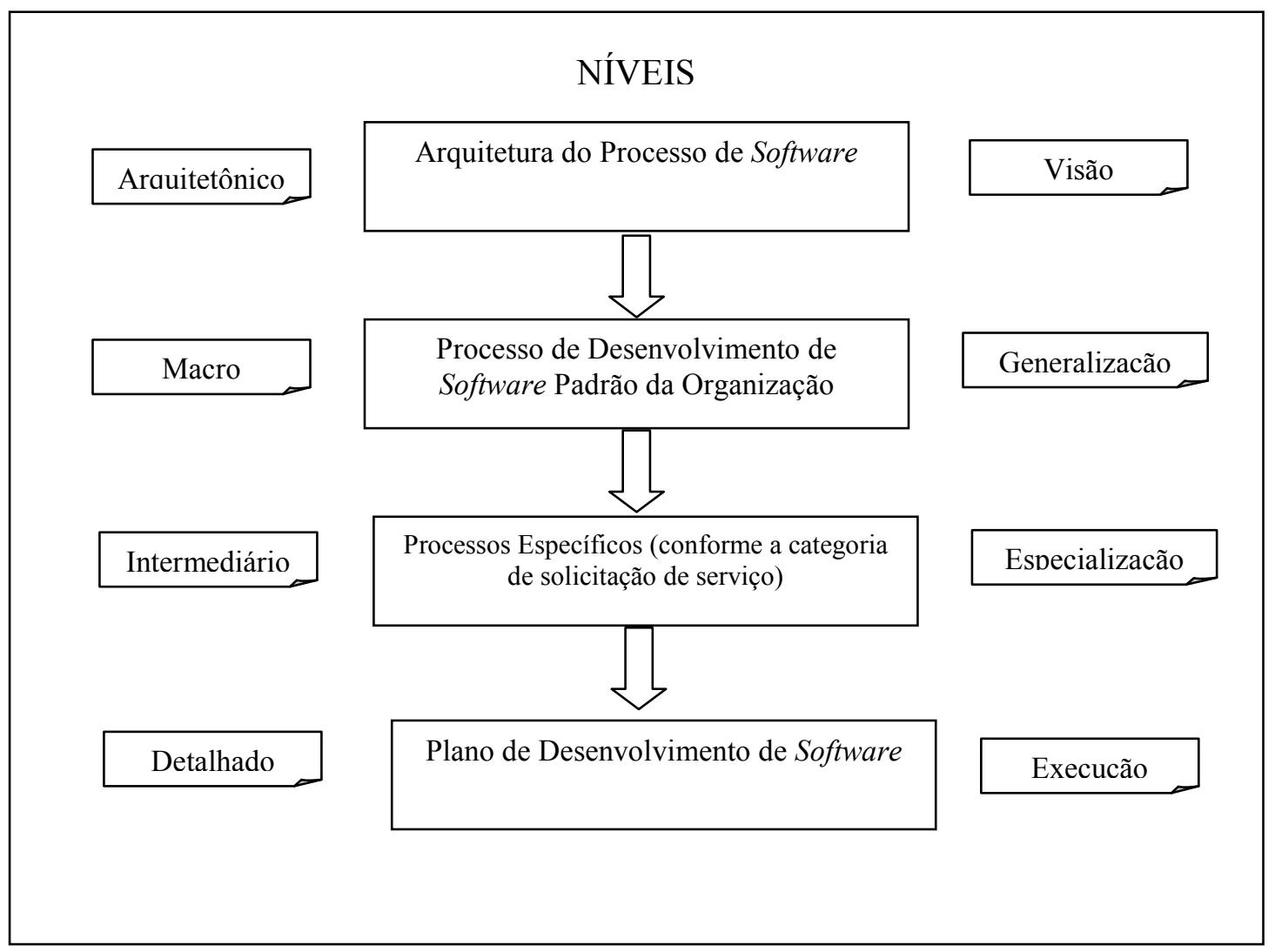

Figura 22 - Níveis de granularidade do processo de software Fonte: FIORINI et al. (1998)

No nível macro tem-se a descrição operacional do processo de software padrão da organização. Busca-se descrever todos os processos básicos e comuns aos projetos de software, de tal forma que se obtenha uma generalização de um processo de software na organização.

No nível intermediário, tem-se a descrição do processo de software definido do projeto escrito em termos de padrões de software, procedimentos, ferramentas e métodos que foram adaptados para atenderem às características específicas dos projetos. Dessa forma, os processos de software adaptados são especializações do processo generalizado.

Entretanto, no nível intermediário, o processo ainda não apresenta detalhes suficientes para sua execução. O plano de desenvolvimento de software, que corresponde ao processo no nível detalhado, faz a ponte entre o processo de software definido do projeto e as especificações de como o projeto será executado. Por exemplo, no nível intermediário, o processo do projeto especifica os papéis (geralmente de projeto, gerente sênior, etc.) e os tipos de artefatos necessários para 
executar uma determinada tarefa, mas não aponta as pessoas que irão assumir os papéis, os artefatos específicos que serão criados nem o cronograma estabelecido. Estes itens estarão definidos no nível detalhado.

\subsubsection{Arquitetura de Definição de Processos}

Conforme cita HUMPHREY (1989), existe um conjunto de elementos fundamentais que devem ser incorporados a quaisquer processos definidos, que é chamado de Processo-Padrão, pois delineia uma estrutura única para o estabelecimento de um processo comum na organização. $O$ autor mostra um conjunto de razões para a definição de um Processo-Padrão:

- Redução dos problemas relacionados a treinamento, revisões e suporte a ferramentas;

- As experiências adquiridas nos projetos são incorporadas ao processo-padrão e contribuem para melhorias em todos os processos definidos; e

- Economia de tempo e esforço na definição de novos processos adequados a projetos.

O Processo-Padrão de Software da Organização é a definição operacional do processo básico que guia o estabelecimento de um processo de software comum para todos os projetos de software da organização. Descreve os principais elementos do processo que cada projeto de software deve incorporar em seu processo definido. Descreve também os relacionamentos como ordem e interfaces, entre os elementos do processo de software. O relacionamento entre os elementos do processo de software, muitas vezes é denominado Arquitetura de Processo de Software. (FIORINI et al.,1998).

A Arquitetura de Definição de Processos, apresentada na Figura 23, tem um enfoque organizacional e foi desenvolvida com base nas diferentes visões para o mapeamento de processos: visão funcional e por processos, visão top-down e bottom-up e níveis de granularidade do processo. Mostra as abstrações do conjunto de processos alinhados à Estrutura Organizacional de Referência de FS, bem como a integração e relacionamento dos elementos fundamentais de definição dos processos. A Arquitetura é composta de cinco partes principais: visões do mapeamento de processos; matriz dos elementos organizacionais e fundamentais para definição de processos; etapas de definição dos processos e modelagem dos processos. 
ARQUITETURA DE DEFINIÇÃO DE PROCESSOS PARA FS

\section{ESTRUTURA ORGANIZACIONAL DA FÁBRICA DE SOFTWARE}

\section{VISÕES DO MAPEAMENTO DE PROCESSOS DA FS}

Visão Estratégica (mapeamento top-down) - Macrofluxo do Processo de Negócio da Organização (visão horizontal)

Visão Funcional - (mapeamento bottom-up) - Fluxos dos Processos das Unidades Organizacionais (visão vertical)

Visão Tática - (mapeamento transversal) - Fluxo do Processo-Padrão de Negócio (visão horizontal)

Visão Operacional (mapeamento transversal) - Fluxos dos Processos de Negócios Específicos (visão horizontal)

Visão Pontual (mapeamento pontual) - Fluxos dos Processos-Chave (visão pontual)

Visão de Execução do Trabalho (alocação de recursos) - Instanciação dos Processos (visão de trabalho)

MODELO DE DEFINIÇÃO DE PROCESSOS PARA FS

MATRIZ DOS ELEMENTOS ORGANIZACIONAIS DE DEFINIÇÃO DE PROCESSOS

\begin{tabular}{|c|c|c|c|}
\hline $\begin{array}{c}\text { Atribuições das áreas } \\
\text { funcionais da FS }\end{array}$ & $\begin{array}{c}\text { Categorias de } \\
\text { processos da FS }\end{array}$ & $\begin{array}{c}\text { Categorias das áreas de } \\
\text { Negócios da FS }\end{array}$ & $\begin{array}{c}\text { Categorias de produtos } \\
\text { e serviços da FS }\end{array}$ \\
\hline $\begin{array}{c}\text { Plataformas } \\
\text { tecnológicas }\end{array}$ & $\begin{array}{c}\text { Ferramentas, técnicas e } \\
\text { métodos }\end{array}$ & $\begin{array}{c}\text { Normas, regras e } \\
\text { procedimentos }\end{array}$ & Artefatos de reuso \\
\hline MATRIZ DOS ELEMENTOS FUNDAMENTAIS DE DEFINIÇÃO DOS PROCESSOS & e & $\begin{array}{l}\text { Perfis e competências } \\
\text { dos profissionais }\end{array}$ \\
\hline $\begin{array}{c}\text { Papéis e } \\
\text { responsabilidades }\end{array}$ & $\begin{array}{c}\text { Artefatos de entrada e } \\
\text { saída }\end{array}$ & $\begin{array}{l}\text { Atividades } \\
\text { subprocessos }\end{array}$ \\
\hline \multicolumn{4}{|c|}{ ETAPAS DE DEFINIÇÃO DE PROCESSOS } \\
\hline $\begin{array}{c}\text { Estudo do método de } \\
\text { trabalho atual }\end{array}$ & Projeto do trabalho & Divisão do trabalho & Design do processo \\
\hline \multicolumn{4}{|c|}{ MODELAGEM DOS PROCESSOS } \\
\hline Matriz de atividades integrada & Fluxo da modelagem do processo & Especificação do Processo \\
\hline
\end{tabular}

Figura 23 - Arquitetura de Definição de Processo para Fábrica de Software

Fonte: elaborada pela autora

A Arquitetura define seis diferentes visões do mapeamento de processos: estratégica, funcional, tática, operacional ou específica, pontual e de execução do trabalho. 
Inicialmente, define-se o processo arquitetônico, isto é, faz-se um mapeamento topdown dos processos por meio da estrutura organizacional, criando-se a visão estratégica do processo organizacional denominado Macrofluxo do Processo de Negócio da Organização.

A partir da visão bottom-up faz-se um mapeamento vertical das principais áreas funcionais envolvidas criando-se a visão funcional denominada Fluxo do Processo da Unidade Organizacional. Apoiadas na análise horizontal, interfuncional, cria-se o Fluxo do Processo-Padrão de Negócio da Organização, que representa a visão tática ou genérica do processo de negócio principal. Com base no Fluxo do ProcessoPadrão, customizado de acordo com a categorização das diferentes solicitações e demandas de produtos e serviços requeridos, definem-se os Processos de Negócios Operacionais ou Específicos da FS. A visão pontual mostra o mapeamento dos processos-chave. A visão de execução do trabalho mostra a instanciação dos processos definidos, assim como a alocação dos recursos necessários, de acordo com uma Planilha de Competências e Perfis dos profissionais, seguindo um Plano de Desenvolvimento de Software ou um Plano de Execução do Serviço.

Com a modelagem dos processos nas diferentes visões apresentadas, e por meio dos fluxos a serem gerados é possível analisar e identificar processos-chave relevantes ou críticos que requeiram os mapeamentos pontuais, assim como possibilitar a identificação e os relacionamentos com os processos dos Modelos de Melhores Práticas.

\subsubsection{Modelo de Definição de Processos}

Os elementos fundamentais que compõem o processo referem-se às questões: quem, o que, como e quando determinada atividade deve ser feita. O "quem" é definido pelos atores, seus papéis e responsabilidades, o "que" é definido pelos artefatos de entrada e saída, o "como" é definido pela seqüência de atividades relacionadas, e o "quando" é definido pelas fases do ciclo de vida, associadas aos cronogramas.

Os papéis possuem atividades que definem o trabalho que executam, e as atividades têm artefatos, como entrada e produzem artefatos como saída (RUP, 2003).

Outros elementos que devem ser considerados na definição do processo de desenvolvimento de software são: ferramentas, técnicas, normas, procedimentos, metodologias, artefatos de reuso, padrões, frameworks e plataformas tecnológicas. 
Com o uso de diagrama IDEF0 - Integration DEFinition Language for Function Modelling (IDEF0, 2005), representa-se o Modelo de Definição de Processos, no qual são indicados as entradas, saídas, regras e mecanismos envolvidos no Modelo, como mostrado na Figura 24, e detalhados, a seguir.

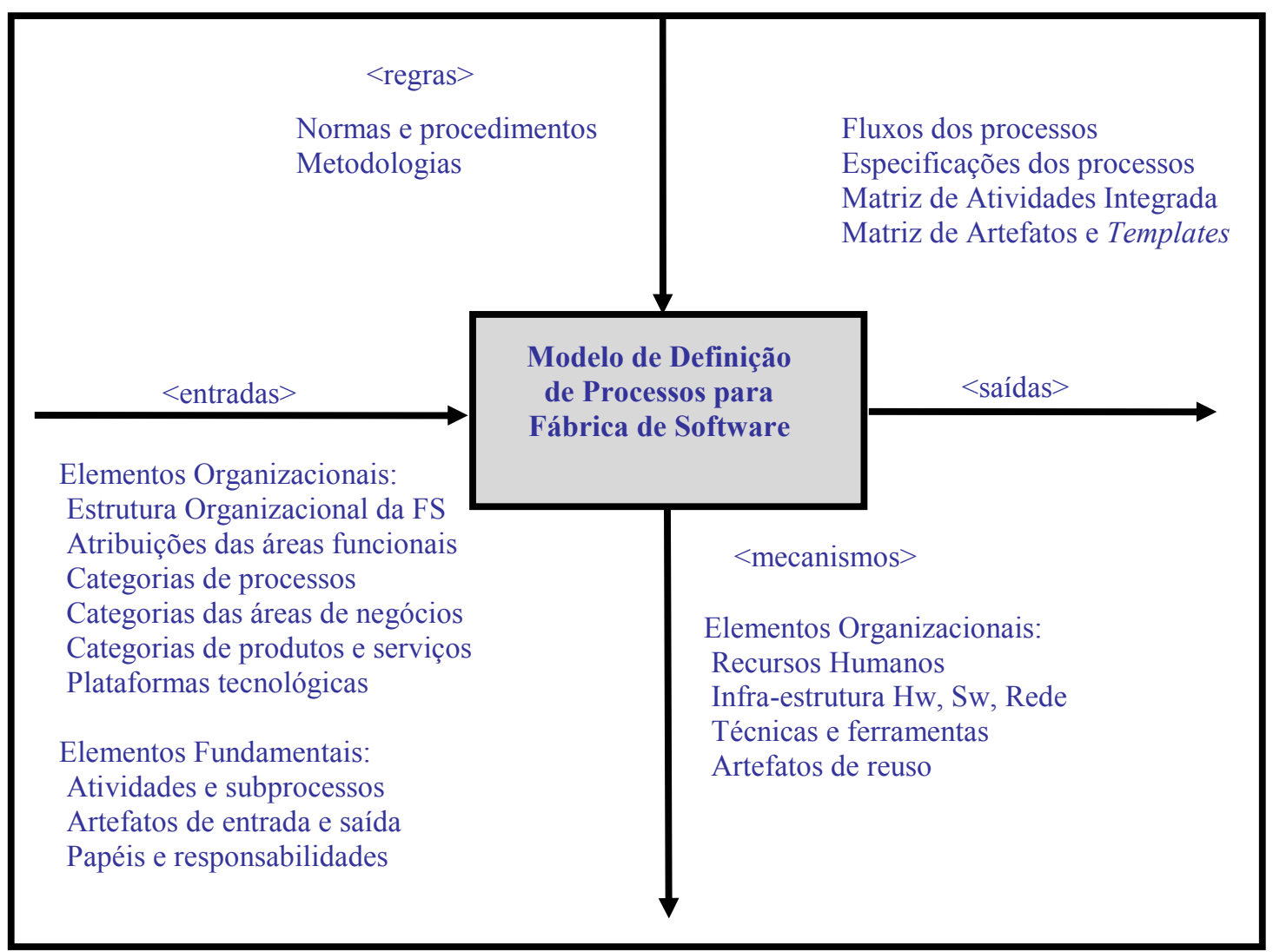

Figura 24 - Modelo de Definição de Processo para Fábrica de Software Fonte: elaborada pela autora

\section{Matriz dos Elementos Organizacionais para a Definição de Processos}

Os componentes organizacionais a serem considerados para a definição dos processos de desenvolvimento de software alinhados à estrutura organizacional da FS são descritos a seguir:

\section{Atribuições das Áreas Funcionais}

Refere-se às atribuições das áreas funcionais da FS que estão diretamente envolvidas nos processos de negócios da organização: relacionamento e atendimento ao cliente, negócios, análise e design, implementação, testes e homologação, planejamento e controle da produção, escritório de projetos, infra-estrutura, suporte e qualidade.

A descrição das atribuições das áreas funcionais deve estar contida no Manual da Organização ou no Manual da Unidade Organizacional, contendo informações, como: missão, visão, objetivos, papéis, responsabilidades, clientes e fornecedores, 
ferramentas, técnicas, metodologias utilizadas, produtos gerados e procedimentos. Estes documentos devem estar normatizados, institucionalizados e divulgados na organização.

\section{Categorias de Processos}

As principais categorias de processos abordadas pela Arquitetura referem-se, sobretudo aos processos de negócios (desenvolvimento, manutenção e engenharia) e produção de software, com o apoio dos processos de gestão, controle, suporte e integração.

\section{Categorias das Áreas de Domínios de Negócios da FS}

São as áreas relacionadas ao domínio de aplicação de negócios dos clientes da FS. Em geral, existe um amplo espectro possível de segmentos de negócios oferecidos no mercado de TI como, por exemplo, Finanças, Produção, Recursos Humanos, Administrativo, Comercial, Marketing, Social, entre outros.

\section{Categorias de Produtos e Serviços}

As categorias de serviços de TI oferecidas pela FS abrangem: modelagem dos processos de negócios, desenvolvimento de projeto novo, desenvolvimento de componentes de software, manutenção evolutiva, manutenção adaptativa, manutenção corretiva, manutenção preventiva, abend's (abnormal end), terceirização, internalização de sistemas, execução de serviços de TI, prospecção de negócios, prospecção tecnológica, entre outros.

Os produtos gerados referem-se aos sistemas, artefatos e componentes de software gerados pela FS. Neste ambiente de grande diversidade, a demanda de serviços e produtos é bastante variada criando diferentes fluxos de processos e aumentado a complexidade dos sistemas de produção.

No que concerne aos serviços de desenvolvimento de sistemas, estes podem abranger todas ou parte das fases do ciclo de vida de sistemas. As categorias de serviços mais comumente solicitadas são:

\section{- Desenvolvimento de Projetos de Sistemas de Software}

Conforme PMBOK (2004): "Projeto é um esforço temporário empreendido para criar um produto, serviço ou resultado exclusivo". Portanto, necessita de objetivos claros, medidas de resultados, datas de início e término que atendam aos requisitos negociados e explícitos das partes interessadas (stakeholders). 


\section{- Desenvolvimento de Componentes de Software}

Um componente pode ser definido como uma unidade de software independente, que encapsula, dentro de si seu projeto e implementação e oferece serviços, por meio de interfaces bem definidas, para o meio externo. A motivação para os componentes não é unicamente relacionada ao reuso. As recentes pressões para liberação de produtos no mercado (time to market), assim como a necessidade de lidar com modificações de maneira rápida e efetiva têm contribuído para a relevância de componentes de produção de software (BARROCA et al., 2005).

\section{- Manutenção de Sistemas de Software}

A Manutenção de Software é definida como: a modificação de um produto de software, depois de liberado para corrigir falhas, melhorar o desempenho ou outros atributos, ou para adaptar o produto a um ambiente alterado.

PRESSMAN (2002) classifica as atividades de manutenção em quatro tipos: corretiva, para corrigir erros não detectados na fase de teste; adaptativa, para acompanhar a evolução relacionada a aspectos não funcionais, como por exemplo, mudanças de plataformas tecnológicas; perfectiva ou evolutiva, para continuar satisfazendo as necessidades do usuário; e preventiva, para melhorar a confiabilidade ou manutenibilidade futura. Na manutenção corretiva, pode-se ter dois tipos de ocorrências: a manutenção programada e a manutenção emergencial, que é realizada como conseqüência do erro ocorrido que precisa ser imediatamente corrigido, comumente denominado "abend" - abnormal end.

\section{Plataformas Tecnológicas}

Uma FS atende a diferentes ambientes tecnológicos como mainframe, plataforma baixa, web, cliente-servidor, sistemas integrados e sistemas distribuídos, o que pode influenciar nos processos da FS, induzindo a diferentes fluxos.

\section{Ferramentas, Técnicas e Métodos}

Esta matriz refere-se à relação de ferramentas, técnicas e métodos de Engenharia de Software existentes ou a serem gradativamente adotadas e implantadas nos diferentes ambientes tecnológicos da empresa. Serve também como apoio organizacional à área de treinamento e capacitação. Ferramentas, técnicas e métodos utilizados afetam diretamente na execução das atividades, assim como os produtos (artefatos) gerados nos processos de desenvolvimento. 


\section{Regras, Normas e Procedimentos}

As regras fazem parte da política da empresa e podem ser classificadas como: administrativas e procedurais, que são normas representadas por manuais ou guias de direções que regem a organização e as unidades funcionais; metodologias referentes a modelos de processos estabelecidos como políticas da empresa; procedimentos que são condutas bem estabelecidas e ordenadas para a realização das atividades.

As normas técnicas podem ser concebidas por meio de metodologias, padrões, frameworks, modelos, técnicas e arquiteturas utilizadas para contribuir na automação e padronização dos processos. As normas de Segurança da Informação, por exemplo, são imprescindíveis aos ambientes de FS.

\section{Artefatos de Reuso}

A partir dos conceitos de reuso de software estudados na Seção 2.4 e realizando-se a análise de domínio por área funcional da FS, criou-se a Tabela 16, que mostra como podem ser instanciados os repositórios de artefatos de reuso nas principais áreas ou processos de produção da FS.

Tabela 16 - Artefatos possíveis de serem reusados no Modelo de FS

\begin{tabular}{|l|l|}
\hline \multicolumn{1}{|c|}{$\begin{array}{c}\text { Denominação da } \\
\text { Área ou Processo }\end{array}$} & \multicolumn{1}{c|}{ Artefatos reusáveis } \\
\hline Negócios & $\begin{array}{l}\text { Planos de projeto, visão e escopo do negócio, regras de negócios, requisitos } \\
\text { funcionais, requisitos não funcionais, frameworks de aplicação empresarial, } \\
\text { modelos de negócios, padrões de processos, casos de uso, estimativas de } \\
\text { custos e prazos, históricos, processos. }\end{array}$ \\
\hline Análise e Design & $\begin{array}{l}\text { Requisitos, especificações, modelos de negócios, estimativas de custos e } \\
\text { prazos, casos de uso, arquiteturas, projetos, padrões, frameworks, históricos, } \\
\text { simulação de sistemas, modelo de dados, prototipação, documentação, } \\
\text { metodologias, processos. }\end{array}$ \\
\hline Implementação & $\begin{array}{l}\text { Casos de uso, código fonte, padrões de programação, frameworks de } \\
\text { linguagens, persistência (dados), interfaces de apresentação (telas), } \\
\text { componentes de negócios, classes, objetos, web services, scripts, } \\
\text { procedures, documentação, metodologias, processos. }\end{array}$ \\
\hline Testes & $\begin{array}{l}\text { Planos de testes, casos de testes, simulação de interfaces, documentação, } \\
\text { metodologias, processos. }\end{array}$ \\
\hline
\end{tabular}

Fonte: compilada pela autora

\section{Perfis e Competências}

Esta matriz contém os dados das competências dos profissionais, que são usados, quando da formação das equipes multifuncionais ou na alocação de um recurso específico. A matriz também auxilia no estabelecimento de um Plano de Gestão por Competências associados à Gestão do Conhecimento na FS. A matriz pode estar no 
formato de planilha, contendo os dados: nome, cargo e perfil de competências em relação às plataformas tecnológicas, metodologias, ferramentas, domínio de negócios, sistemas, linguagens de programação, especializações, experiências adquiridas e treinamentos realizados.

\section{Matriz dos Elementos Fundamentais de Definição de Processos}

Para a análise e mapeamento dos processos, além dos elementos relacionados à organização, é definida a Matriz dos elementos fundamentais que compõem os processos descritos a seguir:

\section{Papéis e Responsabilidades}

Detalhamento das atribuições de papéis e responsabilidades. O papel define o comportamento e as responsabilidades de um indivíduo ou de um conjunto deles (RUP, 2003).

\section{Artefatos de Entrada e Saída}

Artefato é "o que" é gerado ou recebido, ou seja, qualquer peça de informação usada, criada ou modificada durante o curso de desenvolvimento de software. O RUP (2003) fornece modelos (templates) para vários artefatos, sendo totalmente compatíveis com a UML, reforçando a padronização e o reuso. As entradas são objetos que são consumidos ou transformados no processo. As saídas são objetos que são produzidos pelo processo, como resultado da transformação das entradas e podem servir de entrada para outro processo.

\section{Atividades}

Os papéis possuem atividades que definem o trabalho que executam. As atividades possuem artefatos como entrada e produzem artefatos como saída (RUP, 2003). As atividades são executadas em uma determinada ordem, pelas quais os recursos são modificados.

\subsubsection{Diagrama de Modelagem de Processos}

ERIKSSON e PENKER (2000), com o uso de mecanismos de extensão da UML criaram um conjunto de estereótipos que permite desenvolver e representar uma visão do processo de negócio, contendo os seguintes elementos: processo, objetivo ou razão do processo, entradas, saídas, recursos consumidos, atividades realizadas em uma ordem definida e eventos, conforme mostrado na Figura 25. 


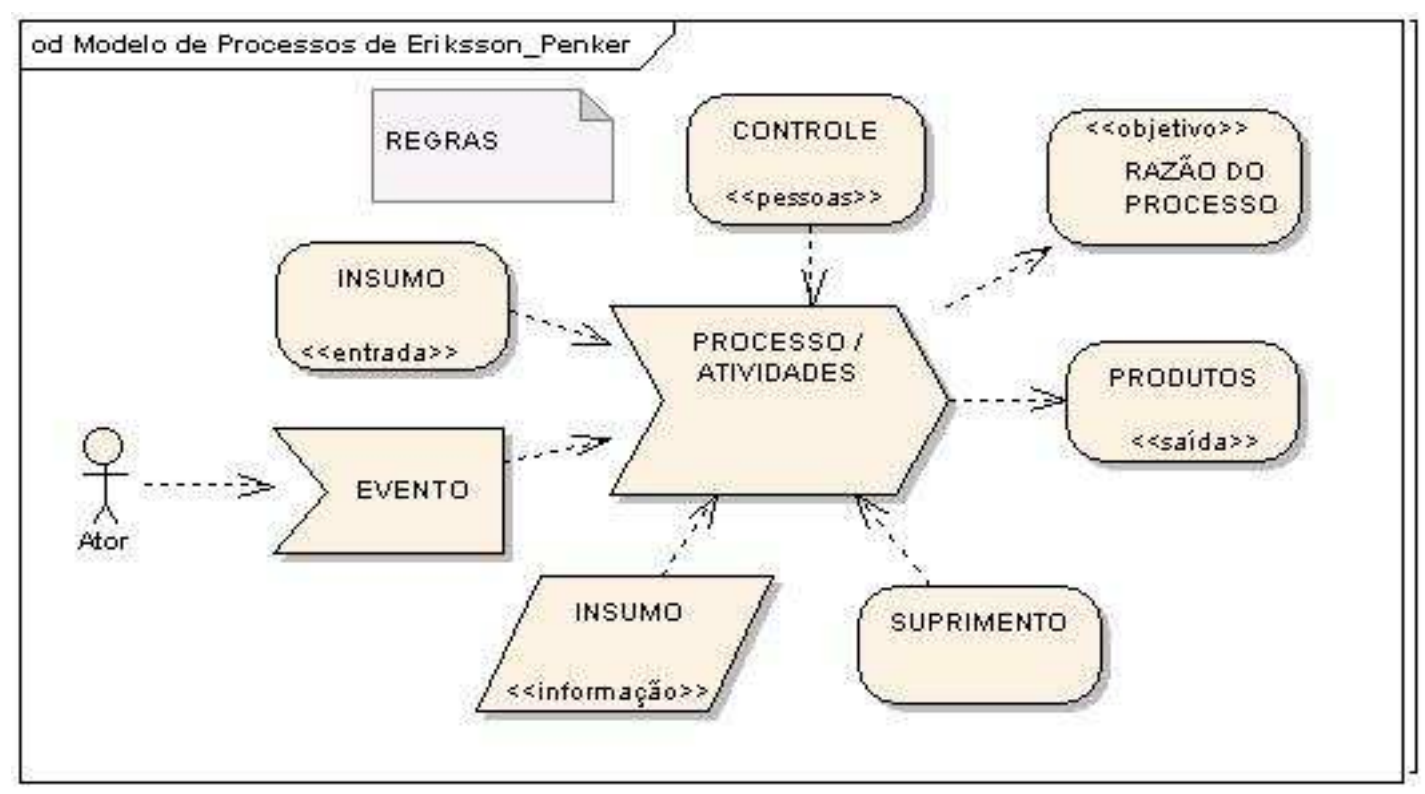

Figura 25 - Modelo de Processos de Negócios

Fonte: ERIKSSON e PENKER (2000)

- Objetivo ou razão do processo: pode ser dividido em subobjetivos associados a áreas específicas do negócio. Corresponde ao estado em que o recurso estará no final do processo;

- Eventos: podem iniciar a execução de um processo, afetar o comportamento e a execução do processo ou concluir um processo;

- Insumos: objetos de entrada que são consumidos ou transformados (refinados) no processo. Podem ser objetos físicos, abstratos, pessoas e informações;

- Produtos: objetos de saída que são produzidos pelo processo, como resultado da transformação das entradas;

- Suprimento: recursos que participam do processo, mas não são consumidos ou transformados. São representados abaixo;

- Objetos de Controle: recursos que controlam o processo. São representados acima;

- Atividades: executadas em uma determinada ordem pelas quais os recursos são modificados; e

- Regras que definem como o negócio deve estar estruturado e como os processos devem ser relacionados. Pode referir-se a normas internas ou leis externas ao negócio, para que os objetivos sejam alcançados. As regras podem ser classificadas como funcionais, comportamentais e estruturais. 
A adoção do BPMN - Business Process Modeling Notation, como método para modelagem dos processos é também bastante apropriada, já que a tendência atual é defini-lo, como padrão para modelagem de processos de negócios, oferecendo a facilidade de implementá-lo posteriormente em uma ferramenta BPMS - Business Process Management System, automatizando e integrando o processo mapeado.

Neste trabalho, desenvolveu-se um modelo simplificado de representação para a modelagem dos processos, baseado no Modelo de ERIKSSON e PENKER (2000), conforme a Figura 26.

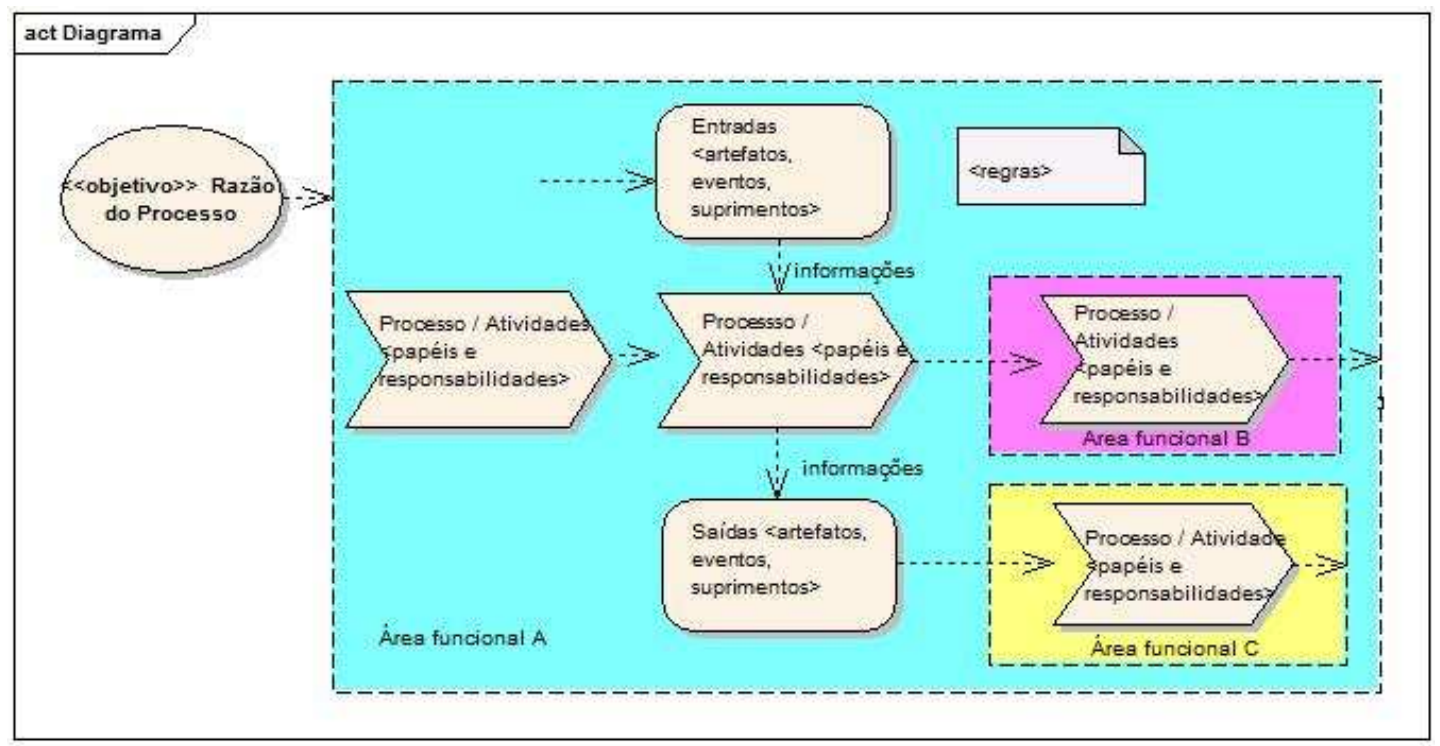

Figura 26 - Diagrama de Representação da Modelagem de Processos Fonte: baseado em ERIKSSON e PENKER (2000)

O diagrama para representação da modelagem do processo criado, identifica o fluxo horizontal das atividades do processo, considerando as regras de precedência e dependência. A figura de elipse identifica o objetivo ou subobjetivo do processo representado. As áreas funcionais ou de domínio do processo são diferenciadas por cores, o que facilita a sua identificação e visualização. Os papéis e responsabilidades são indicados entre parênteses na figura que descreve o processo ou a atividade correspondente. Desta forma, definem-se claramente as atribuições de cada área ou processo, estabelecendo-se o fluxo do processo de negócios por meio de regras e procedimentos predeterminados entre as áreas interfuncionais, possibilitando a transparência e a análise detalhada do processo mapeado. O fluxo mapeado horizontalmente facilita sua construção e visualização dos processos interfuncionais. 


\subsection{Fase 3.2 - Execução: Mapeamento e Definição dos Processos}

Concomitantemente ao mapeamento dos processos, foram sendo identificadas as categorias de processos, descritas a seguir.

\subsubsection{Categorias de Processos}

ALMEIDA (2004) define um modelo multidimensional denominado PRISMA, baseado nos modelos PMBOK e RUP, classificando os processos relacionados à construção de software como:

- Processos Gerenciais: referem-se ao que deve ser feito para se chegar ao objetivo final do projeto, que é o produto de software solicitado pelo cliente. A definição de "o que fazer" deve levar em consideração as características e as condições específicas de cada projeto como prazos, custos, escopo, riscos, etc.;

- Processos de Desenvolvimento: referem-se aos aspectos temporais dos processos de desenvolvimento e acompanhamento do projeto, que devem ser definidos milestones, marcos ou eventos importantes para verificar o andamento do projeto e validar os produtos feitos até então;

- Processos de Engenharia: referem-se aos aspectos técnicos dos processos de engenharia e construção dos produtos intermediários necessários (artefatos ou deliverables) que vão se aprimorando e integrando-se durante o ciclo de vida do projeto, até chegarem ao produto de software, objetivo final do projeto.

Pautado na Estrutura Organizacional de Referência de FS (Seção 5.3.1), na análise das metodologias existentes na EmpresaTI (Seção 6.1.1), na Arquitetura e Modelo de Definição de Processos (Seções 6.3.1; 6.3.2), nos processos definidos no Modelo de ALMEIDA (2004) e nos mapeamentos dos fluxos efetuados, foram identificadas e definidas as principais categorias de processos da FS: Atendimento ao Cliente; Negócios (Desenvolvimento e Engenharia); Gestão e Controle (Projetos, Produção e Qualidade); Suporte Técnico (Engenharia e Infra-Estrutura), mostrados na Figura 27 e, descritos a seguir.

\section{Processos de Atendimento ao Cliente}

O processo de Atendimento ao Cliente envolve os seguintes subprocessos: Relacionamento com o Cliente, Comercialização, Marketing, e Prospecção de Novos Negócios. Faz parte também do Atendimento ao Cliente o processo de Service Desk, 
que compõe os fluxos dos processos de atendimento a reclamações, sugestões e solicitações de modificações e manutenção de sistemas existentes e serviços.

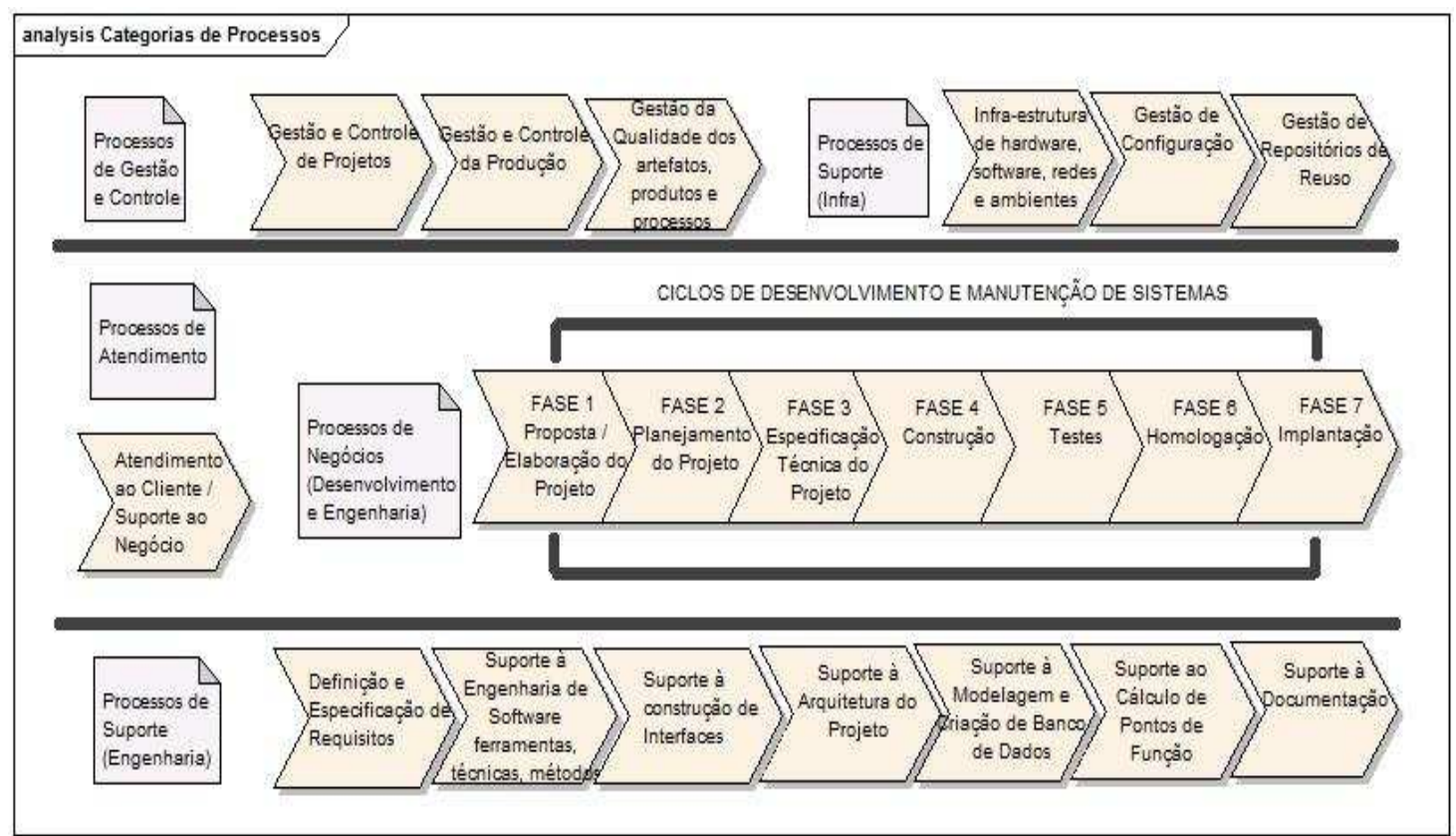

Figura 27 - Categorias de Processos da FS

Fonte: elaborada pela autora

\section{Processos de Negócios}

Os processos de negócios da FS referem-se a um conjunto de atividades realizadas por áreas fim da empresa e são relacionadas a um objetivo de trabalho específico, que adiciona valor ao produto de uma organização. Os processos de negócios da FS englobam os processos de desenvolvimento e processos de engenharia.

\section{Processos de Desenvolvimento}

Os processos de desenvolvimento tratam dos critérios e das condições que serão utilizados para definir a forma ordenada e uniforme de executar atividades por meio de um grupo de regras e procedimentos de seqüenciamento e dependências entre as atividades que devem ser realizadas para a definição e implementação dos produtos previstos pelo projeto. Os processos de desenvolvimento estão divididos em fases que devem acontecer durante o tempo de realização do projeto. Essas fases servem como marcos (milestones) associados a fatos e eventos importantes para o projeto, como entrega de algum produto como protótipo ou versões parciais do software ou reuniões de validação e homologação dos produtos entregues (ALMEIDA, 2004).

Fazem parte deste grupo os processos para: 
- Análise e estudos preliminares do produto a ser construído, identificando os principais requisitos pelos protótipos que devem servir como prova de conceito da viabilidade e da efetividade que o produto final de software deverá possuir;

- Definição e refinamento dos requisitos do produto de software, bem como o detalhamento de todas as atividades e artefatos que deverão ser elaborados durante a construção do produto final do software a ser entregue;

- Construção, testes e validação de cada subproduto gerado e testes, homologação e implantação do produto final do software criado pelo projeto.

\section{Processos de Engenharia}

Conforme ALMEIDA (2004), os processos de engenharia tratam da identificação, seleção, aplicação e controle de técnicas, habilidades e ferramentas utilizadas para elaboração dos produtos (artefatos) gerados durante a execução do projeto, bem como dos papéis técnicos necessários para realização das atividades desses processos. As técnicas, habilidades e ferramentas são classificadas em grupos-afim, de acordo com a natureza e o tipo de informação existente, bem como o perfil das pessoas alocadas nas atividades desses grupos de processos. Fazem parte dos grupos os processos para:

- Identificação, modelagem, detalhamento e refinamento dos processos de negócio envolvidos com o produto final de software a ser construído, bem como o acompanhamento e controle desses requisitos e das mudanças que eles podem sofrer na realização do projeto;

- Identificação, detalhamento e refinamento dos requisitos funcionais, não funcionais e técnicos do produto de software a ser desenvolvido;

- Análise, detalhamento e elaboração dos artefatos de Engenharia de Software necessários à construção do produto de software definido (modelos, diagramas, especificações, etc.);

- Identificação, definição e controle do ambiente de desenvolvimento necessário à realização do projeto, bem como do ambiente de implantação onde o produto de software desenvolvido deverá ser instalado e executado;

- Planejamento, execução, controle e acompanhamento dos testes dos vários artefatos e subprodutos construídos durante o projeto e também do produto final de software construído; 
- Gerenciamento e controle da configuração dos ambientes e o controle de versão dos artefatos e subprodutos construídos pelo projeto; e

- Implementação dos subprodutos gerados baseados na construção de programas, rotinas, funções, classes, tabelas e outras unidades de implementação definidas.

\section{Processos de Suporte}

Os processos de suporte são organizacionais, pois se referem às atividades executadas por áreas-meio da empresa, que dão suporte às áreas fim para a realização e integração dos processos de negócio. Dentre estes, estão os processos da área de Infra-Estrutura e Suporte Técnico. Estes processos devem ser estrategicamente alinhados à estrutura organizacional da empresa, oferecendo a sustentação necessária para execução dos processos de negócios de forma racionalizada.

FERNANDES e TEIXEIRA (2004) nomeiam os processos de Suporte Técnico, como Suporte em Engenharia de Software e relacionam atividades relativas ao:

- Suporte às equipes de desenvolvimento nas técnicas de Engenharia de Software;

- Suporte às equipes de desenvolvimento em ferramentas de gestão e de construção de software;

- Suporte em técnicas de estimativas;

- Suporte nos processos da FS;

- Definição do processo-padrão de software;

- Elaboração de estudos de melhoria nos processos de software;

- Definição de processos de software derivados do processo-padrão definido;

- Participação em projetos de implementações de novos processos, novos clientes e novas tecnologias de processo.

\section{Processos de Gestão e Controle}

Os principais processos de gestão e controle relacionados ao desenvolvimento e manutenção de software citados neste trabalho são: gestão e controle de projetos, gestão e controle da produção, gestão da qualidade e da produtividade.

\section{Processo de Gestão e Controle do Projeto}

ALMEIDA (2004), considera que os processos de gerenciamento dizem respeito ao conjunto de atividades para controle e acompanhamento do projeto, desde sua criação e apresentação formal para o cliente/usuário, até a entrega do produto final e 
o encerramento dos contratos com fornecedores e a finalização do projeto. Deste grupo, fazem parte os processos para:

- Planejamento, definição e controle do escopo, bem como as mudanças que possam ocorrer na realização do projeto;

- Planejamento, definição e controle dos prazos para realização das atividades e dos produtos a serem entregues pelo projeto;

- Planejamento, orçamentação e controle dos custos do projeto;

- Planejamento, análise e controle dos riscos do projeto;

- Planejamento e controle das pessoas alocadas ao projeto;

- Definição e distribuição das informações do projeto;

- Planejamento e controle de qualidade do projeto e dos produtos elaborados;

- Controle dos contratos com fornecedores, parceiros e outras entidades externas envolvidas com o projeto.

\section{Processo de Planejamento e Controle de Produção}

O processo de planejamento e controle de produção tem o objetivo de dar suporte às necessidades estratégicas da FS no que diz respeito a "o que, quando, quanto e com que produzir e comprar" (CONTADOR et al., 1997). Os processos de PCP fazem parte da Gestão de Operações da FS.

As atividades mais usuais executadas pela área de PCP da FS referem-se a:

- Gestão da demanda de serviços;

- Recebimento, designação e liberação de solicitações de serviços;

- Controle e acompanhamento das atividades e recursos alocados;

- Controle e acompanhamento das ordens de serviços dos subcontratados.

Processo de Gestão da Qualidade e Produtividade

Os seguintes aspectos para este processo são apontados por FERNANDES e TEIXEIRA (2004):

- Gestão de sistemas ou certificações sobre a qualidade dos processos e dos produtos da operação;

- Tratamento das informações sobre a qualidade dos processos e dos produtos da operação;

- Verificação de tendências relativas à qualidade dos processos e dos produtos da operação; 
- Análise e identificação de causas de variação da qualidade dos processos e dos produtos;

- Proposições de ações corretivas, preventivas e de melhoria para eliminação de defeitos e falhas na operação;

- Tratamento das informações sobre a produtividade da operação, considerando linhas de serviço, recursos humanos e contas;

- Monitoramento de tendências relativas à produtividade;

- Monitoramento das ações corretivas e preventivas; e

- Execução de auditorias periódicas dos sistemas da qualidade implantados na FS.

\subsubsection{Mapeamento dos Processos}

Inicialmente nesta fase da PA, foram realizadas as seguintes atividades:

- Levantamento das atividades operacionais no "chão de fábrica";

- Levantamento das regras de negócios com todas as gerências envolvidas; e

- Levantamento e reuniões com o pessoal técnico para revisão e definição dos artefatos e templates de entrada e saída.

Seguindo as diretrizes da Arquitetura de Definição de Processos, os fluxos mapeados, no início corresponderam aos seguintes processos: macrofluxo dos processos de negócios; fluxos dos processos das áreas funcionais; fluxo do processopadrão referente ao desenvolvimento de projeto novo; e fluxo dos processos específicos referentes à manutenção evolutiva e adaptativa; manutenção corretiva e abend's.

\section{Visão Estratégica - Processo de Negócio da Organização}

Nesta etapa da pesquisa, conduzida pela área de Racionalização de Processos da EmpresaTI, obteve-se a Visão Estratégica do Processo Organizacional. Com base no estudo das metodologias anteriores existentes na empresa e seguindo os elementos definidos na Arquitetura de Definição de Processos pela análise top-down, gerou-se o macrofluxo do Processo de Negócio (Anexo 1). Para a definição e validação do fluxo, foram efetuadas reuniões realizadas com os diretores e os principais gerentes funcionais de cada área envolvida.

\section{Visão Funcional - Processos Operacionais das Áreas Funcionais}

A reestruturação organizacional da EmpresaTI implicou a redefinição das atribuições de suas áreas funcionais. Na PA foi mapeado o processo referente à Área de Análise 
e Design. Com base no mapeamento top-down obtido na primeira fase, foi feito um mapeamento bottom-up da área funcional. O Anexo 2 mostra o fluxo operacional das atividades da área, representada pela Matriz de Atividades Integrada.

\section{Visão Tática - Processo-Padrão de Negócio}

O mapeamento do processo de maior importância que serviu como guia para a definição e customização dos demais processos de negócios corresponde ao Fluxo do Processo-Padrão de Negócio da Empresa, que mostra a visão tática operacional, da forma mais abrangente possível. Tendo como base o macrofluxo do Processo de Negócio e o Fluxo do Processo Operacional das unidades funcionais, que reflete as atribuições dessas áreas, efetuou-se o mapeamento horizontal do Processo-Padrão de Negócio da Empresa usando o Diagrama de Modelagem de Processos (Seção 6.3.3). O processo-padrão corresponde ao desenvolvimento de projeto novo, uma vez que este processo é o mais completo, e abrange praticamente todas as etapas do ciclo de vida do software.

Pelo levantamento detalhado dos processos com a participação dos gerentes e técnicos das principais áreas envolvidas, foi criado e preenchido o template "Matriz de Atividades Integradas", contendo o detalhamento das atividades descritas nos fluxos. Esta Matriz mostra o relacionamento das áreas funcionais, macroatividades, atividades, papéis e responsabilidades, stakeholders, ferramentas, técnicas, metodologias e procedimentos.

Os principais artefatos de saída gerados na visão tática foram: Fluxo do ProcessoPadrão de Negócio (Anexo 3), Manual do Processo-Padrão (Anexo 4) e a Matriz de Atividades Integradas do Processo-Padrão (Anexo 5).

\section{Visão Operacional - Processos de Negócios Específicos}

Os processos de negócios específicos mapeados na pesquisa-ação foram os correspondentes à manutenção evolutiva e adaptativa (Anexo 6) e manutenção corretiva e Abend (Anexo 7), que foram customizados com base no Fluxo do Processo-Padrão de Negócio.

\section{Visão Pontual - Processos-Chave}

$\mathrm{Na}$ análise dos processos foram encontrados processos que não são tratados de forma corporativa, mas são potenciais candidatos a processo-chave como: arquitetura de 
sistemas; construção de padrões de protótipos de interfaces; análise e cálculo de Pontos de Função (APF).

\section{Revisão e Validação dos artefatos e templates}

Neste ciclo, também, foram feitos levantamentos, revisões e validações dos artefatos e templates, tanto de mainframe como de plataforma baixa, com os técnicos das áreas envolvidas. Os artefatos e templates são gerados e revisados (no formato e conteúdo) durante o processo de desenvolvimento de software e estão organizados em conjunto de informações como no RUP (2003), ou seja, conjunto de artefatos de: gerenciamento, requisitos, análise e design, implementação, testes e implantação.

\subsubsection{Definição e Estabelecimento dos Processos - A MDSI}

Desta forma, os processos de desenvolvimento e manutenção de sistemas da EmpresaTI foram definidos com ênfase nas características de FS. Este projeto denominado MDSI - Metodologia de Desenvolvimento de Sistemas e Integração, contemplou os fluxos mapeados, assim como os artefatos gerados na PA relacionados, a seguir:

- Macrofluxo do Processo de Negócio (Anexo 1);

- Matriz de Atividades Integrada da Unidade Organizacional (Anexo 2);

- Fluxo do Processo-Padrão de Negócio (Anexo 3);

- Especificação do Processo-Padrão - Manual da MDSI (Anexo 4);

- Matriz de Atividades Integradas do Processo-Padrão (Anexo 5);

- Fluxo do Processo de Manutenção Evolutiva e Adaptativa (Anexo 6);

- Fluxo do Processo de Manutenção Corretiva e Abend (Anexo 7).

Seguindo as diretrizes da Arquitetura de Definição de Processos foram coletadas e definidas as matrizes dos elementos organizacionais e fundamentais durante a execução da PA:

- Atribuições das áreas funcionais (Anexo 8);

- Categorias de processos (Anexo 9);

- Áreas de domínios de negócios do setor público (Anexo 10);

- Categorias de serviços (Anexo 11);

- Matriz de produtos (Anexo 12);

- Plataformas tecnológicas (Anexo 13); 
- Ferramentas, técnicas e metodologias (Anexo 14);

- Normas, regras e procedimentos (Anexo 15);

- Artefatos de reuso sugeridos (Anexo 16);

- Papéis e responsabilidades (Anexo 17);

- Artefatos de entrada e saída (Anexo 18);

- Planilha de perfis e competências (Anexo 19).

As ações que culminaram na validação e divulgação do mapeamento dos processos envolveram:

- Uma série de doze reuniões com cada uma das gerências envolvidas: representantes da área de relacionamento com o cliente e negócios; duas gerências de análise e design: formatação e operação; fábrica; qualidade; escritório de projetos; grandes projetos; tecnologia; três gerencias da infraestrutura: produção, mudanças e rede; e racionalização de processos;

- Uma série de três reuniões gerais para validação dos artefatos e templates de entrada e saída com grupos de técnicos de cada área envolvida;

- Uma reunião final promovida pela diretoria de desenvolvimento com todos os gerentes das áreas funcionais envolvidas para consolidação e validação final dos processos mapeados, onde a autora deste trabalho expôs detalhadamente todos os fluxos mapeados;

- Divulgação dos fluxos dos processos com uma série de oito palestras para a EmpresaTI com a participação dos técnicos de todas as áreas envolvidas em dezembro de 2006.

- Para dar continuidade, estabelecer e instituir a MDSI na EmpresaTI, foi proposto um Site com um menu em vários níveis (Anexo 20), podendo disponibilizá-los na Intranet da Empresa ou em um Portal Próprio, com o objetivo de divulgar os fluxos, processos, artefatos e templates definidos, reuso dos artefatos gerados e disseminar o conhecimento gerado.

\subsection{Fase 4 - Avaliação}

Os fluxos dos processos mapeados revelaram-se importantes instrumentos de trabalho para identificar lacunas, pontos críticos e nebulosos, efetuar diagnósticos e avaliações dos processos de desenvolvimento e manutenção de sistemas da EmpresaTI. Além disso, o Fluxo do Processo-Padrão serviu como guia para o 
mapeamento de processos específicos e processos-chave. Os diagnósticos mais relevantes efetuados durante a análise, mapeamento e definição dos processos, assim como as propostas de soluções são mencionadas, a seguir.

\section{- Diagnósticos}

- Em relação às metodologias de desenvolvimento de sistemas anteriormente existentes na EmpresaTI, as principais características em comum observadas foram: metodologias definidas com a visão de projetos; inexistência de área permanente de suporte e acompanhamento da metodologia; e ficavam desatualizadas ou descontinuadas em conseqüência de mudanças organizacionais.

- Na nova estrutura organizacional (Estrutura Organizacional 3), o corpo do conhecimento encontrava-se desagregada em razão da distribuição dos recursos nas diferentes áreas funcionais. Em alguns casos, o conhecimento do negócio concentrou-se na área técnica, em outros, o conhecimento técnico permaneceu na área de negócios, causando conflitos na gestão por competências, e descompasso na distribuição das tarefas. Neste caso, cabia a capacitação e o treinamento do pessoal das áreas relacionadas.

- O processo de arquitetura de software, encontrava-se nebuloso, não havia uma área ou arquitetos de software dedicados exclusivamente a esta atividade, considerada uma das mais importantes para o desenvolvimento dos projetos e incentivo ao reuso de software. Detectou-se a necessidade da determinação dos donos desse processo e defini-lo como um processo-chave, além de identificar e capacitar os profissionais com competências de arquitetos de software.

- Conflitos e dificuldades encontradas na integração das atividades entre as áreas funcionais. Neste caso era preciso melhorar os mecanismos de comunicação, ferramentas e procedimentos pela racionalização dos processos envolvidos.

- Em algumas áreas funcionais existiam divergências entre a definição formal das atribuições e sua realização, por falta de recursos (quantidade ou qualificação), falta de ferramentas ou falta de controle nos processos. No caso, as áreas deveriam receber infra-estrutura, recursos e treinamento adequados para exercer as atribuições definidas.

- Focos de trabalho onde a inteligência e o conhecimento dos negócios e tecnologia concentravam-se nas pessoas, e estas executavam todo o ciclo de desenvolvimento 
de software de ponta a ponta. No caso, o conhecimento implícito teria de se transformar em conhecimento explícito, os sistemas deveriam ser atualizados e documentados, deveria existir, pelo menos, um par de profissionais que dominasse o sistema.

\subsection{Fase 5 - Resultados}

Os fluxos mapeados, assim como os artefatos gerados proporcionaram transparência e conhecimento por parte das áreas envolvidas, dos processos gerenciais e operacionais da EmpresaTI. Constatou-se que houve fácil entendimento da representação dos processos mapeados pelo Diagrama de Modelagem de Processos e observou-se que nem todos os envolvidos conheciam o processo em sua totalidade. Os fluxos dos processos mapeados revelaram-se instrumentos importantes de trabalho para identificar lacunas, pontos críticos e nebulosos, efetuar diagnósticos, identificar pontos de revisões para garantia da qualidade e efetuar avaliações dos processos de desenvolvimento e manutenção de sistemas da EmpresaTI.

Durante as reuniões de validação com gerentes e técnicos, houve várias contribuições possibilitando a identificação de pontos críticos, o refinamento e melhoria dos processos mapeados. As informações levantadas nas reuniões direcionaram parte do detalhamento das modelagens dos processos, das matrizes e dos modelos que o levaram à sua forma final.

Um fator importante que contribuiu para a modelagem dos processos na PA esteve no fato da autora deste trabalho ter experiência profissional na área técnica, atuando com competências de analista de sistemas e analista de processos, tendo a visão técnica e operacional do "chão de fábrica", o que facilitou o entendimento e o detalhamento dos processos interfuncionais e processos relacionados à Engenharia de Software associados aos processos organizacionais.

Em relação às características de FS, apontadas na proposição deste trabalho, foram encontradas as seguintes evidências e obtidos os seguintes resultados:

\section{- Padronização de Processos}

A Arquitetura de Definição de Processos permitiu a criação de processos padronizados abordando seis aspectos: visão estratégica e organizacional, visão funcional, visão tática, visão operacional, visão pontual e visão de execução do trabalho. 
A visão estratégica mostra o macrofluxo do processo de negócio da organização; a visão funcional mostra a visão operacional das unidades funcionais da FS; a visão tática mostra o Processo-Padrão de Negócios da Organização, que serve como referência e guia para o mapeamento dos demais processos relacionados; a visão específica refere-se aos processos operacionais ou específicos como manutenções de sistemas; a visão pontual identifica os processos-chave da FS; e a visão de execução do trabalho, aloca os recursos das demandas solicitadas e executa a solicitação de serviço.

\section{- Reuso de Processos}

Constatou-se que a área de modelagem e criação de banco de dados seguia um processo estruturado de forma sistêmica, o que favorece a padronização e o reuso. $\mathrm{O}$ suporte para a criação, atualização e revisão dos modelos de dados, assim como o uso da respectiva ferramenta passava obrigatoriamente pela área de modelagem de dados, onde se realizava a homologação do modelo de dados, para depois direcionálo à área de criação e atualização de bancos de dados físicos.

Esta área mostrou ser possível centralizar e integrar os modelos de dados e, conseqüentemente, integrar os sistemas, com a padronização do processo por meio de uma visão organizacional. O processo pode ser considerado como um processochave e pode servir como exemplo para a criação de outros processos-chave.

Neste sentido, outros processos podem seguir o padrão do processo de modelagem de dados, como: arquitetura de sistemas, prototipação de interfaces de telas, análise de cálculo de pontos de função (APF), gestão da configuração de software, etc.

\section{- Reuso de Artefatos}

Segundo LIN (1998), os artefatos incluem elementos tangíveis (código, projeto, algoritmo, planos de testes, documentação, etc.) e elementos intangíveis (conhecimento, processos e metodologias).

Neste conceito, os artefatos definidos na Metodologia de Desenvolvimento de Sistemas e Integração - MDSI, possíveis de serem reusados são templates, artefatos de entrada e saída, fluxos dos processos mapeados, os modelos gerados e a documentação da metodologia.

Durante o levantamento do contexto organizacional e mapeamento dos processos, foram detectados artefatos reusados na EmpresaTI como: frameworks para 
desenvolvimento de sistemas na plataforma web, padrões de interfaces para aplicações multimídia, padrões para desenvolvimento na plataforma baixa, rotinas na plataforma mainframe, alguns sistemas corporativos como o Sistema de Controle de Acesso.

Diante desse fato, foram encontradas evidências de reuso de artefatos na EmpresaTI, porém o reuso não é praticado na maior parte das vezes de forma corporativa. Seria necessária a criação de uma área ou processo de Gestão do Conhecimento, com o objetivo de coleta, organização, controle e disponibilização de todo o acervo de conhecimentos e artefatos de reuso gerados pela FS. Outra prática para efetivar a cultura do reuso na organização seria a adoção dos processos definidos pela MDSI de forma corporativa.

\section{- Garantia da Qualidade do Produto}

Durante o mapeamento foi possível identificar quais eram os pontos-chave do processo para garantir a qualidade do produto final. Os principais pontos do processo que necessitavam executar revisões técnicas e check-lists foram em artefatos como os documentos de Visão e Escopo e Especificação de Requisitos, os artefatos produzidos pela área de Análise e Design enviados à área de Implementação, tanto interna, como fábrica externa como: documento de Arquitetura do Software, Modelo de Dados e Especificações de Casos de Uso. Com base nos fluxos mapeados identificou-se claramente estes pontos, sendo possível estipular os respectivos responsáveis por estes processos. Além disso, a área de Testes de Qualidade do Produto podia efetuar testes de homologação dos módulos executáveis dos produtos finais, com base em premissas estipuladas na Norma ISO 9126.

\section{- Gestão de Operações}

Uma das áreas mais importantes para a Gestão de Operações da FS é o PCP Planejamento e Controle de Produção. Na EmpresaTI, as atividades mais usuais executadas pela área de PCP são: gestão da demanda de serviços; recebimento, designação e liberação de solicitações de serviços; controle e acompanhamento das atividades e recursos alocados a partir da Gestão por Competências; e controle e acompanhamento das ordens de serviços dos subcontratados. Desta forma as diferentes áreas da empresa têm condições de obter e gerenciar informações de todo o fluxo de operações referentes ao desenvolvimento e manutenção de sistemas tanto 
internos como externos, inclusive a alta direção recebendo informações agregadas a respeito do desempenho da FS.

\section{- Alinhamento com processos de terceirização}

O projeto MDSI considerou a integração e o alinhamento dos processos e artefatos da Metodologia com os processos e artefatos das FS externas. Uma das experiências que aconteceram no período da PA foi realizar a revisão e avaliação dos artefatos da MDSI com os artefatos utilizados por uma empresa tercerizada. Em relação aos artefatos e templates, não houve muitos conflitos, já que as duas adotavam modelos customizados baseados no RUP e UML. Mas para que a FS externa tivesse resultados efetivos percebeu-se a grande importância do estabelecimento de um processo metodológico de desenvolvimento e manutenção amadurecido por parte tanto da contratante como da contratada. Esta experiência mostrou a validade do estabelecimento da MDSI em relação ao alinhamento, integração e acompanhamento dos processos das empresas terceirizadas.

\section{- Alinhamento dos processos da FS com Modelos de Melhores Práticas}

Os fluxos mapeados deram transparência aos processos, permitindo identificar processos-chave relativos a modelos de melhores práticas e normas de qualidade de software. A Tabela 17 mostra os processos de Modelos de Melhores Práticas relacionados aos processos da FS. Os modelos considerados foram: CMMI, ISO/IEC 12207, PMBOK, RUP e ITIL.

Tabela 17 - Modelos de Melhores Práticas associados aos Processos da FS

\begin{tabular}{|l|l|l|}
\hline \multirow{4}{*}{ Processos da FS } & \multicolumn{1}{|c|}{$\begin{array}{c}\text { Denominação dos Processos } \\
\text { nos Modelos de Melhores Práticas }\end{array}$} & \multicolumn{1}{|c|}{$\begin{array}{c}\text { Modelos de Melhores } \\
\text { Práticas }\end{array}$} \\
\hline \multirow{5}{*}{$\begin{array}{l}\text { Processo } \\
\text { Organizacional }\end{array}$} & Foco no Processo da Organização & CMMI 3 \\
\cline { 2 - 3 } & Definição do Processo da Organização & CMMI 3 \\
\cline { 2 - 3 } & Desempenho do Processo Organizacional & CMMI 4 \\
\cline { 2 - 3 } & Análise Causal e Resolução & CMMI 5 \\
\cline { 2 - 3 } & Inovação e Melhoria Organizacional & CMMI 5 \\
\cline { 2 - 3 } & $\begin{array}{l}\text { Treinamento Organizacional } \\
\text { Treinamento }\end{array}$ & $\begin{array}{c}\text { CMMI 3 } \\
\text { ISO/IEC 12207 }\end{array}$ \\
\cline { 2 - 3 } & Gerência & ISO/IEC 12207 \\
\cline { 2 - 3 } & Melhoria & ISO/IEC 12207 \\
\cline { 2 - 3 } & Infra-Estrutura & ISO/IEC 12207 \\
\hline Gestão de Projetos & Gerência Quantitativa do Projeto & PMBOK / RUP \\
\cline { 2 - 3 } & $\begin{array}{l}\text { Gerenciamento de Projeto } \\
\text { Gerência }\end{array}$ & $\begin{array}{l}\text { PMO/IEC 12207 } \\
\text { PMOK / CMMI 2 }\end{array}$ \\
\cline { 2 - 3 } & $\begin{array}{l}\text { Planejamento de Projeto } \\
\text { Acompanhamento e Controle de Projeto }\end{array}$ & PMBO / CMMI 2 \\
\hline
\end{tabular}




\begin{tabular}{|c|c|c|}
\hline Processos da FS & $\begin{array}{c}\text { Denominação dos Processos } \\
\text { nos Modelos de Melhores Práticas }\end{array}$ & $\begin{array}{c}\text { Modelos de Melhores } \\
\text { Práticas } \\
\end{array}$ \\
\hline & $\begin{array}{l}\text { Gerência da Integração do Projeto } \\
\text { Gerência Integrada de Projeto }\end{array}$ & $\begin{array}{l}\text { PMBOK } \\
\text { CMMI } 3\end{array}$ \\
\hline & $\begin{array}{l}\text { Gerência do Escopo do Projeto } \\
\text { Gerência do Tempo do Projeto } \\
\text { Gerência de Custo do Projeto }\end{array}$ & $\begin{array}{l}\text { PMBOK } \\
\text { PMBOK } \\
\text { PMBOK }\end{array}$ \\
\hline & $\begin{array}{l}\text { Gerência da Qualidade do Projeto } \\
\text { Garantia da Qualidade de Processo e Produto } \\
\text { Garantia da Qualidade }\end{array}$ & $\begin{array}{l}\text { PMBOK } \\
\text { CMMI } 2 \\
\text { ISO/IEC } 12207 \\
\end{array}$ \\
\hline & Gerência de Recursos Humanos do Projeto & PMBOK \\
\hline & Gerência das Comunicações do Projeto & PMBOK \\
\hline & $\begin{array}{l}\text { Gerência dos Riscos do Projeto } \\
\text { Gerência de Risco }\end{array}$ & $\begin{array}{l}\text { PMBOK } \\
\text { CMMI } 3 \\
\end{array}$ \\
\hline & $\begin{array}{l}\text { Gerência das Aquisições do Projeto } \\
\text { Gerência de Acordo com Fornecedores } \\
\text { Aquisição e Fornecimento }\end{array}$ & $\begin{array}{l}\text { PMBOK } \\
\text { CMMI } 2 \\
\text { ISO/IEC } 12207\end{array}$ \\
\hline & $\begin{array}{l}\text { Análise de Decisão e Resolução } \\
\text { Resolução de Problemas }\end{array}$ & $\begin{array}{l}\text { CMMI } 3 \text { / ITIL } \\
\text { ISO/IEC } 12207 \text { / ITIL }\end{array}$ \\
\hline & Documentação & ISO/IEC 12207 \\
\hline & Manutenção & ISO/IEC 12207 \\
\hline & Melhoria & ISO/IEC 12207 \\
\hline & Infra-Estrutura & ISO/IEC 12207 / ITIL \\
\hline & Treinamento & ISO/IEC 12207 \\
\hline \multirow{8}{*}{$\begin{array}{l}\text { Desenvolvimento } \\
\text { (Negócios) }\end{array}$} & Modelagem de Negócios & RUP \\
\hline & $\begin{array}{l}\text { Gerência de Requisitos } \\
\text { Desenvolvimento de Requisitos } \\
\text { Requisitos }\end{array}$ & $\begin{array}{l}\text { CMMI } 2 \\
\text { CMMI } 3 \\
\text { RUP / ISO/IEC } 12207\end{array}$ \\
\hline & $\begin{array}{l}\text { Gerência da Qualidade de Processo e Produto } \\
\text { Garantia da Qualidade }\end{array}$ & $\begin{array}{l}\text { CMMI } 2 \\
\text { ISO/IEC } 12207\end{array}$ \\
\hline & $\begin{array}{l}\text { Gerência de Configuração } \\
\text { Gerência de Configuração e Mudança }\end{array}$ & $\begin{array}{l}\text { CMMI } 2 \text { / ISO/IEC } 12207 \\
\text { RUP / ITIL }\end{array}$ \\
\hline & $\begin{array}{l}\text { Verificação } \\
\text { Validação } \\
\text { Revisão Conjunta, Validação CMMI }\end{array}$ & $\begin{array}{l}\text { CMMI } 3 \text { / ISO/IEC } 12207 \\
\text { CMMI } 3 \text { / ISO/IEC } 12207 \\
\text { ISO/IEC 12207, CMMI }\end{array}$ \\
\hline & Medição e Análise & CMMI 2 \\
\hline & Documentação & ISO/IEC 12207 \\
\hline & Manutenção & ISO/IEC 12207 \\
\hline \multirow[t]{7}{*}{$\begin{array}{l}\text { Desenvolvimento e } \\
\text { Engenharia } \\
\text { (Análise) / } \\
\text { Suporte Técnico }\end{array}$} & $\begin{array}{l}\text { Análise e Design } \\
\text { Projetos } \\
\text { Solução Técnica } \\
\text { Integração de Produto }\end{array}$ & $\begin{array}{l}\text { RUP } \\
\text { ISO/IEC } 12207 \\
\text { CMMI } 3 \\
\text { CMMI } 3\end{array}$ \\
\hline & $\begin{array}{l}\text { Gerência da Qualidade de Processo e Produto } \\
\text { Garantia da Qualidade }\end{array}$ & $\begin{array}{l}\text { CMMI } 2 \\
\text { ISO/IEC } 12207\end{array}$ \\
\hline & $\begin{array}{l}\text { Gerência de Configuração } \\
\text { Gerência de Configurąão e Mudança }\end{array}$ & $\begin{array}{l}\text { CMMI } 2 \text { / ISO/IEC } 12207 \\
\text { RUP / ITIL }\end{array}$ \\
\hline & $\begin{array}{l}\text { Verificação } \\
\text { Validação } \\
\text { Revisão Conjunta }\end{array}$ & $\begin{array}{l}\text { CMMI } 3 \text { / ISO/IEC } 12207 \\
\text { CMMI } 3 \text { / ISO/IEC } 12207 \\
\text { ISO/IEC 12207 }\end{array}$ \\
\hline & Medição e Análise & CMMI 2 \\
\hline & $\begin{array}{l}\text { Verificação } \\
\text { Validação } \\
\text { Validação e Verificação } \\
\text { Revisão Conjunta }\end{array}$ & $\begin{array}{l}\text { CMMI } 3 \\
\text { CMMI } 3 \\
\text { ISO/IEC } 12207 \\
\text { ISO/IEC } 12207 \\
\end{array}$ \\
\hline & Documentação & ISO/IEC 12207 \\
\hline
\end{tabular}




\begin{tabular}{|c|c|c|}
\hline Processos da FS & $\begin{array}{c}\text { Denominação dos Processos } \\
\text { nos Modelos de Melhores Práticas }\end{array}$ & $\begin{array}{l}\text { Modelos de Melhores } \\
\text { Práticas }\end{array}$ \\
\hline & Manutenção & ISO/IEC 12207 \\
\hline \multirow{8}{*}{$\begin{array}{l}\text { Desenvolvimento e } \\
\text { Engenharia } \\
\text { (Implementação) / } \\
\text { Suporte Técnico }\end{array}$} & $\begin{array}{l}\text { Implementação } \\
\text { Codificação }\end{array}$ & $\begin{array}{l}\text { RUP } \\
\text { ISO/IEC } 12207\end{array}$ \\
\hline & $\begin{array}{l}\text { Teste } \\
\text { Teste / Integração }\end{array}$ & $\begin{array}{l}\text { RUP } \\
\text { ISO/IEC } 12207\end{array}$ \\
\hline & $\begin{array}{l}\text { Gerência da Qualidade de Processo e Produto } \\
\text { Garantia da Qualidade }\end{array}$ & $\begin{array}{l}\text { CMMI } 2 \\
\text { ISO/IEC } 12207\end{array}$ \\
\hline & $\begin{array}{l}\text { Gerência de Configuração } \\
\text { Gerência de Configuração e Mudança }\end{array}$ & $\begin{array}{l}\text { CMMI } 2 \text { / ISO/IEC } 12207 \\
\text { RUP / ITIL }\end{array}$ \\
\hline & Medição e Análise & CMMI 2 \\
\hline & $\begin{array}{l}\text { Verificação } \\
\text { Validação } \\
\text { Revisão Conjunta } \\
\end{array}$ & $\begin{array}{l}\text { CMMI } 3 \text { / ISO/IEC } 12207 \\
\text { CMMI } 3 \text { / ISO/IEC } 12207 \\
\text { ISO/IEC } 12207\end{array}$ \\
\hline & Documentação & ISO/IEC 12207 \\
\hline & Manutenção & ISO/IEC 12207 \\
\hline \multirow{6}{*}{$\begin{array}{l}\text { Desenvolvimento e } \\
\text { Engenharia (Testes } \\
\text { e Homologação) / } \\
\text { Suporte Técnico }\end{array}$} & $\begin{array}{l}\text { Teste } \\
\text { Testes e Integração }\end{array}$ & $\begin{array}{l}\text { RUP } \\
\text { ISO/IEC } 12207\end{array}$ \\
\hline & $\begin{array}{l}\text { Gerência da Qualidade de Processo e Produto } \\
\text { Garantia da Qualidade }\end{array}$ & $\begin{array}{l}\text { CMMI } 2 \\
\text { ISO/IEC } 12207\end{array}$ \\
\hline & $\begin{array}{l}\text { Gerência de Configuração } \\
\text { Gerência de Configuração e Mudança }\end{array}$ & $\begin{array}{l}\text { CMMI } 2 \text { / ISO/IEC } 12207 \\
\text { RUP / ITIL }\end{array}$ \\
\hline & $\begin{array}{l}\text { Verificação } \\
\text { Validação } \\
\text { Revisão Conjunta } \\
\end{array}$ & $\begin{array}{l}\text { CMMI } 3 \text { / ISO/IEC } 12207 \\
\text { CMMI } 3 \text { / ISO/IEC } 12207 \\
\text { ISO/IEC } 12207\end{array}$ \\
\hline & Documentação & ISO/IEC 12207 \\
\hline & Manutenção & ISO/IEC 12207 \\
\hline \multirow{3}{*}{ Qualidade } & $\begin{array}{l}\text { Garantia da Qualidade de Processo e Produto } \\
\text { Garantia da Qualidade }\end{array}$ & $\begin{array}{l}\text { CMMI } 2 \\
\text { ISO/IEC } 12207 \\
\end{array}$ \\
\hline & $\begin{array}{l}\text { Verificação } \\
\text { Validação } \\
\text { Revisão Conjunta }\end{array}$ & $\begin{array}{l}\text { CMMI } 3 \text { / ISO/IEC } 12207 \\
\text { CMMI } 3 \text { / ISO/IEC } 12207 \\
\text { ISO/IEC } 12207\end{array}$ \\
\hline & Auditoria & ISO/IEC 12207 \\
\hline \multirow{11}{*}{ Infra-Estrutura } & $\begin{array}{l}\text { Resolução de Problemas } \\
\text { Implantação } \\
\text { Instalação }\end{array}$ & $\begin{array}{l}\text { ISO/IEC } 12207 \\
\text { RUP } \\
\text { ISO/IEC } 12207 \\
\end{array}$ \\
\hline & Operação & ISO/IEC 12207 \\
\hline & $\begin{array}{l}\text { Garantia da Qualidade de Processo e Produto } \\
\text { Garantia da Qualidade }\end{array}$ & $\begin{array}{l}\text { CMMI } 2 \\
\text { ISO/IEC } 12207 \\
\end{array}$ \\
\hline & $\begin{array}{l}\text { Gerência de Configuração } \\
\text { Gerência de Configuração e Mudança }\end{array}$ & $\begin{array}{l}\text { CMMI } 2 \text { / ISO/IEC } 12207 \\
\text { RUP / ITIL }\end{array}$ \\
\hline & Ambiente & RUP / ITIL \\
\hline & Gerência de Acordo de Nível de Serviços & ITIL \\
\hline & Gerência de Capacidade e Disponibilidade & ITIL \\
\hline & Service-Desk & ITIL \\
\hline & Gerência de Incidentes & ITIL \\
\hline & Gerência de Liberações & ITIL \\
\hline & Gerência de Problemas & ITIL \\
\hline \multirow{4}{*}{$\begin{array}{l}\text { Planejamento e } \\
\text { Controle de } \\
\text { Produção }\end{array}$} & Gerência de Recursos Humanos & PMBOK \\
\hline & Gerência do Tempo & PMBOK \\
\hline & Gerência de Custo & PMBOK \\
\hline & Medição e Análise & CMMI 2 \\
\hline
\end{tabular}

Fonte: elaborada pela autora 
Observa-se que alguns Modelos abordam os mesmos processos. No caso de mais de um Modelo ser implantado simultaneamente, pode-se originar conflitos em definir quem é o dono do processo. Por exemplo, quase todos os modelos tratam do processo de Gestão da Configuração, que pode ser implantado tanto pela área de Infra-Estrutura por meio do Modelo ITIL, como pela área de Desenvolvimento por meio do Modelo CMMI. 


\section{CICLO 3 - ANÁLISE DO IMPACTO DAS MUDANÇAS NOS PROCESSOS}

Como visto no Ciclo 2, a Metodologia de Desenvolvimento de Sistemas e Integração - MDSI foi definida e as etapas concluídas: levantamento, análise e mapeamento dos processos, revisão dos artefatos e templates, validação, documentação e divulgação. Por meio dos resultados do Ciclo 2 verificou-se que é possível mapear e definir processos com características de FS em uma organização de TI do setor público, considerando os aspectos, estratégicos, operacionais e técnicos.

Porém, o estabelecimento, ou seja, a institucionalização dos processos mapeados não se realizou de forma efetiva na EmpresaTI. A dificuldade de estabelecimento da MDSI foi percebida quando no primeiro semestre de 2007 uma nova mudança administrativa e em conseqüência mudança organizacional ocorreu na EmpresaTI, o que reforçou a idéia da influência que provoca o aspecto da cultura organizacional de empresas públicas nos processos operacionais.

\subsection{Fase 1 - Diagnóstico}

No início de 2007, dentre os projetos estratégicos encontravam-se, novamente, a atualização e a implementação da Metodologia de Desenvolvimento de Sistemas alinhada à nova estrutura organizacional da empresa. Desta forma, o Projeto MDSI necessitou ser revisado e reestruturado. Para isso, fazia-se necessário iniciar um novo ciclo de atualização e validação dos fluxos mapeados, de acordo com as novas regras de negócios e novas atribuições das áreas funcionais, sendo a análise da nova estrutura organizacional, o primeiro passo para iniciar a reavaliação dos processos.

\section{- Análise da Estrutura Organizacional 4}

A Estrutura Organizacional 4 mostrada na Figura 28, volta a ser verticalizada, com o objetivo de agilizar e melhorar o atendimento ao cliente. Este modelo está organizado por três diretorias, cada uma composta de gerências de relacionamento constituída de gerentes e analistas de negócios que atendem a grupos de clientes específicos em diversificados domínios de negócios. Cada diretoria tem uma gerência de desenvolvimento composta de analistas de sistemas, desenvolvedores e especialistas.

Além das Diretorias de Relacionamento e Desenvolvimento esta estrutura possui duas Superintendências: uma de Tecnologia e Inovação e outra de Suporte ao 
Desenvolvimento. A primeira atende a projetos ligados à Tecnologia, Geoprocessamento, Governo Eletrônico e Informações Estratégicas. A segunda, compõe as áreas: Qualidade; Planejamento e Controle de Produção; Escritório de Projetos; Qualidade do Produto; Metodologia e Integração; e Racionalização de Processos. A Diretoria de Infra-Estrutura é composta das áreas: Mudanças, Produção, Serviços, Segurança, Telecomunicações e Rede.

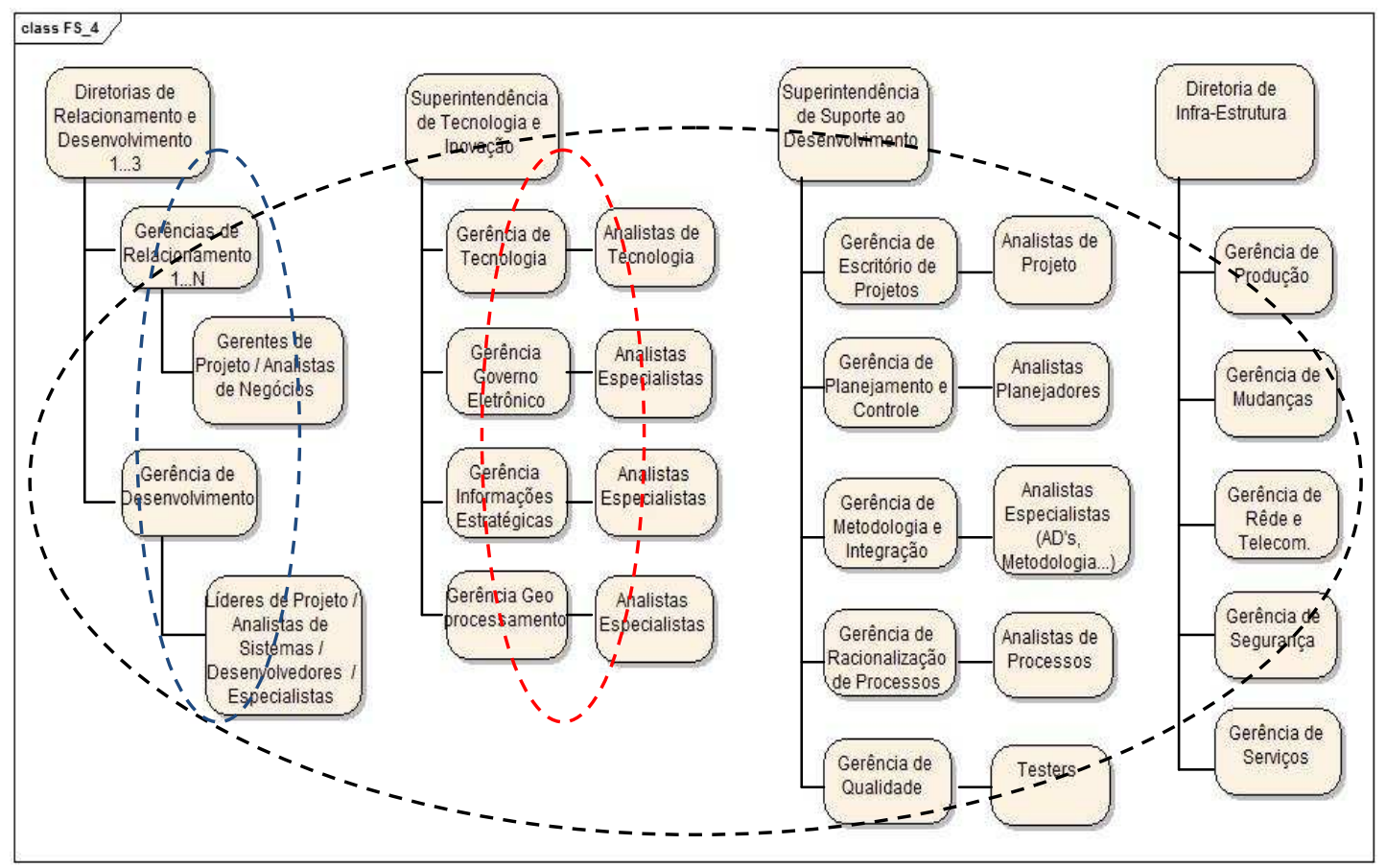

Figura 28 - Estrutura Organizacional da EmpresaTI - Orientada a Clientes

Esta estrutura tem como vantagem a maior proximidade da equipe de trabalho com o cliente, facilitando a gestão e controle do projeto e agilidade no atendimento. A desvantagem está na dificuldade de padronização dos sistemas e processos de forma corporativa e, em conseqüência, na integração dos sistemas, base de dados e reuso de artefatos e processos de software de forma sistêmica.

\subsection{Fase 2 - Planejamento}

O cronograma de planejamento (Anexo 21) da etapa de revisão e validação da MDSI com a participação da autora com esforços da área de Racionalização de Processos e Metodologia e Integração, compreendeu o período de agosto a novembro de 2007 e contemplou as seguintes atividades: 
- Revisão e atualização dos processos mapeados: Macrofluxo do processo de negócio, Fluxo do Processo-Padrão de Negócio, Fluxo dos Processos de Manutenção: Evolutiva, Adaptativa, Corretiva e Abend;

- Validação com gerentes das áreas envolvidas;

- Revisão e adequação de artefatos e templates com fornecedores terceirizados; e

- Revisão e atualização dos artefatos, templates e documentação da MDSI.

\subsection{Fase 3 - Execução}

Esta fase compreendeu as ações relativas à revisão e atualização da MDSI.

\subsubsection{Revisão da MDSI}

Como no Ciclo 2 já haviam sido definidas as matrizes dos elementos que compõem o processo referente à Arquitetura de Definição de Processos; desta vez, a mudança acarretou apenas a revisão das atribuições das áreas funcionais, atualizando a matriz de papéis e responsabilidades e a matriz de atividades integradas, já caracterizandose como um processo de melhoria contínua.

Segue a lista dos fluxos atualizados:

- Macrofluxo do Processo de Negócio;

- Matriz de Atividades Integrada da Unidade Organizacional;

- Fluxo do Processo-Padrão de Negócio;

- Manual do Processo-Padrão de Negócio;

- Matriz de Atividades Integradas do Processo-Padrão;

- Fluxo do Processo de Manutenção Evolutiva e Adaptativa;

- Fluxo do Processo de Manutenção Corretiva e Abend.

A validação do mapeamento dos processos envolveu uma série de oito reuniões com: cada uma das três gerências da área de desenvolvimento; e cada uma das gerências: metodologia e integração; racionalização de processos; qualidade do produto; escritório de projetos; e planejamento e controle de produção.

Outras ações relevantes foram efetuadas neste ciclo:

- Ação 1: foi efetuada uma análise do impacto causado pela mudança da estrutura organizacional nos processos de negócios da EmpresaTI, e apresentado aos novos diretores. Neste estudo foram mostradas as vantagens e desvantagens da estrutura 
verticalizada e da estrutura matricial, estudada anteriormente no presente trabalho. Os pontos de atenção mais críticos apontados foram:

- Dificuldades na padronização dos sistemas e processos;

- Dificuldades na integração de sistemas, base de dados e sistemas corporativos;

- Dificuldades na flexibilização para utilização dos recursos entre as diretorias; e

- Dificuldades na integração do planejamento e controle de produção de forma global.

- Ação 2: continuidade das atividades para efetuar o alinhamento e integração dos processos, artefatos e templates da Fábrica de Software terceirizada com os definidos na MDSI.

- Ação 3: por ocasião de um projeto da área de Infra-Estrutura para implantação de uma ferramenta de Gestão da Configuração, foi criado um grupo de trabalho multidisciplinar com integrantes da área de desenvolvimento, infra-estrutura, processos, metodologia e integração, onde a autora atuava. O trabalho inicial referiase ao mapeamento do processo de Gestão da Configuração, que foi efetuado com base no fluxo do Processo-Padrão de Negócio. O mapeamento do fluxo de versionamento de itens de configuração possibilitou o entendimento do processo operacional da gestão da configuração por parte de todos os integrantes do grupo. $\mathrm{O}$ fluxo mapeado serviu como base para executar um novo mapeamento, gerado pelos técnicos da área de infra-estrutura focando a visão técnica, mostrando o fluxo das atividades relacionadas ao uso da ferramenta nos ambientes operacionais de desenvolvimento, homologação e produção. Desta forma o Processo-Padrão de Negócio mostrou-se como importante guia de condução e mapeamento de outros processos-chave.

\subsection{Fase 4 - Avaliação}

Esta fase compreendeu a verificação da influência e dos impactos das mudanças organizacionais e cultura organizacional causadas nos processos.

PIRES e MACEDO (2006) descrevem que a cultura organizacional é um conceito essencial à construção das estruturas organizacionais. Percebe-se, então, que a cultura de uma organização é um conjunto de características que a diferencia em relação a qualquer outra. 
A EmpresaTI conviveu por muito tempo com a verticalização do processo formando um contingente de técnicos ponta-a-ponta, impedindo a especialização, e difícultando a adoção de um modelo matricial. Desta forma, a implantação de uma nova estrutura organizacional que quebre o modelo verticalizado torna-se complexa, já que esta mudança afeta diretamente os processos operacionais, a gestão do conhecimento, a gestão por competências e a cultura organizacional, além dos resultados serem alcançados a médio e longo prazos.

Constatou-se que alguns diagnósticos efetuados no Ciclo 2, continuavam existindo em maior ou menor proporção no Ciclo 3, mostrando evidências que existem questões "crônicas" que persistem na empresa, independente da estrutura organizacional adotada e, que devem ser analisadas e resolvidas. Estas questões referem-se a:

- Ausência de uma área efetiva e permanente de suporte técnico com visão organizacional, acompanhamento e melhoria contínua da qualidade dos processos e produtos;

- Gestão do conhecimento desagregada, em conseqüência das constantes mudanças organizacionais; e

- Dificuldades em implantar processos organizacionais que incentivem a cultura do reuso.

Uma das soluções para corrigir estas questões encontra-se no fortalecimento de áreas ou processos com foco corporativo, responsáveis pela integração, suporte e alinhamento técnico, operacional e gerencial dos diferentes grupos de trabalho. Estes processos podem ser estrategicamente posicionados e adequados à estrutura organizacional vigente, visando a uma maior produtividade e qualidade nos projetos de TI.

\subsection{Fase 5 - Resultados}

Na mudança da estrutura matricial para a estrutura verticalizada, em relação à revisão dos modelos e artefatos produzidos na MDSI, não houve grandes dificuldades em sua atualização. A MDSI mostrou-se facilmente adaptável a diferentes estruturas organizacionais. No modelo matricial os fluxos eram conduzidos e denominados pelas áreas funcionais, no movo modelo os fluxos passaram a ser conduzidos e denominados pelos processos, procurando seguir uma visão de processos e 
desvincular da estrutura funcional. Realizaram-se ajustes com as novas regras de negócios e melhorias propostas nas reuniões de validação com os gerentes das áreas envolvidas.

Em relação às mudanças organizacionais, concluiu-se que constantes mudanças no modelo organizacional da Empresa e/ou em novas regras de negócios e/ou alterações nas atribuições das áreas funcionais afetam diretamente tanto os aspectos operacionais e técnicos como os culturais da FS. Desta forma, criam-se dificuldades para o estabelecimento e amadurecimento de uma metodologia de desenvolvimento e manutenção de sistemas adequada e alinhada à estratégia de negócios da Empresa, agravando-se pela inexistência de grupos permanentes de suporte e acompanhamento dos processos relacionados à Metodologia de Desenvolvimento de Sistemas.

Neste contexto, chega-se à conclusão que para a definição e estabelecimento de uma Metodologia de Desenvolvimento de Sistemas, abrangendo características de FS, não basta focar apenas a visão de projeto e produto, mas sim focar a metodologia com uma visão de processos, entender todo o contexto organizacional, incluindo a análise da estrutura e cultura organizacional da empresa.

\subsubsection{Diagrama dos Componentes Organizacionais de Análise da FS}

Uma visão geral dos processos e componentes organizacionais de análise da FS para o desenvolvimento da Metodologia de Desenvolvimento de Sistemas e Integração (MDSI) é mostrada no Diagrama da Figura 29. Esses componentes foram tratados de forma direta ou indireta para o mapeamento, definição, reestruturação e estabelecimento dos processos de FS na EmpresaTI. O Diagrama mostra o posicionamento dos Modelos criados neste trabalho dentro do contexto organizacional, com o objetivo maior de alinhamento, integração e reuso corporativos. 


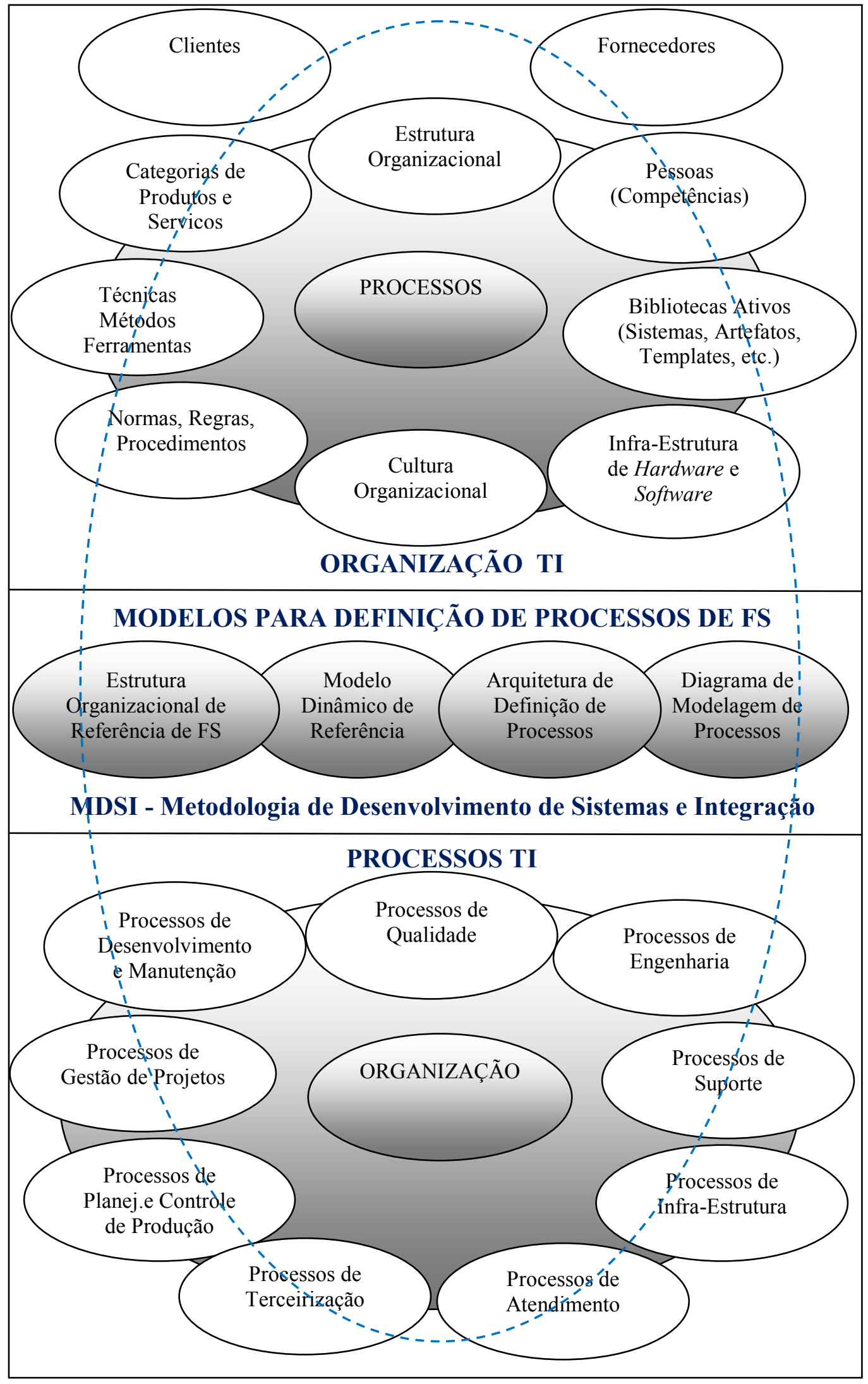

Figura 29- Diagrama dos componentes organizacionais de análise da FS Fonte: elaborada pela autora 


\section{CONSIDERAÇÕES FINAIS}

Este trabalho apresentou uma proposta para o mapeamento, definição, reestruturação e estabelecimento de processos de Fábrica de Software (FS) em uma organização produtora de software do setor público.

Por intermédio da Pesquisa-Ação (PA) foi possível mostrar os caminhos trilhados para analisar e validar esta proposição. Ao longo do desenvolvimento do trabalho foi possível constatar a real importância da visão organizacional de processos em uma empresa de TI.

Pelo fato da empresa estudada atender ao setor público, muitas mudanças ocorreram durante a pesquisa-ação. Em função desta dinâmica, novos estudos foram se incorporando ao contexto estudado, como por exemplo, a cultura organizacional, o que trouxe mais informações e geração de conhecimento do complexo ambiente estudado.

Vale ressaltar que a maior fonte de informações e o maior patrimônio de uma empresa produtora de software estão contidos no conhecimento, experiências e competências das pessoas, que representam a principal base de sustentação para o funcionamento de uma FS.

Outro ponto importante a ressaltar é que os líderes atuem como mentores; tenham uma visão sistêmica e abrangente; adotem os processos definidos; ultrapassem as fronteiras da organização e negociem em relação às restrições do curto prazo, facilitando a gestão do fluxo do trabalho por meio dos processos definidos.

A seguir detalham-se as principais conclusões deste trabalho, as contribuições e sugestões para trabalhos futuros.

\subsection{Conclusões}

O objetivo principal deste trabalho (Seção 1.3) teve a seguinte proposição:

"É possível mapear, definir, reestruturar e estabelecer processos e conceitos de Fábrica de Software em uma organização de TI do setor público, considerando os aspectos: padronização de processos, reuso de artefatos, segmentação de atividades, gestão de operações, terceirização, estrutura e cultura organizacional com o objetivo de integração e alinhamento corporativo". 
Com estes propósitos, as pesquisas e as investigações bibliográficas (Capítulo 2) focaram disciplinas relacionadas a conceitos e processos de FS. O trabalho foi conduzido em campo por meio de uma pesquisa-ação (PA) (Capítulo 3) em uma organização produtora de software que atende ao setor público (Capítulo 4).

Nos ciclos de desenvolvimento da PA (Capítulos 5, 6 e 7), as evidências empíricas relatadas mostraram as seguintes conclusões:

- Foi realizado o mapeamento e definição dos processos de desenvolvimento e manutenção da EmpresaTI com foco em características de FS (Seção 5.3) e, alinhadas às estruturas organizacionais vigentes (Seção 5.1.1). Este projeto foi denominado MDSI - Metodologia de Desenvolvimento de Sistemas e Integração (Seção 6.4.3). No mapeamento e definição dos processos foram considerados processos-chave que incentivam a cultura do reuso de processos e artefatos. Os fluxos mapeados revelaram-se importantes instrumentos de trabalho para efetuar diagnósticos e identificar processos organizacionais estratégicos e operacionais (Seção 6.4);

- Foi criado o Fluxo do Processo-Padrão (Anexo 3), sua especificação (Anexo 4) e a Matriz de Atividades Integrada (Anexo 5), que possibilitou o mapeamento e definição de demais processos padronizados determinados pela Arquitetura de Definição de Processos (Seção 6.3.1). Constatou-se que a Arquitetura de Definição de Processos é adaptável a diferentes estruturas organizacionais, considerando-se o posicionamento estratégico dos processos dentro das diferentes estruturas (Capítulo 7);

- Os aspectos de integração e alinhamento corporativos foram constatados no mapeamento dos processos pelas relações interfuncionais entre os processos ou áreas-chave que promovem esta integração e alinhamento (Seção 6.4);

- Houve evidências mostrando características de FS na EmpresaTI (Seções 6.5; 6.6) como: padronização de processos, reuso de artefatos de software, gestão de operações, terceirização, segmentação de atividades, sistemas corporativos e alinhamento com modelos de melhores práticas. Porém estes indícios foram encontrados pontualmente e não de forma corporativa, dificultando a adoção efetiva de um Modelo de FS. 
- As ressalvas são pertinentes às dificuldades encontradas para o estabelecimento dos processos, que não se efetivou de forma corporativa, em razão das constantes mudanças organizacionais, cultura organizacional, e inexistência de áreas e grupos de especialistas dedicados exclusivamente ao propósito de estabelecer, acompanhar e melhorar continuamente estes processos (Capítulo 7). Neste ponto, a proposta é a criação de um grupo de trabalho multidisciplinar permanente ou uma área responsável pelo acompanhamento, suporte, treinamento e execução de melhoria contínua nos processos e metodologia, além de grupos específicos de especialistas em suporte a técnicas, métodos, ferramentas e qualidade de Engenharia de Software com visão organizacional e sistêmica.

Os objetivos específicos traçados inicialmente (Seção 1.3) foram:

1 - Estudar conceitos, características e processos sobre Fábrica de Software, com base na literatura, assim como nas disciplinas relacionadas ao contexto da pesquisa.

- Conclusões: A fundamentação teórica (Capítulo 2) envolveu uma ampla pesquisa bibliográfica pela diversidade do tema pesquisado. A revisão da literatura foi realizada continuamente, desde o início até o término do trabalho, de forma que informações relevantes não ficassem excluídas do trabalho.

2 - Propor modelos conceituais para guiar e aplicar na PA.

- Conclusões: os modelos criados baseados na fundamentação teórica, experiência profissional e pesquisa empírica serviram como guia e instrumento de trabalho para o mapeamento, implementação e melhoria dos processos, assim como ao entendimento do complexo contexto do ambiente de pesquisa. Os modelos propostos foram: Estrutura Organizacional de Referência de Fábrica de Software (FS) (Seção 5.3.1); Modelo Dinâmico de Referência de FS (Seção 5.3.2); Arquitetura de Definição de Processos para FS (Seção 6.3.1); Modelo de Definição de Processos (Seção 6.3.2); Diagrama de Representação da Modelagem de Processos (Seção 6.3.3) e Diagrama dos Componentes Organizacionais de Análise da FS (Seção 7.5.1).

3 - Planejar, estruturar e executar a PA concretizando os objetivos definidos.

- Conclusões: neste trabalho, o método de Pesquisa-Ação (Seção 3.2) adotado permitiu uma integração dos aspectos teórico-conceituais relacionados à pesquisa com os aspectos práticos e de implementação dos modelos que se mostraram 
funcionalmente viáveis e possíveis de serem aplicados em projetos reais. A organização da PA em ciclos e fases (Seção 3.3) auxiliou a compreensão e a redação do trabalho. O objetivo principal da PA para a organização estudada referia-se à criação de uma Metodologia de Desenvolvimento de Sistemas e Integração (MDSI), o que foi realizada com sucesso (Seção 6.4.3).

\subsection{Contribuições}

A contribuição mais significativa deste trabalho é a abordagem do processo de desenvolvimento e manutenção de sistemas por intermédio de uma visão do processo organizacional e não com a visão de projeto. Esta visão organizacional possibilita analisar os impactos que as mudanças organizacionais e a cultura organizacional causam nos processos estratégicos, táticos, operacionais e pontuais de uma empresa produtora de software, com o objetivo maior de alinhamento, integração e reuso corporativos, com base nas características de FS.

Os benefícios para a EmpresaTI são pertinentes às seguintes contribuições:

- Tomada de consciência em relação à influência e impacto das mudanças organizacionais e cultura organizacional de empresas de TI do setor público nos processos de desenvolvimento e manutenção de software;

- Percepção da importância do fortalecimento de áreas técnicas de suporte e acompanhamento com visão organizacional; e

- Definição da Metodologia de Desenvolvimento de Sistemas e Integração (MDSI) com foco organizacional. O projeto MDSI está em andamento na EmpresaTI até a data final de redação deste trabalho, mantendo a premissa de continuidade.

Os ganhos de conhecimento obtidos pela pesquisa referem-se aos seguintes fatores:

- Proposição de uma Estrutura Organizacional de Referência de FS segmentada em especializações, de acordo com os principais processos-chave relativos ao desenvolvimento de software, com foco no reuso de artefatos e processos;

- Proposição de uma Arquitetura de Definição de Processos, com os modelos associados, contendo as principais estratégias a serem seguidas para o mapeamento e definição de processos em uma organização produtora de software; 
- Uso do método de Pesquisa-Ação (PA), o que pode contribuir ao aperfeiçoamento deste método, e que permite uma integração maior de aspectos teóricos e práticos;

- Uso dos modelos como instrumentos de trabalho e como guias para empresas que desejem explicitar seus processos e queiram criar metodologias que busquem estabelecer processos de FS em seu ambiente produtivo;

- Melhor entendimento do contexto organizacional e cultura organizacional de empresas produtoras de software do setor público.

- Estudo da influência e impactos de diferentes estruturas organizacionais e cultura organizacional na gestão de processos de desenvolvimento de software.

\subsection{Trabalhos Futuros}

Durante o desenvolvimento deste trabalho, surgiram outras questões, mas não fizeram parte do escopo desta pesquisa. Desta forma, ficam sugestões de alguns temas para estudos futuros:

- Desenvolvimento de metodologias para integração e alinhamento dos processos e artefatos de desenvolvimento e manutenção de sistemas das empresas produtoras de software contratantes e as Fábricas de Software externas;

- Criação de infra-estrutura para gerar e utilizar repositórios de processos e artefatos de reuso de software em ambientes de FS;

- Desenvolvimento de mecanismos de Gestão do Conhecimento para os sistemas legados e em manutenção, como a transformação do conhecimento implícito em conhecimento explícito para utilização de forma corporativa;

- Estudo da Gestão por Competências em um ambiente de FS;

- Criação de um Modelo de "Fábrica" ou "Oficina" de Manutenção de Software em larga escala com Metodologias Ágeis;

- Estudo do impacto e influência das mudanças organizacionais do setor público nos processos operacionais das empresas públicas de TI. 


\section{ANEXOS}

Anexo 1- Visão Estratégica - Macrofluxo do Processo de Negócio

(Fluxo Resumido)

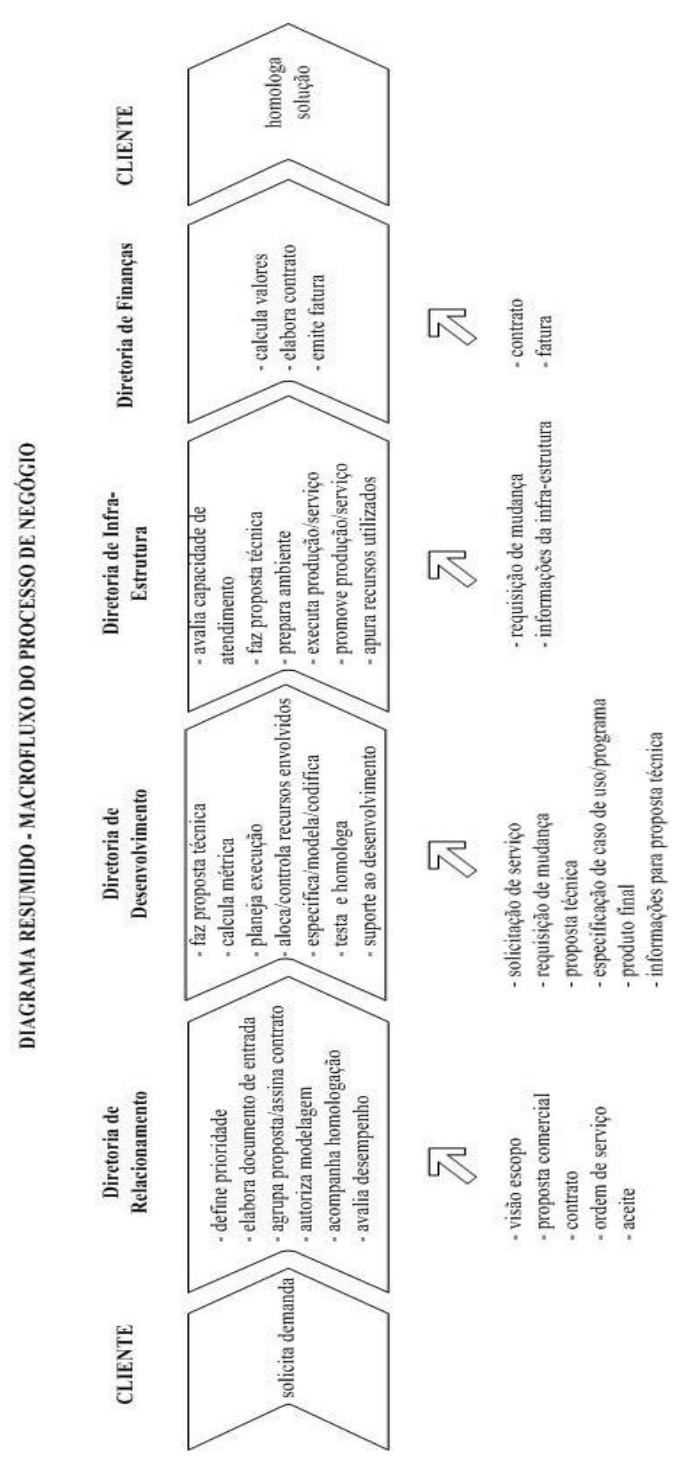


Anexo 2 - Visão Funcional - Matriz de Atividades Integrada - Unidade Organizacional

\begin{tabular}{|c|c|c|c|c|c|c|c|c|c|c|c|}
\hline | & & 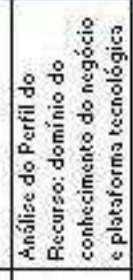 & & $\begin{array}{l}8 \\
8 \\
8 \\
3 \\
3 \\
3\end{array}$ & & & & & 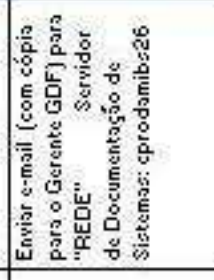 & & 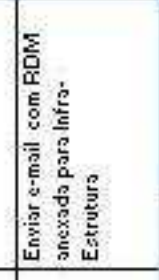 \\
\hline 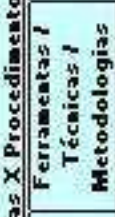 & & 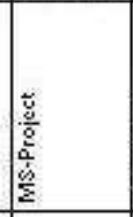 & & 3 & 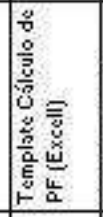 & 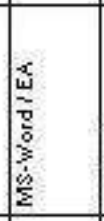 & 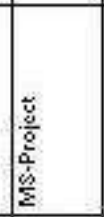 & 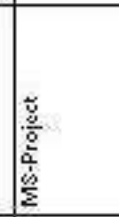 & & 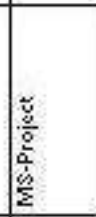 & \\
\hline 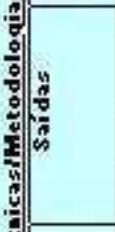 & 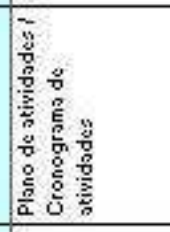 & 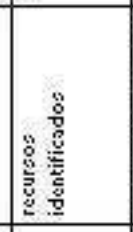 & 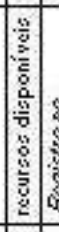 & 2 & 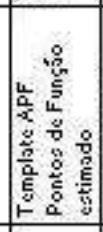 & 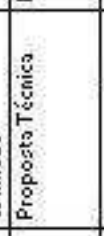 & 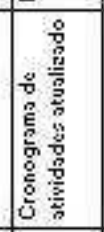 & 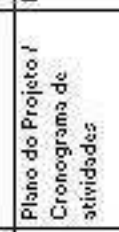 & 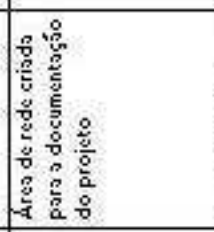 & 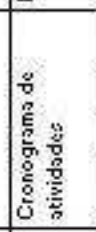 & 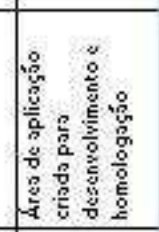 \\
\hline 题 & 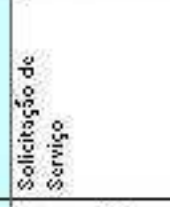 & 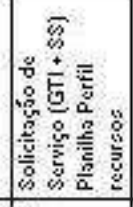 & & 8 & 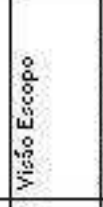 & 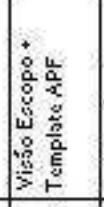 & 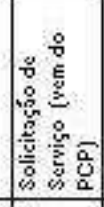 & 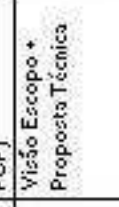 & 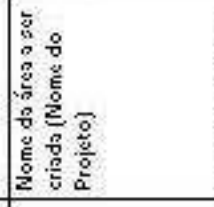 & 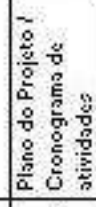 & a \\
\hline 等 & 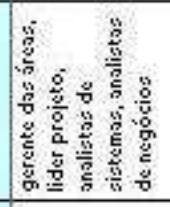 & 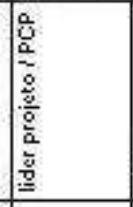 & 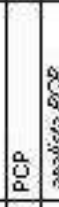 & & 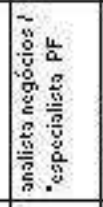 & 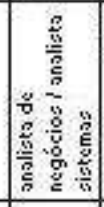 & \begin{tabular}{|l|l}
$\frac{2}{2}$ \\
$\frac{2}{2}$ \\
$\frac{2}{2}$ \\
$\frac{2}{2}$ \\
$\frac{2}{2}$ \\
$\frac{2}{2}$ \\
\end{tabular} & 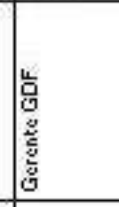 & 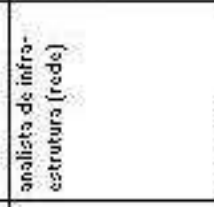 & 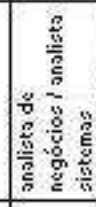 & 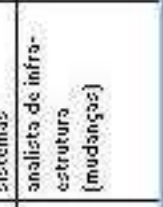 \\
\hline 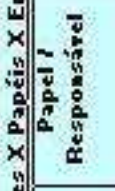 & 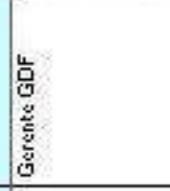 & 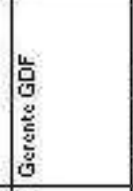 & 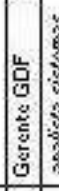 & 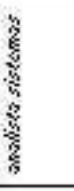 & 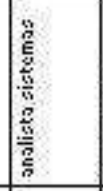 & 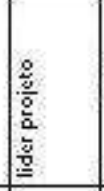 & 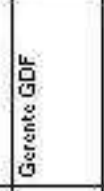 & 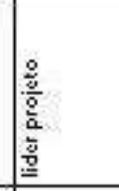 & $\frac{2}{\frac{2}{3}}$ & $\begin{array}{l}\frac{2}{2} \\
\frac{2}{2} \\
\frac{2}{2} \\
\frac{2}{2} \\
\frac{2}{2}\end{array}$ & 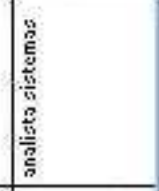 \\
\hline 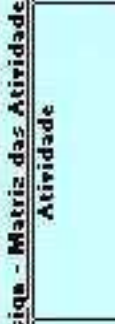 & 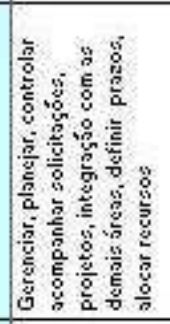 & 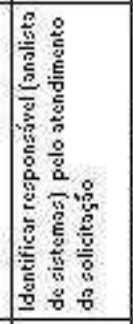 & 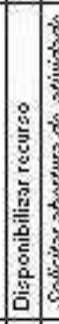 & 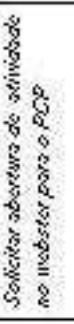 & 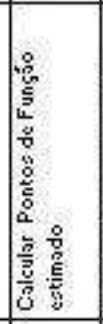 & 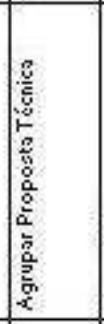 & 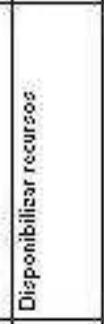 & 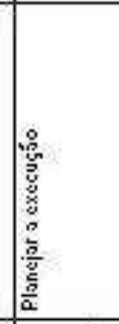 & 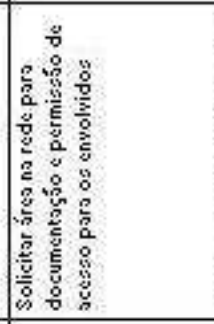 & 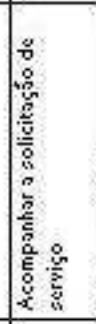 & 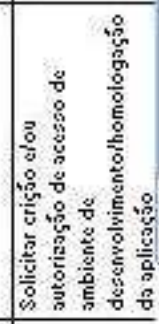 \\
\hline 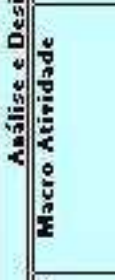 & 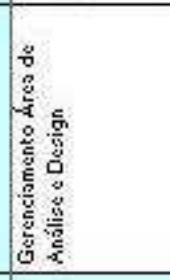 & 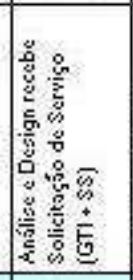 & 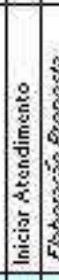 & 政 & 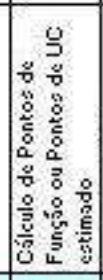 & 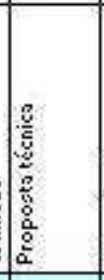 & 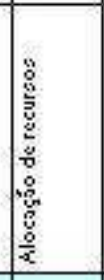 & 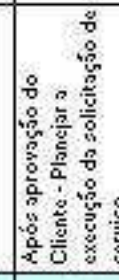 & 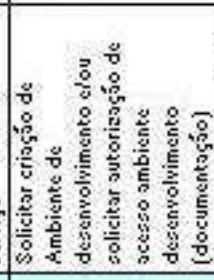 & 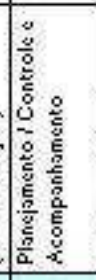 & 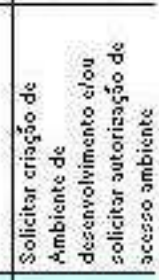 \\
\hline $\mathscr{z}$ & 总 & 容 & 岕部 & S & 峞 & 岁 & 容 & 崖 & 䓌 & 容 & 容 \\
\hline$\sqrt{2}$ & - & la & $\mid-1$ & 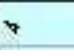 & wo & . & F & $\left.\right|_{\infty}$ & 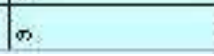 & I & $F$ \\
\hline
\end{tabular}


Anexo 3 -Visão tática - Fluxo do Processo-Padrão de Negócio

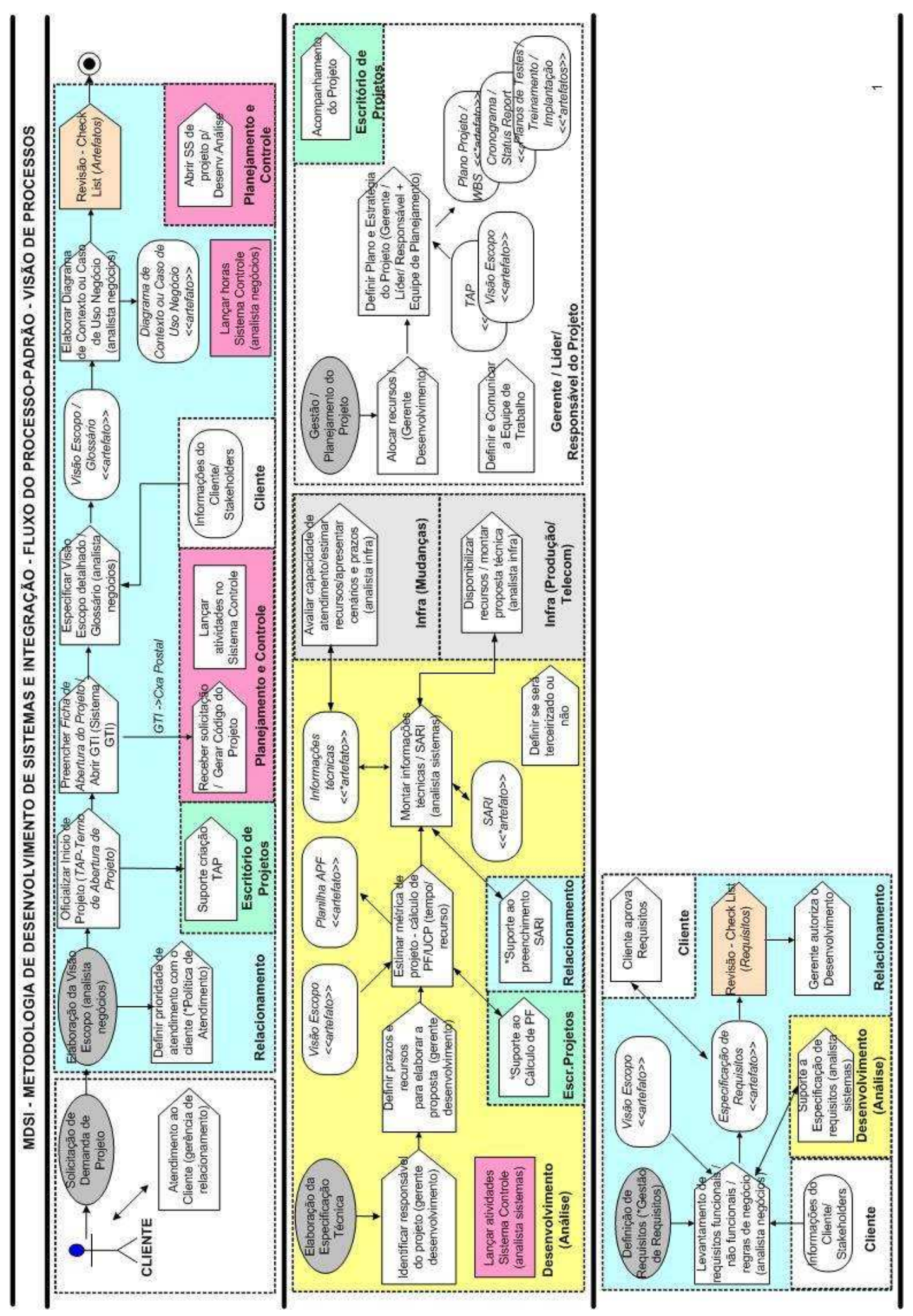




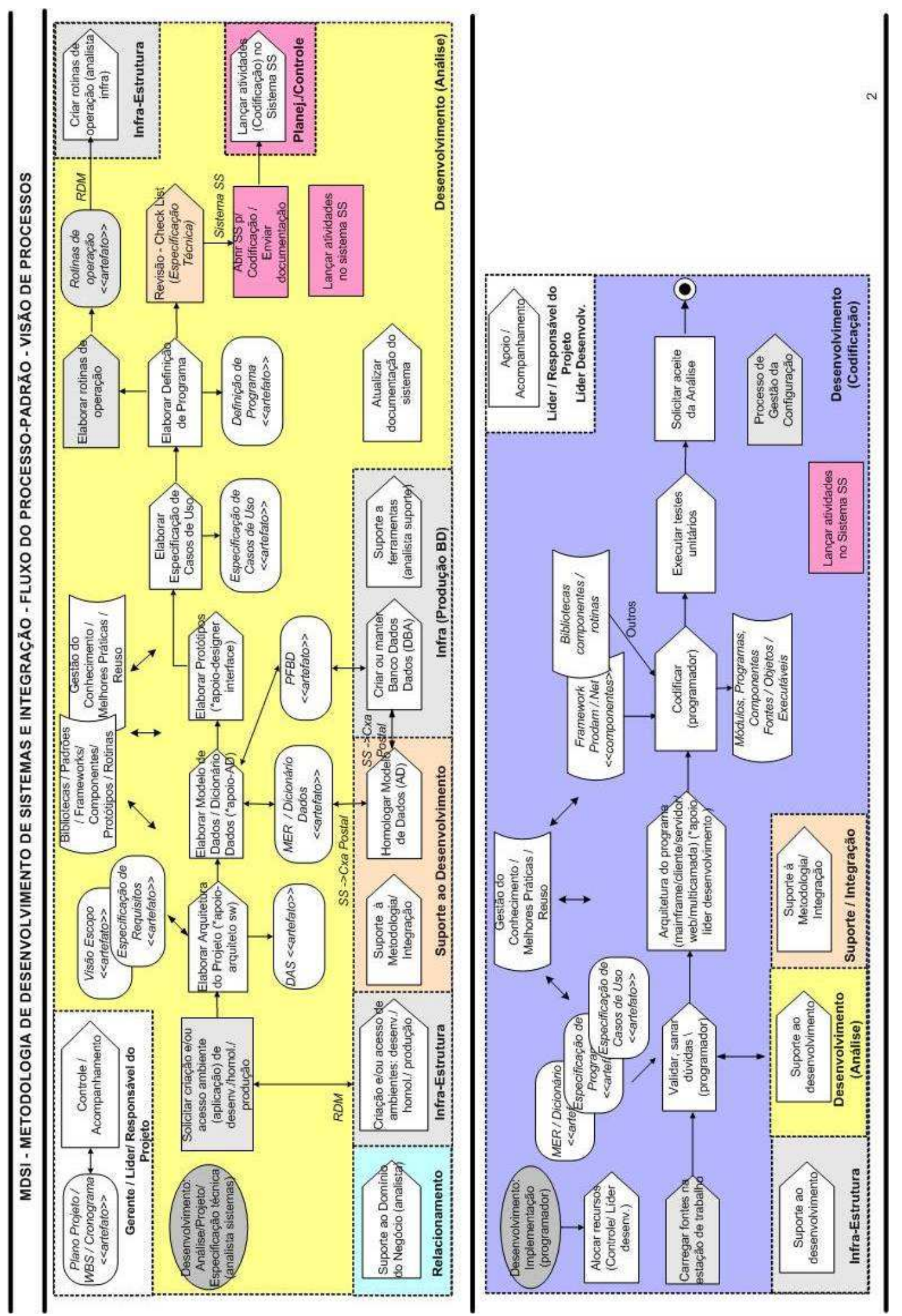




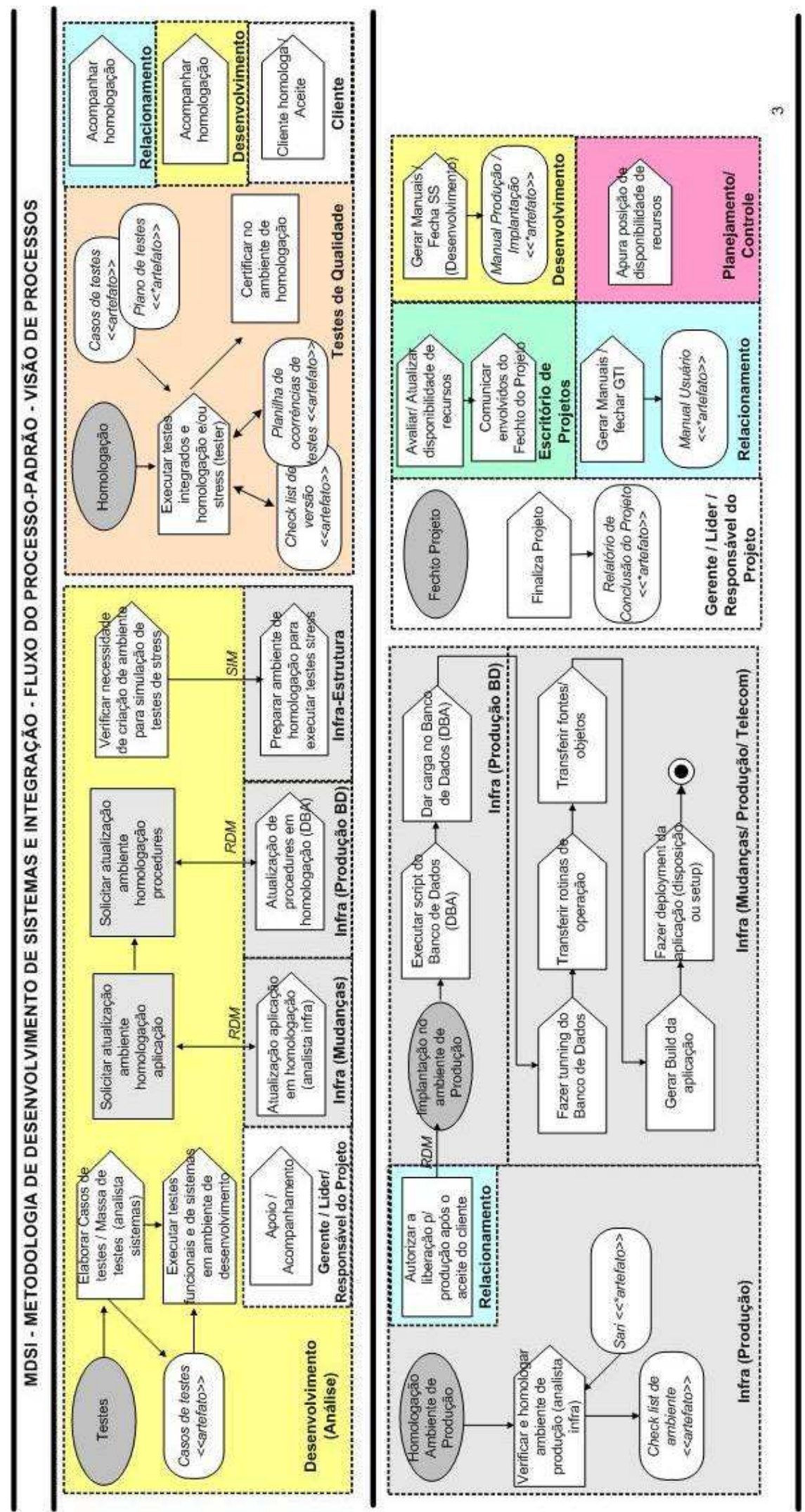


Anexo 4 - Especificação do Processo-Padrão - Manual da MDSI

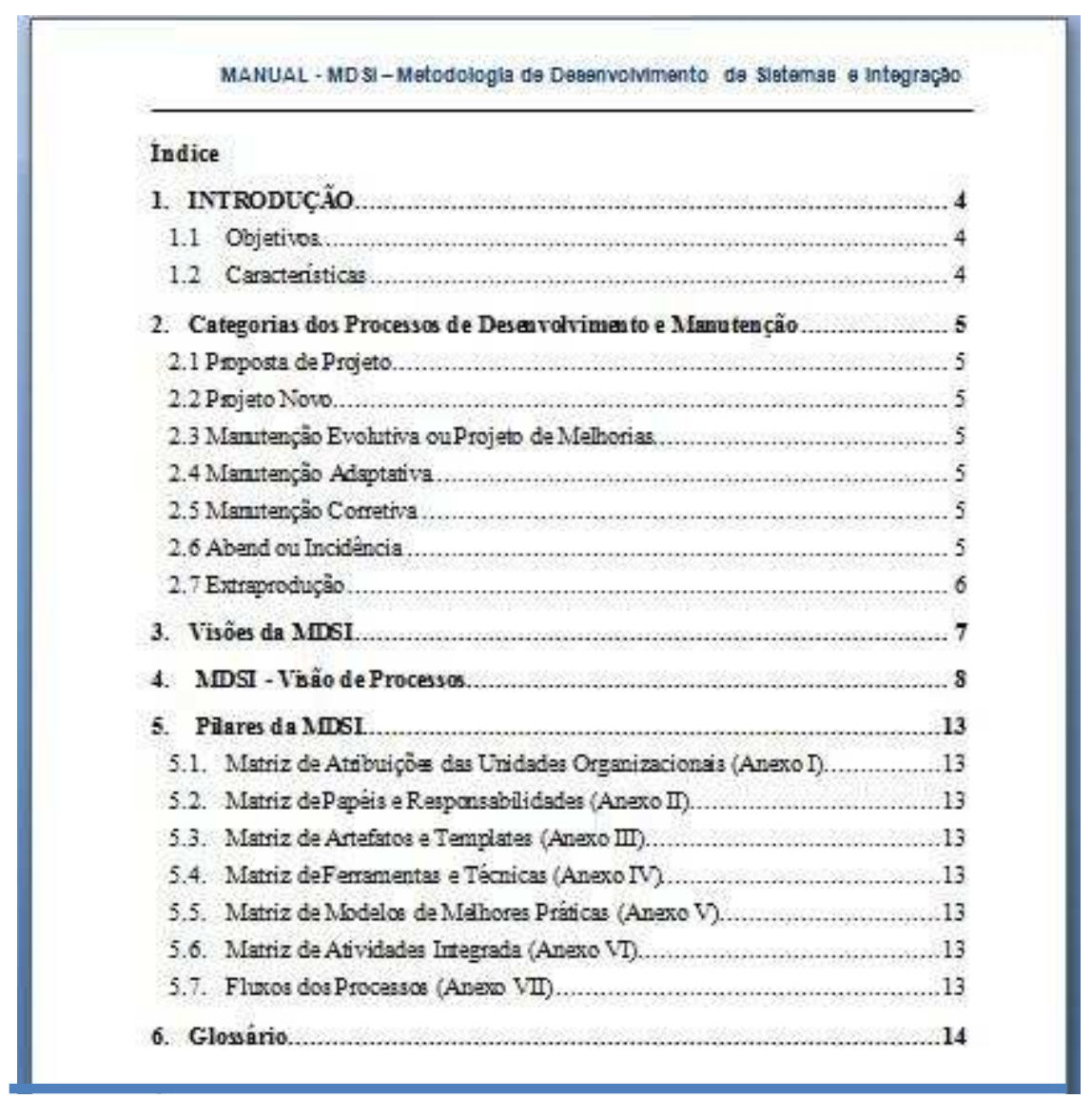

\begin{tabular}{|l|}
\hline \multicolumn{1}{|c|}{ MDSI - ESPECIFICAÇÃO DO PROCESSO-PADRÃO } \\
\hline FASE 1 - PROPOSTA DO PROJETO \\
\hline Objetivo: Realizar Proposta de Projeto solicitada por um cliente externo ou órgão interno. \\
Atividades: \\
- Levantar necessidade de negócio e requisitos que o produto ou serviço do projeto deverá \\
satisfazer; \\
- Elaborar o documento Visão e Escopo do Projeto; \\
- Elaborar o documento de Informações Técnicas; \\
- Desenvolver a Proposta de Projeto; \\
- Análise, Checkist e Revisão da documentação da Proposta; \\
- Gerar Contrato do Projeto; \\
- Emitir Ordem de Serviço. \\
Documentos: \\
Visão Escopo; Planilha APF - Análise de Ponto de Função; Informações Técnicas para a \\
Proposta; Proposta Comercial; Contrato do Projeto; OS - Ordem de Serviço; Checklist da \\
documentação da Proposta. \\
Responsáveis: \\
Diretos: cliente; gerente de relacionamento; analista de negócios; analista de sistemas. \\
Indiretos: Desenvolvimento; Suporte ao Desenvolvimento (Planejamento e Controle, Escritório \\
de Projetos, Qualidade, Metodologia e Integração); Infra-Estrutura (Mudanças, Produção, Rede); \\
Segurança; Financeiro; Comercialização; Jurídico. \\
\hline FASE 2 - PLANEJAMENTO, GESTÃO E CONTROLE DO PROJETO \\
\hline Objetivo: Realizar análise detalhada da solicitação, alocar recursos e pessoas, gerar o Plano de \\
Desenvolvimento do Projeto contendo os cronogramas e as etapas do projeto. \\
\hline
\end{tabular}




\section{MDSI - ESPECIFICAÇ̃̃O DO PROCESSO-PADRÃO}

\section{Atividades:}

- Elaborar Plano e Estratégia do Projeto;

- Estruturar e formalizar a equipe de projeto;

- Solicitar criação de áreas em servidores de rede para documentação;

- Administrar os cronogramas operacionais do projeto;

- Controlar e acompanhar a execução das etapas do projeto;

- Realizar comunicações, notificações e avisos relevantes ao bom andamento dos projetos;

- Assegurar o cumprimento dos prazos acordados;

- Negociar o andamento das Solicitações de Serviços;

- Coordenar e registrar reuniões e eventos dos projetos;

- Elaborar o Plano de Testes, Implantação, Treinamento.

Documentos:

Artefatos de Gestão de Projetos: Plano do Projeto; WBS (Work Breakdown Structure);

Cronogramas; Planos de Testes, Plano de Treinamento, Plano de Implantação, entre outros.

Responsáveis:

Diretos: gerente, líder ou responsável do projeto

Indiretos: Relacionamento; Desenvolvimento (Análise e Programação); Suporte ao

Desenvolvimento (Planejamento e Controle, Escritório de Projetos); Infra-Estrutura (Mudanças;

Produção; Rede); Segurança.

\section{FASE 3 - ELABORAÇÃO DE VISÃO ESCOPO / DEFINIÇÃO DE REQUISITOS}

Objetivo: Realizar análise da solicitação do cliente, definir os requisitos de negócios, as metas e os riscos do projeto. Levantar requisitos funcionais, não funcionais e regras de negócios. Avaliar recursos, custos e prazos estimados envolvidos.

\section{Atividades:}

- Identificar, priorizar e planejar a solicitação;

- Elaborar o documento Visão e Escopo do Projeto;

- Levantar e elaborar Especificação de Requisitos;

- Análise, Checkist e Revisão do documento Visão Escopo e Especificação de Requisitos;

- Registrar, classificar e acompanhar as solicitações no Sistema de Solicitação de Serviço;

- Levantar Informações Técnicas, necessidades de recursos (hardware e software);

- Calcular Pontos de Função estimados.

\section{Documentos:}

Visão Escopo; Planilha APF (Análise de Pontos de Função); Informações Técnicas para o Projeto; OS - Ordem de Serviço; SS - Solicitação de Serviço para a área de Desenvolvimento (Análise); Checklist da Visão Escopo, Especificação de Requisitos.

\section{Responsáveis:}

Diretos: cliente; usuário; gerente de projeto; analista de negócios

Indiretos: Desenvolvimento (Análise); Suporte ao Desenvolvimento (Planejamento e Controle, Escritório de Projetos, Qualidade, Metodologia e Integração); Infra-Estrutura (Mudanças, Produção, Rede).

\section{FASE 4 - ANÁLISE E DESIGN}

Objetivo: Preparar arquitetura e definição completa e detalhada das funções, dados e interrelacionamentos entre sistemas e serviços a serem implementados.

\section{Atividades:}

- Solicitar para a área de Infra-Estrutura a criação e atualização de ambientes de desenvolvimento, homologação e produção para a aplicação;

- Detalhar e especificar os requisitos do sistema e funcionalidades;

- Elaborar a Arquitetura do Projeto (com o apoio de Arquitetos de Software);

- Elaborar o Modelo Lógico de Dados - MER, Dicionário de Dados e Projeto Físico de Banco de

Dados - PFBD (com o apoio de AD's e DBA's);

- Elaborar os protótipos de telas e relatórios (com o apoio de web-designers);

- Definir os Controles (Acesso, Segurança);

- Definir e Detalhar os Casos de Uso;

- Definir e Detalhar Programas, Rotinas, Componentes;

- Especificar rotinas de operação;

- Calcular Ponto de Função detalhado (APF); 


\section{MDSI - ESPECIFICAÇ̃̃O DO PROCESSO-PADRÃO}

- Complementar documento de Especificação de Requisitos;

- Elaborar Casos de Testes.

Documentos:

Especificação de Requisitos detalhada; Especificação de Casos de Uso, Especificação de Programas; Documento de Arquitetura do Software; Protótipos de telas e relatórios; Modelo Lógico de Dados; Projeto Físico de Banco de Dados; Dicionário de Dados; Planilha de Cálculo de Ponto de Função; SS para Codificação; Ckecklist da Qualidade.

Responsáveis:

Diretos: analista de sistemas; administrador de dados; administrador de banco de dados Indiretos: Relacionamento; Suporte ao Desenvolvimento (Planejamento e Controle, Escritório de Projetos, Qualidade, Metodologia e Integração); Infra-Estrutura (Mudanças; Produção; Rede).

\section{FASE 5 - IMPLEMENTAÇÃO}

Objetivo: Fase de construção da aplicação, onde os produtos definidos na fase de Análise e Design são desenvolvidos e testados no ambiente de desenvolvimento.

Atividades:

- Verificar e validar os documentos recebidos;

- Elaborar arquitetura de programas;

- Codificar programas, casos de uso, componentes, rotinas, etc.;

- Executar testes unitários no ambiente de desenvolvimento.

Documentos:

Conjunto de programas, casos de uso, componentes, rotinas, scripts, stored procedures.

Responsáveis:

Diretos: desenvolvedor; analista de sistemas

Indiretos: Relacionamento; Suporte ao Desenvolvimento (Qualidade, Planejamento, Integração); Infra-Estrutura (Mudanças; Produção; Rede).

FASE 6 - TESTES E HOMOLOGAÇÃO

Objetivo: Testar o sistema como um todo e suas interfaces com outros sistemas, em ambiente de desenvolvimento e homologação.

Atividades:

- Solicitar atualização do ambiente de homologação;

- Elaborar Casos de Testes;

- Elaborar Massa de Testes;

- Executar testes integrados e de homologação;

- Executar Ckecklist do produto final;

- Certificar no ambiente de homologação;

- Solicitar liberação e atualização do ambiente de produção após aceite do cliente.

Documentos:

Casos de Testes; Plano de Testes; Planilha de Ocorrências de Testes; Ckecklist

Responsáveis:

Diretos: tester de qualidade; analistas de sistemas; analista de negócios; responsável do projeto Indiretos: Infra-Estrutura (Mudanças; Produção; Rede)

\section{FASE 7 - IMPLANTAÇÃO}

Objetivo: Transferir os produtos para o ambiente de produção, liberando o sistema para utilização pelo cliente. Acompanhar o processo de implantação em ambiente de produção, de forma a garantir o seu funcionamento no período inicial e dar treinamento ao cliente.

Atividades:

- Atualizar o ambiente de produção;

- Executar e acompanhar o Plano de Implantação;

- Executar e acompanhar o Plano de Treinamento;

- Fechar as atividades no sistema de controle de projetos e recursos;

- Encerrar o Projeto.

Documentos:

Relatório de conclusão do Projeto; Plano de Treinamento; Plano de Implantação

Responsáveis:

Diretos: gerente, líder ou responsável do projeto, analista de negócios, analista de sistemas; 


\section{MDSI - ESPECIFICAÇÃO DO PROCESSO-PADRÃO}

analista de Infra-Estrutura.

Indiretos: Suporte ao Desenvolvimento (Escritório de Projetos, Qualidade, Planejamento,

Integração); Infra-Estrutura (Mudanças; Produção; Rede); Segurança. 
Anexo 5 - Matriz de Atividades Integradas do Processo-Padrão

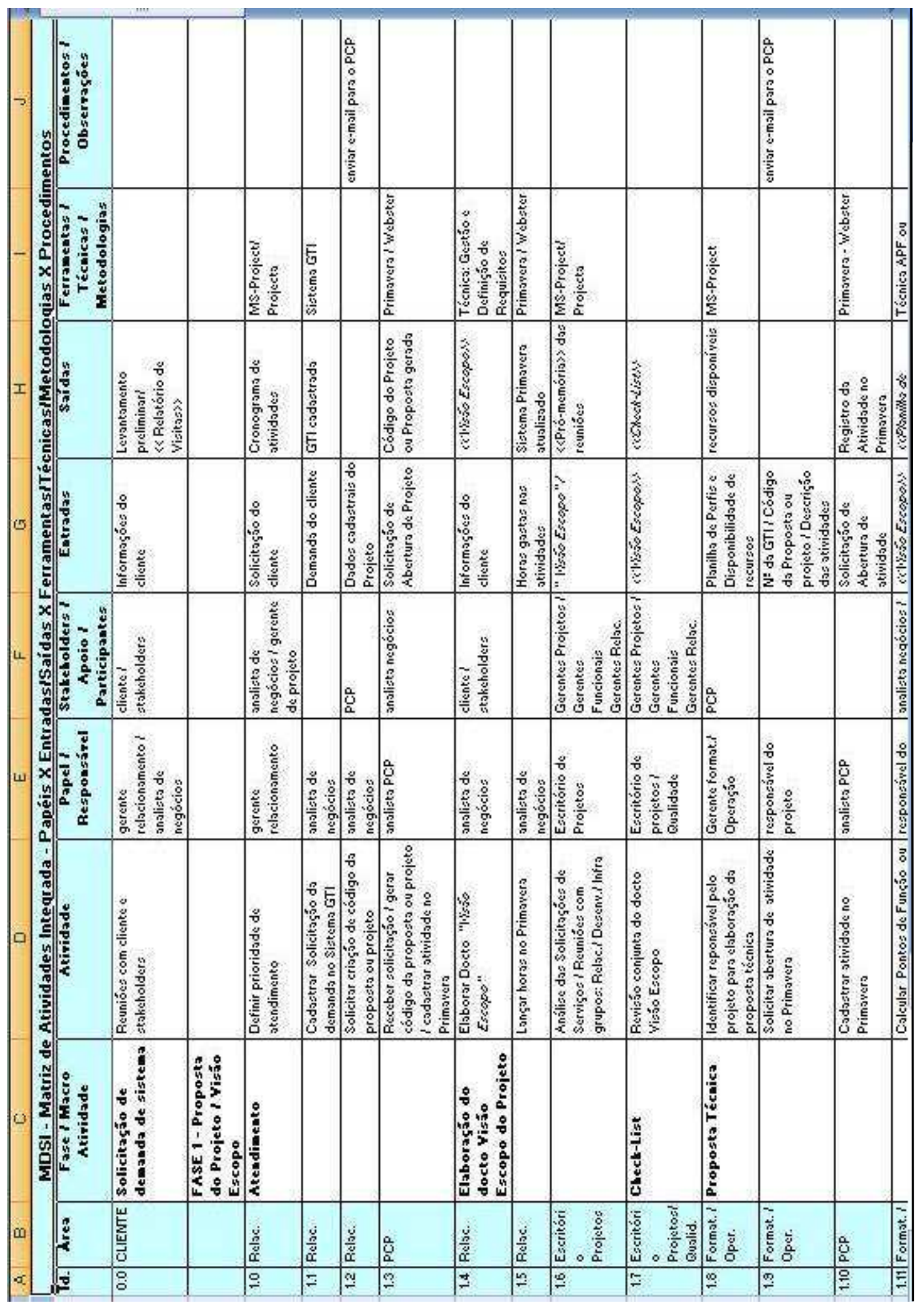


Anexo 6 - Fluxo do Processo de Manutenção Evolutiva e Adaptativa

(Exemplo: pag. 1)

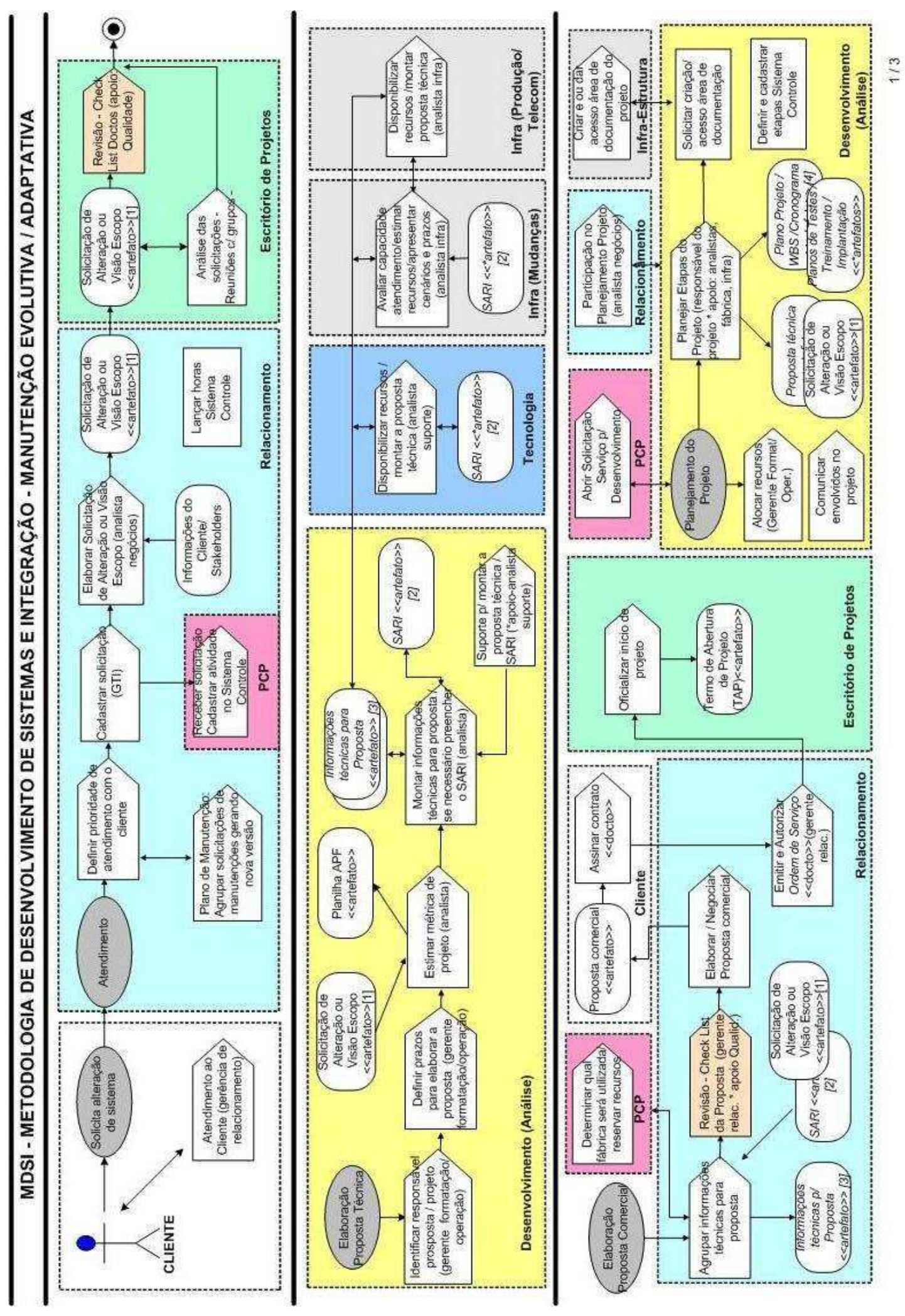


Anexo 7 - Fluxo do Processo de Manutenção Corretiva e Abend

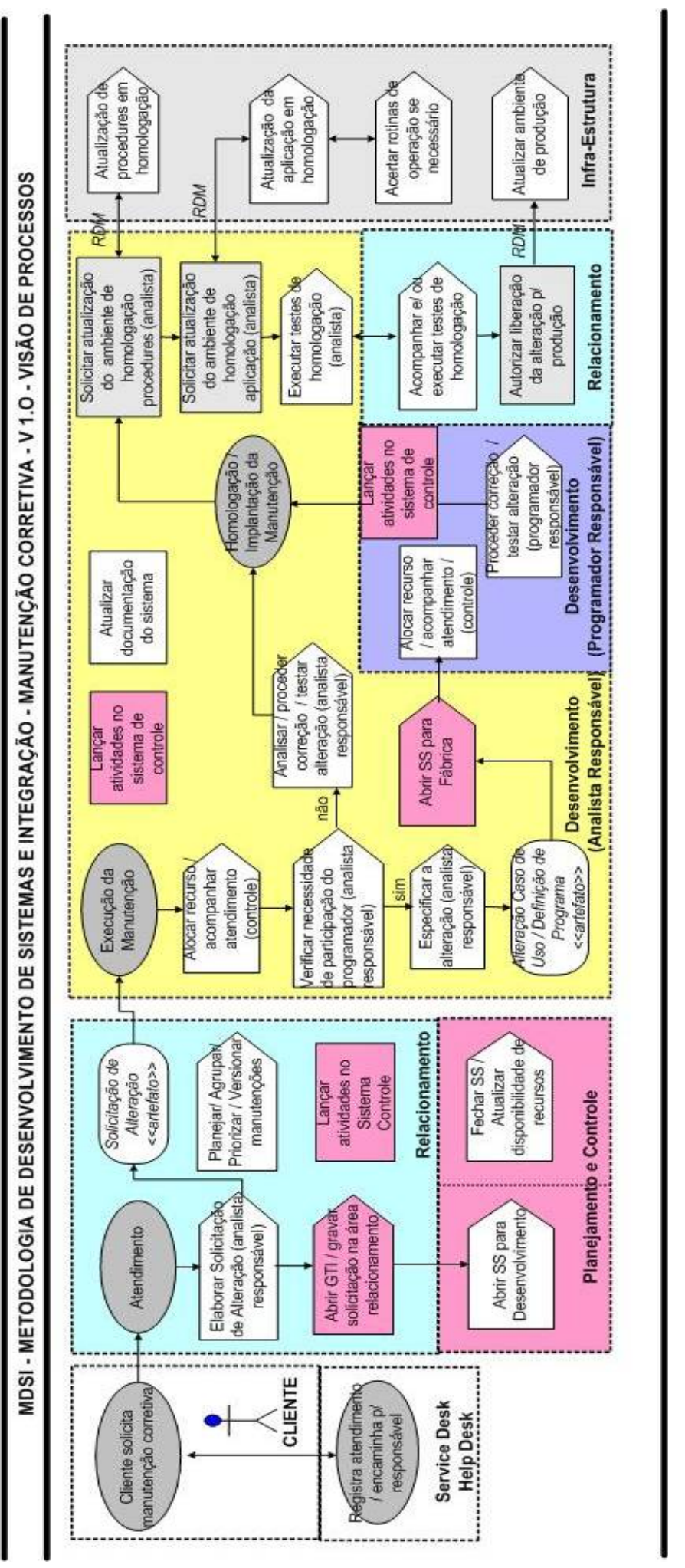


Anexo 8 - Atribuições das Áreas Funcionais da FS

\begin{tabular}{|c|c|}
\hline Áreas Funcionais & Atribuições das Áreas Funcionais \\
\hline $\begin{array}{l}\text { Relacionamento e } \\
\text { Atendimento ao Cliente } \\
\text { Pré-Venda } \\
\text { Service-Desk }\end{array}$ & $\begin{array}{l}\text { O objetivo do atendimento ao cliente é negociar e caracterizar a } \\
\text { solicitação da forma mais completa possível, definindo um documento } \\
\text { Visão e Escopo do Projeto que contemple: plano de comunicação, } \\
\text { risco, qualidade, custos, prazos e escopo do projeto (RUP 2003). } \\
\text { A área de Pré-Venda é responsável pelo relacionamento com o } \\
\text { cliente, comercialização e marketing dos produtos oferecidos, bem } \\
\text { como captar os anseios do cliente. } \\
\text { O Service Desk é a unidade que centraliza e atende usuários e clientes } \\
\text { em relação a reclamações, sugestões e solicitações de modificações e } \\
\text { manutenções em sistemas existentes e serviços, direcionando as } \\
\text { mesmas aos responsáveis de acordo com os processos estabelecidos. }\end{array}$ \\
\hline Escritório de Projetos & $\begin{array}{l}\text { Segundo o PMBOK, um Escritório de Projetos (Project Management } \\
\text { Office - PMO) é uma unidade organizacional que centraliza e } \\
\text { coordena o gerenciamento de projetos sob seu domínio. } \\
\text { O PMO concentra-se no planejamento, na priorização e na execução } \\
\text { coordenada de projetos e subprojetos, vinculados aos objetivos gerais } \\
\text { de negócios da matriz ou do cliente. } \\
\text { Os PMO podem operar de modo contínuo, desde o fornecimento de } \\
\text { funções de apoio ao gerenciamento de projetos na forma de } \\
\text { treinamento, software, políticas padronizadas e procedimentos, até o } \\
\text { gerenciamento direto real e a responsabilidade pela realização dos } \\
\text { objetivos do projeto. }\end{array}$ \\
\hline $\begin{array}{l}\text { Planejamento e Controle de } \\
\text { Produção (PCP) }\end{array}$ & $\begin{array}{l}\text { A área de PCP, segundo CONTADOR et al. (1997), tem a função } \\
\text { básica de controlar o processo de produção em todos os seus níveis e } \\
\text { dar suporte às necessidades estratégicas da fábrica no que diz respeito } \\
\text { a 'o que, quando, quanto e com que produzir e comprar'. Dentre as } \\
\text { principais funções do PCP, se destacam: } \\
\text { - Planejar as atividades de produção; } \\
\text { - Saber a situação corrente da produção; } \\
\text { - Ser capaz de reagir eficazmente a situações inesperadas que ocorrem } \\
\text { na produção. }\end{array}$ \\
\hline Infra-Estrutura & $\begin{array}{l}\text { A área de Infra-Estrutura é responsável pelo suporte em relação a } \\
\text { todos os recursos de hardware, software e serviços necessários à } \\
\text { execução dos processos de produção. Em geral esta área compreende } \\
\text { as unidades: gestão de mudanças, gestão de produção, gestão de } \\
\text { telecomunicações, rede e segurança e gestão de serviços. } \\
\text { Segundo o ITIL (2005), a gestão de mudanças tem como objetivo } \\
\text { controlar todas as mudanças que possam causar impacto na habilidade } \\
\text { da área de TI em entregar serviços, por meio de um processo único e } \\
\text { centralizado de aprovação, programação e controle de mudanças, para } \\
\text { assegurar que a infra-estrutura de TI permaneça alinhada aos } \\
\text { requisitos dos negócios com o menor risco possível. } \\
\text { No RUP (2003) a disciplina denominada "Ambiente", tratada pela } \\
\text { Infra-estrutura é definida com os objetivos: } \\
\text { - Manter o foco nas atividades necessárias para configurar o processo } \\
\text { para o projeto; } \\
\text { - Descrever as atividades requeridas para desenvolver as diretrizes } \\
\text { básicas para suporte ao projeto; } \\
\text { - Fornecer, para a organização de desenvolvimento de software, o } \\
\text { ambiente de processos e ferramentas que suportarão a equipe de } \\
\text { desenvolvimento e instalação do software. }\end{array}$ \\
\hline Negócios & $\begin{array}{l}\text { As seguintes atribuições fazem parte desta área: } \\
\text { - Modelagem de negócios consiste em entender a estrutura e a } \\
\text { dinâmica da organização na qual o software será entregue; identificar }\end{array}$ \\
\hline
\end{tabular}




\begin{tabular}{|c|c|}
\hline Áreas Funcionais & Atribuições das Áreas Funcionais \\
\hline & $\begin{array}{l}\text { problemas correntes na organização e possíveis aperfeiçoamentos; } \\
\text { assegurar que o cliente, o usuário final e os desenvolvedores possuam } \\
\text { a mesma compreensão da empresa ou organização; produzir os } \\
\text { requisitos de software necessários para suportar os objetivos da } \\
\text { organização (KRUCHTEN, 2003). } \\
\text {-Levantamento de requisitos comumente realizado por analistas de } \\
\text { negócios, consiste em estabelecer e manter o consentimento entre } \\
\text { clientes e stakeholders sobre o que o software deve fazer; fornecer } \\
\text { uma melhor compreensão dos requisitos aos arquitetos e } \\
\text { desenvolvedores de software; definir os limites do software; fornecer } \\
\text { as bases para o planejamento das iterações, estimativa de custo e } \\
\text { tempo de desenvolvimento; definir as interfaces do software com base } \\
\text { nas necessidades e objetivos dos usuários (KRUCHTEN, 2003). }\end{array}$ \\
\hline Análise e Design & $\begin{array}{l}\text { KRUCHTEN (2003) relaciona as seguintes atividades para esta área: } \\
\text { - Transformar os requisitos dentro de um design do que será o } \\
\text { software; } \\
\text { - Desenvolver uma arquitetura para o software; } \\
\text { - Adaptar o design para aspectos de desempenho. } \\
\text { A especificação técnica, comumente realizada por analistas de } \\
\text { sistemas, com o suporte de AD's, DBA's, analistas de suporte, infra- } \\
\text { estrutura e especialistas de ferramentas e plataformas tecnológicas } \\
\text { envolvem as atividades: } \\
\text { - Análise e modelagem do sistema usando diagramas UML como: } \\
\text { diagramas de casos de uso, classes, componentes, seqüência, } \\
\text { atividades, voltados para ambientes em baixa plataforma. Para } \\
\text { ambientes em mainframe, os diagramas referem-se à análise } \\
\text { estruturada ou essencial como diagramas de contexto, DFD e } \\
\text { fluxogramas; } \\
\text { - Prototipação de telas, relatórios e documentos (com o apoio de } \\
\text { designers de interface gráfica); } \\
\text { - Especificação do sistema e programas ou casos de uso; } \\
\text { - Análise de reuso de artefatos de software (com o apoio de analistas } \\
\text { de domínio); } \\
\text { - Modelagem lógica e física de dados, gerando o Modelo Entidade } \\
\text { Relacionamento (MER) (com o apoio de AD's e DBA's); } \\
\text { - Análise de Pontos de Função (APF) (com o apoio de especialistas } \\
\text { em Pontos de Função). }\end{array}$ \\
\hline Implementação & $\begin{array}{l}\text { KRUCHTEN (2003) relaciona as seguintes atividades para a área de } \\
\text { implementação: } \\
\text { - Preparar a organização do código em termos de implementação de } \\
\text { subsistemas, organizados em camadas (layers); } \\
\text { - Implementar classes e objetos em termos de componentes (código } \\
\text { fonte, binários, executáveis,etc). Para sistemas em mainframe, } \\
\text { implementar os programas ou rotinas de acordo com a análise } \\
\text { estruturada ou essencial; } \\
\text { - Testar os componentes desenvolvidos como unidades; } \\
\text { - Integrar os resultados obtidos por implementadores individuais (ou } \\
\text { em equipes) em um sistema executável. }\end{array}$ \\
\hline Testes e Homologação & $\begin{array}{l}\text { KRUCHTEN (2003) relaciona as seguintes atividades para a área de } \\
\text { testes: } \\
\text { - Verificar a interação entre os objetos; } \\
\text { - Verificar a integração de todos os componentes de software; } \\
\text { - Verificar se todos os requisitos foram implementados corretamente; } \\
\text { - Verificar os defeitos e assegurar que eles sejam tratados antes da } \\
\text { entrega do software; } \\
\text { - O produto é testado de uma forma integrada (analista de negócios, } \\
\text { analista de sistemas, cliente, stakeholders), identificando possíveis }\end{array}$ \\
\hline
\end{tabular}




\begin{tabular}{|c|c|}
\hline Áreas Funcionais & Atribuições das Áreas Funcionais \\
\hline & $\begin{array}{l}\text { erros antes da entrega do produto final. } \\
\text { - Ao final dos testes, o produto é homologado e empacotado de acordo } \\
\text { com os padrões, sendo instalado nos servidores e ativado em } \\
\text { produção. Durante algum tempo, uma equipe de suporte ao cliente } \\
\text { estará ativa até que o sistema fique estável. }\end{array}$ \\
\hline Suporte Técnico & $\begin{array}{l}\text { A área de Suporte Técnico é composta de profissionais para atividades } \\
\text { de apoio ou especialistas em diferentes expertises, com o objetivo de } \\
\text { prover o auxílio nas atividades de desenvolvimento de software, } \\
\text { incentivando a padronização, integração e reuso de técnicas, } \\
\text { ferramentas e metodologias. As atividades de suporte compreendem: } \\
\text { - Engenharia e Arquitetura de Software; } \\
\text { - Modelagem de dados e criação de Banco de Dados (AD's - } \\
\text { administradores de dados e DBA's - administradores de Banco de } \\
\text { Dados); } \\
\text { - Análise de Pontos de Função ou Pontos de Casos de Uso } \\
\text { (especialista de APF ou UCP); } \\
\text { - Padrões de Prototipação de interfaces gráficas (designers de } \\
\text { interface, analistas de multimídia); } \\
\text { - Frameworks ou arquiteturas de sistemas e programas (arquitetos de } \\
\text { software); } \\
\text { - Especialistas de ferramentas por plataforma tecnológica (mainframe, } \\
\text { plataforma baixa, cliente servidor, web, sistemas integrados). }\end{array}$ \\
\hline Qualidade & $\begin{array}{l}\text { Esta área está voltada à qualidade do processo, tendo como } \\
\text { atribuições: } \\
\text { - Customização do processo organizacional para os projetos; } \\
\text { - Orientação das equipes; } \\
\text { - Avaliação periódica do uso do processo customizado; } \\
\text { - Levantamento e acompanhamento da resolução de não } \\
\text { conformidades e conflitos; } \\
\text { - Levantamentos de oportunidades de melhorias técnicas e de } \\
\text { processos; coleta de medidas e disponibilização de métricas. }\end{array}$ \\
\hline
\end{tabular}


Anexo 9 - Categorias de Processos da FS

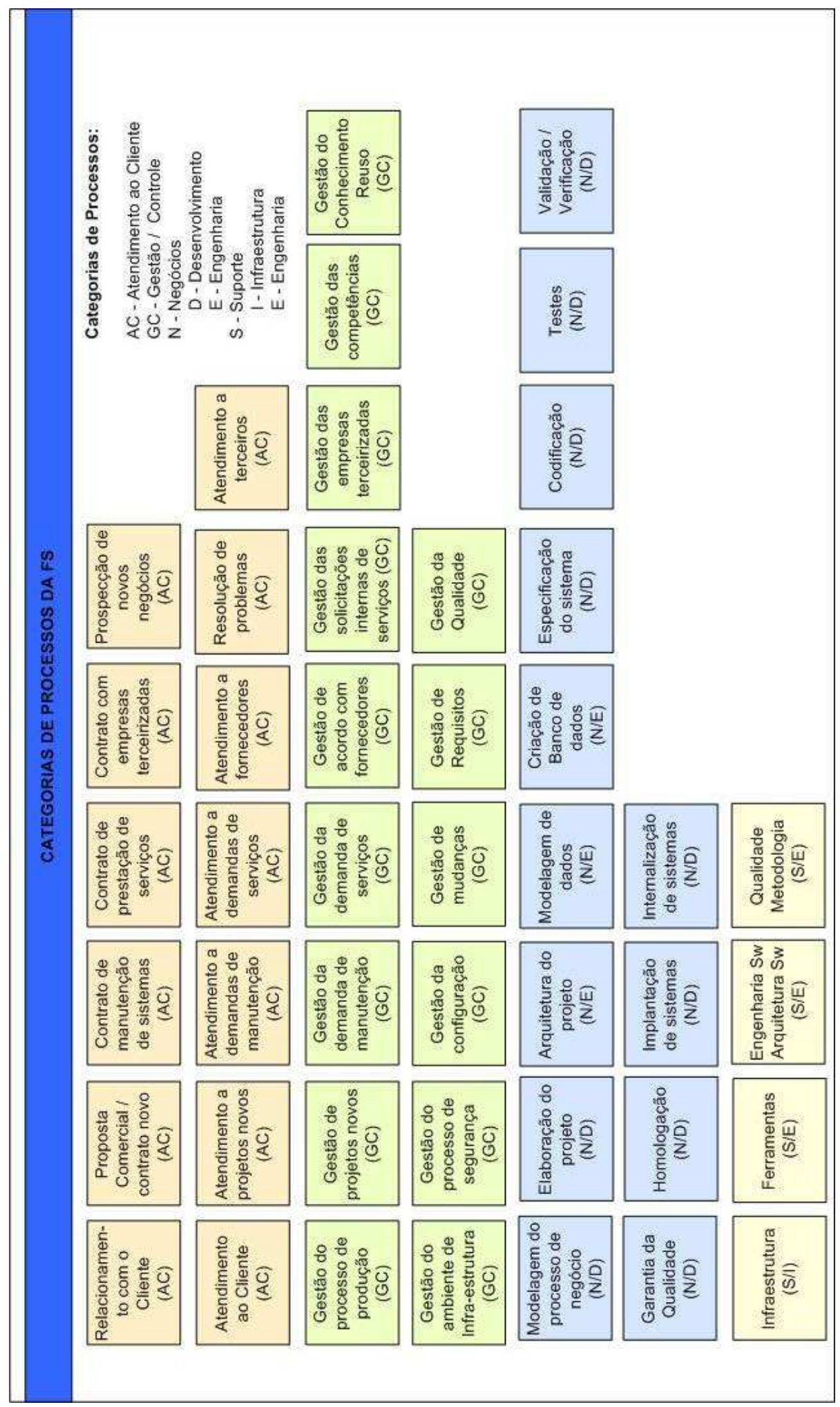


Anexo 10 - Áreas de Domínio de Negócios do Setor Público

\begin{tabular}{|l|}
\hline \multicolumn{1}{|c|}{ Categorias das áreas de domínios de negócios do setor público } \\
\hline Gestão Municipal \\
\hline Governo e Planejamento \\
\hline Desenvolvimento Urbano \\
\hline Finanças \\
\hline Saúde \\
\hline Educação \\
\hline Assistência e Desenvolvimento Social \\
\hline Cultura \\
\hline Trabalho \\
\hline Esportes \\
\hline Verde e Meio Ambiente \\
\hline Habitação \\
\hline Serviços \\
\hline Turismo \\
\hline Transportes \\
\hline Geoprocessamento \\
\hline Entre outros .... \\
\hline
\end{tabular}

Anexo 11 - Categorias de Serviços da Fábrica de Software

\section{Categorias de Serviços da FS}

Desenvolvimento de Projetos Novos

Desenvolvimento de componentes

Manutenção evolutiva

Manutenção adaptativa

Manutenção corretiva

Manutenção preventiva

Resolução de abends / Correções urgentes

Sistemas terceirizados: aquisição, internalização, auditoria, desenvolvimento

Serviços eventuais ou específicos: relatórios, portais, data warehouse, multimídia, cubos

Prospecção de novos negócios

Prospecção tecnológica

Mapeamento de Processos

Serviços do Data Center ...

Entre outros ...

Anexo 12 - Matriz de Produtos (Exemplos)

\begin{tabular}{|l|}
\hline \multicolumn{1}{|c|}{ Exemplos de Produtos } \\
\hline Gestão de Sistemas da Saúde \\
\hline Gestão de Sistemas da Educação \\
\hline Sistema de Informação \\
\hline Geoprocessamento \\
\hline Portal Municipal \\
\hline Sistema de Atendimento ao Cidadão \\
\hline Gestão de Sistemas de Finanças \\
\hline
\end{tabular}




\begin{tabular}{|l|}
\hline Portal de Pagamentos \\
\hline Cadastro de Contribuintes \\
\hline Gestão Net \\
\hline Entre outros ..... \\
\hline
\end{tabular}

Anexo 13 - Matriz de Plataformas Tecnológicas

\begin{tabular}{|l|}
\hline \multicolumn{1}{|c|}{ Plataformas Tecnológicas } \\
\hline Mainframe \\
\hline Cliente Servidor \\
\hline Plataforma Baixa \\
\hline Web \\
\hline Sistemas Integrados \\
\hline Sistemas Distribuídos ... \\
\hline
\end{tabular}

Anexo 14- Matriz de Ferramentas, Técnicas e Metodologias

(Exemplos)

\begin{tabular}{|c|c|c|}
\hline Fase do Projeto & Ferramentas / Linguagens & Técnicas / Metodologias \\
\hline $\begin{array}{l}\text { Negócios } \\
\text { Proposta do Projeto }\end{array}$ & Ex: Project & $\begin{array}{l}\text { Técnicas para levantamento } \\
\text { de Negócios e Proposta de } \\
\text { Solução }\end{array}$ \\
\hline $\begin{array}{l}\text { Visão e Escopo do } \\
\text { Negócio / Requisitos }\end{array}$ & Ex: Caliber & Definição de Requisitos \\
\hline $\begin{array}{l}\text { Planejamento e Gestão } \\
\text { do Projeto }\end{array}$ & Ex: Project & $\begin{array}{l}\text { Metodologia de Gestão de } \\
\text { Projetos - PMBOK }\end{array}$ \\
\hline \multirow{8}{*}{$\begin{array}{l}\text { Desenvolvimento: } \\
\text { Análise e Design }\end{array}$} & Ex: Erwin & $\begin{array}{l}\text { Modelagem de Banco de } \\
\text { Dados }\end{array}$ \\
\hline & Ex: SQL, DB2 & $\begin{array}{l}\text { Criação, Manipulação e } \\
\text { Testes de Banco de Dados }\end{array}$ \\
\hline & Ex: EA, Visio & $\begin{array}{l}\text { Criação de protótipos de } \\
\text { interfaces de telas e } \\
\text { relatórios }\end{array}$ \\
\hline & Ex: EA, Visio, Endevor & $\begin{array}{l}\text { Modelagem e Arquitetura de } \\
\text { Sistemas, UML, Análise } \\
\text { Estruturada, Análise } \\
\text { Orientada a Objetos. }\end{array}$ \\
\hline & Ex: EA & $\begin{array}{l}\text { Especificação de Casos de } \\
\text { Uso e Programas }\end{array}$ \\
\hline & Ex: Endevor & $\begin{array}{l}\text { Especificação de rotinas de } \\
\text { operação, JCL }\end{array}$ \\
\hline & Ex: Visual Source Safe & $\begin{array}{l}\text { Gestão da Configuração } \\
\text { (Documentação e } \\
\text { Versionamento) }\end{array}$ \\
\hline & Planilha Excel APF & $\begin{array}{l}\text { APF - Técnica de Análise } \\
\text { por Pontos de Função ou } \\
\text { UCP - Pontos por Casos de } \\
\text { Uso }\end{array}$ \\
\hline $\begin{array}{l}\text { Desenvolvimento: } \\
\text { Implementação }\end{array}$ & $\begin{array}{l}\text { Exs: DotNet, Access, ASP, C, } \\
\text { CICS/DB2, Clipper, COBOL, CSP, } \\
\text { Delphi, EasyTrieve, Excel, Flash, } \\
\text { HTML, Java, Oracle, PHP, PL/SQL, } \\
\text { SQLSERVER/VB, VB, Websphere }\end{array}$ & $\begin{array}{l}\text { Programação OO, } \\
\text { Programação Estruturada, } \\
\text { Arquitetura Multicamadas, } \\
\text { Sistemas Integrados }\end{array}$ \\
\hline
\end{tabular}




\begin{tabular}{|l|l|l|}
\hline \multicolumn{1}{|c|}{ Fase do Projeto } & \multicolumn{1}{|c|}{ Ferramentas / Linguagens } & \multicolumn{1}{|c|}{ Técnicas / Metodologias } \\
\hline & $\begin{array}{l}\text { Exs: MSSQL, Oracle, DB2, IMS, } \\
\text { PostGreSQL,Sybase, MySQL; }\end{array}$ & $\begin{array}{l}\text { Manipulação de Banco de } \\
\text { Dados e Testes untários }\end{array}$ \\
\cline { 2 - 3 } & Exs: Visual Source Safe & $\begin{array}{l}\text { Gestão da Configuração } \\
\text { (versionamento) }\end{array}$ \\
\hline Testes e Homologação & $\begin{array}{l}\text { Exs: MSSQL, Oracle, DB2, IMS, } \\
\text { PostGreSQL,Sybase, MySQL; }\end{array}$ & $\begin{array}{l}\text { Manipulação de Banco de } \\
\text { Dados e Testes de } \\
\text { homologação }\end{array}$ \\
\hline & Ferramentas para testes & $\begin{array}{l}\text { Técnicas para testes de } \\
\text { qualidade }\end{array}$ \\
\hline $\begin{array}{l}\text { Planejamento e Controle } \\
\text { de Produção- PCP }\end{array}$ & $\begin{array}{l}\text { Sistema de Solicitação de Serviços, } \\
\text { Sistema de Controle de Demandas }\end{array}$ & $\begin{array}{l}\text { Técnicas para Gestão e } \\
\text { Controle da Produção }\end{array}$ \\
\hline
\end{tabular}

Anexo 15 - Matriz de Normas, Regras e Procedimentos

Ex: Normas de Segurança da Informação

\begin{tabular}{|l|}
\hline \multicolumn{1}{|c|}{ Normas e Políticas de Segurança da Informação } \\
\hline Política de Segurança da Informação \\
\hline Utilização do Correio Eletrônico \\
\hline Acesso à Internet \\
\hline Acesso ao Mainframe \\
\hline Acesso Lógico \\
\hline Acesso de Redes de Terceiros à Rede Corporativa \\
\hline Certificação Digital \\
\hline
\end{tabular}

Anexo 16 - Matriz de Artefatos de Reuso Sugeridos

\begin{tabular}{|l|l|}
\hline \multicolumn{1}{|c|}{$\begin{array}{c}\text { Denominação da } \\
\text { Área }\end{array}$} & \multicolumn{1}{c|}{ Artefatos reusáveis } \\
\hline $\begin{array}{l}\text { Negócios/ } \\
\text { Requisitos }\end{array}$ & $\begin{array}{l}\text { Planos de projeto, requisitos funcionais, requisitos não funcionais, frameworks } \\
\text { de aplicação empresarial, modelos de processos de negócios, arquiteturas de } \\
\text { projetos, padrões de processos, casos de uso, estimativas de custos e prazos, } \\
\text { históricos, processos. }\end{array}$ \\
\hline Análise, e Design & $\begin{array}{l}\text { Requisitos, especificações, modelos de negócios, estimativas de custos e } \\
\text { prazos, casos de uso, cálculos de pontos de função, arquiteturas de sistemas, } \\
\text { projetos, padrões, frameworks, históricos, simulação de sistemas, modelos de } \\
\text { dados, prototipação, documentação, metodologias, processos. }\end{array}$ \\
\hline Implementação & $\begin{array}{l}\text { Casos de uso, código fonte, padrões de programação, frameworks de } \\
\text { linguagens, persistência (dados), interfaces de apresentação (telas), } \\
\text { componentes de negócios, classes, objetos, web services, documentação, } \\
\text { metodologias, processos. }\end{array}$ \\
\hline Testes & $\begin{array}{l}\text { Planos de testes do sistema, casos e procedimentos, detalhes da simulação de } \\
\text { interfaces, casos de testes unitários, documentação, metodologias, processos. }\end{array}$ \\
\hline
\end{tabular}


Anexo 17 - Matriz de Papéis e Responsabilidades

\begin{tabular}{|c|c|c|}
\hline Área & Papéis & Responsabilidades \\
\hline $\begin{array}{l}\text { Unidade } \\
\text { Organizacional }\end{array}$ & Gerente Funcional & $\begin{array}{l}\text { Responsável por planejar, acompanhar, controlar e } \\
\text { articular os recursos humanos, de hardware e software } \\
\text { para a realização das demandas de serviços. Elaborar a } \\
\text { gestão de acordos de níveis de serviços (SLA's) com as } \\
\text { demais gerências envolvidas. Elaborar junto ao PCP a } \\
\text { logística de recursos humanos para o atendimento das } \\
\text { ordens de serviços }\end{array}$ \\
\hline $\begin{array}{l}\text { Atendimento e } \\
\text { Relacionamento } \\
\text { com o Cliente }\end{array}$ & $\begin{array}{l}\text { Gerente de } \\
\text { Atendimento }\end{array}$ & $\begin{array}{l}\text { Responsável pelo relacionamento e atendimento ao } \\
\text { cliente, articulando soluções para o cliente, orientado ao } \\
\text { planejamento estratégico da empresa. }\end{array}$ \\
\hline $\begin{array}{l}\text { Escritório de } \\
\text { Projetos }\end{array}$ & $\begin{array}{l}\text { Gerente ou Líder de } \\
\text { de Projetos }\end{array}$ & $\begin{array}{l}\text { Os gerentes de projetos trabalham na coordenação de } \\
\text { recursos e na garantia de consistência para diferentes } \\
\text { aspectos do projeto. Os processos de gestão envolvem } \\
\text { ações como planejamento, acompanhamento e controle } \\
\text { das etapas do projeto, dos cronogramas, realizar } \\
\text { comunicações e integração da equipe do projeto. Negociar } \\
\text { as SLA's com as áreas envolvidas. }\end{array}$ \\
\hline Negócios & $\begin{array}{l}\text { Analista de } \\
\text { Negócios }\end{array}$ & $\begin{array}{l}\text { Responsável por entender as necessidades do cliente e do } \\
\text { usuário, suas estratégias e metas articulando soluções para } \\
\text { o negócio do cliente. Elaborar o Documento Visão e } \\
\text { Escopo contendo o contexto do negócio, riscos e } \\
\text { requisitos do projeto. Este documento permite o processo } \\
\text { de aprovação do projeto pelo cliente assim como o início } \\
\text { do desenvolvimento do projeto. }\end{array}$ \\
\hline Análise e Design & $\begin{array}{l}\text { Analista } \\
\text { de Sistemas }\end{array}$ & $\begin{array}{l}\text { Responsável por validar a documentação definida pelo } \\
\text { Analista de Negócio e a gerar todo o desenho da solução: } \\
\text { Modelo de Casos de Uso; Protótipos; Modelo de Classes } \\
\text { e/ou MER; Arquitetura do Sistema, entre outros. } \\
\text { Especificar os Módulos que compõem o Sistema ou } \\
\text { Projeto, gerando um documento de Especificação Técnica } \\
\text { a ser enviado para a Fábrica de Implementação; efetuar o } \\
\text { cálculo dos pontos de função; realizar testes funcionais } \\
\text { para a solução desenhada. }\end{array}$ \\
\hline Implementação & Desenvolvedores & $\begin{array}{l}\text { Com base na documento de Especificação Técnica, os } \\
\text { desenvolvedores são responsáveis em codificar e testar os } \\
\text { módulos referentes às aplicações, de acordo com a } \\
\text { plataforma tecnológica e linguagem de programação } \\
\text { específica definida no projeto. }\end{array}$ \\
\hline $\begin{array}{l}\text { Qualidade do } \\
\text { Produto }\end{array}$ & Testers & $\begin{array}{l}\text { Responsável por validar o Plano de Teste, elaborar os } \\
\text { Casos de Testes, acompanhar a execução dos testes, } \\
\text { unificar as planilhas de erros geradas e elaborar o } \\
\text { Relatório Final dos Testes. } \\
\text { Responsável por execução os testes, analisar falhas de } \\
\text { testes; registrar os resultados dos testes. Encaminhar } \\
\text { falhas apontadas para serem corrigidas pelo } \\
\text { desenvolvedor. Reavaliar apontamentos de falhas } \\
\text { corrigidas pelo desenvolvedor. }\end{array}$ \\
\hline $\begin{array}{l}\text { Planejamento e } \\
\text { Controle de } \\
\text { Produção }\end{array}$ & Planejadores & $\begin{array}{l}\text { Analisar as demandas em andamento. Distribuir e } \\
\text { administrar a carga de serviço, com base na negociação } \\
\text { com cada uma das áreas. Administrar trocas de } \\
\text { prioridades das solicitações. Negociar com o } \\
\text { Relacionamento, Análise, Implementação e Testes os } \\
\text { esforços e datas. Gerar e elaborar programação das Ordens }\end{array}$ \\
\hline
\end{tabular}




\begin{tabular}{|c|c|c|}
\hline Área & Papéis & Responsabilidades \\
\hline & & $\begin{array}{l}\text { de Serviço. Administrar as distribuições de Ordens de } \\
\text { Serviço para a Análise e Implemetnação, interna ou } \\
\text { externa. Acompanhar e manter histórico do Nível de } \\
\text { Solicitações de Serviços (SLA). Confrontar Pontos de } \\
\text { Função Estimado x Pontos de Função Contados. Manter } \\
\text { histórico de Pontos de Função. }\end{array}$ \\
\hline \multirow[t]{6}{*}{ Suporte } & Arquiteto & $\begin{array}{l}\text { Responsável por apoiar e participar com os analistas de } \\
\text { sistemas da elaboração do Diagrama da Arquitetura do } \\
\text { Sistema. Responsável por apoiar os desenvolvedores na } \\
\text { arquitetura dos programas, planejando inclusive reuso de } \\
\text { componentes. }\end{array}$ \\
\hline & $\begin{array}{l}\text { Administrador de } \\
\text { Dados (AD) }\end{array}$ & $\begin{array}{l}\text { Responsável por apoiar e participar com os analistas de } \\
\text { sistemas da elaboração do Projeto Lógico de Banco de } \\
\text { Dados e Dicionário de Dados, gerando o Modelo Entidade } \\
\text { Relacionamento (MER) ou o Modelo de Classes. }\end{array}$ \\
\hline & $\begin{array}{l}\text { Administrador de } \\
\text { Banco de Dados } \\
\text { (DBA) }\end{array}$ & $\begin{array}{l}\text { Responsável pela criação e manutenção do Projeto Físico } \\
\text { de Banco de Dados, bem como pela performance das } \\
\text { tabelas, durante seu ciclo de vida. }\end{array}$ \\
\hline & $\begin{array}{l}\text { Analista de Suporte } \\
\text { a Ferramentas }\end{array}$ & $\begin{array}{l}\text { Responsável pelo suporte a ferramentas e ambientes } \\
\text { tecnológicos. }\end{array}$ \\
\hline & $\begin{array}{l}\text { Designer de } \\
\text { Interface Gráfica }\end{array}$ & $\begin{array}{l}\text { Responsável por definir a interface gráfica do sistema, } \\
\text { definir a estrutura gráfica e navegacional do sistema, gerar } \\
\text { padrões de telas, relatórios e consultas. }\end{array}$ \\
\hline & $\begin{array}{l}\text { Especialista em } \\
\text { cálculo de Ponto de } \\
\text { Função }\end{array}$ & $\begin{array}{l}\text { Responsável pelo auxílio ao Cálculo de Ponto de Função, } \\
\text { por meiodas técnicas e ferramentas pregadas no IFPUG } \\
(2005) \text {. }\end{array}$ \\
\hline Qualidade & $\begin{array}{l}\text { Analista de } \\
\text { Qualidade }\end{array}$ & $\begin{array}{l}\text { Apoiar a equipe de analistas, desenvolvedores e } \\
\text { especialistas na utilização das técnicas e processos de } \\
\text { desenvolvimento. }\end{array}$ \\
\hline Infra-Estrutura & $\begin{array}{l}\text { Analistas de Infra- } \\
\text { estrutura }\end{array}$ & $\begin{array}{l}\text { Responsáveis pela disponibilidade de serviços em } \\
\text { administração de redes e infra-estrutura; suporte de } \\
\text { hardware operacional como gestão de ambientes de } \\
\text { desenvolvimento, homologação e produção de um } \\
\text { sistema. Responsáveis pela gerência de mudanças e } \\
\text { configuração de software. }\end{array}$ \\
\hline
\end{tabular}

Anexo 18 - Matriz de Artefatos de Entrada e Saída

\begin{tabular}{|c|c|c|c|}
\hline \multicolumn{4}{|c|}{ MATRIZ DE ARTEFATOS DE ENTRADA E SAÍDA } \\
\hline Id & Fase & Artefato & Descrição \\
\hline 1 & Visão e Escopo & Visão e Escopo & $\begin{array}{l}\text { Permite conhecer dados importantes dos negócios, } \\
\text { apresentar características e necessidades, capturar os } \\
\text { objetivos do projeto, apresentando o que se deseja e qual } \\
\text { a finalidade do projeto a ser desenvolvido, ou seja, o } \\
\text { conjunto de metas e objetivos. Contém o contexto do } \\
\text { negócio, visão, escopo, riscos, requisitos e cronogramas. } \\
\text { Por meio deste documento, os envolvidos têm uma visão } \\
\text { do produto a ser desenvolvido. As informações contidas } \\
\text { no documento Visão Escopo são utilizadas para o } \\
\text { processo de aprovação do projeto, permitindo identificar } \\
\text { questionamentos relacionados ao projeto e atuando como } \\
\text { um regulador para que futuras decisões possam ser }\end{array}$ \\
\hline
\end{tabular}




\begin{tabular}{|c|c|c|c|}
\hline \multicolumn{4}{|c|}{ MATRIZ DE ARTEFATOS DE ENTRADA E SAÍDA } \\
\hline Id & Fase & Artefato & Descrição \\
\hline & & & validadas. \\
\hline 2 & Visão e Escopo & $\begin{array}{l}\text { Modelo de Casos } \\
\text { de Uso ou } \\
\text { Diagrama de } \\
\text { Contexto }\end{array}$ & $\begin{array}{l}\text { O Modelo de Caso de Uso é definido como "o conjunto } \\
\text { de todos os diagramas de caso de uso". Seu objetivo é } \\
\text { modelar os requisitos funcionais delimitados pelo } \\
\text { documento de Visão e Escopo. Ele é a principal } \\
\text { ferramenta para que todos os stackholders, técnicos e não } \\
\text { técnicos possam compartilhar uma visão do sistema. } \\
\text { O Diagrama de Contexto mostra uma visão macro } \\
\text { (inicial) das funcionalidades que se pretende desenvolver } \\
\text { no projeto. } \\
\text { Opcionalmente estes diagramas podem estar contidos no } \\
\text { Documento de Visão e Escopo }\end{array}$ \\
\hline 3 & Visão e Escopo & Glossário & $\begin{array}{l}\text { Documento contendo a descrição dos acrônimos, termos e } \\
\text { abreviações que necessitem ser documentados e } \\
\text { detalhados com o objetivo de criar uma linguagem } \\
\text { comum do projeto a todos os envolvidos. Este documento } \\
\text { vai sendo complementado durante todo o processo de } \\
\text { desenvolvimento. }\end{array}$ \\
\hline 4 & $\begin{array}{l}\text { Especificação } \\
\text { Técnica }\end{array}$ & $\begin{array}{l}\text { Arquitetura do } \\
\text { Projeto }\end{array}$ & $\begin{array}{l}\text { Este documento contém informações e diretrizes gerais } \\
\text { referentes às tecnologias adotadas no projeto. Identifica e } \\
\text { define tecnologias e padrões a serem adotados no projeto. } \\
\text { Registra considerações a respeito da possibilidade ou } \\
\text { impossibilidade técnica de atendimento ao escopo } \\
\text { definido no documento de Visão e Escopo. }\end{array}$ \\
\hline 6 & $\begin{array}{l}\text { Definição de } \\
\text { Requisitos }\end{array}$ & $\begin{array}{l}\text { Especificação de } \\
\text { Requisitos }\end{array}$ & $\begin{array}{l}\text { O documento Especificações de Requisitos captura todos } \\
\text { os requisitos de sistema incluindo os requisitos funcionais } \\
\text { e os não funcionais. Os requisitos funcionais são } \\
\text { modelados nos casos de uso do modelo de casos de uso, já } \\
\text { os requisitos não funcionais são detalhados apenas neste } \\
\text { documento em capítulo apropriado. Entre os requisitos } \\
\text { não funcionais estão incluídos: } \\
\text { Requisitos legais e de regulamentação, e padrões de } \\
\text { aplicativo. } \\
\text { Atributos de qualidade do sistema a ser criado, incluindo } \\
\text { requisitos de usabilidade, confiabilidade, e desempenho. } \\
\text { Requisitos do Usuário associados a alternativas de } \\
\text { implementação do sistema. } \\
\text { Definição de requisitos de segurança e contingência } \\
\text { específicos de segurança física e lógica, e plano de } \\
\text { contingência de sistemas a ser implementado. } \\
\text { Outros requisitos, como sistemas operacionais e } \\
\text { ambientes, requisitos de compatibilidade e restrições de } \\
\text { design que irão compor a base tecnológica do sistema. }\end{array}$ \\
\hline 7 & $\begin{array}{l}\text { Análise e } \\
\text { Design }\end{array}$ & $\begin{array}{l}\text { Arquitetura do } \\
\text { Software }\end{array}$ & $\begin{array}{l}\text { Apresentar uma visão geral abrangente da arquitetura do } \\
\text { sistema, utilizando visões arquiteturais diferentes para } \\
\text { ilustrar os diversos aspectos do sistema como visão de } \\
\text { casos de uso, visão lógica, visão de processo, visão de } \\
\text { implantação, visão de implementação. Capturar e } \\
\text { transmitir as decisões significativas do ponto de vista da } \\
\text { arquitetura que foram tomadas em relação ao sistema. }\end{array}$ \\
\hline
\end{tabular}




\begin{tabular}{|c|c|c|c|}
\hline \multicolumn{4}{|c|}{ MATRIZ DE ARTEFATOS DE ENTRADA E SAÍDA } \\
\hline Id & Fase & Artefato & Descrição \\
\hline 8 & $\begin{array}{l}\text { Análise e } \\
\text { Design }\end{array}$ & $\begin{array}{l}\text { Especificação de } \\
\text { Casos de Uso }\end{array}$ & $\begin{array}{l}\text { O modelo de casos de uso representa passo a passo as } \\
\text { atividades que se espera do sistema. Apresentando não } \\
\text { somente as atividades (conjunto de funcionalidades) como } \\
\text { também identifica os atores que irão interagir com o } \\
\text { sistema. Com base em sua modelagem gráfica, é possível } \\
\text { visualizar de maneira clara o relacionamento entre atores } \\
\text { e atividades, bem como compreender o que exatamente } \\
\text { será contemplado pelo projeto. Serve ainda, como um } \\
\text { contrato estabelecido entre o cliente e os desenvolvedores } \\
\text { e também é usado como fonte de informações essenciais } \\
\text { para atividades de análise, design e teste. Especificações } \\
\text { que não sejam contempladas por um modelo de Casos de } \\
\text { Uso, podem ser feitas no documento Definição de } \\
\text { Programa. }\end{array}$ \\
\hline 9 & $\begin{array}{l}\text { Análise e } \\
\text { Design }\end{array}$ & $\begin{array}{l}\text { Definição de } \\
\text { Programa }\end{array}$ & $\begin{array}{l}\text { Descrição das ações que o programa deve contemplar, tais } \\
\text { como consistências lógicas e físicas, cálculos, regras de } \\
\text { negócios, etc. Usado em geral para definição de } \\
\text { programas em mainframe. }\end{array}$ \\
\hline 10 & $\begin{array}{l}\text { Análise e } \\
\text { Design }\end{array}$ & $\begin{array}{l}\text { Modelo de } \\
\text { Domínio: } \\
\text { Diagrama de } \\
\text { classes } \\
\text { conceitual }\end{array}$ & $\begin{array}{l}\text { É definido como um diagrama de classes conceituais, } \\
\text { onde o objetivo é entender o domínio, o contexto do } \\
\text { sistema, sendo representado em um nível alto de } \\
\text { abstração, descrevendo os conceitos mais importantes. }\end{array}$ \\
\hline 11 & $\begin{array}{l}\text { Análise e } \\
\text { Design }\end{array}$ & $\begin{array}{l}\text { Modelo de } \\
\text { Design: } \\
\text { Diagramas de } \\
\text { classes, } \\
\text { seqüência, } \\
\text { estados, } \\
\text { atividades, } \\
\text { pacotes }\end{array}$ & $\begin{array}{l}\text { É construído principalmente com diagramas de classes de } \\
\text { implementação, onde além de seu conteúdo e } \\
\text { relacionamentos, representam os serviços que o sistema } \\
\text { deverá fornecer aos usuários finais. Este modelo descreve } \\
\text { a realização dos casos de usos anteriormente descritos. O } \\
\text { modelo de design pode ser complementado com: } \\
\text { Diagrama de Seqüência; Diagrama de Estados; Diagrama } \\
\text { de Atividades; Diagrama de Pacotes, etc. }\end{array}$ \\
\hline 12 & $\begin{array}{l}\text { Análise e } \\
\text { Design } \\
\text { (Banco de } \\
\text { Dados) }\end{array}$ & $\begin{array}{l}\text { MER - Modelo } \\
\text { Entidade } \\
\text { Relacionamento }\end{array}$ & $\begin{array}{l}\text { Representação lógica das informações da área de } \\
\text { negócios em um modelo baseado em entidades, seus } \\
\text { atributos e nos relacionamentos entre essas entidades. }\end{array}$ \\
\hline 13 & $\begin{array}{l}\text { Análise e } \\
\text { Design } \\
\text { (Banco de } \\
\text { Dados) }\end{array}$ & $\begin{array}{l}\text { Dicionário de } \\
\text { Dados }\end{array}$ & $\begin{array}{l}\text { O Dicionário de Dados documenta a estrutura lógica } \\
\text { criada para o banco de dados. Descreve as estruturas } \\
\text { (entidade, atributo, relacionamento, consistências) e suas } \\
\text { características, tais como: domínio de valores possíveis, } \\
\text { regras de negócio e tipo de dado do atributo }\end{array}$ \\
\hline 14 & $\begin{array}{l}\text { Análise e } \\
\text { Design }\end{array}$ & $\begin{array}{l}\text { PFBD - Projeto } \\
\text { Físico de Banco } \\
\text { de Dados }\end{array}$ & $\begin{array}{l}\text { Representação física das informações, projetada a partir } \\
\text { do modelo de dados, visando a implementação de uma } \\
\text { base de dados eficiente que garanta aspectos de } \\
\text { segurança e performance. A análise considera o } \\
\text { gerenciador de banco de dados a ser utilizado, volume de } \\
\text { dados e acessos à base }\end{array}$ \\
\hline 15 & $\begin{array}{l}\text { Análise e } \\
\text { Design }\end{array}$ & $\begin{array}{l}\text { Planilha de } \\
\text { Análise de Ponto } \\
\text { de Função }\end{array}$ & $\begin{array}{l}\text { Planilha para contagem do tamanho do sistema, pelo } \\
\text { Pontos de Função. O processo de cálculo de Pontos de } \\
\text { Função está contido no Function Point Counting } \\
\text { Practices Manual (CPM) publicado e comercializado pelo } \\
\text { International Function Point Users Group, (IFPUG, } \\
\text { 2005). } \\
\text { O Cálculo de Ponto de Função pode ser estimado, quando } \\
\text { feito no início do projeto ou detalhado quando feito no } \\
\text { final do projeto. }\end{array}$ \\
\hline
\end{tabular}




\begin{tabular}{|c|c|c|c|}
\hline \multicolumn{4}{|c|}{ MATRIZ DE ARTEFATOS DE ENTRADA E SAÍDA } \\
\hline Id & Fase & Artefato & Descrição \\
\hline 16 & Testes & Casos de Testes & $\begin{array}{l}\text { Artefato derivado a partir dos Casos de Uso. Consiste na } \\
\text { definição de um conjunto específico de entrada de testes, } \\
\text { condições de execução e resultados esperados. }\end{array}$ \\
\hline 17 & Testes & Plano de Testes & $\begin{array}{l}\text { Neste artefato é realizada a definição das metas e dos } \\
\text { objetivos dos testes no escopo da iteração (ou projeto), os } \\
\text { itens-alvo, a abordagem adotada, os recursos necessários } \\
\text { e os produtos que serão liberados. O principal objetivo é } \\
\text { ganhar a aceitação e aprovação dos envolvidos no esforço } \\
\text { de teste. O documento deve evitar informações que não } \\
\text { serão compreendidas ou que serão consideradas } \\
\text { irrelevantes pelos envolvidos. O Plano de Testes } \\
\text { direciona, orienta e restringe o esforço de teste, } \\
\text { priorizando os produtos liberados úteis e necessários. }\end{array}$ \\
\hline 18 & Testes & $\begin{array}{l}\text { Planilha de } \\
\text { ocorrências de } \\
\text { testes }\end{array}$ & $\begin{array}{l}\text { Este artefato consiste no registro dos dados de entrada e } \\
\text { de saída capturados durante a execução dos testes e que } \\
\text { tenham apresentado algum tipo de erro, classificando esse } \\
\text { tipo de erro e a prioridade de correção. Além do } \\
\text { apontamento do erro para correção, permite a realização } \\
\text { de um diagnóstico de falhas. }\end{array}$ \\
\hline 19 & Revisão & Checklist & $\begin{array}{l}\text { Checklist de artefatos gerados durante o processo de } \\
\text { desenvolvimento e manutenção de sistemas }\end{array}$ \\
\hline 20 & $\begin{array}{l}\text { Planejamento, } \\
\text { Gestão e } \\
\text { Controle de } \\
\text { Projetos }\end{array}$ & $\begin{array}{l}\text { Gestão de } \\
\text { Projetos }\end{array}$ & $\begin{array}{l}\text { Plano do Projeto; WBS - Work Breakdown Structure; } \\
\text { Cronogramas; Plano de Gerenciamento de Projetos } \\
\text { (Planos de Testes, Implantação, Treinamento) entre } \\
\text { outros. }\end{array}$ \\
\hline 21 & $\begin{array}{l}\text { Infra-Estrutura } \\
\text { (Mudanças) }\end{array}$ & $\begin{array}{l}\text { Requisição de } \\
\text { Mudança }\end{array}$ & $\begin{array}{l}\text { Descreve as alterações, ambientes e versões dos itens a } \\
\text { serem alterados solicitadas para à Gerência de Infra- } \\
\text { Estrutura Mudanças }\end{array}$ \\
\hline 22 & $\begin{array}{l}\text { Planejamento e } \\
\text { Controle do } \\
\text { Desenvolvimen } \\
\text { to }\end{array}$ & $\begin{array}{l}\text { OS - Ordem de } \\
\text { Serviço da } \\
\text { Entrada da } \\
\text { Solicitação de } \\
\text { Serviço do } \\
\text { Cliente }\end{array}$ & $\begin{array}{l}\text { Registro das demandas de solicitações de serviço de } \\
\text { sistemas de informações do cliente (das áreas de } \\
\text { relacionamento para o PCP) }\end{array}$ \\
\hline 23 & $\begin{array}{l}\text { Planejamento e } \\
\text { Controle do } \\
\text { Desenvolvimen } \\
\text { to }\end{array}$ & $\begin{array}{l}\text { SS - Solicitação } \\
\text { de Serviço para } \\
\text { Desenvolvimento }\end{array}$ & $\begin{array}{l}\text { Registro das solicitações de serviço das áreas de negócios } \\
\text { para as áreas de desenvolvimento (análise e } \\
\text { implementação) }\end{array}$ \\
\hline 24 & Reuniões & Ata de reuniões & Documento destinado para registro de reuniões \\
\hline 25 & Treinamento & $\begin{array}{l}\text { Plano de } \\
\text { Treinamento }\end{array}$ & $\begin{array}{l}\text { Plano de treinamento para os usuários finais, } \\
\text { administradores do sistema, etc. Neste documento devem } \\
\text { constar informações tais como: perfil do(s) usuário(s); } \\
\text { necessidade de treinamento por perfil; um cronograma } \\
\text { com o local, data, identificação dos instrutores, } \\
\text { quantidade de treinandos e a necessidade dos recursos } \\
\text { necessários (infra-estrutura / equipamentos) }\end{array}$ \\
\hline 26 & Implantação & $\begin{array}{l}\text { Manual do } \\
\text { Usuário }\end{array}$ & $\begin{array}{l}\text { Manual, documentos, helps on line, apresentações, que } \\
\text { permitam ao usuário realizar consultas para entender } \\
\text { como utilizar o sistema, ou mesmo sanar dúvidas que } \\
\text { possam surgir. Esses materiais de treinamento e auxílio } \\
\text { são criados no início do projeto, de desenvolvimento dos } \\
\text { requisitos e casos de uso, e devem ser refinados durante o } \\
\text { decorrer do projeto. }\end{array}$ \\
\hline 27 & Implantação & $\begin{array}{l}\text { Manual de } \\
\text { Instalação }\end{array}$ & $\begin{array}{l}\text { Como instalar o sistema em Produção nas diversas } \\
\text { plataformas tecnológicas existentes }\end{array}$ \\
\hline
\end{tabular}


Anexo 19 - Planilha de Perfis e Competências

\begin{tabular}{|c|c|c|c|c|c|c|c|c|c|c|c|c|c|}
\hline \multicolumn{14}{|c|}{ Gestão de Perfis de Competênícias } \\
\hline RECURSO & ASP 3 & VB & C\# & .NET & DELPHI & JAVA & $S Q L$ & ORACLE & HTML & $\mathrm{COBOL}$ & Outros & Alocação & Área \\
\hline Funcionário 1 & $\begin{array}{c}\text { Conhece } \\
\text { pouco } \\
\end{array}$ & $\cdot$ & $\cdot$ & Conhece & $\begin{array}{c}\text { Conhece } \\
\text { pouco }\end{array}$ & $\begin{array}{c}\text { Conhece } \\
\text { pouco }\end{array}$ & Conhece & . & Conhece & & & Nă้อ & Teste \\
\hline Funcionário 2 & & & & . & & & & & & & & Sim & Teste \\
\hline Funcionário 3 & $\begin{array}{c}\text { Conhece } \\
\text { pouco }\end{array}$ & $\cdot$ & $\cdot$ & Domina & . & - & . & . & Domina & & & Nล้๊ & Desenvolvimento \\
\hline Funcionário 4 & Conhece & $\cdot$ & \begin{tabular}{|c|}
$\cdot$ \\
\end{tabular} & Conhece & . & Domina & Domina & . & Conhece & & & Na๊o & Desenvolvimento \\
\hline Funcionário 5 & Domina & Conhece & \begin{tabular}{|c|} 
Conhece \\
pouco \\
\end{tabular} & $\begin{array}{c}\text { Conhece } \\
\text { pouco }\end{array}$ & Conhece & . & Conhece & . & Domina & & & Sim & Desenvolvimento \\
\hline Funcionário 6 & & & & & & & & & & Domina & & Sim & Teste \\
\hline Funcionário 7 & Conhece & Conhece & $\cdot$ & Conhece & . & Domina & Conhece & $\begin{array}{c}\text { Conhece } \\
\text { pouco }\end{array}$ & Domina & & & Nă้ & Desenvolvimento \\
\hline Funcionário 8 & Conhece & • & . & . & $\begin{array}{c}\text { Conhece } \\
\text { pouco }\end{array}$ & . & Conhece & . & Conhece & & & Sim & Desenvolvimento \\
\hline Funcionário 9 & . & . & $\begin{array}{c}\text { Conhece } \\
\text { pouco }\end{array}$ & $\begin{array}{c}\text { Conhece } \\
\text { pouco } \\
\end{array}$ & $\begin{array}{c}\text { Conhece } \\
\text { pouco }\end{array}$ & Domina & Domina & Conhece & Conhece & & & Nร้อ & Desenvolvimento \\
\hline
\end{tabular}

Anexo 20 - Site da MDSI - Metodologia de Desenvolvimento de Sistemas e Integração

\begin{tabular}{|c|c|c|c|}
\hline $\begin{array}{c}\text { Nome do } \\
\text { item }\end{array}$ & Sub-itens & Nome dos templates & $\begin{array}{l}\text { Link dos } \\
\text { arquivos }\end{array}$ \\
\hline Apresentação & Apresentação MDSI & & \\
\hline $\begin{array}{l}\text { Manual } \\
\text { MDSI }\end{array}$ & $\begin{array}{l}\text { MDSI - Metodologia de } \\
\text { Desenvolvimento de Sistemas e } \\
\text { Integração }\end{array}$ & & \\
\hline \multirow{4}{*}{$\begin{array}{l}\text { Fluxos dos } \\
\text { Processos de } \\
\text { Negócios }\end{array}$} & $\begin{array}{l}\text { Fluxo para Projetos Novos / } \\
\text { Projeto de Melhorias }\end{array}$ & & \\
\hline & $\begin{array}{l}\text { Fluxo para Manutenção } \\
\text { Adaptativa }\end{array}$ & & \\
\hline & $\begin{array}{l}\text { Fluxo para Manutenção } \\
\text { Corretiva }\end{array}$ & & \\
\hline & Fluxo para Abend & & \\
\hline \multirow[t]{3}{*}{ Matrizes } & Matriz de Atividades Integradas & Matriz_atividades & \\
\hline & Matriz de Artefatos e Templates & Matriz_artefatos & \\
\hline & $\begin{array}{l}\text { Matriz de papéis e } \\
\text { responsabilidades }\end{array}$ & Matriz_responsabilidades & \\
\hline \multirow{9}{*}{$\begin{array}{l}\text { Templates } \\
\text { MDSI }\end{array}$} & \multirow[t]{3}{*}{ Relacionamento e Negócios } & Visão e Escopo & \\
\hline & & $\begin{array}{l}\text { Definição e Especificação de } \\
\text { Requisitos }\end{array}$ & \\
\hline & & Atas de Reuniões & \\
\hline & \multirow[t]{5}{*}{ Análise, Design e Especificação } & $\begin{array}{l}\text { Documento de Arquitetura do } \\
\text { Software }\end{array}$ & \\
\hline & & Especificação de Casos de Uso & \\
\hline & & Definição de Programa & \\
\hline & & Rotina de Operação & \\
\hline & & Casos de Testes & \\
\hline & Todas as áreas & Glossário & \\
\hline \multirow{3}{*}{$\begin{array}{l}\text { Templates } \\
\text { (Outras } \\
\text { Áreas) }\end{array}$} & Qualidade & Planilha de Ocorrências de Testes & \\
\hline & Qualidade & Check-ist & \\
\hline & Infra-Estrutura & $\begin{array}{l}\text { Solicitação de Avaliação de } \\
\text { Recursos de Infra-Estrutura }\end{array}$ & \\
\hline
\end{tabular}




\begin{tabular}{|l|l|l|l|}
\hline $\begin{array}{c}\text { Nome do } \\
\text { item }\end{array}$ & \multicolumn{1}{|c|}{ Sub-itens } & \multicolumn{1}{|c|}{ Nome dos templates } & $\begin{array}{c}\text { Link dos } \\
\text { arquivos }\end{array}$ \\
\hline \multirow{3}{*}{} & Infra-Estrutura & Requisição de Mudanças & \\
\cline { 2 - 4 } & Infra-Estrutura & $\begin{array}{l}\text { Controle de Acompanhamento da } \\
\text { Execução }\end{array}$ & \\
\hline
\end{tabular}

Anexo 21 - Cronograma do Projeto MDSI - $3^{\circ}$ Ciclo

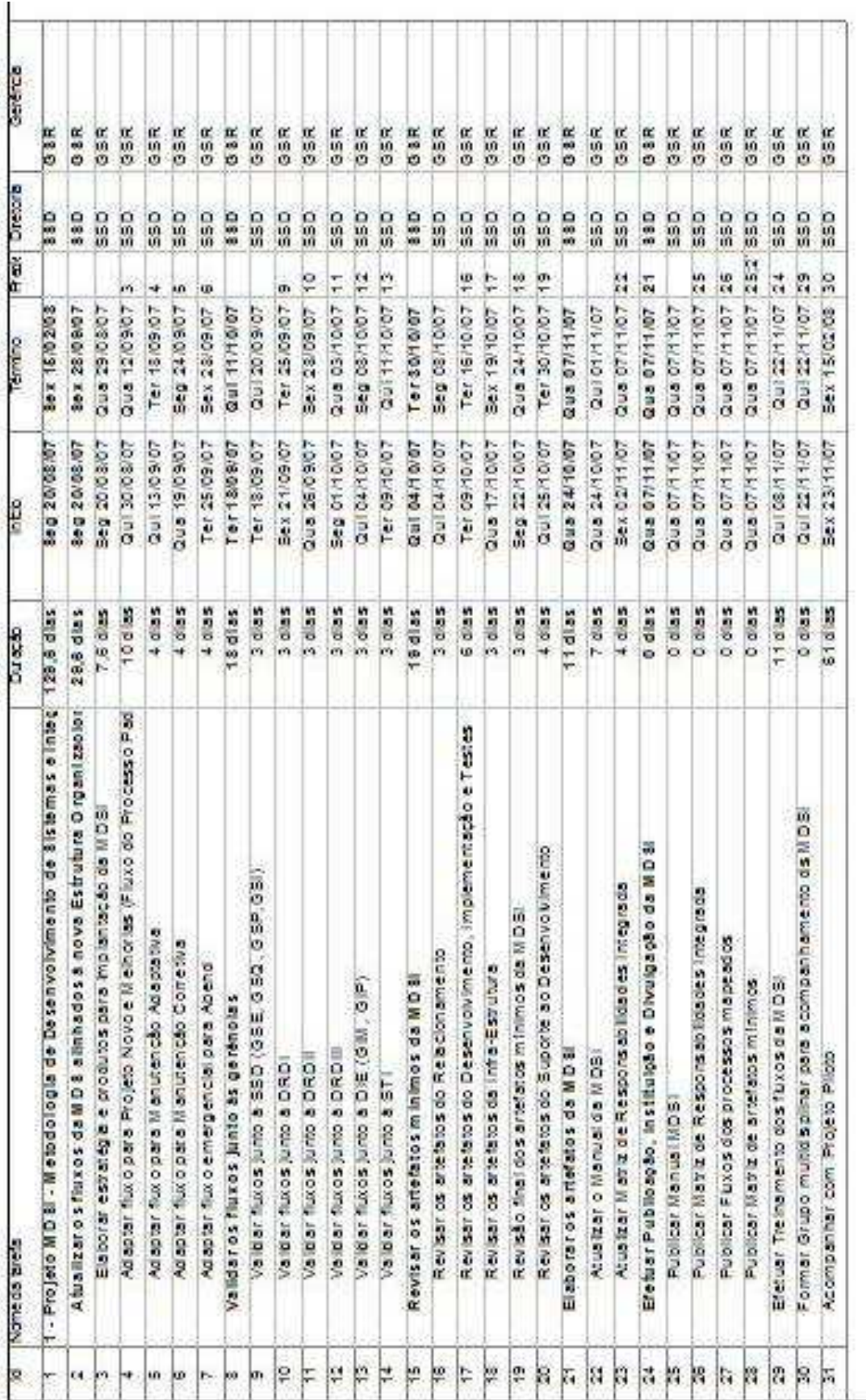




\section{REFERÊNCIAS BIBLIOGRÁFICAS}

AAEN, L.; B $\varnothing$ TTCHER, P.; MATHIASSEN, L. The Software Factories: Contributions and Illusions. IN: Proceedings of the Twentieth Information System Research Seminar in Scandinavia, Oslo, 1997.

ABEPRO, Associação Brasileira de Engenharia de Produção. Disponível em $<$ http://www.abepro.org.br/>. Acesso em: 15 nov 2007.

AGILE MANIFESTO, About the Manifesto, 2001. Disponível em $<$ http://agilemanifesto.org/>. Acesso em: 15 jan 2005.

ALEXANDER, C.; ISHIKAWA S.; SILVESTEIN, M. A Pattern Language. Oxford University Press, 1977.

ALMEIDA, P. A. PRISMA: Proposta de um modelo multidimensional para o gerenciamento de projetos de desenvolvimento de software, Dissertação (Mestrado) IPT, Instituto de Pesquisas Tecnológicas. São Paulo, 2004.

AlVARENGA NETTO, C. A. A. Definindo Gestão por Processos: características, vantagens. IN: LAURINDO, Fernando J. B.; ROTONDARO, Roberto G. Gestão Integrada de Processos e da Tecnologia da Informação. São Paulo: Atlas, 2006.

AMBLER, S. Strategic Reuse Management and the Rational Unified Process (RUP), Flashline, Inc., 2004. Disponível em: <http://www.flashline.com/docs/ WAMBLER03.PDF>. Acesso em: 15 jan 2004.

APPLETON, B. Patterns and Software: Essential Concepts and Terminology, 2000. Disponível em: <http://www.cmcrossroads.com/bradapp/docs/patterns-intro.html $>$. Acesso em: 20 jan 2004.

ATKINSON, C. et al., Component-based Software Engineering: The Kobra Approach. IN: International Workshop on Component-Based Software Engineering, Limerick, $\quad$ Irlanda: 2000. Disponível em: $<$ http://www.sei.cmu.edu/cbs/cbse2000/papers/indez.html>. Acesso em: 15 jan 2006.

BARROCA, L.; GIMENES, I. M. S.; HUZITA, E. H. M. Conceitos Básicos. IN: GIMENES, I. M. S; HUZITA, E. H. M., Desenvolvimento Baseado em Componentes. Rio de Janeiro: Ciência Moderna, 2005.

BASILI, V. R.; CALDIERA, G.; CANTONE, G. A reference Architecture for the Component Factory. Revista ACM, Jan. 1992.

BECK, K. Extreme Programming Explained. Addison, 2000.

BOOCH, G., JACOBSON, I., RUMBAUCH, J. The Unified Software Development Process. EUA: Addison-Wesley, 1999.

BPMI, Business Processs Management Initiative. Disponível em: $<$ http://www.bpmi.org/>. Acesso em: 15 jan 2006. 
BPMN, Business Processs Management Notation. Disponível em: $<$ http://www.bpmn.org/>. Acesso em: 15 jan 2006.

BRAGANÇA, J. O.; BECKER, L. C. A. F.; LONGO, F.H. Modernização dos Processos de Aquisição, Desenvolvimento e Manutenção de Sistemas Informatizados na Gestão Pública - A Abordagem Técnica. VI CONIP - Congresso Nacional de Informática Pública, São Paulo, 2003.

BRYMAN, A. Research Methods and Organizational Studies. Inglaterra: Urwin Hyman Ltd., 1989.

BUSCHMANN, F. et al. Pattern-Oriented Software Architecture: A System of Patterns. New-York: John Wiley, 1996.

CAMEIRA, F. R.; CAUlliRAUX, H. Engenharia de Processos de Negócios: considerações metodológicas com vistas à análise e integração de processos. IN: SIMPOI - Simpósio Internacional de Melhoria da Qualidade, São Paulo, 2000.

CARBONE, P. P. Cultura organizacional no setor público brasileiro: desenvolvendo uma metodologia de gerenciamento da cultura. RAP - Revista de Administração Pública, Rio de Janeiro, mar./abr. 2000.

CASTOR, M. E. Fábrica de Software: Passado, Presente e Futuro. Artigo UNIBRATEC- União dos Institutos Brasileiros de Tecnologia, Revista Científica, Recife, Pernambuco, 2005. Disponível em: <http://www.unibratec.com.br/ revistacientifica/diretorio/edicao1/artigo_fabricasw_tecnologus_final.pdf $>$. Acesso em: 10 jan 2006.

CHEESMAN, J.; DANIELS, J. UML Components. Addison-Wesley, 2000.

CHENG, J. A reusability-based software development environment. Software Engineering Notes, 4(19):57-62, 1994.

CHIAVENATO, I. Teoria Geral da Administração. Rio de Janeiro: Campus, 1999.

CHRISSIS, M. B et al. CMMI: Guideline for Process Integration and Product Improvement. Addison-Wesley, 2007.

CLEMENTS, P.; NORTHROP, L. Software Product Lines: Practices and Patterns. Boston: Addison-Wesley, 2002.

CMI, Conselho Municipal de Informática - Decreto $\mathrm{N}^{\circ} 41.591$, de 04 de janeiro de 2002. Disponível em: http://portal.prefeitura.sp.gov.br/empresas_autarquias/ prodam/cmi/decretos_resolucoes/Decretos/0004. Acesso em: 15 set 2005.

CMI, Conselho Municipal de Informática - Decreto $\mathrm{N}^{\mathrm{o}} 45.992$, de 22 de junho de 2005. Disponível em: <http://portal.prefeitura.sp.gov.br/empresas_autarquias/ prodam/cmi/decretos_resolucoes/decretos/0004> Acesso em: 15 set 2005 . 
CMMI, Capability Maturity Model Integration. Pittsburg: SEI - Software Engineering Institute, Carnegie Mellon University, 2000. Disponível em: $<$ http://sei.cm.edu/cmmi/cmmi.html $>$. Acesso em: 15 set 2005

COAD, P. Object-Oriented Patterns. Communications of the ACM, V. 35. $\mathrm{n}^{\circ}$, p.152-159, setembro 1992.

COHEN, S. "Object-oriented tecnhology and domain analysis. IN: $5^{\text {th }}$ International Conference on Software Reuse, Vitória, Canadá, 1998, IEEE Press, p.86-93, 1998.

CONTADOR, J. C. et al. Gestão de Operações - A Engenharia de Produção a serviço da modernização da empresa. São Paulo: Edgard Blücher, 1997.

CONTADOR, J. C.; CONTADOR, J. L. Programação e Controle da Produção para Indústria Intermitente. IN: CONTADOR, J. C. et al. Gestão de Operações - A Engenharia de Produção a serviço da modernização da empresa. São Paulo: Edgard Blücher, 1997.

CORREAA, H.; GIANESI, I. Sistemas de Planejamento e Controle da Produção. IN: CONTADOR, J. C. et al. Gestão de Operações - A Engenharia de Produção a serviço da modernização da empresa. São Paulo: Edgard Blücher, 1997.

COSTA, I. Contribuição para o aumento da qualidade e produtividade de uma Fábrica de Software através da padronização do processo de recebimento de serviços de construção de softwares. Tese (Doutorado) - Escola Politécnica, Universidade de São Paulo. São Paulo, 2003.

COUGHLAN, P; COGHLAN, D. Action Research for Operation Management. International Journal of Operations and Production Management, v.22, n. 2, p.220240, 2002.

CURTIS, B. et al. Process Modelling. Communications of the ACM, New York, v.35, n9, Sept, 1992.

CUSUMANO, M. A. Japan's Software Factories. Oxford University Press, 1991.

CUSUMANO, M. A. Software Reuse In Japan. Colorado Springs, 1992.

DAVENPORT, T. H. Reengenharia de Processos: Como inovar a empresa através da tecnologia da informação. Rio de Janeiro: Campus, 1994.

DAVENPORT, T. H. Putting the Enterprise into the Enterprise System. Boston: Harvard Business Review, July-August, 1998.

DAVENPORT, T. H.; PRUSAK, L. Conhecimento Empresarial: Como as organizações gerenciam o seu capital intelectual. Rio de Janeiro: Campus, 1998.

DAVIS, M. M.; AQUILANO, J. N.; CHASE B. R. Fundamentos da Administração da Produção. Porto Alegre: Bookman, 2003. 
DURSCKI, R. C. et al. Linhas de Produto de Software: riscos e vantagens de sua implantação. IN: VI Simpósio Internacional de Melhoria de Processos de Software SIMPROS, São Paulo, 2004.

DUSINSK, L.; KATWIJK, J. Reuse Dimensions. Proceedings of then Symposium on Software reusability SSR'95, ACM Press, 1995.

D'SOUZA, D.; WILLS, A. Objects, components, and frameworks: The catalysis approach. Boston: Addison Wesley, 1998.

ERIKSSON, H.; PENKER, M. Business Modeling with UML: business patterns at work. New York: John Wiley e Sons, 2000.

FABRI, J. A. Uma proposta de Modelo para a criação e a organização de processos de produção em um contexto de Fábrica de Software, Tese (Doutorado) - Escola Politécnica, Universidade de São Paulo. São Paulo, 2007.

FAYAD, M. E., SCHIMIDT, D. C. Object-Oriented Application Frameworks. Communications of the ACM, V. 40, no 10, p. 32-38, 1997.

FERNANDES, A. A.; TEIXEIRA D. S. Fábrica de Software: Implantação e Gestão de Operações. São Paulo: Atlas, 2004.

FIORINI, S. T. Arquitetura para Reutilização de Processos de Software. Tese (Doutorado), PUC - Pontifícia Universidade Católica. Rio de Janeiro, 2001.

FIORINI, S. T.; STAA, A. V.; BATISTA, R. M. Engenharia de Software com CMM. Brasport, 1998.

FLEURY, M.T.; FISCHER, R. M. Cultura e Poder nas Organizações. São Paulo: Atlas, 1996.

FLEURY, A. Aprendizagem e inovação organizacional. São Paulo: Atlas, 1997.

FLEURY, A.; FLEURY, M.T.L.; Estratégias Empresarias e Formação de Competências, São Paulo: Atlas, 2000.

FRAKES, W. B. ; ISODA, T., Successs factors of systematic reuse. IEEE Software, set. 1994.

GAMMA, E. et al. Design Patterns elements of reusable of object-oriented software, Addisson Wesley, 1995.

GARTNER, Pesquisa divulgada na XI Conferência Anual em São Paulo, Computerworld, ago. 2006.

GOMMA, H., Reusable software requirements and architectures for families of systems. IN: Journal of System and Software, p 189-202, nov 1996. 
GONÇALVES, J. E. L. Os novos desafios da empresa do futuro. RAE - Revista de Administração de Empresas, jul/set. 1997.

GONÇALVES, J. E. L. As empresas são grandes coleções de processos. RAE Revista de Administração de Empresas, jan/mar. 2000.

GREENFIELD, J.; SHORT, K. Software Factories, Assembling Application with Patterns, Models, Frameworks and Tools. OOPSLA'03, ACM, California, USA, 2003.

GREENFIELD, J. O caso das fábricas de software. Artigo Microsoft Corporation, julho/2004. Disponível em: <http:www.microsoft.com/brasil/msdn/Tecnologia/ arquitetura/FabricasdeSoftware.mspx>. Acesso em: 15 ago 2004.

GRISS, M., FAVARO, J. \& D'ALESSANDRO, M., "Integrating feature modeling with rseb". IN: International Conference on Software Reuse, Vitória, Canadá, 1998, Proceedings; ACM/IEEE, p.76-85. EUA: 1998.

GUIMARÃES, T. A. A nova administração pública e a abordagem da competência. RAP - Revista de Administração Pública, Rio de Janeiro, maio/jun. 2000.

HAMMER, M., A Empresa voltada para processos. Entrevista, Management, jul/ago. 1998.

HAMMER, M., A Agenda, o que as empresas devem fazer para dominar esta década. Rio de Janeiro: Campus, 2002.

HARRINGTON, J. Aperfeiçoando Processos Empresariais. São Paulo: Makron Books, 1993.

HAX, A.; CANDEA, D. Production and Inventory Management. Prentice Hall, 1984.

HOLLENBACH, C.; FRAKES, W. Software Process Reuse in an Industrial Setting. Fourth International Conference on Software Reuse, Orlando, Flórida, IEEE Computer Society Press, Los Almitos, CA, 1996.

HUHNS, M. et al. Enterprise Information Modeling and Model Integration, IN: Proceedings of the First International Conference Integration Modeling Techniques (ICEIMT), South Carolina, MIT Press, 1992.

HUMPHREY, W. S. Managing the Software Process. Addison Wesley, 1989.

HUMPHREY, W. S. Software and the Factory Paradigm IN: Software Enginering Journal EUA: IEEE, set. 1991.

IDEF0 - Integration Definition Language for Function Modeling, 1993. Disponível em: <http://www.idef.com/ pdf/idef0.html>. Acesso em: 15 jan 2005.

IFPUG - International Function Point Users Group. Disponível em: <www.ifpug.org>. Acesso em: 15 jan 2005. 
ISO 9001:2000 - Sistemas de Gestão da Qualidade: Requisitos, 2000.

ISO/IEC 9126 - Information Technology: Software Product Evaluation, 1991.

ISO/IEC 12207 - Tecnologia da Informação: Processos de Ciclo de Vida de Software. Rio de Janeiro: ABNT - Associação Brasileira de Normas Técnica, 1998.

ISO/IEC 15504 - Information Technology: Software Process Assessment, 1998.

ITIL - Information Technology Infrastructure Library. Disponível em $<$ http://www.itil.co.uk e http://www.itsmf.com.br>. Acesso em: 15 jan 2005.

JACOBSON, I. et al. Software Reuse: Architecture, Process and Organization for Business Success. ACM Press, 1997.

JACOBSON, I.; GRISS, M \& JONSSON, P. Sofware Reuse: Architecture, Process and Organization for Business Success, Nova York: Addison-Wesley, 1997.

JOHNSON, R. E. How to design frameworks. 1998. Disponível em: <http://stwww.cs.uiuc.edu/users/johnson/cs497/notes98/day18.pdf.>. Acesso em: 15 jan 2004.

KANG, K. Form: A feature-oriented reuse method with domain-specific reference architectures, Department of Computer Science and Engineering Pohang University of Science and Tecnology (postech). Pohang, Kyoungbuk: 1998.

KRUCHTEN, P. Architectural Blueprints - The "4+1" View Model of Software Architecture. IEEE Software 12 (6), Nov. 1995.

KRUCHTEN, P.; KROLL P. The Rational Unified Process and Introduction, Addison-Wesley, 2003.

KRUCHTEN, P. Introdução ao RUP - Rational Unified Process, Rio de Janeiro: Ciência Moderna, 2004.

LARMAN, C. Utilizando UML e padrões uma introdução à análise e ao projeto orientado a objetos e ao desenvolvimento iterativo, Porto Alegre: Bookman, 2007.

LAURINDO, F. J. B.; ROTONDARO, R. G., Gestão Integrada de Processos e da Tecnologia da Informação. São Paulo: Atlas, 2006.

LEME, R. A. S. Engenharia de Produção e Administração Industrial - Palestra proferida na I Semana da Engenharia de Produção, out. 1965. IN: CONTADOR, J. C. et al. Gestão de Operações - A Engenharia de Produção a serviço da modernização da empresa. São Paulo: Edgard Blücher, 1997.

LIMA, C. A. N. Administração Pública para Concursos. Rio de Janeiro: Elsevier, 2005.

LIN, W. C. Managing software reuse. USA: Prentice Hall, 1998. 
MALDONADO. J. C. et al. Padrões e frameworks de software: Notas didáticas. ICMC-USP, São Carlos, S.P 2000. Disponível em <http: //www.icmc.sc.usp.br>. Acesso em: 15 jan 2004.

MARTELANE, R. O relacionamento entre os corpos permanentes e nãopermanentes na organização pública - um modelo. IN: Reunião Anual da ANPAD, Salvador, 1991.

MATSUMOTO, Y. Essence of Toshiba Software Factory, IEEE Life Fellow, 2002.

MIGUEL, P. A. C. Estruturação de Desenvolvimento de Produtos e Implantação de um Método de Suporte: Uma intervenção por meio de Pesquisa-ação, Tese (Livre Docência) - Escola Politécnica, Universidade de São Paulo. São Paulo, 2005.

MINTZBERG, H. Criando Organizações Eficazes - Estruturas em cinco configurações. São Paulo: Atlas, 2003.

MONTEIRO, M. H. Porque é o BPM - Business Process Management, uma das apostas para a mudança na Administração Pública? Revista Informação e Informática, $\mathrm{n}^{\circ}$ 28, Lisboa, Portugal, 2004.

MSF - Microsoft Solutions Framework. Disponível em <http://www.microsoft.com/ technet/itsolutions/msf/default.mspx>. Acesso em: 15 jan 2005.

NAKANO, D. N.; Fleury, A. C. C. Métodos de Pesquisa na Engenharia de Produção. IN: XVI ENEGEP - Encontro Nacional de Engenharia de Produção, Anais. Piracicaba: UNIMEP/ABEPRO, 1996.

NONAKA, I; TAKEUCHI, H. Criação de Conhecimento na Empresa. São Paulo: Campus, 1997.

OLIVEIRA JR., M. M. Administração do conhecimento em redes corporativas globais. Tese (Doutorado), Faculdade de Economia e Administração, Universidade de São Paulo. São Paulo, 1999.

OMG - OBJECT MANAGEMENT GROUP. Disponível em < http://www.omg.org/>. Acesso em: 15 jan 2005.

PAULA FILHO, W. P. Engenharia de Software - Fundamentos, métodos e padrões. Rio de Janeiro: Livros Técnicos e Científicos, 2003.

PAULK, M. C. et al. The Capability Maturity Model: Guidelines for Improving the Software Process. SEI, Addison-Wesley Longman Inc., 1994.

PFLEEGER, S. L.; ATLEE, J.M. Software Engineering - Theory and Practice, USA: Prentice Hall, 2006.

PIRES, J. C. S; MACEDO K. B. Cultura Organizacional em Organizações Públicas no Brasil. RAP - Revista de Administração Pública, Rio de Janeiro, Jan./fev. 2006. 
PIRES, R. S. I. Gestão Estratégica da Produção. Piracicaba: UNIMED, 1995.

PMBOK, PROJECT MANAGEMENT INSTITUTE. A guide to the Project Management Body of Knowledge. Pennsylvania: Project Management Institute Inc., 2004.

PMSP, Empresa de Tecnologia da Informação e Comunicação. Disponível em: $<$ http://portal.prefeitura.sp.gov.br/empresas_autarquias/prodam $>$. Acesso em: $15 \mathrm{jan}$ 2005.

PRASAD, B. Concurrent Engineering Fundamentals: integrated product and process development. USA: Prentice Hall, 1997.

PRESSMAN, R. S. Engenharia de Software. Rio de Janeiro: McGraw-Hill, 2002.

PRIETO-DIAZ, R. Status Report: Software Reusability. IEEE Software, mai. 1993.

PRIETO-DIAZ, R.; ARANGO, G. Domain Analysis and Software Systems Modeling. California: IEEE Computer Society Press Tutorial, 1991.

RUP, Rational Unified Process, Version 2003.06.00.65, Rational Software, 2003, CD-ROM.

SANTOS, R. P. C. Engenharia de Processos - Análise do Referencial TeóricoConceitual, Instrumentos, Aplicações e Casos. Dissertação (Mestrado), COPPE, UFRJ - Universidade Federal do Rio de Janeiro. Rio de Janeiro, 2002.

SAUR, R. A. C., A Tecnologia da Informação na Reforma do Estado. Brasília: ENAP, Textos para Discussão, 1996.

SCHALL, E. Public sector succession: a strategic approach to sustaining innovation. Washington: Public Administration Review, jan./fev. 1997.

SCHEER, A. W. ARIS - Business Process Framework. Verlog Berlin: Heidelberg Springer, 1998.

SHAW, M.; GARLAN, D. Software Architecture. Perspectives on emerging discipline. Prentice Hall, 1996.

SIMOS, M. "Organization Domain Modeling: Domain Engineering as a comethodology to object-oriented techniques", Fusion Newsletter, v. 4.4., California: Hewlett-Packard Laboratories, p.13-16, out 1996.

SLACK, N. et al. Administração da Produção. São Paulo: Atlas, 1996.

SOFTEX - Sociedade para Promoção da Excelência do Software Brasileiro, A indústria de software no Brasil 2002: fortalecendo a economia do conhecimento. MIT - Massachussets Institute of Technology, Brasil Coordenação Geral Sociedade SOFTEX, Campinas, 2002. 
SOMMERVILLE, I. Engenharia de Software. Addison Wesley, 2003.

SPARKS, G. The Business Process Model, 2000. Disponível em $<$ http://www.sparxsystems.com.au>. Acesso em: 15 jan 2005.

SWANSON, K. et al. The application software factory: applying total quality techniques to system development, MIS Quartely, 1991.

SZYPERSKY, C. Component Software: Beyond Object-Oriented Programming. ACM Press, Addison Wesley, 1998.

TEIXEIRA, D. Fábricas de Software, tudo em nome da estratégia dos clientes, Anuário de Informática, 2006. Disponível em <www.anuarioih.com.br/ anuih/2006/pdfs/> Acesso em: 01 fev 2007.

TEIXEIRA, F. J. Gerenciando Conhecimento. Rio de Janeiro: SENAC, 2000.

THIOLLENT, M. Metodologia da Pesquisa-Ação. São Paulo: Cortez, 2004.

TRINDADE, A. L. P. Um papel da ensinagem na preservação do conhecimento em ambientes de Fábrica de Software, Tese (Doutorado) - Escola Politécnica, Universidade de São Paulo. São Paulo, 2006.

UML - Unified Modelling Language. Disponível em: <http://www.uml.org/.>. Acesso em: 15 jan 2005.

VASCONCELLOS, E. Estrutura das Organizações. São Paulo: Pioneira, 1989.

VERNADAT, F. B. Enterprise Modeling and Integration: Principles and Applications. London: Chapman e Hall, 1996.

VISIO, Microsoft Visio. Disponível em: <http://office.microsoft.com/en-us/visio/ FX100487861033.aspx>. Acesso em: 15 jan 2005.

WEBER, K. et al. Modelo de Referência para Melhoria de Processos de Software: uma situação brasileira. IN: XXX CLEI - Conferência Latino-Americana de Informática, Arequipa, Peru, set. 2004.

WERNER, C. M. L.; BRAGA, R. M. M., A Engenharia de Domínio e o Desenvolvimento Baseado em Componentes. IN: GIMENES, I. M. S; HUZITA, E. H. M., Desenvolvimento Baseado em Componentes. Rio de Janeiro: Ciência Moderna, 2005.

YIN, R. K. Estudo de Caso - Planejamento e Métodos. Porto Alegre: Bookman, 2001 .

ZARIFIAN, P. Objetivo Competência: por uma nova lógica. São Paulo: Atlas, 2001. 